By

ABDULMALIK S. AL-SALMAN

\author{
Bachelor of Science \\ King Saud University \\ Riyadh, Saudi Arabia \\ 1988 \\ Master of Science \\ University of Georgia \\ Athens, Georgia \\ 1992
}

Submitted to the Faculty of the

Graduate College of the

Oklahoma State University

in partial fulfillment of

the requirements for

the Degree of

DOCTOR OF PHILOSOPHY

July, 1996 
Thesis
19960
A46lp 


\section{AN ARABIC PROGRAMMING ENVIRONMENT}

Thesis Approved:
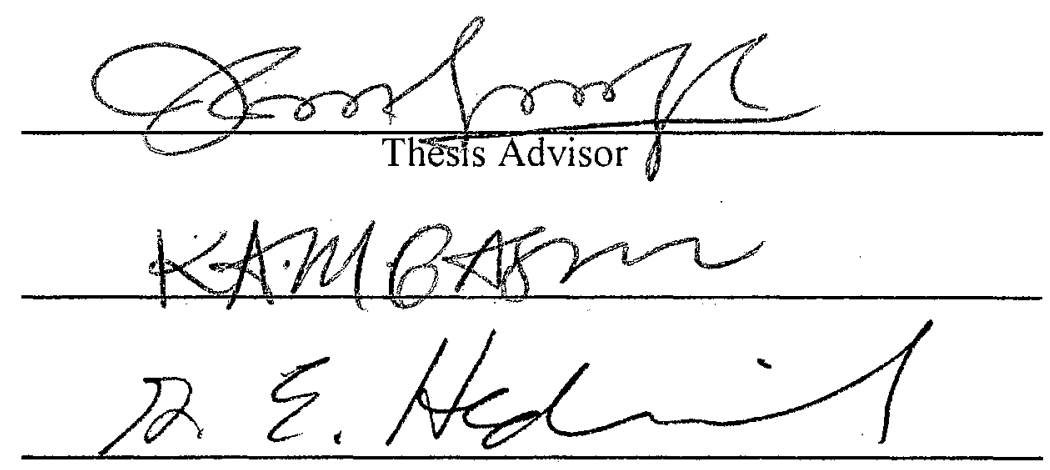

$H . x_{\mu}$

Ihomas C. Collino

Dean of the Graduate College 


\section{ACKNOWLEDGMENTS}

Praises be to ALLAH, the Lord of the universe, without his bounty I would not have come to Oklahoma or finished this work.

I wish to express my deep gratitude and sincere appreciation to my major professor, Dr. K. M. George, for his scientific guidance, moral support and continuos encouragement and understanding. My thanks are extended to the members of my advisory committee, Dr. G. E. Hedrick, Dr. K. Gasem, and Dr. H. Lu, for their valuable suggestions and encouragement during the course of this project.

I would also like to give a special appreciation to my parents and my wife for their support and encouragement all the time. I am also thankful to all my friends in Stillwater who made my staying here very enjoyable.

I also forward my thanks to my home country, Saudi Arabia, the land of goodness. 


\section{TABLE OF CONTENTS}

Chapter

$\underline{\text { Page }}$

1. INTRODUCTION $\ldots \ldots \ldots \ldots \ldots \ldots \ldots \ldots \ldots \ldots \ldots \ldots$

1.1 OBJECTIVES AND MOTIVATION . . . . . . . . . . . 2

1.2 DESIGN GUIDELINES . . . . . . . . . . . . . 3

2. CHARACTERISTICS OF THE ARABIC LANGUAGE $\ldots \ldots \ldots \ldots 6$

3. RELATED WORK $\ldots \ldots \ldots \ldots \ldots \ldots \ldots \ldots \ldots \ldots \ldots \ldots \ldots \ldots$

3.1 STANDARDIZATION . . . . . . . . . . . . . . . 13

3.2 INPUT AND OUTPUT FACILITIES $\ldots \ldots \ldots \ldots \ldots \ldots \ldots$

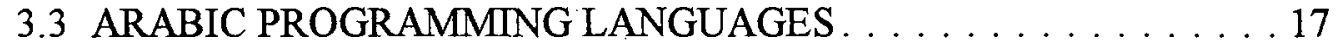

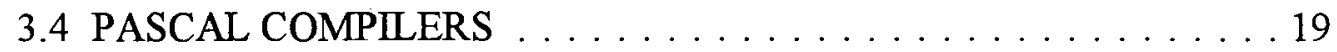

4. THE APE DESIGN AND IMPLEMENTATION $\ldots \ldots \ldots \ldots \ldots 21$

4.1 MAIN WINDOW . . . . . . . . . . . . . . . . . 22

4.2 APE DIALOG BOXES . . . . . . . . . . . . . . . . 27

4.3 COMPILATION AND EXECUTION PROCESS . . . . . . . . 33

4.4 APE ALGORITHMS . . . . . . . . . . . . . . . . . 37

4.5 HELP WINDOWS . . . . . . . . . . . . . . 50

5. DESIGN AND IMPLEMENTATION OF THE ARABIC

PASCAL COMPILER $\ldots \ldots \ldots \ldots \ldots \ldots \ldots \ldots \ldots \ldots \ldots \ldots \ldots \ldots \ldots$

5.1 THE SCANNER . . . . . . . . . . . . . . . . . . . . 54

5.2 THE PARSER . . . . . . . . . . . . . . . . . . 59

5.3 THE CODE GENERATOR $\ldots \ldots \ldots \ldots \ldots \ldots \ldots 4$

5.4 THE ERROR HANDLER $\ldots \ldots \ldots \ldots \ldots \ldots \ldots \ldots \ldots . \ldots 92$

5.5 EXAMPLES OF ARABIC PASCAL PROGRAMS . . . . . . 92

6. CONCLUSION AND FUTURE WORK $\ldots \ldots \ldots \ldots \ldots \ldots \ldots$

6.1 SYSTEM REQUIREMENTS $\ldots \ldots \ldots \ldots \ldots \ldots \ldots$

6.2 SYSTEM LIMITATIONS . . . . . . . . . . . . . . . . . 97

6.3 FUTURE WORK . . . . . . . . . . . . . . . 97

REFERENCES $\ldots \ldots \ldots \ldots \ldots \ldots \ldots \ldots \ldots \ldots \ldots \ldots \ldots \ldots$ 
A. APE MESSAGES $\ldots \ldots \ldots \ldots \ldots \ldots \ldots \ldots \ldots \ldots \ldots \ldots$

A.1 INFORMATIVE MESSAGES $\ldots \ldots \ldots \ldots \ldots \ldots \ldots \ldots \ldots 11$

A. 2 ERROR MESSAGES . . . . . . . . . . . . . . . . . 112

A.3 DIALOG MESSAGES $\ldots \ldots \ldots \ldots \ldots \ldots \ldots \ldots \ldots \ldots$

B. LIST OF WORDS AND SYMBOLS IN THE

ARABIC PASCAL . . . . . . . . . . . . . . . . . 115

B.1 RESERVED WORDS . . . . . . . . . . . . . . . . . 115

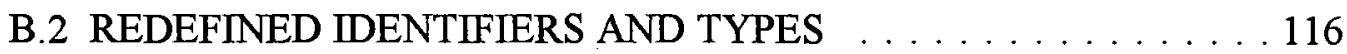

B.3 BUILT-IN FUNCTIONS AND PROCEDURES $\ldots \ldots \ldots \ldots 116$

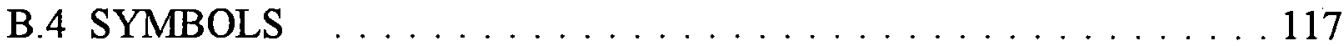

C. SYNTAX DIAGRAMS FOR THE ARABIC PASCAL $\ldots \ldots \ldots \ldots 118$

D. ERROR MESSAGES $\ldots \ldots \ldots \ldots \ldots \ldots \ldots \ldots \ldots \ldots \ldots \ldots \ldots$

D. 1 COMPILER ERROR MESSAGES . . . . . . . . . . . . . . . . 127

D.2 RUN-TIME ERROR MESSAGES . . . . . . . . . . . . . . . 130

E. TEST PROGRAMS $\ldots \ldots \ldots \ldots \ldots \ldots \ldots \ldots \ldots \ldots \ldots$ 


\section{LIST OF TABLES}

Table

Page

4.1 Actions related to the MDI Dialog Box. . . . . . . . . . . . 38

4.2 Actions related to the File Dialog Box . . . . . . . . . . . . . 40

4.3 Actions related to the Text window . . . . . . . . . . . . 41

4.4 Actions related to the Find Dialog Box . . . . . . . . . . . . . . 44

4.5 Actions related to the Replace Dialog Box . . . . . . . . . . . . . 44

4.6 Actions related to the GoTo line Dialog Box. . . . . . . . . . . . . . . 45

4.7 Actions related to the Print Dialog Box . . . . . . . . . . . . . . 46

4.8 Actions taken by the Option handler . . . . . . . . . . . . . 47

5.1 Sizes (in bytes) of deferent data types . . . . . . . . . . . . . . 66

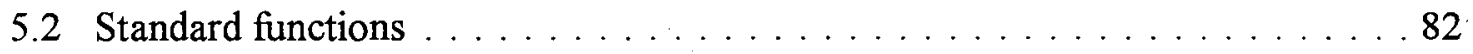

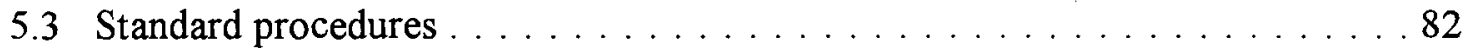

5.4 Simple relations and operations in Arabic Pascal and Assembly . . . . . . . . . 91 


\section{LIST OF FIGURES}

Figure

Page

4.1 Main User-Windows Interactions $\ldots \ldots \ldots \ldots \ldots \ldots \ldots \ldots \ldots \ldots$

4.2 A snapshot of the Main Window . . . . . . . . . . . . . . 23

4.3 The main window after closing all files. . . . . . . . . . . . 23

4.4 Drop-down Submenus . . . . . . . . . . . . . . . . . . . . . . 24

4.5 Examples of a Dialog Box and a message window . . . . . . . . . 25

4.6 File Dialog Box (With Open File Title) . . . . . . . . . . . . . . 28

4.7 Find and Replace Dialog Box . . . . . . . . . . . . . . 31

4.8 GoTo Dialog Box . . . . . . . . . . . . . . . . . . . . . . 32

4.9 Print Dialog Box . . . . . . . . . . . . . . . . . . 32

4.10 A snapshot of the compilation windows (unsuccessful compilation) . . . . . 35

4.11 A snapshot of the compilation windows (successful compilation) . . . . . . 36

4.12 The APE including the execution window . . . . . . . . . . 36

4.13 Software Architecture of the APE . . . . . . . . . . . . . 37

4.14 The main help window . . . . . . . . . . . . . . . 51

4.15 Partial display of the APE interface help window $\ldots \ldots \ldots \ldots \ldots$

4.16 Partial display of the Arabic Pascal help window . . . . . . . . . . . 52

5.1 Organization of the Arabic Pascal Compiler . . . . . . . . . . . 53

5.2 Symbol Table Node Data Structure . . . . . . . . . . . . . . . . . . . 64

5.3 An Example of a symbol table . . . . . . . . . . . . . . 65

5.5 Scope structure of a Pascal program . . . . . . . . . . . . . 67

5.6 A Snapshot of the Scope Stack of the program in Figure $5.5 \ldots \ldots$. . . . 68 


\section{NOMENCLATURE}

APC Arabic Pascal Compiler

APE Arabic Programming Environment 


\section{CHAPTER 1}

\section{INTRODUCTION}

Throughout the world, computers play an important role in people's life. The concept of literacy starts to shift from not knowing how to read and write to not knowing how to operate and utilize computers. For instance, in Saudi Arabia many houses have computers either to be used for scientific purposes or just for entertainment. Computer classes have been introduced in all high schools. Education planners in Saudi Arabia are nowadays thinking seriously of introducing computer classes not only in middle schools, but also in elementary schools [Min87, DAM92, Gne94, FE95, GFA95, Man95]. The main difficulty facing such planing is the lack of good skills in English language prior to college. Thus, to enhance computer teaching in Arab countries is to Arabize computers in all levels: hardware interfaces such as operating systems, software interfaces such as applications, and programming languages.

Every Arab national feels and appreciates the extreme importance of computer Arabization. Computer Arabization can be defined as the conversion of well-tested and well-proven computer software to enable Arabic-speaking users to utilize it effectively and efficiently. This work is a small contribution to this end.

This dissertation is comprised of six chapters, including this introduction. The rest of this chapter states the main objectives and motivations. It also defines the design

guidelines for developing the Arabic Programming Language Environment. Chapter 2 is 
devoted to explain the main characteristics of the Arabic language. Understanding these characteristics is essential for designing an Arabic software. Chapter 3 discusses related work. Chapter 4 describes the design and implementation of the Arabic Programming Environment (APE). Chapter 5 explains the design and implementation of the Arabic Pascal Compiler (APC). The APE and APC complement each other. Chapter 6 concludes the work and states the avenues for future work.

The dissertation also has five appendixes. Appendix A lists and explains the APE messages. Appendix B lists the words and symbols that are used in the Arabic Pascal language. Appendix $\mathrm{C}$ shows the syntax diagrams for the Arabic Pascal language. Appendix D lists and explains the compilation error messages and the run-time error messages. Finally, Appendix E lists a set of test programs used as a validation suit.

\subsection{OBJECTIVES AND MOTIVATION}

The main objective towards the Arabization of computing is to be able to write programs in Arabic. Arabic programming languages and their environments should be available as other international programming languages to enhance the advancements in the Arab world. Programming language environment is an integrated set of tools for program development such as editor, compiler, linker, and debugger. So, it is substantially different from any Arabic word processors available in the market. Arabic language, in general, has many unique features that makes it different from all European languages. Consequently, developing an Arabic environment is different from developing an environment for other languages. Because of the importance of understanding the Arabic characteristics, we have dedicated a chapter, Chapter two, for describing those characteristics. 
Arabic Pascal design and implementation was motivated by the need of a simple, structured, and powerful Arabic programming language to be used as a general purpose programming language, especially in teaching programming concepts. From an educational point of view, it is obvious that learning new concepts is more effective if the native language is used. Few years ago, such a project was not applicable because there were no mature Arabic environment systems that can handle efficiently the Arabic characters. Moreover, there was no need for such project because most computer users and programmers were educated adults who knew the English language and could easily program in English. However, this situation has changed.

\subsection{DESIGN GUIDELINES}

Several key factors influence the design of the environment. The Arabic environment should have the ability to read and display Arabic characters. Moreover, everything in the editor (writing direction, menus, tool-bar, status-bar, etc.) should be presented from right to left to accommodate the Arab users. These two features pose the major obstacle to developing such an environment. Also, to address a wide group of users and programmers, this work has to be built on top of a popular machine that can support Arabic character set. This led to using IBM PC and compatibles which are popular and widely available machines with numerous clones. They also support a reasonable Arabic interface under both MS-DOS and MS-Windows.

Since MS-Windows has a better user interface than MS-DOS, MS-Windows is chosen as the base platform for the work. MS-Windows version 3.0 and later can support Arabic characters with some applications for Arab users. What remains to be done is to

develop some tools that are able to handle right alignments. The Arabic programming 
environment can be viewed as an editor complemented with compiling and running facilities. The editor should accept Arabic text with basic tools for editing, such as opening a file, saving it, cutting, copying, and pasting. Chapter 4 explains in detail the APE interface and its capabilities.

To address wide group of programmers, The selected programming language has to be well-known in its original design. Therefore, the shift from English programming language environment to Arabic programming language environment has to be minimal at least in this stage of Arabization. May be later, when many programmers get a long with Arabic programming languages, more independent Arabic programming languages can be designed. We have chosen Pascal language as a model to follow for many reasons. Among these are:

- Pascal is the most widespread programming language in the education field in Saudi Arabia and to some extent in other countries as well.

- Pascal is a fairly small language with relatively simple syntax that can easily be understood.

- Pascal is a structured language.

Instead of defining a new programming language that may have no link to any existing language, we chose to follow the standard Pascal [Coo83, Tib81]. By doing this, the ability to switch from English Pascal to Arabic Pascal becomes easy for teachers who know English Pascal and want to teach their students the Arabic Pascal. Similarly, switching from Arabic Pascal to English Pascal becomes easy for students who want to pursue the field of programming language or want to study some other English programming languages like $\mathrm{C}$ or FORTRAN. The Arabic Pascal, however, is not oriented to any specific purpose or group; it is a general purpose programming language that can be utilized by beginners as well as experts. 
Translating the English Pascal to Arabic Pascal can be done in an easy, but inefficient way, that is translating the Arabic syntax (source code) to English and then feeding it to the regular English Pascal compiler. Unfortunately, this approach does not solve the problem of English difficulties due to the following reasons:

- Users will receive all compiler messages in English. These are difficult to be understood by a person who is not proficient in English.

- Debugging the source program is almost impossible.

- There is no way to improve or modify the programming language to suit the Arabic native speakers.

- It is important to build a complete and coherent project that contains only Arabic interface.

Accordingly, the Arabic Pascal language and compiler should be a stand alone software, not a front end to any Latin high level programming language. 


\section{CHAPTER 2}

\section{CHARACTERISTICS OF THE ARABIC LANGUAGE}

To effectively build a good Arabic software, one should fully understand the main characteristics of the Arabic language. The Arabic language has many unique features that are different from many other languages. The following is a list of the main characteristics of the Arabic language [AA89, AA93, Ben87, Cas85, EEN89, Ham89, Ham94a, KH93].

1. Arabic, like other Semitic scripts, is written and read from right to left.

2. While text is written from right to left, numbers can be written and read from right to left or from left to right. Most Arabs read numbers and write them from left to right.

3. It has 28 basic characters.

4. In addition to the basic 28 characters, Arabic has special letters such as

$$
\text { arsis }
$$

and HAMZA letters such as

$$
\text { s، أه ؤ، كi، لأ }
$$

5. Even though the basic alphabet consists of 28 letters, it is extended to some 90 elements by additional shapes, marks, and vowels [TA90].

6. Some Arabic characters can be fused to form new shapes. For example, ' $y$ ' is composed of ' $\mathrm{J}$ ' and ' $T$ '. ' $T$ ' is also composed of ' $\mathrm{f}$ ' and ' $\mathrm{P}$ ' [TA90]. 
7. Arabic is a cursive script --like English handwriting-- links the letters of a single word.

8. Arabic script is extremely complex due to the context sensitivity of its written characters. Letters have up to four different forms: isolated, at the beginning, in the middle, and at the end of a word.

9. Most of the characters have three shapes depending on their position within the word.

10. All characters are consonants except the letters Alif, Waw, and Ya [Sim90]. Actually, these three characters are consonants with attached vowel sounds.

11. Most characters (17 out of 28 ) have a dot, two dots, or three dots associated with the character and can be above, below, or inside the character.

12. Arabic also may use stretch character forms to add emphasis or aesthetics to the written word.

13. No upper or lower cases exist in Arabic.

14. Arabic has vowels. Vowels are special shapes with Arabic words. It is good to have them in writing to avoid possible ambiguity, but they are not necessary in most cases. The vowels can be inferred from the context. Nowadays, most writers ignore them [Bec87].

15. Similar to accent marks in European languages, Arabic has diacritical signs. These signs are used to mark short vowels and emphasize or loosen a letter's sound [TA90].

16. A special feature of the Arabic alphabet is the large number of diacritics, points, and slashes, which are used to differentiate consonants or to represent vowels.

17. Some groups of characters have the same shape with slight change in the number of dots or the position of these dots [Jam91]. The dots and their positions are important in distinguishing between different characters [Gor90].

18. The Arabic characters are written cursively with frequent vertical overlap in handwritten form. For example, the first three characters of 's 'can be written by 
hand above each other. Even in the printed characters, vertical overlapping is clear in the first two characters in the last example.

19. The pronunciation of the character, and hence the meaning of the word containing that character, differs according to the diacritic imposed over it. For example, 'Laś' (sentences) is completely deferent from ' "كax' (camel) even though they have the same set of characters.

20. Arabic, like Latin, is a synthetic language rather than a predominantly analytical language, such as English [FF93]. That means that the syntactical relationship of nouns, for instance, is indicated by case endings and that verbs are inflected by means of prefixes, infixes and suffixes to indicate the various persons, numbers, genders, derived forms, moods and tenses. On the other hand, a language such as English a separate noun or pronoun is required to indicate the person, number, etc.

21. A major characteristic feature of the Arabic language is that most of its words are built up from roots, whereas English words are generated from stems [AA94]. Surface affix removal processes produce word stems while deep affix removal processes produce word root [Alk91].

22. The key to searching the Arabic lexicon is the root of the word, whereas the stem is the key in English. A lexicon is a list of words in which each word is associated with its syntactic properties [AA94]. The most important property is the syntactic category such as whether the word is a verb or a noun.

23. The Arabic language is an inflectional language whereas English is an analytic language [AA94]. The derivation in Arabic is based on morphological patterns and the verb in Arabic plays a greater inflectional role than in English.

24. Particles and affixed pronouns can be combined to Arabic words. This characteristic is not available in English. 
25. The structure of Arabic language is different from that of Indo-European languages, including English. For instance, the phrase "PACKED ARRAY" should be reversed in Arabic to "مصفوفة مربوطة". This is because in the Arabic language the adjective follows the nominal phrase, contrary to the English.

26. The Arabic language accepts the principle of abbreviation. Both types of abbreviation, forming a word from the first letters of a sequence of words and selecting a prefix or a postfix from a word was popular in many Arabic works of literature. For examples,

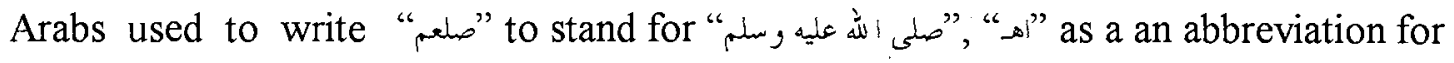
"نتهى" "ندئن" and" as a postfix for".

27. Finally, Arabic is highly flexible in word order, whereas English imposes a large number of constraints on word order.

Not all of the above characteristics affect the Arabic Pascal language and its environment. The features that deal with the formation of words, the structure of sentences, or the different shapes of characters are not directly related to this work. However, the following issues are affected by the characteristics of the Arabic language.

- The Arabic Pascal environment writes text from right to left. For numbers, we have adopted the MS-Windows approach. This approach lets the cursor move to the left while the newly entered digit appears to the right of the previous digits. In other words, the user starts by typing the most significant digit. This approach may cause some editing problems (deleting, copying, selecting, etc.) because the cursor position does not match with the insertion position. However, this approach simulates the way of writing by the majority of Arabs.

- For the sake of simplicity and flexibility, the Arabic Pascal does not accept the diacritical signs. Most Arabs easily can read a text without the need for diacritical signs. 
- Even though the standard Pascal does not allow the underscore character as part of identifiers as well as keywords, the Arabic Pascal does. The reason is that the Arabic is a script language (links the letter of a single word). Unlike English, it is hard to read the concatenation of two words without a space or an underscore. For example, the

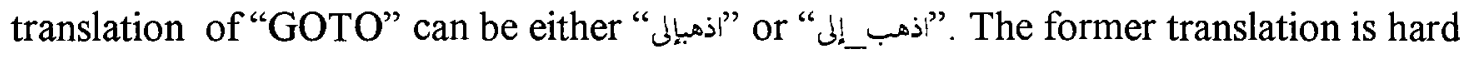
to read. The underscore character is inserted between concatenated words to increase the readability.

- The Arabic Pascal applies the principle of abbreviation whenever applicable. For example, the translation of "EOF" is "نها_"نهاية_ملفن" which stands for "Another example is "Lr-" as a translation for "COS".

- The letter "" is sometimes used instead of "p" or "?". To give some kind of flexibility to the Arabic Pascal, the letter "p" can be used instead of "p" or "?" for keywords only, not user identifiers. The same criterion is applied for " $"$ " and " "." at the end of keyword, and

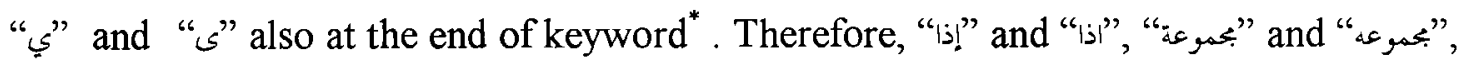
"حرني" "حرى" and etc. are the same keywords.

\footnotetext{
" In fact, the letters are not interchangeable from the orthagraphic point of view, but some Arabs use them as interchangeable letters. The Arabic Pascal tolerates this common mistake.
} 


\section{CHAPTER 3}

\section{RELATED WORK}

Software developed for English and other European languages may not be convenient for Arab users because of the nature of the language and its writing system. For example, Arabic editing environments are different from European ones. These differences exist not only in character shapes and direction of writing, but also in language structure as mentioned in Chapter 2.

The development in computer Arabization may also serve many other languages that are derived from the Arabic language or at least use a similar character set, such as, Farsi, Urdu, Malay. Therefore, almost all applications that are developed for the Arabic language can be adapted easily to these languages.

Arabized computers become essential in the Arab world with the widespread use of computers in education, business, and other aspects of life. However, the use of computers in many Arab countries was, and may still be, in its infancy compared with the West. A mission report published by the United Nations Development Program Regional Bureau for Arab States in 1984 stated that all areas of computer applications are missing except to some degree in management business applications [UN84]. This mission described that there is a very little utilization of computers in health, education, biology, agriculture, physics, geology, mining, construction, project management, and engineering design. 
Mahjoub and Mandorah [MM87] explained the main reasons for the slow development of computer sciences in the Arab world as:

1. weak educational programs in the universities,

2. absence of national programs to introduce technology to the public,

3. lack of good Arabic software,

4. lack of Arabic text books and references,

5. high cost of Arabic computer systems, and

6. weak research activities in computer science with lack of communication and coordination among the Arab researchers.

Arabization is the process of making computers accessible to the Arab users by utilizing only the Arabic language. Since the Arabic language has several unique characteristics, which differ from the English or Latin languages, the Arabization of computers is significantly different from English or Latin modes. There are many aspects or avenues where the Arabization of computers took place. Among these aspects are standardization [MM87, Smi90, Bak87], information systems [Mou87, BKN86, AG90, Mor90, Tek90, Ali90,Alk91, Abu92, Alk92, Ham94b], pattern recognition [Ami88, ES89, Gor90, AU92, Aly89, Jam91, AHD94, Mah94, AMG94, EG88, GUA92, NA94, AFC94, AG95], artificial intelligence and expert systems [NEE88, EEN89, AH88, Ibr91, Als92, AA93, KH93, ELS93, QHA93, MM94], Arabic morphological analysis [Cha87, EH89, RS93, FF90, Fed92, FF93, AMA94a, AA91, AA94, Ali87, Ali88, Ali89, Ali90, NH94], input and output facilities [Cas85, Kha86, Del86, TNS86, Bec87, Smi90, Alk90, KC91], word processing (including spelling and grammar checking) [AA88b, Mic93, ELS93, Ham94a], operating systems [Kal85, MM87, Tay87, AA88a, Sau86, Ela90, Tab90, Mic92, Tab93], transliteration and translation [IDF89, AFC94, NM91, MM95, MT95], Islamic sciences [AM95, Ali87, AK88, MA94, Abd90, Ahm94, Hi190, Ala90, Alm90, 
Man90, MA94, Far90, Ald94], programming languages [MM87, Alkh, Najla, Bas95, AYE90, DM86, Ela86, CS92, CS95], and other fields in computer science [Del85, ZRN87, Ale94, EB90, AM94, Gne94, MA85, HE86, Bak86, Ela87, Far89, AM87, Mac90, Eld87, FE95]. The following three sections briefly discuss the status and the advancements in the most relevant issues to my work, namely: standardization, input and output facilities, and programming languages. The fourth section reviews the history of Pascal compilers. Before discussing these issues, we should point out that the accessibility of information and literature in the Arabization subject is difficult due to the lack of information exchange among the Arab countries and the lack of electronic (automated) information availability. For example, if a conference proceeding or a paper is published in one of the Arab countries, it is difficult to know about it or to access it unless it is distributed to other countries (which is not the case for many reasons, such as political situations).

\subsection{STANDARDIZATION}

There are at least three aspects in the Arabized computers that need standardization: character coding, keyboard layout, and Arabic computer terms. Unfortunately, there is not enough progress in the process of standardization in both character coding and computer terms. The absence of an agreed upon set of standards for character coding has a very negative impact on the process of Arabization. The keyboard has, to some extent, a standard layout inherited from the Arabic typewriters. The differences in the keyboard layout exist on the auxiliary marks and the special characters.

The absence of a responsible organization in the Arab world to take care of standardization led to many Arabic character coding systems. The first attempt to standardize the Arabic characters coding was done by Saudi Arabian Standards 
Organization (SASO) in 1980 by calling for an international symposium [MM87]. However, the weak interaction between the researchers and manufacturers resulted in the hasty adoption of standards. The various features of the Arabic language coupled with the absence of an agreed set of standards for character coding and keyboard layout have led to several approaches in Arabization, some examples of these approaches can be found in [ASM82, Mah85, Man85, Dav86, Sau86, Mic88, Almua].

As yet, there is no standard code (ASCII) for Arabic characters. For example, NCR has almost six different character maps for its Arabic terminals and printers; and IBM has at least 12 , seven of them at least for the IBM PC [cf. Smi90]. Arabized MS Windows has different character set from the Arabized MS DOS. In other words, an Arabic text that is written using 'EDIT' under MS DOS cannot be viewed with 'NOTEPAD' under MS Windows. This led to inconsistency in every software that needs to support both Arabic DOS and Arabic Windows.

Since the shape of the character is determined by the character itself and adjacent characters, there are two approaches for character coding:

1. Each character has a single code regardless of its shape.

2. Each character shape has its own code. In this case a single character may have up to four different codes. The total number of codes is over ninety.

Most computer systems use the first approach to avoid the large number of codings. The appropriate shape can be determined by a software depending on the contextual analysis.

On the other hand, the standardization of computer terms in Arabic language is not better than the standardization of character coding. An attempt to put some rules and boundaries for the Arabization of terms was conducted by Bakry [Bak87]. The failure in Arabized computer terms start even in the translation of the word "computer" itself. There are at least three translations: "حمبيوتر", "حاسوب", The last translation is actually 
writing the word "computer" as is in Arabic (transliteration). The same criterion is applied for many other terms.

\subsection{INPUT AND OUTPUT FACILITIES}

An Arabic text must confront three main classes of problems when displayed on screen or printed by a printer [Del86, Bec87, Smi90]. The first class is caused by the Arabic cursive nature. The computer must be able to handle a sequence of isolated typed characters and display or print them in a smooth flow Arabic text. This process is called contextual formatting. Automatic text concatenation requires an algorithm that accepts Arabic characters and then alters or selects the proper shapes of the entered characters according to their positions within a word; then displays the text on screen in a syntactically correct manner [KC91]. Since there are over 90 shapes, the correct shape within the a word needs a complex analysis [KC91]. Not only do we face this huge number of shapes, but also some shapes require double width, for example 'w' in its isolated or ending forms.

To illustrate the dependency of the character shape on the position of the character within the word, let us take the character 's' (Ha). It has four different shapes:

1. Isolated. For example ‘مرهز

2. At the beginning. For example ' Jo'.

3. In the middle. For Example 'هo'.

4. At the end. For example 'مدرسه'.

Moreover, Arabic characters in a word are either connectable or not connectable to its successor according to the characteristics of the character. The process of connecting or disconnecting a character requires a complex analysis [KC91]. The Arabic version of MS-Windows provides all the required analyses to display the Arabic text. 
The second class of problems comes when numerals are embedded in the text. Arabic or Indian numerals can be written starting from right to left or left to right. Also they can be read starting from right or starting from left [Del86]. Currently, there is no standard for implementing numerals in Arabic computer systems. In some systems, when entering numerals, the cursor stays in one place and the numerals stream off to the left, since numerals run left to right [Smi90].

The third class of problems in displaying text arises when a mixture of Arabic and a European language has to be used. The computer must be able to intermix right-to-left and left-to-right characters and place each character in its proper relative position in the text line. This process is called directional layout. To illustrate the problem of directional layout, let us take an example of an early attempt to mix English with Arabic text in the NCR system [Cas85]. In that system, the English text needs to be reversed. Therefore, the name "AbdulMalik Al-Salman" needs to be keyed into an Arabic document as "namlaS-1A kilaMludbA". Of course, newer systems introduced easier methods for the mixed documents. Examples of bilingual editors on the IBM PC are the Arabic Word Perfect and the Arabic MS Word [Mic93].

Printing the Arabic script needs more effort than displaying the text on the computer screen because it involves some hardware problems such as printer head movement. Printing Arabic scripts also needs a complex analysis, similar to the screen display. Furthermore, printing an Arabic text depends on the type of the printer; the dot matrix printer needs more management than laser printer [kha86]. At the beginning of the last decade, Arabic printers were limited and they also lacked standardization. This fact led to the limitation of using computers in the Arab world. In conclusion, Arabic printers should have the ability to print from right to left, to print also from left to right for bilingual texts, and to perform contextual analysis. 


\subsection{ARABIC PROGRAMMING LANGUAGES}

Experimentation with Arabic programming language environments has been limited and the work on Arabized programming language has been relatively sparse. There are two definitions for Arabization of programming languages [MM87]:

1. Programming language Arabization is to be able to perform input/output in Arabic. This approach is very easy to achieve when the computer screen and printer can deal with Arabic characters. However, it does not enhance the process of computer Arabization.

2. Programming language Arabization is to write programs in Arabic language which, of course, include the I/O. This approach is followed in this dissertation.

Most of the early programming languages reported in the literature are either a translation of the BASIC programming language or similar in nature to BASIC language. Al-Khawarizmi is a BASIC-like programming language that runs under the $\mathrm{CP} / \mathrm{M}$ operating system [Alkh]. It has control statements, but not iteration statements. BASIC صنحر (SAKHR) is a translation of the BASIC programming language [Bas95]. It runs under صنر (SAKHR) computers. A third Arabic programming language is Najla [Najla]. It is one of the best translations of BASIC with some enhancements. This programming language is running under AlFarabi computers. One of the problems of the previous Arabic programming languages is they are built for non-popular machines. The fourth Arabic programming language is ARabic BasIc (ARBI) [AYE90]. It is an Arabic programming language that runs under MS DOS. It is compatible with GWBASIC. In ARBI, the Latin characters may appear only in the $\mathrm{I} / \mathrm{O}$ statements.

Dehlawi and Mandorah listed several programming languages that are similar in nature to Latin BASIC or assembly language [DM86]. The first language is called "غريب" 
(GAREB). The name is the abbreviation of the "لغة بريجة عربية للحاسبيات" (Arabic Computer Programming Language). It is a subset of the BASIC language; and it was built in AlMousel University, Iraq [DM86]. The second language is called " البوارزمي" (AlKawarizmi). It is different from the one mentioned before. This language was designed to be used by children under 15 years old. It is also a subset of the BASIC language. The third one is an Arabic assembly language. It was designed for a hypothetical machine just to simplify the concept of assembly language to Arab students.

Another programming language that is also related to Arabic was developed by Suleiman and Citrin [SC92, SC95]. The objective of that project is to build a visual programming language that can support any language including Arabic. That project supports the thesis that visual languages are well suited for programmers whose native language is not English. A visual programming language presents most of the syntactic and semantic information in a "BLOX-like" notation (regularized version of flowcharts) [SC95]. The idea of visual programming saves some effort in writing the source code, but it has some drawbacks. It is neither suitable for large programs nor for sophisticated ones that require dealing with records and pointers. Moreover, writing the source code usually takes only a short time compared with the process of debugging the program to make it running. In that project, there was no mention of how the debugging takes place. Finally, it is hard for a person to switch from the visual programming environment to the textual environment when he or she needs to learn more in computer science. We, however, follow the textual environment approach believing that it is more appropriate for the general purpose programming languages.

Finally, a theoretical specification for an Arabic programming language was introduced by El-Affendi [Ela86]. Its structure was translated from Modula, Pascal, and some other languages. It supports five basic types: real, integer, character, boolean, and 
pointer. Moreover, it has four data structures: array, record, file, and set. There are three control statements: if ... then, repeat ... until, and case statement. Some issues are not defined in that specification. Among these are input/output handling, reserved words, for statement, while statement, mathematical operators, and built-in functions and procedures. However, it would be a good attempt if it were implemented.

\subsection{PASCAL COMPILERS}

It is unknown when exactly the first compiler was constructed as the first programming language is undetermined [Sam72]. In general, the concept of high level programming languages started in the early 1950's. Among the oldest programming languages (with their compilers) are FORTRAN, COBOL, and ALGOL 60. Throughout the 1950's and 1960's, compilers were considered very difficult programs to construct. For instance, the first complete FORTRAN compiler took about 18 staff-years to construct [ASU86].

The first known Pascal compiler was developed in 1968 [Wir71]. That compiler was written in FORTRAN. The second compiler was written in Pascal itself in late 1969. After being written, the compiler was then translated by hand into CDC 6000 assembly language and into ICL1900 assembly language [WQ72].The first portable version of Pascal compiler, developed in 1975, is the Pascal- P-compiler [Ber78, PD82]. Rather than producing code for any particular machine, it produces an intermediate code, known as Pcode, for a hypothetical stack machine. The P-compiler itself was written in Pascal and compiles a subset of the Standard Pascal. A practical implementation of the P4 Pascal compiler was designed for the Intel 8085A microcomputer [DP80]. 
The principles and techniques for building compilers have been discussed deeply and widely in many sources [ASU86, Bac79, CJ88, DP80, Eld94, Gri71, Hed75, Mak91, PD82, PP92, Pys88, Wir71, WQ72, Ho190, Hen90]. On the other hand, there are many commercially available compilers for Pascal (usually extended version of Pascal) as well as other programming languages. An example of a Pascal language and compiler is Turbo Pascal [BTP89]. 


\section{CHAPTER 4}

\section{THE APE DESIGN AND IMPLEMENTATION}

The APE [Als96] is designed to be an environment analogous to the programming environments in the PCs. To the best of my knowledge, the APE is the first Arabic programming language environment under MS-Windows. Editing, compilation, and execution environments are all under MS-Windows. Editing and compilation windows have been implemented using Visual Basic [Ama94b]. The execution window has been implemented using C language and low-level MS-Windows system calls. The execution window has to be controlled only by the user program, not by the user. In other words, the user should be prevented from altering the window's output. Moreover, once the input is entered, it cannot be changed.

The APE is a multiple-document environment that runs under the Arabic version of MS-Windows. Therefore, the programmer can open more than one file at the same time, but only one file is active at a time. The APE has only one Toolbar and one Statusbar, and all commands are routed to the active file. The highlighted window is the window that has the focus (active window). Figure 4.1 illustrates the main user-windows interactions.

This chapter has five sections. Section 4.1 explains the design of the main window. Section 4.2 shows the various dialog boxes in the APE. Section 4.3 discusses the 
compilation and execution process. Section 4.4 explains the main APE algorithms. The last section shows some of the APE help windows.

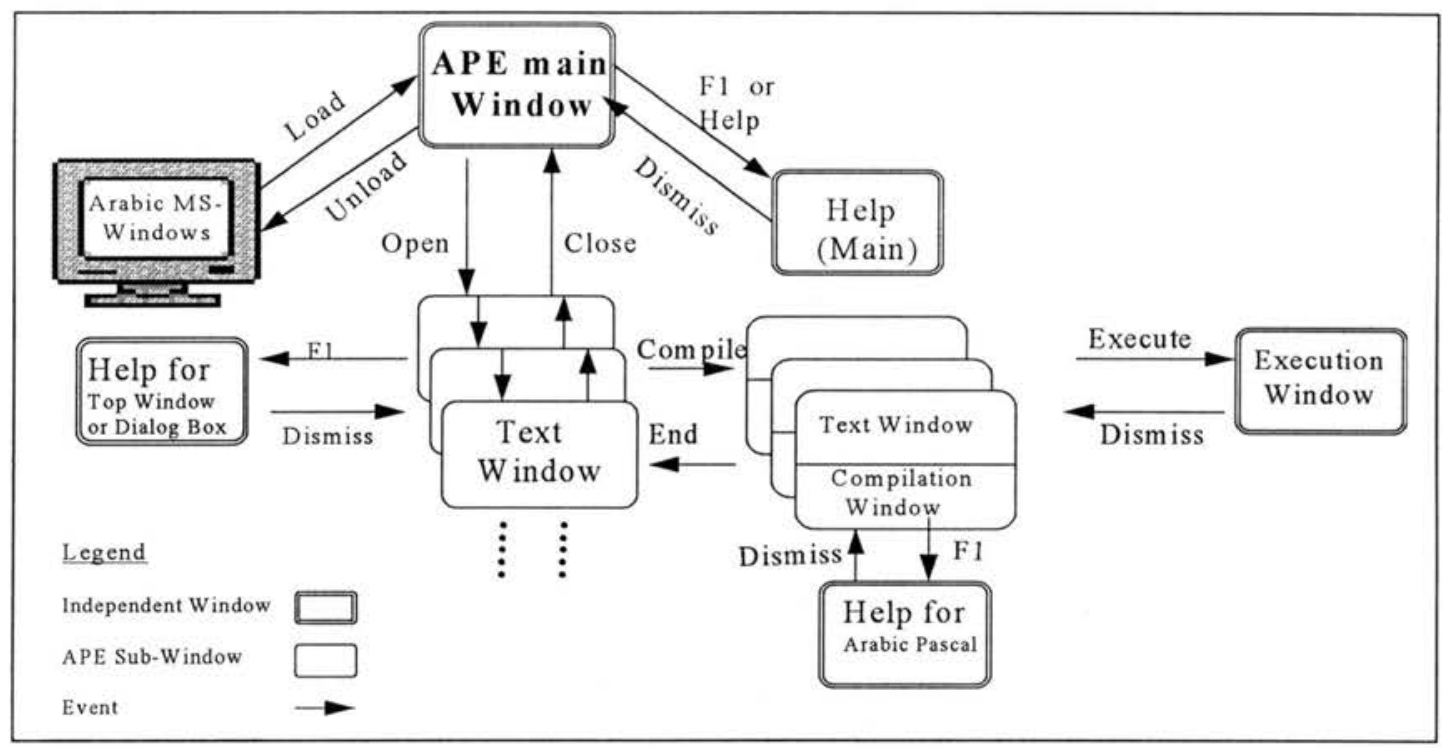

Figure 4.1 Main User-Windows Interactions

\subsection{MAIN WINDOW}

When the user runs the APE, the main window (Figure 4.2) will show up on the screen. The window is maximized with a single, empty file window. The following subsections explain the various areas in that window.

\subsubsection{The software/file title}

This area has the software title "باسكال العربي" (Arabic Pascal), followed by the file name. When a user runs the software, the file name will be "بدون_عنوان:ا" (Untitled :1). Since the text window is in its maximized mode, the software title and the file name come in the same area. If the text window is not in its maximized mode, the file name will appear only on top of the text window, which is separate from the software title. As provided by the MS-Windows, the "US" icon converts the writing mode to English when clicked. The " $\varepsilon$ " 
icon converts the writing mode to Arabic. The default mode in the APE is Arabic. If all files are closed, the main window (called MDI Window) will look like Figure 4.3.

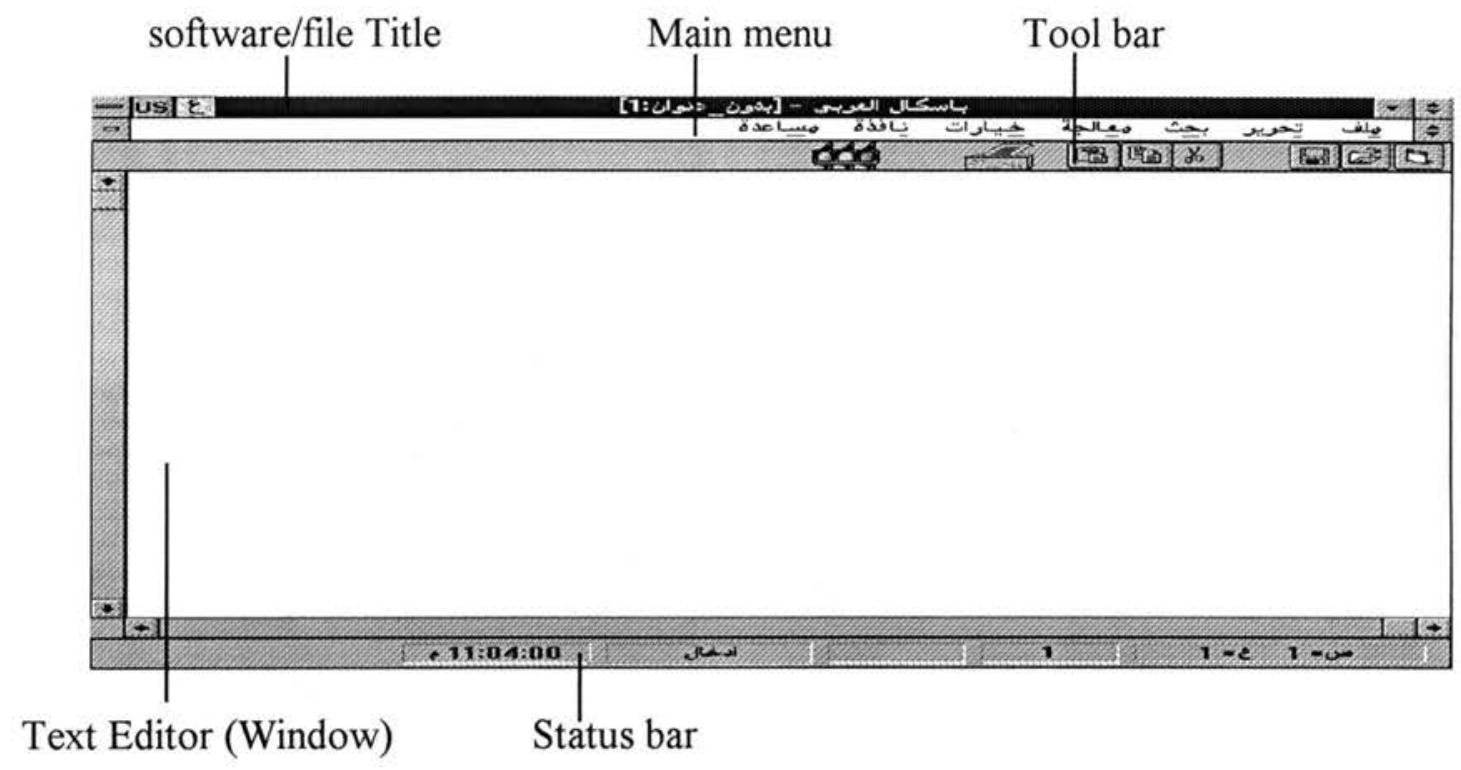

Figure 4.2 A snapshot of the Main Window

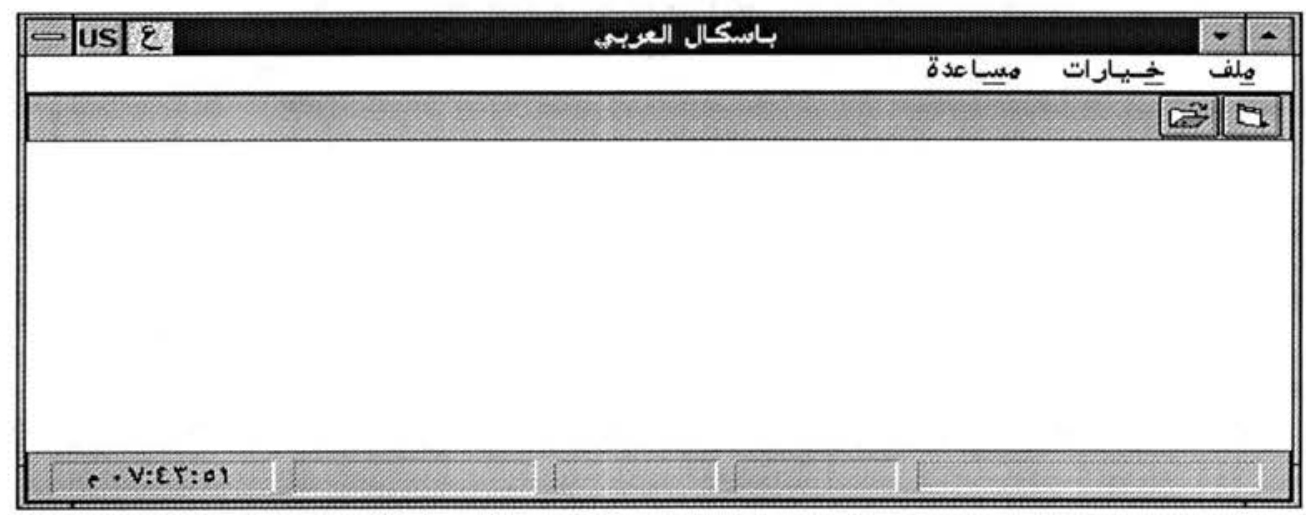

Figure 4.3 The main window after closing all files (MDI Window)

\subsubsection{Main Menu}

Figure 4.4 (a-f) shows the drop-down submenus in the main window that has at least one file. The following is a translation of these menus (top to bottom). The help menu does not have submenu. 
(a) File (New, Open, Close, Save, Save As, Print, Exit, List of the most recently used files).

(b) Edit (Undo, Cut, Copy, Paste, Select All, Date and Time).

(c) Find (Find Only, Find and Replace, GOTO line, GOTO end).

(d) Compilation (Compile, Run, End of Compilation). Section 4.3 gives more explanation about the compilation process.

(e) Options (Toolbar, Statusbar, Font reduction, Font enlargement). The toolbar and statusbar items are used to make the toolbar and the statusbar, respectively, visible or not visible.

(f) Window (Cascade, Tile, Arrange-icons, List of opened files).

(g) Help. $\quad$ (see Section 4.5).

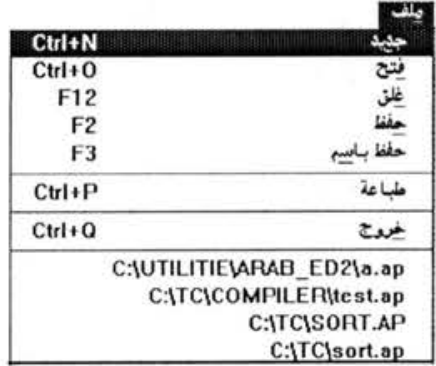

(a)

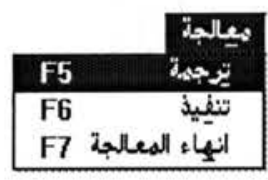

(d)

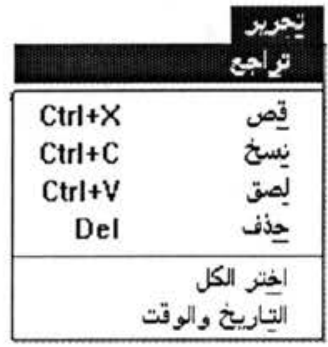

(b)

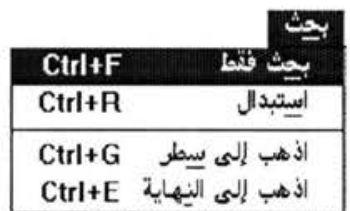

(c)

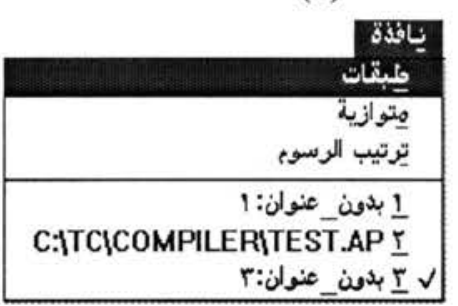

(f)

Figure 4.4 Drop-down Submenus

If the main window has no opened files (as shown in Figure 4.3), the main menu consists of only three submenus: file, options, and help. The file submenu has only new, open, exit, and the list of the most recently used files. The options submenu has toolbar and statusbar. 
Due to the absence of character set coding standardization, the APE requires the file names to be in English. If the file name is written in Arabic, it may appear as a junk of symbols under the MS-DOS. Also, due to the inconsistency in the Arabic keyboard layout and the absence of the translation of the function keys, the APE uses English short-cut keys, such as F3 and $\mathrm{Ctrl}+\mathrm{P}$.

It should be pointed out that all dialog boxes are provided in Arabic including the command buttons. Moreover, all messages are displayed in Arabic. Figure 4.5 (a) shows the Find Dialog Box, and Figure 4.5 (b) shows an example of a message window given to the user when trying to leave a document without saving. The details of the dialog boxes are explained in Section 4.2. The list of possible messages the user can get from the APE is explained in Appendix A.

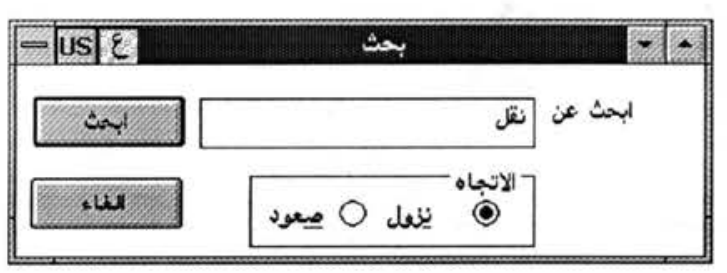

(a) A Find Dialog Box

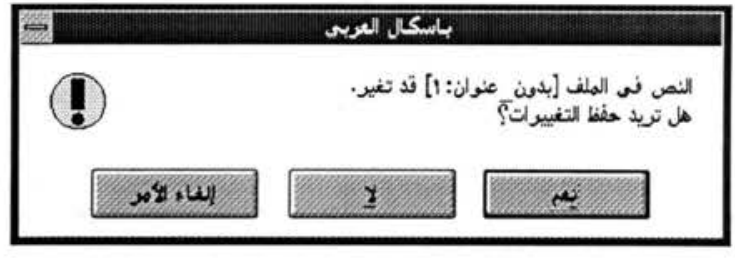

(b) Saving file message

Figure 4.5 Examples of a Dialog Box and a message window

\subsubsection{Tool bar}

It has nine icons. The first three (from the right) are for file operations: open a new file, open an old file, and save the current file. The next three are for editing operations: cut, copy, and paste a selected text. The seventh icon is for printing. The user can print the source program, the compilation output, and the results of running the program. The print command can only print a displayed window. In other words, if a window (source code, compilation output, or result) has been dismissed by the user, the print command cannot print the information that was in that window. The eighth icon is used for compiling 
command. The last icon (not visible in Figure 4.2) is used for executing a successfully compiled program. The left side of this bar is used for displaying a brief explanation of the tool bar icons and status bar items when the mouse passes over them.

\subsubsection{Text Editor}

When a new file is displayed on the screen, the cursor will be placed in the rightmost side of the first line. The default mode of writing is Arabic. Since this editor is designed for programming purposes, the APE allows only one font style "Simplified Arabic Fixed." This font has been chosen because all characters have the same width in it, which is recommended in writing programs. While writing, the cursor will move to the left. When the text cursor reaches the left edge of the enclosing window, the cursor stays at the left edge, and scrolls the previous text to the right to accommodate the newly typed characters. Similarly, reaching the bottom line in the window causes an automatic upward scrolling to accommodate the new text. The horizontal scroll bar is used to move the contents of the text window horizontally through the editing area. Note that the indicator of the horizontal scroll bar is placed in the right-most of the bar. Similarly, the vertical scroll bar (in the left side of the editing area) is used to move the contents of the text window vertically through the editing area. The vertical scroll bar is placed to the left hand side to suit the Arabic language nature. Pressing ENTER causes the cursor to jump to the beginning of the next line (rightmost side). It should be pointed out that some keyboard keys work in reverse manner in the Arabic mode. These keys are

a) Backspace key deletes the previous character (the character in the right of the cursor),

b) Home key returns the cursor to the rightmost character of the current line,

c) End key sends the cursor to the last character in the Arabic text (the lower left character), and

d) Tab key will cause the cursor to jump eight spaces to the left. 
The functions of the other keys remain the same as the English mode.

To edit (cut, copy, etc.) a part of the file, that part has to be selected (highlighted).

The selection in the Arabic text should be compatible with the Arabic direction of writing. For example, if the user starts the selection in the middle of a line and drags-down, the left-hand side of the first line should be selected (not the right-hand side as the case in English text)

\subsubsection{Status bar}

It consists of five items. They are from right to left as follows:

a) Current line number and column number. It indicates the current cursor position. Double clicking on this item causes the GOTO line Dialog Box to appear.

b) Number of lines. It shows the last line number. Double clicking on this item causes the cursor to jump to the end of the file.

c) Modification indicator. This item indicates if the file has been altered or not. If the file is new or not modified since its load time, this item is blank. Whenever a printable character is pressed, this item reflects this change by indicating that the file has been

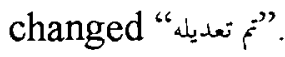

d) Insert/Overwrite mode. The default of the Text Editor is insert mode. When the user presses Ins key, the mode is flipped.

Time indicator. It displays the current system time in Arabic.

\subsection{APE DIALOG BOXES}

The APE has five dialog boxes: File, Find, Replace, GoTo line, and Print. All these dialog boxes have to be dismissed before performing any action outside them. Moreover, all these dialog boxes are movable to any place within the Main Window. The default 
language for all these dialog boxes is Arabic except the File dialog box where the default language is English because the file names should be in English to preserve the compatibility between MS-DOS and MS-Windows.

\subsubsection{File Dialog Box}

This dialog box is activated when the user wants to perform one of these functions: open, save, or save as. The general format of the File dialog box is shown in Figure 4.6. This figure shows the File dialog box in the case of opening a file. The same dialog box, with different title, is activated when the user wants to save a new file or rename (save as) an old file. Therefore, the title of the dialog box can be:

- Open File (فتح ملف),

- Save File(حفظ ملف), or

- Save As (حفظ باسم).

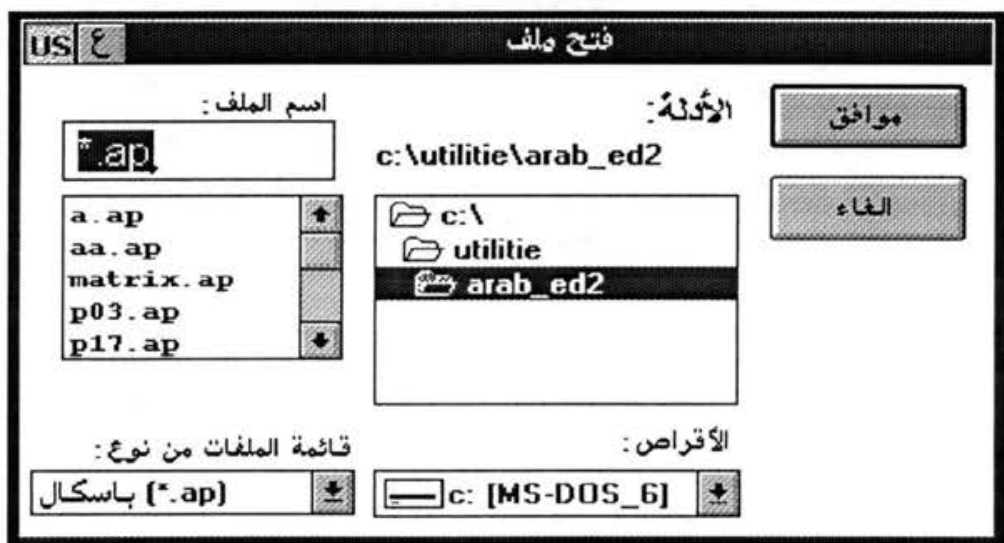

Figure 4.6 File Dialog Box (With Open File Title)

The File dialog box uses the commonly used format for opening and saving files. There are five display boxes and two command buttons.

1. File list box (فائمة الملفات). At the design phase, the APE sets the file pattern to be the list of all files that has the extension of $a p$ (Arabic Pascal) within the current directory. The user can choose the needed file by clicking the mouse or using the arrow keys. Double 
clicking a file name is equivalent to selecting a file and pressing ENTER or clicking OK (موافق) button.

2. List files of type (قائمة الملفات من نوع). This box controls the file pattern. It has a direct effect on the File list box. The default file pattern is *.ap. The user has the choice to change it to the pattern ** (list all files within the current directory).

3. Directory box (iالألة). This box highlights the current directory during the opening of the File dialog box. The user can alter the current directory by clicking the needed directory or using the arrow keys. Changing the current directory automatically changes the File list box content.

4. Drive list box (الأقراص). It displays the available drives in the computer. Changing the current drive causes a change in both directory box and file list box.

5. File name box. This box is editable by the user. The user can write the file name to be opened or saved. The APE offers the user the option of explicitly typing a drive, path, file name, and file pattern. When a file name is typed, it is selected in the File list box. If a pattern is typed, the directory and drive list boxes are updated. Also, the File list box displays the file names which satisfy the pattern.

6. OK (موافق) button. It is the default command button (i.e., pressing ENTER is equivalent to clicking this button). Clicking this button causes the selected or typed file to be opened or saved.

7. Cancel (إلغاء) button. Cancel the action of opening or saving a file. It returns the APE to the status before calling the File dialog box.

\subsubsection{Find Dialog Box}

This dialog box is activated when the user wants to find a particular word or set of words within the text window. The format of this dialog box is shown in Figure 4.5 (a). 
There are two display boxes and two command buttons.

1. Search string box. In this box, the user can type the desired text string. The cursor is placed in the right side of the box for the Arabic text. If the user wants to type an English text, the 'US' button has to be clicked or Alt + left-Shift has to be pressed. If the user selects a specified string from the text window, it will appear automatically in the search string box.

2. Direction box. This box specifies the search direction with respect to the current cursor position, either up or down. The default direction is down. The search will continue in the same direction until the end of the file is reached (in case of down direction) or the beginning of it is reached (in case of up direction).

3. Search (بإ) button. It is the default command button (i.e., pressing ENTER is equivalent to clicking this button). Clicking this button causes the APE to start searching for the typed string. If the search-string is found in the text window, it will be highlighted. Clicking this button again causes the APE to search for the second occurrence of that string, and so on. If the search-string is not found in the direction specified, a message is displayed to the user.

4. Cancel (إلغاء) button. Cancel the search process. The search dialog box will not terminate until this button is clicked or the left-upper icon is clicked.

\subsubsection{Replace Dialog Box}

This dialog box is activated when the user wants to find and replace a particular word or set of words within the text window. The format of this dialog box is shown in Figure 4.7 . 


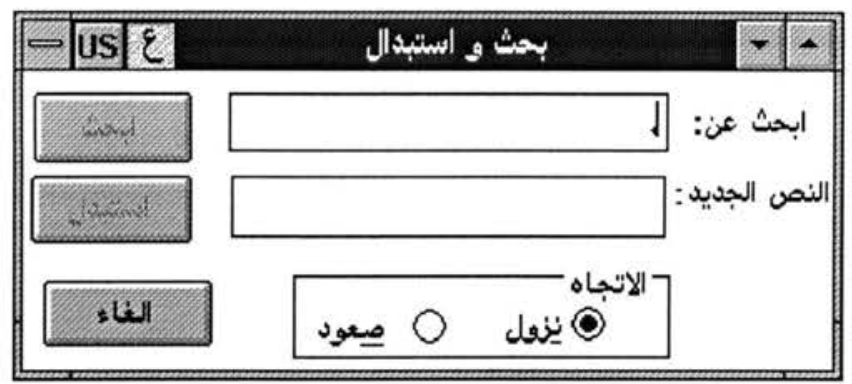

Figure 4.7 Find and Replace Dialog Box

There are three display boxes and three command buttons.

1. Search string box. The function of this box is similar to the function of the search string box in the Find dialog box.

2. Replace string box. The user may type the text that is going to replace the string in the search string box. If this box is empty that means the user wants to delete the text in the search string box. As in the search string box, the default language is Arabic.

3. Direction box. The function of this box is similar to the function of the direction box in the Find dialog box.

4. Search (ابحت button. The function of this box is similar to the function of the search button in the Find dialog box.

5. Replace (استبدل) button. This button is inactive (does not respond) until the first occurrence of the search-string is found. When the user clicks this button, the current highlighted text is replaced with the string in the replace string box.

6. Cancel (إلغاء) button. The function of this box is similar to the function of the cancel button in the Find dialog box.

\subsubsection{GoTo Line Dialog Box}

This dialog box is activated when the user wants to go to a specific line in the text window. The format of this dialog box is shown in Figure 4.8. 


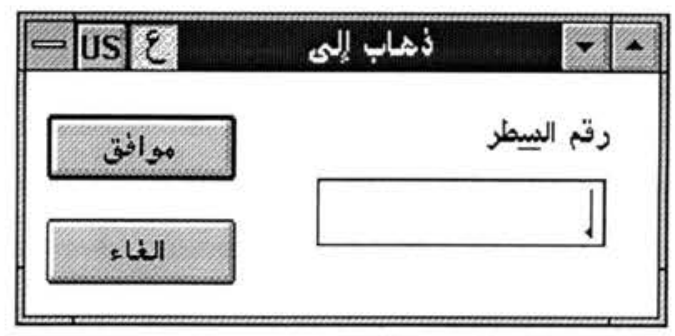

Figure 4.8 GoTo Dialog Box

There are one text box and two command buttons.

1. Line number box. If the user writes a number and presses ENTER (or clicks OK button), the cursor will jump to the beginning of that line number. If the number is invalid (negative number, no number is entered, or a non numeric character), nothing will be performed. If the number is larger than the last line in the text window, the cursor will jump to the last line in the document. Jumping to the first line in the text window can also be accomplished by pressing $\mathrm{Ctrl}+$ Home keys.

2. OK (موافت) button. It is the default command button. Clicking this button causes the cursor to jump to the specified line.

3. Cancel (إلغاء) button. It returns the APE to the status before calling the GoTo dialog box.

\subsubsection{Print Dialog Box}

It is activated when the user wants to print the current source code, compilation output, or the execution results. The format of this dialog box is shown in Figure 4.9.

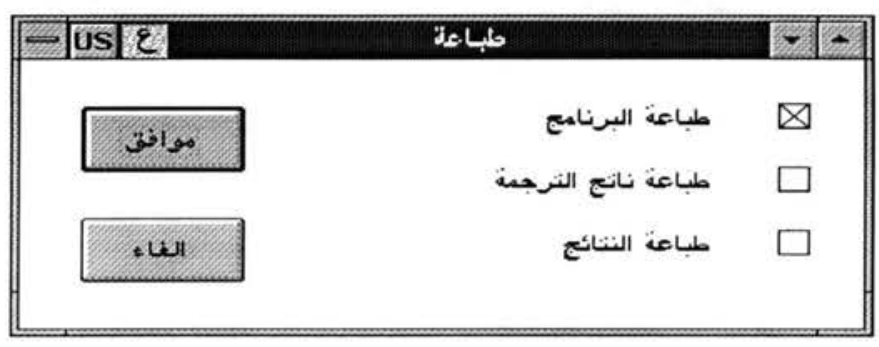

Figure 4.9 Print Dialog Box 
There are three check boxes and two command buttons.

1. Program check box. The default of this box is checked. When this box is checked, the APE will print the current user program (text window content). The APE prints at the beginning of each page the file name. Each page will have at most 50 lines followed by the page number.

2. Compilation-output check box. The default of this box is not checked. When this box is checked, the APE will print the current compilation window content (explained in the following section). The APE prints at the beginning of each page the following phrase نتيجة ترجمة >اسم الملف> (the result of compiling <file name>). Each page will have at most 50 lines followed by the page number. If the compilation window is invisible, the printer prints nothing.

3. Result check box. The default of this box is not checked. When this box is checked, the APE will print the current execution window content (explained in the following section).

The APE prints at the beginning of the first page the following phrase (the results). If the execution window is invisible, the printer prints nothing.

4. OK (موانت) button. It is the default command button. Clicking this button causes the attached printer, if any, to start printing the checked boxes.

5. Cancel (إلغاء) button. It returns the APE to the status before calling the Print dialog box.

\subsection{COMPILATION AND EXECUTION PROCESS}

When a programmer compiles a program, the APE window splits into two windows, the program window and the compilation window (display window). The 
compilation window contains the error messages, if any, and some other helpful information such as time of compilation, number of lines compiled. During the compilation process, a yellow traffic light icon turns on to indicate that the compilation process is in progress. If there is no error, the green light will be on. In case of errors, the red light will be on. There is a direct connection between each error message and its corresponding line in the source code that produces the error. Figure 4.10 depicts the APE windows after an unsuccessful compilation. The highlighted lines are the statement in the source code that causes the error and the corresponding error message. Note that the text color of the compilation window is red indicating that some errors has been encountered. Note also that the traffic light of the execution icon is turned red. The APE also supports interactive modification of the source code. In other words, the programmer can switch from the compilation window to the source code window easily without loosing any of these windows. Switching from a window to another can be accomplished by pressing the tab key. Figure 4.11 shows the APE windows after a successful compilation. Note that both the text color of the compilation window and the execution traffic icon are in green.

When a program is error-free, it becomes ready for execution. the APE creates a new window for execution when the user executes a program. The default language in the execution window is Arabic. If a run-time error occurs, an error message will be displayed and the execution will be aborted. As long as the source code is not altered, the programmer can execute the program as many times as necessary without the need for recompilation. Figure 4.12 shows the execution window after the end of an execution process. The program shown partially in this figure creates a linked list and then displays its elements as first-in last-out. Pressing F7 (End of Compilation) dismisses the compilation and execution windows and returns the program window to its original size. 
The execution window and the Print dialog box are designed by the APE to be the top-most windows in the system. Therefore, both windows will be on top of all other windows even if the user switches to another software. The title of the execution window is the name of the executable file. When the execution terminates, the window will be locked (the window content cannot be altered) and its title will indicate the termination of the execution.

If a user program has neither a read from the standard input nor a write to the standard output, the execution window will not show up. Also if there is read from the standard input and the output is to be sent to a file, the execution window has to be dismissed before the output file can be opened. When the execution window is dismissed, the buffered output is transferred to the output file.

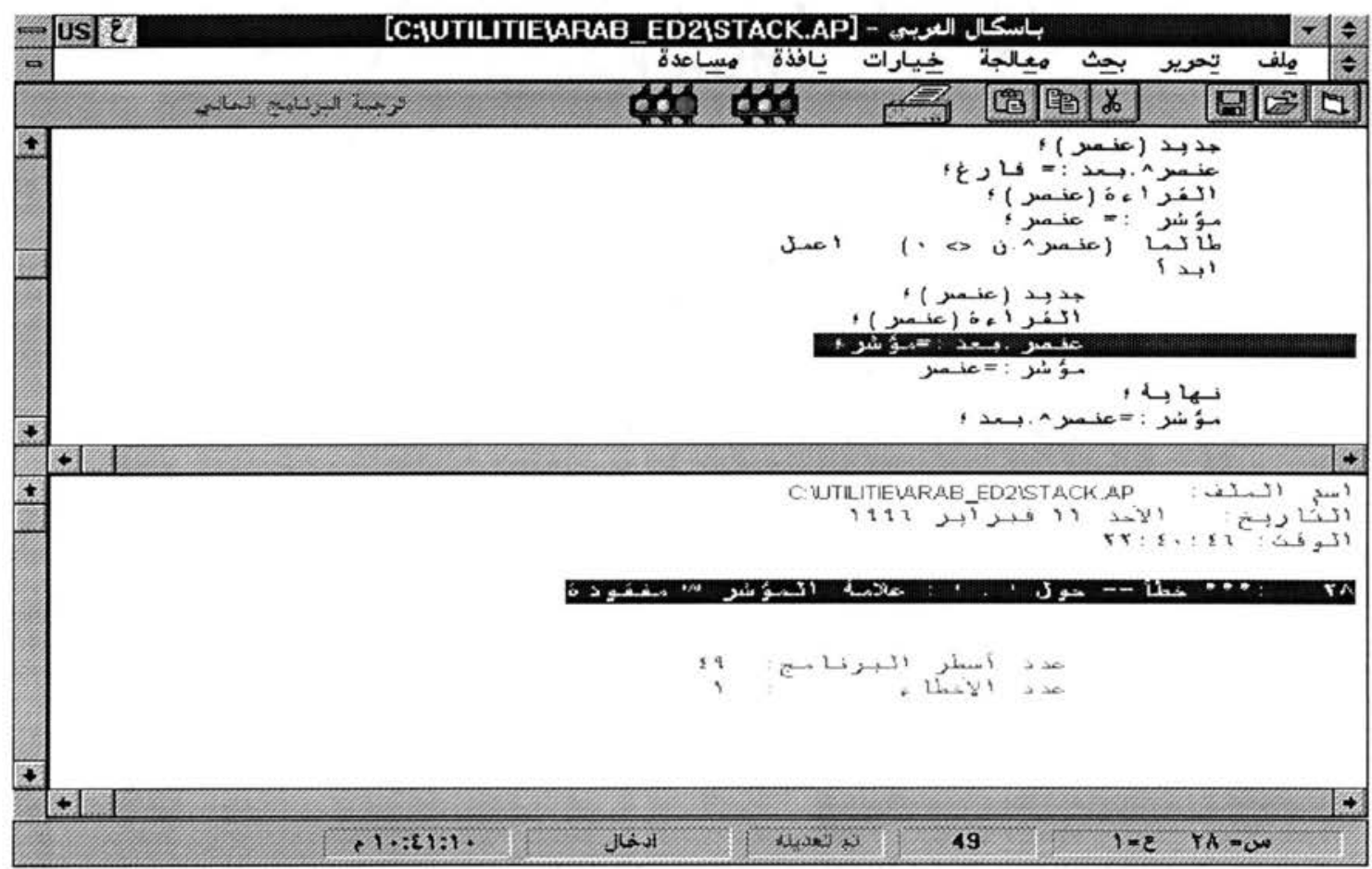

Figure 4.10 A snapshot of the compilation window (unsuccessful compilation) 


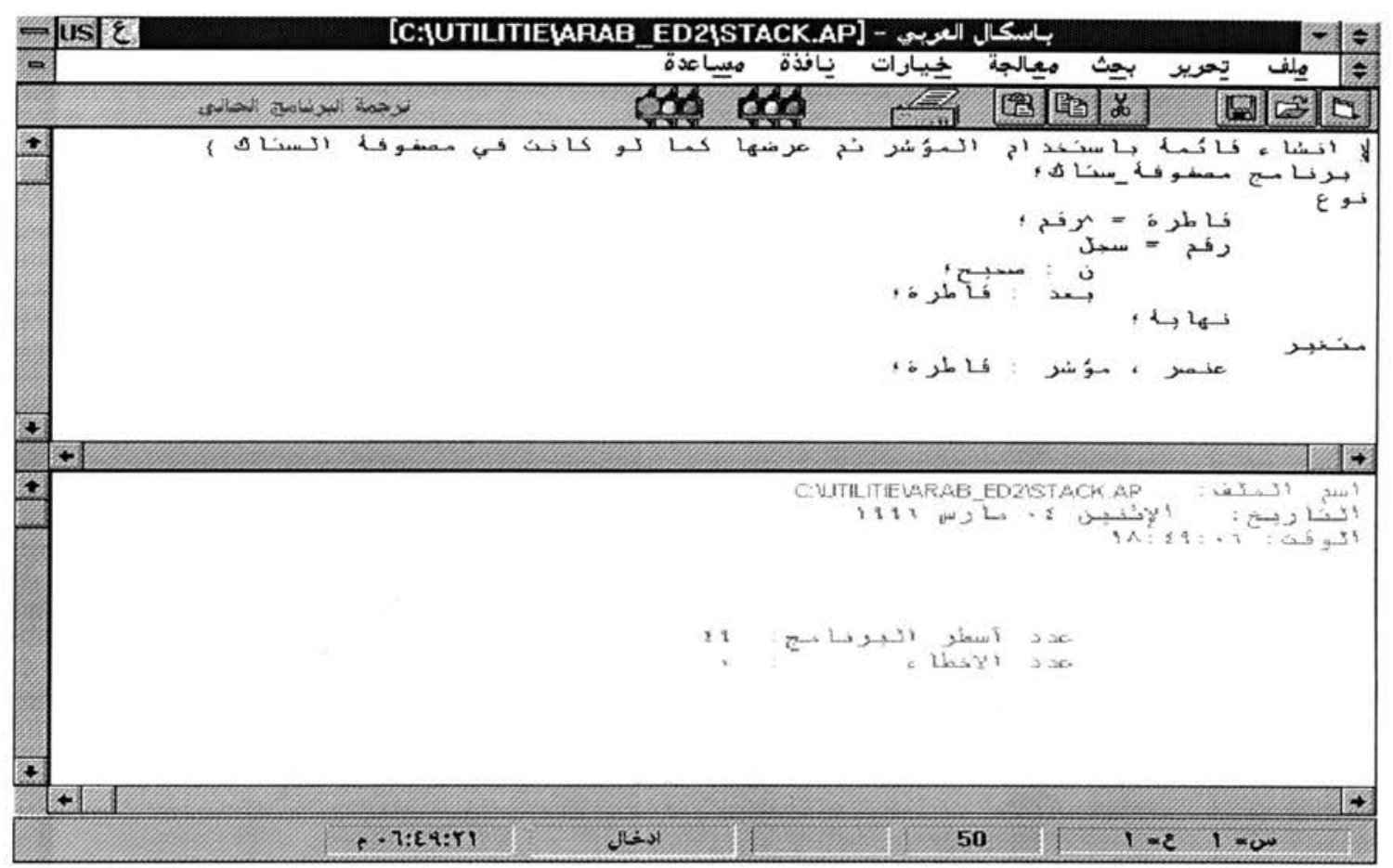

Figure 4.11 A snapshot of the compilation window (successful compilation)

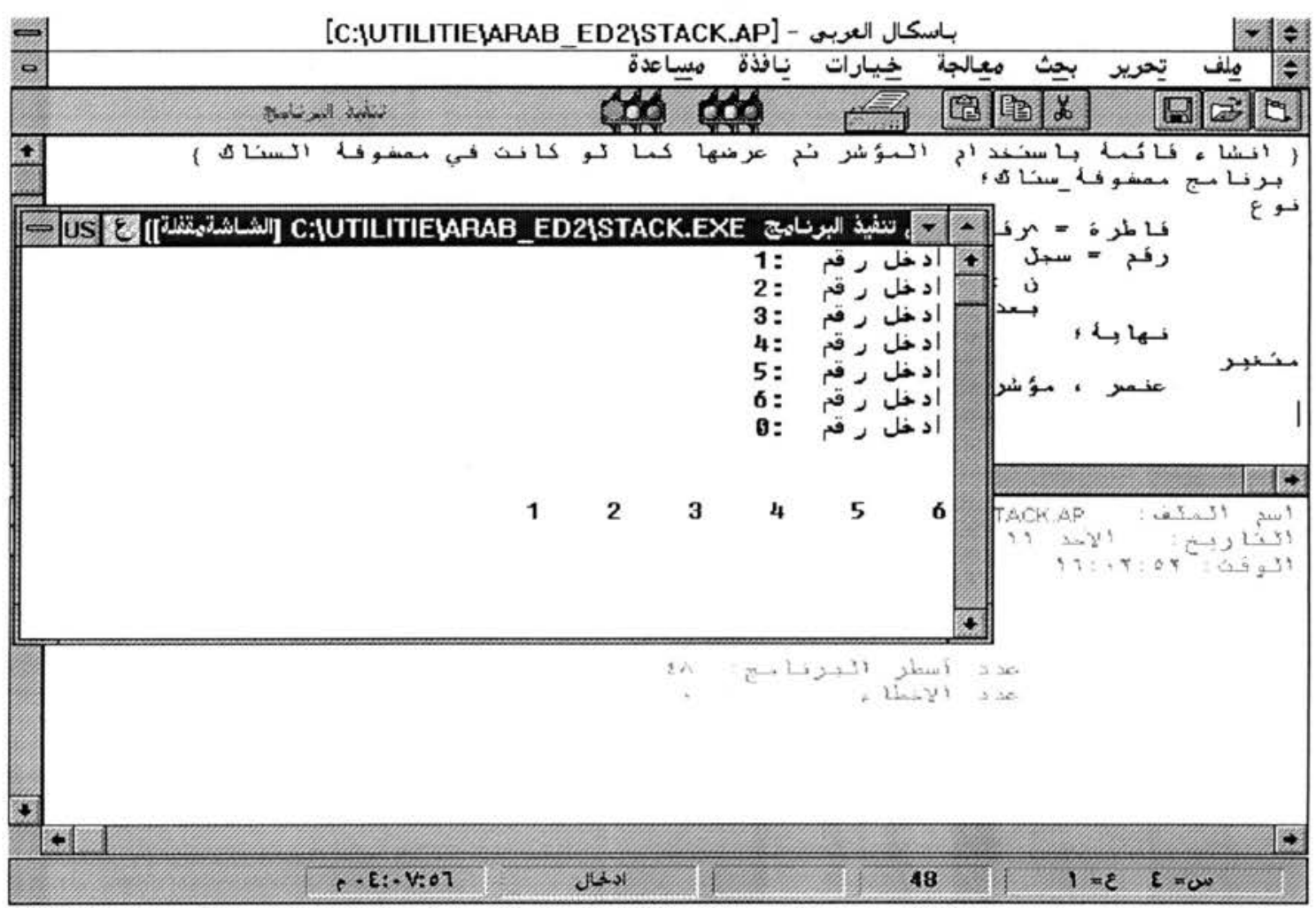

Figure 4.12 The APE including the execution window 


\subsection{APE ALGORITHMS}

The APE has been developed using Visual Basic which is an event-driven programming language. Figure 4.13 illustrates the general software architecture of the APE. A dialog box in the figure is a special window that prompts the user to supply information needed by the software to continue with the application. A handler is a piece of code that performs some actions in response to some events. As shown in the figure, there are mainly ten handlers that control the APE functions. The following subsections describe the algorithms and actions of these handlers. The last subsection (4.4.11) sketches the algorithm for controlling the execution window

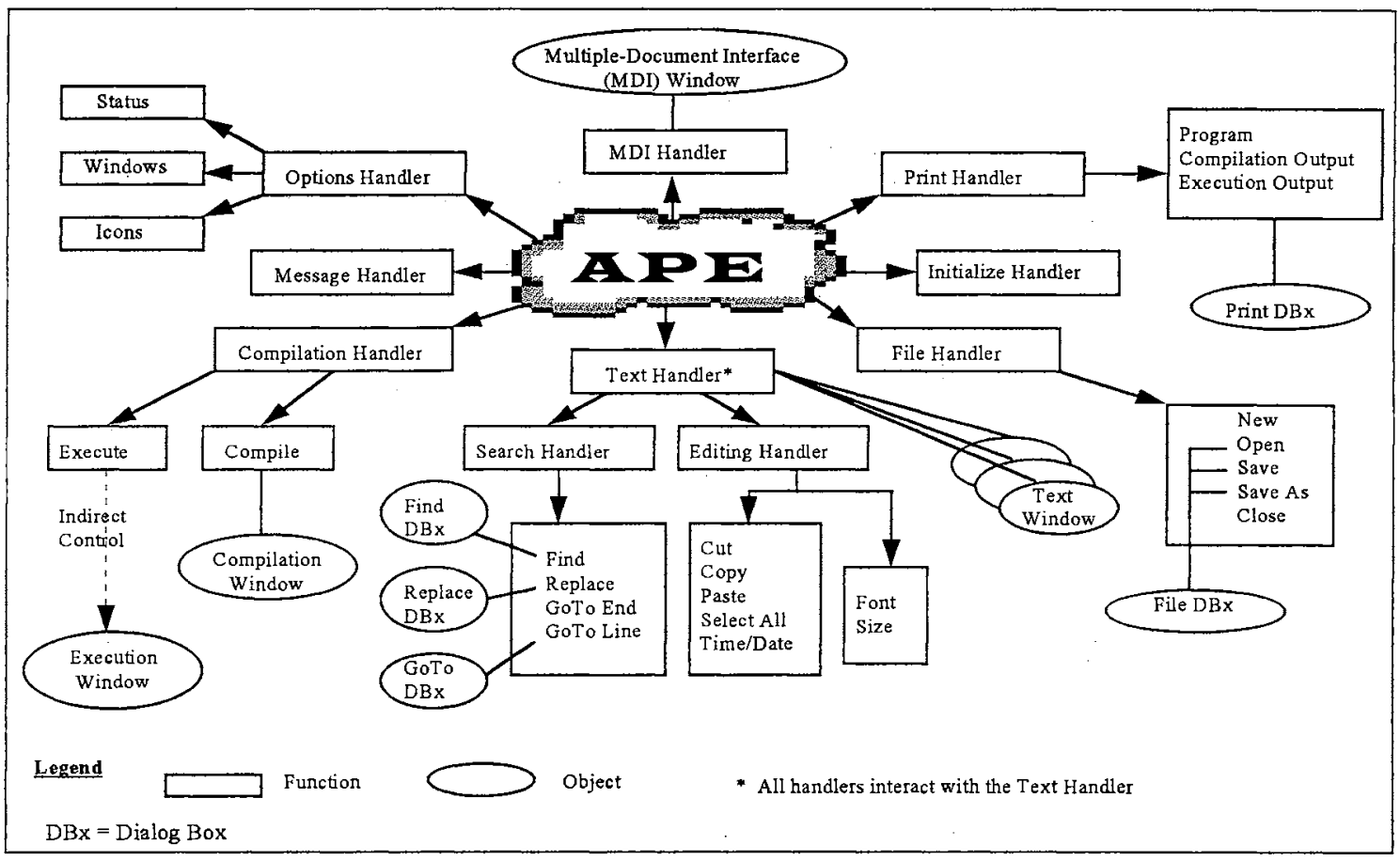

Figure 4.13 Software Architecture of the APE

\subsubsection{MDI handler}

The MDI handler is the handler that is responsible for all actions to be taken in response to the main window events. The MDI handler also handles the events for all the 
objects included in the MDI window such as toolbar icons, statusbar items, and the menu items that are available when there is no file opened (as in Figure 4.3). Table 4.1 describes the actions related to the MDI window.

Table 4.1 Actions related to the MDI Window

\begin{tabular}{|c|c|c|}
\hline Object & Event & Action \\
\hline MDI window & load & $\begin{array}{l}\text { show the MDI window, call Initialize } \\
\text { handler, get the most-recently-used-files, } \\
\text { and open a new text window. }\end{array}$ \\
\hline MDI window & unload & $\begin{array}{l}\text { close/save all opened files (text windows) } \\
\text { and quit the Help Window, if any. }\end{array}$ \\
\hline New-icon and menu-new & click & call File new (see File handler) \\
\hline $\begin{array}{l}\text { all icons in the toolbar and } \\
\text { all items in status bar }\end{array}$ & move over & display a help message \\
\hline open-icon and menu-open & click & call File open (see File handler) \\
\hline save-icon & click & call Save file (see File handler) \\
\hline cut-icon & click & call Cut procedure (see Editing handler) \\
\hline copy-icon & click & call Copy procedure (see Editing handler) \\
\hline paste-icon & click & call Paste procedure (see Editing handler) \\
\hline print-icon & click & show the Print dialog box \\
\hline compile-icon & click & $\begin{array}{l}\text { call Compile procedure (see Compilation } \\
\text { handler) }\end{array}$ \\
\hline run-icon (red or yellow lights) & click & display a correction message \\
\hline run-icon (green) & click & $\begin{array}{l}\text { call Execute procedure (see Compilation } \\
\text { handler) }\end{array}$ \\
\hline menu-exit & click & $\begin{array}{l}\text { perform Window-Close function (system } \\
\text { command) }\end{array}$ \\
\hline status-position & double-click & show the GoTo dialog box \\
\hline status-size & double-click & $\begin{array}{l}\text { move the cursor to the end of the text } \\
\text { window }\end{array}$ \\
\hline menu-option-toolbar & click & flip the visibility of the toolbar \\
\hline menu-option-statusbar & click & flip the visibility of the statusbar \\
\hline menu-recent-files & click & call opening-file (see File handler) \\
\hline menu-help & click & $\begin{array}{l}\text { open the main software help window } \\
\text { (contains information about the APE and } \\
\text { the Arabic Pascal) }\end{array}$ \\
\hline-- & F1 key & display the APE help window \\
\hline toolbar & resize & $\begin{array}{l}\text { call Options handler to adjust the icons } \\
\text { according to the new dimensions }\end{array}$ \\
\hline statusbar & resize & $\begin{array}{l}\text { call Options handler to adjust the items } \\
\text { according to the new dimensions }\end{array}$ \\
\hline
\end{tabular}




\subsubsection{Initialize Handler}

Most of the initializations to dialog boxes take place during the design phase. As it is known in Visual Basic [Ama94b], any window or dialog box can be initialized to specific size, place, and attributes during a so-called 'design mode'. Therefore, the APE initial windows are designed by choosing the appropriate properties. However, the initialize handler performs the necessary initializations for non-dialog box related issues. These issues are:

Defining the global constants

Declaring the MS-Windows library functions and procedures that are used by the $A P E$

Converting the keyboard to the Arabic mode

Setting the following:

the working directory to the directory containing the APE insert/overwrite mode to insertion cursor position to line one column one (right side)

Software title to 'باسكال العربي' (Arabic Pascal)

font size to 12

\subsubsection{File Handler}

The File handler deals with all activities related to files including the File dialog box. The procedures that handle the actual file opening, saving, and checking are as follows:

1. Open-file procedure

show the File dialog box

get the file name from the File dialog box 
unload File dialog box

if the file exists call opening-file procedure (see next)

update the most-recently-used-files to include this file

2. Opening-file procedure

open the file for reading and writing and load it in a text window

if the file size is over $32 k$, display an error message to the user

make all icons visible to the user

set the cursor in the upper-right corner

set the line and column numbers to 1

calculate the file length (in terms of lines) and display it in the status bar

3. New-file procedure

show a text window titled as "untitled : index"

make all icons visible to the user

set the line and column number to 1

4. Save-file procedure

if the file has no name (untitled) show the File dialog box and get a file name from the user

if file name already exists, display a warnning message to the user

write the text window content in the file

update the most-recently-used-files to include this file name

The actions related to the File dialog box are described in Table 4.2

Table 4.2 Actions related to the File Dialog Box

\begin{tabular}{|l|l|l|}
\hline \multicolumn{1}{|c|}{ Object } & \multicolumn{1}{|c|}{ Event } & \multicolumn{1}{c|}{ Action } \\
\hline file-type box & click & $\begin{array}{l}\text { select either } * * \text { or } * \text {.ap } \\
\text { update the file name box and file list accordingly }\end{array}$ \\
\hline directories box & change & $\begin{array}{l}\text { propagate directory changes to current directory path } \\
\text { and file list }\end{array}$ \\
\hline drives box & change & propagate drive change to current directory path and \\
\hline
\end{tabular}




\begin{tabular}{|l|l|l|}
\hline & & file list \\
\hline file list box & click & echo the selected name in the file name box \\
\hline file list box & double-click & $\begin{array}{l}\text { echo the selected name in the file name box and do as } \\
\text { OK click }\end{array}$ \\
\hline file name box & change & if empty then disable the OK button \\
\hline--- & F1 key & display the file help window \\
\hline OK button & click & $\begin{array}{l}\text { if incorrect name then send a message } \\
\text { else return the file name }\end{array}$ \\
\hline Cancel button & click & hide the File dialog box \\
\hline File dialog box & load & set the keyboard language to English \\
\hline File dialog box & unload & set the keyboard language back to Arabic \\
\hline
\end{tabular}

\subsubsection{Text Handler}

The main function of the Text handler is to control the events that happen in the text window. The Text Handler has control over the Editing Handler and the Search Handler which are specialized handlers that deal with text editing and search activities within the text window, respectively. Table 4.3 describes the actions taken when an event occurs in the text window.

Table 4.3 Actions related to the Text window

\begin{tabular}{|l|l|l|}
\hline \multicolumn{1}{|c|}{ Object } & Event & \multicolumn{1}{c|}{ Action } \\
\hline text window & resize & adjust the text window to the new size \\
\hline text window & unload & $\begin{array}{l}\text { close the active text window (save the file, if needed) } \\
\text { If all text windows are closed, make all icons related to } \\
\text { text window invisible, and refresh the statusbar (the APE } \\
\text { window will looks like Figure 4.3) }\end{array}$ \\
\hline menu-close & click & same as event 'unload' above \\
\hline menu-save & click & same as save-icon \\
\hline menu-save-as & click & show the File dialog box \\
\hline menu-print & click & same as print-icon \\
\hline menu-undo & click & undo the last editing action \\
\hline menu-cut & click & same as cut-icon \\
\hline menu-copy & click & same as copy-icon \\
\hline menu-paste & click & same as paste-icon \\
\hline menu-delete & click & delete the last keyed character or the highlighted text \\
\hline menu-select-all & click & call Editing handler \\
\hline menu-date & click & call Editing handler \\
\hline menu-find & click & call Search handler \\
\hline menu-replace & click & call Search handler \\
\hline menu-Goto-line & click & call Search handler \\
\hline menu-Goto-end & click & let cursor jump to the end of the text window \\
\hline
\end{tabular}




\begin{tabular}{|c|c|c|}
\hline menu-compile & click & same as compile-icon \\
\hline menu-run & click & same as run-icon (green and red) \\
\hline $\begin{array}{l}\text { menu- } \\
\text { compilation-end }\end{array}$ & click & $\begin{array}{l}\text { hide the run-icon, hide the compilation window, restore } \\
\text { the original font size for text window, and perform text- } \\
\text { window-resize }\end{array}$ \\
\hline menu-reduce-font & click & call Editing handler \\
\hline menu-enlarge-font & click & call Editing handler \\
\hline menu-cascade & click & call Options handler \\
\hline menu-tile & click & call Options hander \\
\hline menu-arrange & click & call Options handler \\
\hline $\begin{array}{l}\text { menu-list-of- } \\
\text { opened-files }\end{array}$ & click & $\begin{array}{l}\text { bring to front (to be the active text window) the chosen } \\
\text { file }\end{array}$ \\
\hline-- & F1 key & display the APE help window \\
\hline text window & change & $\begin{array}{l}\text { modify the file status (in statusbar) to 'Modified' } \\
\text { modify the file size (number of lines), if needed. }\end{array}$ \\
\hline text window & $\begin{array}{l}\text { got } \\
\text { focus }\end{array}$ & $\begin{array}{l}\text { calculate the current line number and the current column } \\
\text { number and display that in the statusbar. Calculate the file } \\
\text { size and display that in the statusbar }\end{array}$ \\
\hline text window & $\begin{array}{l}\text { key } \\
\text { down }\end{array}$ & $\begin{array}{l}\text { (used for control keys) if Ins key is pressed modify the } \\
\text { statusbar }\end{array}$ \\
\hline $\begin{array}{l}\text { compilation } \\
\text { window }\end{array}$ & $\begin{array}{l}\text { got } \\
\text { focus }\end{array}$ & $\begin{array}{l}\text { if the text color is green (no errors), then there is no } \\
\text { correspondence between the text window and the } \\
\text { compilation window } \\
\text { else if the line starts with a number then highlight it and } \\
\text { its corresponding line in the text window }\end{array}$ \\
\hline $\begin{array}{l}\text { compilation } \\
\text { window }\end{array}$ & key up & $\begin{array}{l}\text { ignore all keys except ENTER and TAB, } \\
\text { if ENTER do as got focus } \\
\text { if TAB switch from/to the text window }\end{array}$ \\
\hline
\end{tabular}

\subsubsection{Editing Handler}

This handler does the actual editing functions. There are two types of editing functions: functions related to selected text or insertion in current position (namely cut, copy, paste, select all, and time/date) and functions related to the entire text window (namely font size).

1. Cut: copy selected text to Clipboard and delete selected text from the text window

2. Copy: copy selected text to Clipboard

3. Paste: place text from Clipboard into the current position in text window

4. Select all: highlight all the text in the text window

5. Time/date: insert the current date and time in the current cursor position

5. Reduce font: reduce the font size by 1 
6. Enlarge font: increase the font size by 1

\subsubsection{Search Handler}

The search handler takes care of searching activities. There are three dialog boxes related to this handler: Find, Replace, and GoTo line: Tables 4.4, 4.5, and 4.6 describe the actions related to these dialog boxes, respectively. The main algorithm of the search handler is as follows:

case find:

if there is a highlighted text in the text window, copy it in the search-string

else copy the previous search-string, if any, in the current search-string

show the find dialog box call find-string (performed if the user clicks search, see next) case replace:

if there is a highlighted text in the text window, copy it in the search-string

else copy the previous search-string, if any, in the current search-string show the replace dialog box call find-string (performed if the user clicks either search or replace, see next)

case GoTo line:

show the GoTo line dialog box (the action is taken within the dialog box, see table 4.6) 
The algorithm for find-string is as follows:

if the direction of search is down (from the cursor position and downward)

copy the text from the current cursor position to the end of the text window into a temporary string

find the first occurrence of the search-string

else copy the text from the current cursor position to the beginning of the text window into a temporary string

find the last occurrence of the search-string

if the search-string is not found display a message to the user

else highlight the found text in the text window

move the cursor to the end of that occurrence

Table 4.4 Actions related to the Find Dialog Box

\begin{tabular}{|l|l|l|}
\hline \multicolumn{1}{|c|}{ Object } & Event & \multicolumn{1}{c|}{ Action } \\
\hline $\begin{array}{l}\text { Find dialog } \\
\text { box }\end{array}$ & load & make find button disabled and the search direction down \\
\hline direction & click & flip the direction of search \\
\hline-- & F1 key & display find help window \\
\hline find button & click & read the search-string, then call find-string \\
\hline cancel button & click & $\begin{array}{l}\text { save the text in the search-string box and unload the find } \\
\text { dialog box }\end{array}$ \\
\hline search-string & change & $\begin{array}{l}\text { if the search string is empty, disable the find button, } \\
\text { else enable it }\end{array}$ \\
\hline
\end{tabular}

Table 4.5 Actions related to the Replace Dialog Box

\begin{tabular}{|l|l|l|}
\hline \multicolumn{1}{|c|}{ Object } & \multicolumn{1}{c|}{ Event } & \multicolumn{1}{c|}{ Action } \\
\hline $\begin{array}{l}\text { Replace dialog } \\
\text { box }\end{array}$ & load & $\begin{array}{l}\text { make find and replace buttons disabled, and the search } \\
\text { direction down }\end{array}$ \\
\hline direction & click & same as in find dialog box \\
\hline-- & F1 key & display replace help window \\
\hline find button & click & $\begin{array}{l}\text { read the search-string, then call find-string, and enable the } \\
\text { replace button }\end{array}$ \\
\hline replace button & click & $\begin{array}{l}\text { cut the original text, read the replace-string, if any, paste } \\
\text { the replace-string, then call find-string }\end{array}$ \\
\hline search-string & change & same as in find dialog box \\
\hline
\end{tabular}


Table 4.6 Actions related to the GoTo line Dialog Box

\begin{tabular}{|c|c|c|}
\hline Object & Event & Action \\
\hline OK button & click & $\begin{array}{l}\text { read the line-number } \\
\text { if valid number }(>0) \text { move the cursor to the beginning of the } \\
\text { specified line } \\
\text { unload the GoTo dialog box }\end{array}$ \\
\hline Cancel button & click & unload the GoTo dialog box \\
\hline-- & F1 key & display goto help window \\
\hline
\end{tabular}

\subsubsection{Print Handler}

The print handler is the piece of code that is responsible for printing the source code, the compilation output, and the execution results. There is only one dialog box related to this handler. Table 4.7 describes the actions related to that dialog box. The main algorithm of the print handler is as follows:

case print the source code (user program):

copy the text window content in a temporary file for formatting

the page-header gets the file name (to be printed on top of

$$
\text { all pages) }
$$

call do-printing (see below)

case print the compilation output:

if there is no compilation window, display an error message and then exit

copy the compilation window content in a temporary file for

$$
\text { formatting }
$$

the page-header gets the following string:

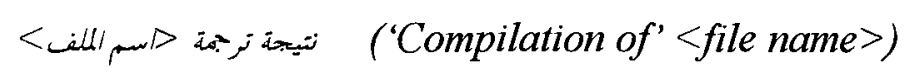

call do-printing (see below)

case printing the execution result:

if there is no execution window, display an error message 
and then exit

copy the execution window content in a temporary file for

formatting

the page-header gets the string النتائج ('The Results')

call do-printing (see below)

The algorithm for do-printing is as follows:

while there is a line

copy the line in a temporary buffer

if top of the page, print the page-header

copy the line to the printer buffer

if bottom of the page, print the page number centered and

increment the page number

if last line, print empty lines until the page end then print the page number

send print command to the printer

Table 4.7 Actions related to the Print Dialog Box

\begin{tabular}{|l|l|l|}
\hline \multicolumn{1}{|c|}{ Object } & Event & \multicolumn{1}{c|}{ Action } \\
\hline Print program-check-box & click & flip the program-check-box (enabled/disabled) \\
\hline Print compilation-check-box & click & $\begin{array}{l}\text { flip the compilation-check-box } \\
\text { (enabled/disabled) }\end{array}$ \\
\hline Print result-check-box & click & flip the result-check-box (enabled/disabled) \\
\hline OK button & click & start printing the checked boxes \\
\hline--- & F1 key & display print help window \\
\hline Cancel & click & unload the Print dialog box (do not print) \\
\hline
\end{tabular}

\subsubsection{Options Handler}

This handler is responsible of keeping track of the statusbar, the opened windows, and the icons, if any. Table 4.8 describes the action taken for each request received by the option handler. 
Table 4.8 Actions taken by the Option handler

\begin{tabular}{|l|l|}
\hline \multicolumn{1}{|c|}{ Request } & \multicolumn{1}{c|}{ Action } \\
\hline Cascade windows & make a system call to cascade all available text windows \\
\hline Tile windows & make a system call to tile all available text windows \\
\hline Arrange minimized windows & make a system call to arrange all icons \\
\hline $\begin{array}{l}\text { resize (window max. to } \\
\text { normal) the MDI window }\end{array}$ & $\begin{array}{l}\text { if the toolbar is visible, shift all the toolbar icons left to fit } \\
\text { in the normal window. Do the same for all items in the } \\
\text { statusbar, if it is visible. If there is a text window, resize } \\
\text { it. }\end{array}$ \\
\hline $\begin{array}{l}\text { resize (from normal to max.) } \\
\text { the MDI window }\end{array}$ & $\begin{array}{l}\text { if the toolbar is visible, shift all the toolbar icons right to } \\
\text { start from the right corner in the maximized window. Do } \\
\text { the same for all items in the statusbar, if it is visible. If } \\
\text { there is text window, resize it. }\end{array}$ \\
\hline
\end{tabular}

\subsubsection{Message Handler}

Whenever a message needs to be sent to the user, this handler is called. This handler is responsible for displaying the message in Arabic (including the command buttons) with right alignment. Messages can be classified based on their content into three types: error messages, informative messages, and dialog messages. The first two types require only an OK button. For dialog messages, the message handler displays two (yes or no) buttons or three (yes, no, and cancel) buttons depending on the message content. Moreover, the message handler may include either an exclamation icon or a question icon within the message. The message handler takes the user response and passes it to the caller to take the appropriate actions. Appendix A lists all APE messages.

\subsubsection{Compilation Handler}

The compilation handler is the mediator between the APE and the Arabic Pascal Compiler (APC). This handler has two main functions: compilation process and execution process. 
1. Compilation process

disable the run-icon, if it was enabled

turn on the yellow signal indicating the compilation progress

split the main window into two windows: text window (reduce its font size)

and compilation window

set the compilation window as a read-only window

if the file (text window) was not saved, save it

call the APC to compile the current file

if there is no error, set the color of the compilation window text to green

and turn on the green traffic light.

else set the color of the compilation window text to red and turn on the red traffic light

display the APC output

if no errors (arrange the program for execution)

call the Turbo Assembler to assemble the program

call the Turbo Linker to link the program

delete the assembly and object files

else highlight the first error in compilation window and its

corresponding line in the text window

2. Execution process

find the executable file name that corresponsds to the active text window execute the program (the execution window handler is responsible for creating and managing the execution window) 


\subsubsection{Execution window handler}

As stated earlier the execution window has to be controlled only by the user program. Therefore, this handler has to make the cursor movement based on the user program. For example, if the user program has some input, the cursor should be shown, otherwise no cursor is shown. If a user types mistakenly some input and then erases it, it should be removed from the input buffer. There are many functions that are handled by this handler, the main ones are:

1. Show cursor

create the caret (cursor)

if the cursor reaches the left side of the window, move it to the next line at the right side of the window

else decrement the cursor position by 1 (move to the left for Arabic)

2. Write text

if the user text is longer than the window zise, break the line into sublines (to control the Arabic display)

count the line characters to move the cursor accordingly

display the text

3. Read text

wait for the user input

keep track of the user input:

if backspace erase the last character from the input buffer and adjust the cursor

if ENTER accept the input buffer and move the cursor to the next line (right side)

if TAB move the cursor 8 spaces 


$$
\begin{aligned}
& \text { if Control keys ignore } \\
& \text { else insert in the input buffer }
\end{aligned}
$$

4. Paint window (required when the execution window is resized or scrolled [Cro94]])

find the area in the execution window that has been altered

(need to be re-painted)

refresh the window

redisplay the text

5. Initialize window

create the window (titled with file name)

show the cursor if there is input

open a text-file to capture the user program input and output

(used when printing the result)

6. Terminate execution

close the text-file

change the window title to indicate the termination of execution

destroy the caret (cursor)

\subsection{HELP WINDOWS}

In general, the creation of the on-line help is separate from the MS-Windows application and it can be invoked as a stand-alone application. After the creation of on-line help, it can be attached to the software. The APE provides an on-line help file that explains the necessary information needed for dealing with the system. When the user clicks the help menu, the main help window is displayed. This window (Figure 4.13) gives an introduction of the system and leads to two other windows: the APE interface help 
window (Figure 4.14 shows part of this window) and the Arabic Pascal help window (Figure 4.15 shows part of this window). When the user presses F1 key, an explanation about the top most window will be displayed. If, say, the main window is shown (and there is no dialog boxes), the APE interface help window will be displayed. If the user opens the search dialog box and presses F1 key, a help window will show up to explain the search dialog box, and so on.

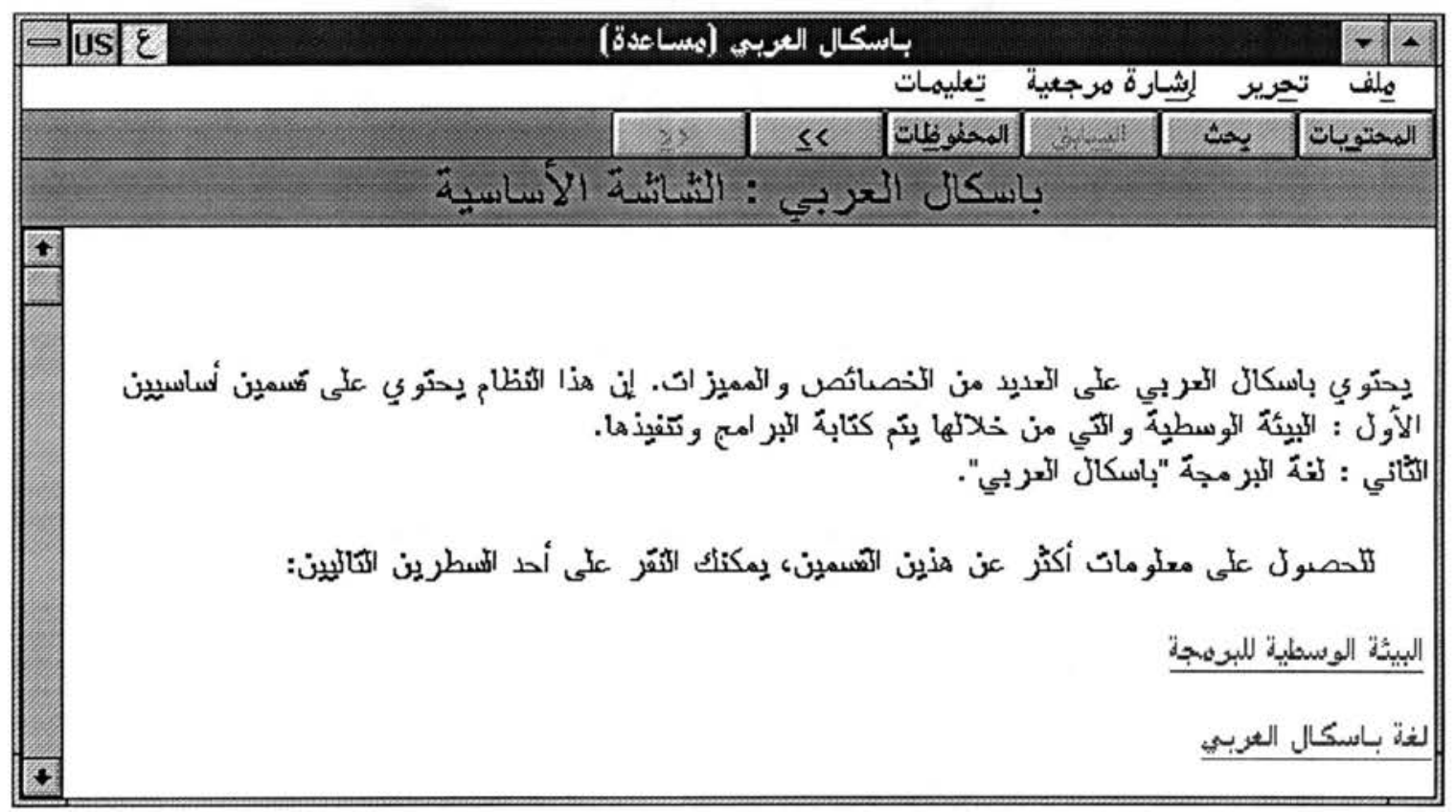

Figure 4.14 The main help window 


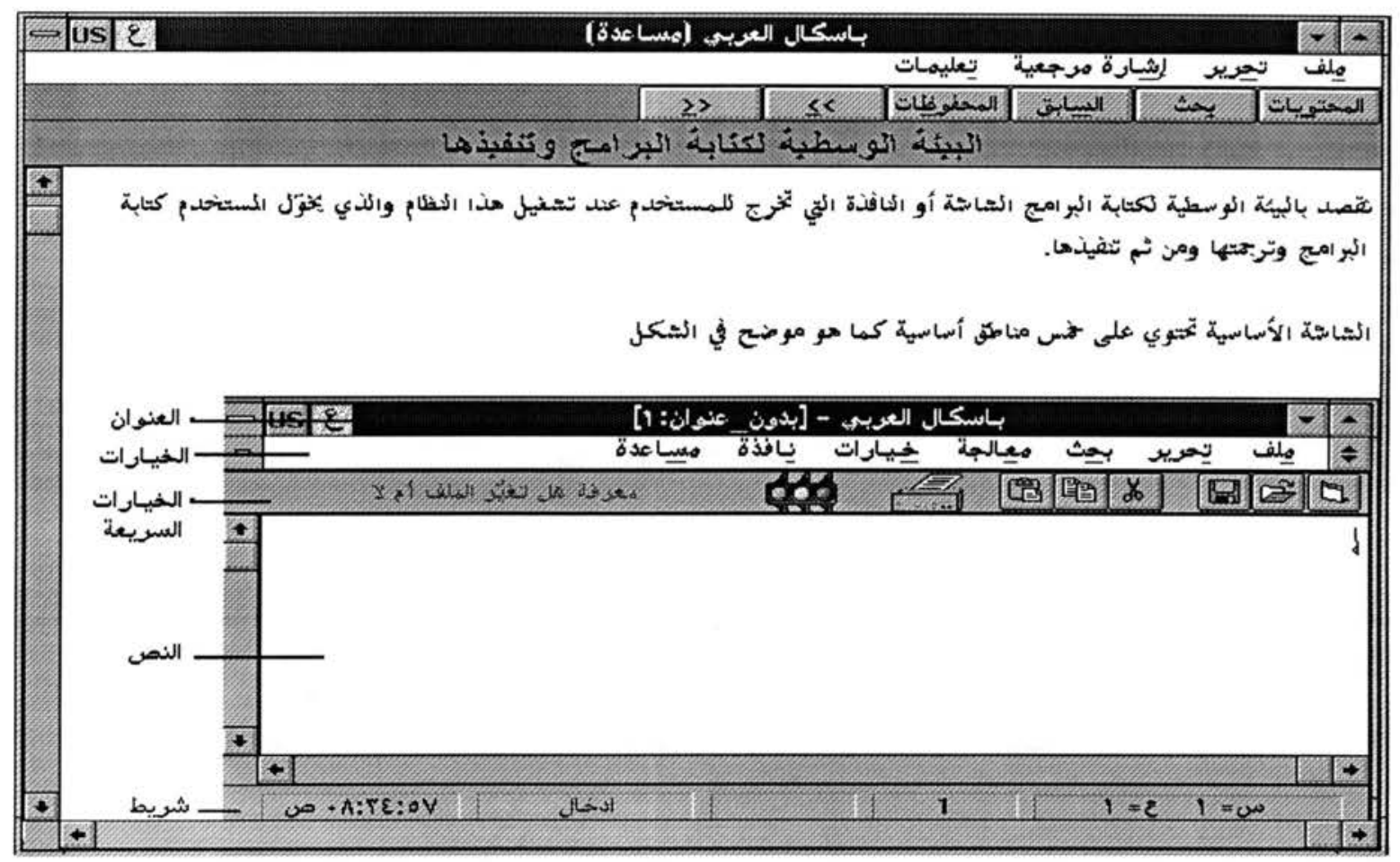

Figure 4.15 Partial display of the APE interface help window

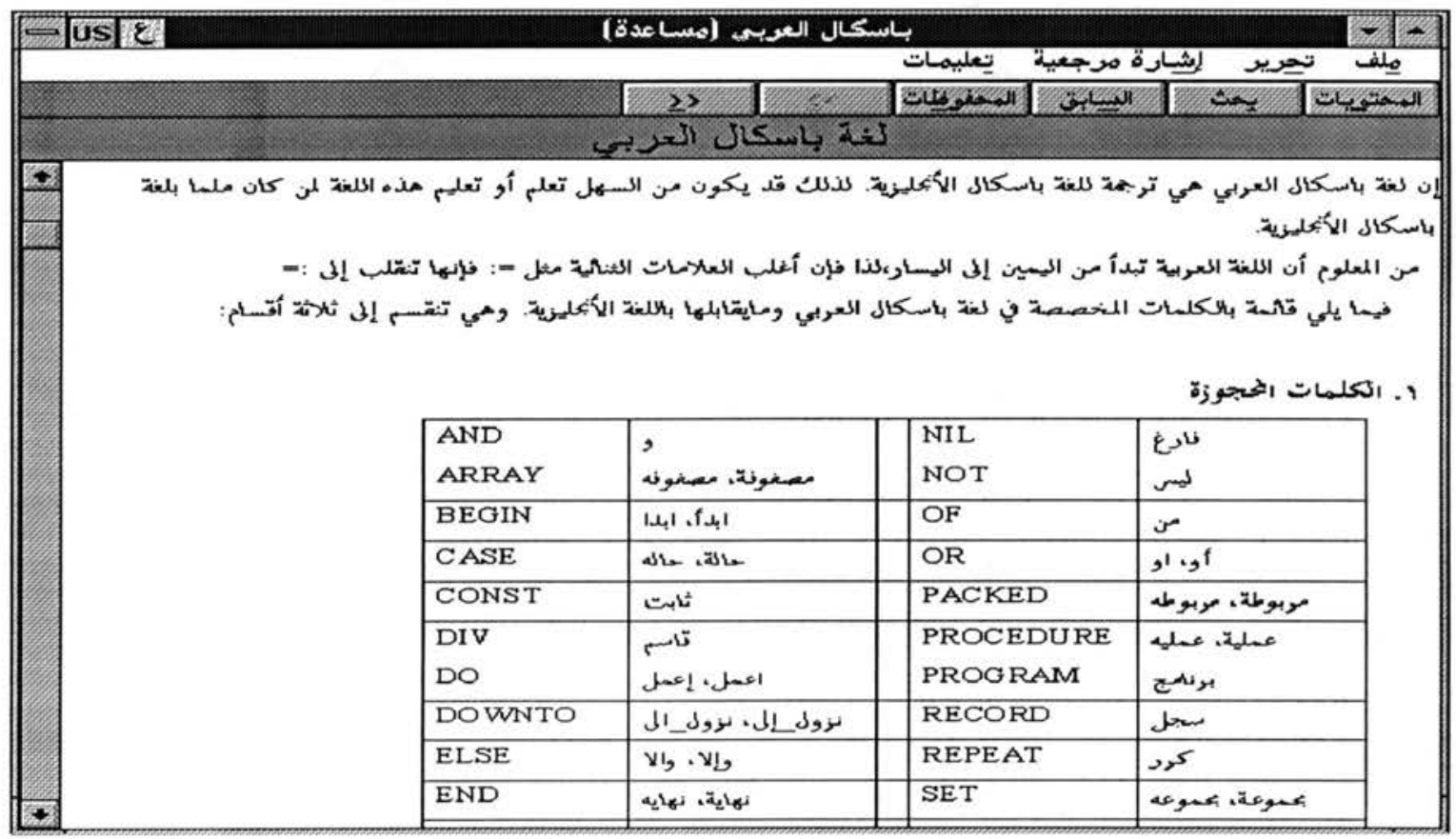

Figure 4.16 Partial display of the Arabic Pascal help window 


\section{CHAPTER 5}

\section{DESIGN AND IMPLEMENTATION OF THE ARABIC PASCAL COMPILER}

A compiler is a computer program that accepts as input the text of a program expressed in a given programming language (source code) and produces an equivalent program in another language (assembly code or object code) [Mak91]. Figure 5.1 shows the main parts of the Arabic Pascal Compiler (APC) with their most common interfaces.

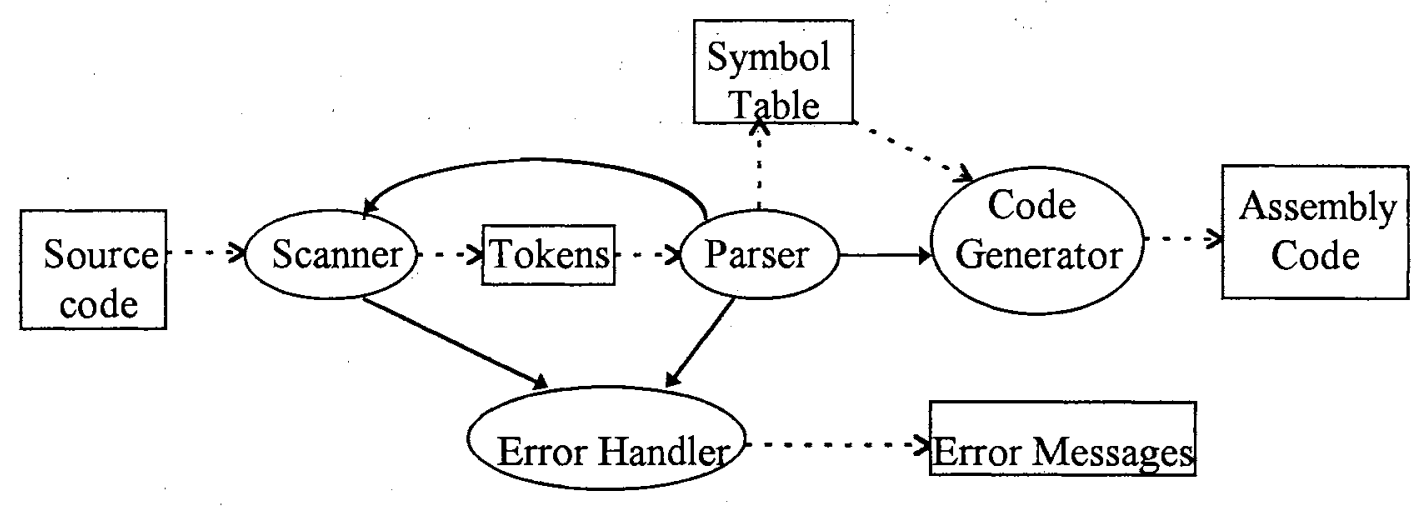

\section{Legend:}

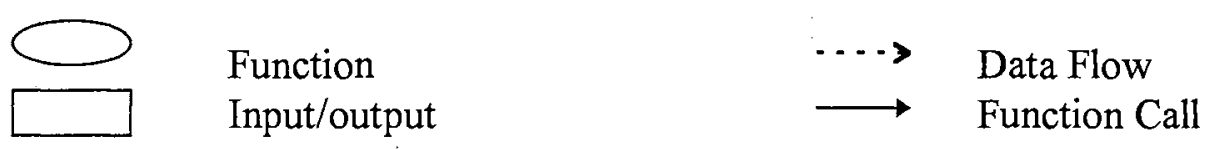

Figure 5.1 Organization of the Arabic Pascal Compiler

As shown in Figure 5.1, there are four essential functions: the scanner, the parser, the code generator, and the error handler. The basic function of the scanner is to read the source text file as a string of characters and to recognize from it a stream of words, 
numbers, and symbols. Each word, number, or symbol is called a token [CJ88]. Details of scanner functions are discussed in Section 5.1. The fundamental task of the parser is to take the stream of tokens as input, build symbol tables, analyze the source program based on the syntax, check the correctness of different types, and finally call the code generator. Section 5.2 is devoted to the description of the parser. The final segment in the APC is the code generator. It generates an equivalent assembly code for the source program. Explanation of the code generator is presented in Section 5.3. During the process of compilation, if an error occurs the error handler is invoked. More explanation of the error handler is in Section 5.4. The last section, Section 5.5, gives examples of two Arabic Pascal programs along with their equivalent English Pascal programs.

The APC is developed in $\mathrm{C}$ and compiled using Turbo $\mathrm{C}$. The compiler generates 8086 assembly code. The generated code is assembled and linked using Turbo Assembler and Turbo Linker [BTA93]. Therefore, the targeted machine is IBM PC or compatibles. We chose this machine because it is the most widely used machine at the personal level. The compiler requires an Arabic interface to write and edit the Arabic Pascal programs.

Before starting the explanation of various parts and algorithms of the APC, we should point out that almost all examples and reserved words mentioned in this chapter are from the Standard English Pascal [Coo83, Tib81, WH86]. Appendixes B-E are devoted to explain the structure and the terms in the Arabic Pascal language.

\subsection{THE SCANNER}

Most of the compiler runtime is spent on lexical analysis in the scanner [PP92, p.48]. The scanner reads line by line from the input file, reducing each line to manageable tokens (words, numbers, strings, and special symbols). It is therefore incumbent upon a 
compiler designer to exert some effort in making the scanner efficient. Since regular grammar is sufficient to fully define all different types of tokens in the Arabic Pascal, a finite-state automaton is adequate to implement the scanner. The scanner performs four major tasks:

1. Removing extraneous blanks, carriage returns, and new-line characters.

2. Removing comments.

\section{Identifying tokens.}

4. Reporting errors it discovers by calling the error handler.

There are two common approaches for the compilation process. The first approach performs the compilation in multi-phases. Each phase is completed for a given source program before the next phase starts. This approach is called multi-pass compilation. An example of this approach is the two-pass compilation which has two scan phases. In the first scan, the compiler resolves all forward references. The second scan does the rest of the compilation. The second approach interleaves or carries out in parallel the phases of compilation in one step. It is called one-pass compilation. This approach solves the problem of forward references by leaving holes in the code where the address needs to appear. When the target address becomes known, the compiler returns to the output code and patches the offset or the branch address with the correct value. This method is called backpatching [Pys88]. The APC uses the latter approach because it better suits blockstructured languages.

Unlike the usual scanning, the Arabic Pascal scanner scans the source code from right to left instead of from left to right. The scanning should be done in this way because the Arabic writing and reading are from right to left. Moreover, the Arabic Pascal scanner does not have the problem of upper and lower cases because these are not applicable in the Arabic characters. 
In the Arabic Pascal, the comment is enclosed between two curly brackets. The comment can appear wherever a blank can in the source program. Therefore, a comment is not allowed to be within a single identifier or a number. Whenever the scanner encounters a comment, it simply skips that text and deals with it as if it were a single space.

\subsubsection{APC Tokens}

The Arabic Pascal has several types of tokens: reserved words, identifiers, strings, special symbols, and numbers.

\section{A) Reserved Words}

There are 35 distinct reserved words in the Arabic Pascal language (see Appendix B). Every time a word is encountered, the scanner has to check if this word is a reserved word. For this reason, searching for reserved words should be done efficiently. Therefore, instead of putting all the reserved words in one string array, the Arabic Pascal scanner groups them based on their length to speed up the search process. There are eight groups of reserved words with an average of four to five in each group. Based on the length of the scanned word, only the reserved words with same length are checked. Moreover, the reserved words in each group is alphabetically ordered. As mentioned in Chapter 2, some reserved words can be written in more than one way, such as 'ذا! ' and' which are considered as one reserved word equivalent to 'if'. Therefore, there are a total of 52 reserved words.

\section{B) Identifiers}

Any word that is not a reserved word is considered to be an identifier. An identifier can be a program name, a procedure name, a function name, a constant, a type, a variable, or a directive (there is only one directive in the Arabic Pascal " $" \mathrm{z}-\mathrm{y}$ " which is a translation 
of the Standard Pascal "FORWARD"). No blanks may appear within an identifier. The APC limits the identifier length to 80 . Due to the reasons explained in Chapter 2, the APC accepts the underscore character as part of the identifier.

\section{C) Strings}

A string in the Arabic Pascal is enclosed between two double-quote characters and it is not allowed to use a double-quote character inside a string. The reason for using double-quote instead of single-quote (as in the Standard Pascal) is that the Arabic language usually uses double-quote for quotation.

\section{D) Special characters (Symbols)}

Special symbols in the Arabic Pascal consist of either one or two characters. Examples of one-character symbols are,$+[,<$, and :. Examples of two-character symbols are $\Rightarrow,=:$, and $<$. Note that almost all double-character symbols are written in reverse order with respect to the English Pascal (=: instead of :=) for an obvious reason: the Arabic language reads from right to left. Note also that the greater-than symbol is $<$ and the smaller-than symbol is $>$. See Appendix B, Section B.4 for the list of symbols in the Arabic Pascal.

\section{E) Numbers}

Scanning numbers may be the hardest part to implement in the scanner (see Appendix $\mathrm{C}$ for the syntax of the Arabic Pascal numbers). The Arabic Pascal can accept

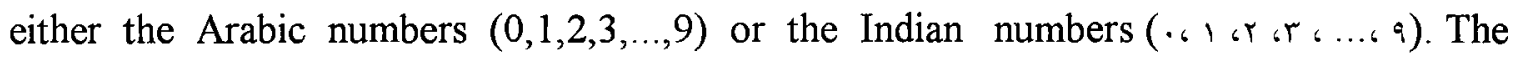
character ' $"$ ' in the Arabic Pascal is equivalent to the ' $E$ ' or ' $\mathrm{e}$ ' character in the English Pascal. The range of integer in the Arabic Pascal is between -32768 and +32767 . The scanner limits the number of digits to 20 digits including the signs [BTA93]. It also limits the exponent value in the range of -37 to +37 [BTA93]. 
Fortunately, the Arabic language and the English language read numbers in the same way: from left to right. That means, both languages consider the left-most digit as the highest significant digit. For this fact, accumulating the value of a number is the same in both languages. It should be pointed out that the comma in the Indian numbers stands for the decimal point. Therefore, under almost all Arabized software, the dot key in the keyboard is printed on the computer screen as a comma in the case of choosing to write in the Indian numbers set.

\subsubsection{The Scanner Algorithm}

The scanner is called by the parser which requests the next token. Whenever the scanner is invoked, it returns the next token from the source code. The general algorithm for getting a token is as follows:

skip-blanks;

select (based on the first character)

case alphabet: get-identifier;

case digit: $\quad$ get-number;

case quote: get-string;

case end-of-file: return end-of-file;

else get-symbol;

Hence, there are four different algorithms for extracting tokens:

1. Get-identifier. It follows syntax diagram (2), Appendix C. The identifier starts with an alphabet character followed by no more than 80 alphabets, digits, or underscores. If the identifier is among the reserved words, the specific reserved word is returned to 
the caller (parser), otherwise an identifier token is returned to the parser to insert it in the symbol table.

2. Get-number. It follows syntax diagram (29), Appendix C. There are three possible types of numbers: integer, decimal floating-point (e.g., 34.23), and scientific notation which has the e-notation, 'w' in Arabic Pascal, (e.g., $23 \mathrm{e} 4$ and 4.5e-5). When the scanner encounters a dot, it has to check that it is not followed by another dot, if so then the double dots are another token used for subranges.

3. Get-string. It simply returns the sequence of characters, including spaces, that is enclosed by double-quote character. The new-line character is not acceptable within the string.

4. Get-symbol. There are 21 symbols, five of which are double-character symbols: -, +, $*, 1,),(,=],,[, \wedge, 6, \imath, ., . .,:,:=,<,<=,<,>,>=$

When the scanner is invoked for the first time, it opens the source file and prints some header information (such as file-name and time of compilation) in the compilation output.

\subsection{THE PARSER}

The part of a compiler that knows the source language's syntax is the parser [Hen90]. The parser controls the translation process since it analyzes the source program based on the syntax. It calls the scanner to provide it with tokens. It also handles symbol table functions. Finally it calls the code generator to generate the assembly code.

The APC is designed as a top-down parser (recursive descent) [ASU86, Pys88, PP92, Eld94]. Top-down parsing constructs the parse tree from the root downwards to the terminal symbols at the leaves. In other words, the parser starts at the topmost nonterminal symbol of the grammar down to the terminal ones. The recursive descent parsing 
method is so called because it is implemented by a set of recursive procedures, one to correspond to each non-terminal of the grammar [Eld94]. The Arabic Pascal parser follows RL(1) grammar: Right-to-left scan, Left-most derivation with one look-ahead token. The RL(1) is exactly as LL(1) for the English language. The "Left-most derivation" of the grammar assumes that the grammar of the Arabic Pascal is written in the conventional way (from left-to-right) with Arabic terminal words and English words for non-terminals. The one look-ahead token approach infers that there is no backtracking. An advantage of following top-down parsing is the ease of construction, and once constructed, it is also easy to read and develop. The main drawback, however, is the slow speed in execution and difficulties in code optimization.

An alternative approach is bottom-up parsing. This parsing technique is harder to implement but has some advantages [Hol90, p. 337]. The main advantages are the ability to parallelize the process of parsing and the feasibility of automating the parsing. This approach starts with the terminal symbols and works its way up to the topmost nonterminal symbol. In other words, the tree is constructed from leaves of the parse tree to its root.

\subsubsection{Syntax Diagrams}

In order for the parser to work correctly, it needs to know the exact description for the source language syntax. There are several approaches to describe a language. Among these approaches are context-free grammar and syntax diagrams [ASU86]. The Arabic Pascal is relatively a simple language that can be fully recognized using syntax diagrams [JW74]. Syntax diagrams are graphical representations of the syntax rules. Appendix $\mathrm{C}$ gives a full description of the Arabic Pascal syntax via syntax diagrams. However, not all the details of the language rules can be expressed by the syntax diagrams 
(or any other approach). For example, syntax diagrams cannot indicate the limits of integer value, and they cannot express the type checking. The Arabic Pascal parser is designed in a way that reflects the syntax diagrams. Of course, the syntax diagrams that are representing the lowest-level syntactic entities, such as identifier and number tokens, are used to write the scanner.

In Appendix C, syntax diagrams 35-39 give a complete syntax description of the Arabic Pascal expressions. They also implement the full operator precedence as follows (See Appendix B, for the Arabic operators):

\section{Operator}

not.

$*, /$, div, $\bmod$, and

,,+- or

$=,<,>,<,<=,>=$, in

\section{precedence}

1 (highest)

2

3

4 (lowest)

\subsubsection{Symbol Tables}

The symbol table is used to maintain all needed information about all identifiers. It must be able to insert, access, and update information efficiently. Therefore, Binary Search Tree (BST) is chosen as the data structure for symbol table. In this BST, each identifier and its associated information form a node. Figure 5.2 shows the data structure of the identifier node in the symbol table. The identifier classification determines the identifier role in the program such as: label, constant, type, variable, procedure name, etc. Based on the identifier classification, certain information is kept in the node. The Serial number is used to assign a unique number for each identifier. The use of it will be explained later in Section 5.3. The scope is a means to keep track of the identifier scope. The size is used to determine the size in bytes of the identifier. This information is utilized 
by the code generator to generate the required memory space for each identifier. The sizes of different types are presented in Table 5.1. The size of compound types, such as arrays and records, are the total size of their elements. Left Ptr and Right Ptr are used to construct the BST. In Variable node (Figure $5.2(\mathrm{~b})(8)$ ), if Relation-Ptr is Null, the variable has no reference to type section such as the variable $t$ in the following declaration:

\section{$t:$ (hour, minute, second)}

On the other hand, the Other Information is omitted if the Relation-Ptr is not Null. In Formal parameter node (Figure 5.2 (b)(9), the Relation-Ptr cannot be Null because the type of the formal parameter variable is either a simple type or a type that is defined in the type section. The Next-Ptr is used in the Variable node to relate all variables of the same type that are defined in one statement. For example,

$$
\begin{gathered}
j, k, l \quad: \text { integer; } \\
n, m \quad: \text { integer; }
\end{gathered}
$$

The Next-Ptr will link $j, k$, and $l$ together, and link $\mathrm{n}$ and $m$ together, but there is no relation between the two lists except they are of the same type. The Next-Ptr is essential because the type definition of variables comes after listing the variables. When the parser encounters the type definition (which is in the previous example "integer") it fills the rest of information based on that type. The Next-Ptr in the Formal Parameter node is used to relate all formal parameters of one procedure or function.

An example of a symbol table structure is shown in Figure 5.3. For the sake of simplicity, the predefined types' nodes are not shown in the figure. The int-ptr and the char-ptr are pointers to the integer type node and char type node, respectively.

To reduce the symbol table size, to avoid naming conflict in the symbol table, and to preserve the principle of scope easily, the APC constructs more than one symbol table. The main two symbol tables are that contain the pre-defined identifiers and the user's 
global identifiers, if any. For each local procedure or function, a separate symbol table is created. Whenever an identifier is referenced in the source code, the search starts from the local scope to the surrounding scopes until it is found or the main symbol table is reached.

The main source of feeding symbol tables is the declaration part of the program, procedure, or function. The global symbol table is initialized with pre-defined types, constants, functions, and procedures.

- The predefined types are: integer, real, boolean, char, and text. Type boolean is an enumeration type with two constant identifiers true and false.

- The pre-defined constants are: true, false, and nil.

- The pre-defined procedures are: read, readln, write, writeln, new, dispose, reset, and rewrite.

- The pre-defined functions are: abs, arctan, chr, cos, eof, eoln, exp, ln, odd, ord, pred, round, sin, sqr, sqrt, succ, and trunc. 
(a) General Node Structure

\begin{tabular}{|c|c|}
\hline \multicolumn{2}{|c|}{ Identifier Name } \\
\hline Classific & ation \\
\hline Serial Ni & imber \\
\hline Scope & \\
\hline Size (byt & \\
\hline $\begin{array}{r}\text { Rest } \\
\text { Inforr }\end{array}$ & $\begin{array}{l}\text { of } \\
\text { nation }\end{array}$ \\
\hline Left Ptr & Right Ptr \\
\hline
\end{tabular}

Classification $=$ (label, constant, type, variable, func_name, proc_name, built-in_func, built-in_proc, formal parameter).

Serial Number: a unique number for each identifier.

(b) Rest of Information (based on the Classification)
(1) Label
(2) Constant
(3) User Procedure

(4) User function

(5) Built-in Proc

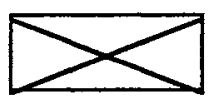

\begin{tabular}{|l|}
\hline value \\
\hline Relation Ptr \\
\hline
\end{tabular}

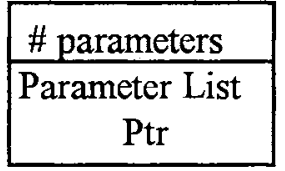

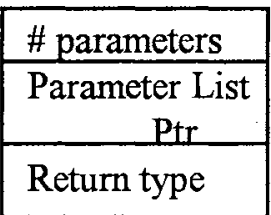

\begin{tabular}{|c|}
\hline \# parameters \\
\hline $\begin{array}{c}\text { List of Valid } \\
\text { types }\end{array}$ \\
\hline
\end{tabular}

(6) Built-in Func

(7) Type

(8) Variable

(9) Formal Parameter

\begin{tabular}{|c|}
\hline \# parameters \\
\hline $\begin{array}{l}\text { List of Valid } \\
\text { types }\end{array}$ \\
\hline Return type \\
\hline
\end{tabular}

\begin{tabular}{|c|}
\hline Sub-Classification \\
\hline $\begin{array}{c}\text { Other } \\
\text { Information }\end{array}$ \\
\hline Relation-Ptr \\
\hline
\end{tabular}

\begin{tabular}{|c|}
\hline Sub-Classification \\
\hline $\begin{array}{c}\text { Other } \\
\text { Information }\end{array}$ \\
\hline Next-Ptr \\
\hline Relation-Ptr \\
\hline
\end{tabular}

\begin{tabular}{|l|}
\hline Sub-Classification \\
\hline value/reference \\
\hline Other Info. \\
\hline Next-Ptr \\
\hline Relation-Ptr \\
\hline
\end{tabular}

$\underline{\text { Sub-Classification }}=($ char, integer, real, boolean, enumeration, sub-range, record, array file, pointer, set).

Relation-Ptr is used in constant, type, and variable to relate one class to another. For example, time $=$ (hour, minute, second). Hour is a constant related to time.

(c) Other Information (based on the Sub-Classification)
(1) char, integer, real, (2) enum.
(3) sub-range
(4) record
(5) array
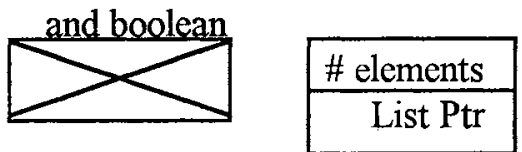

\begin{tabular}{|l|}
\hline Range type Ptr \\
\hline Min value \\
\hline Max value \\
\hline
\end{tabular}

\section{Field Sym.} Table Ptr

(8) set

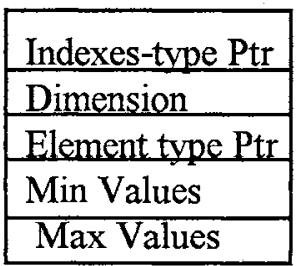

(6) file

File element type

File element Ptr
(7) pointer

\begin{tabular}{|l|}
\hline Ptr element type \\
\hline Ptr element Ptr \\
\hline
\end{tabular}

Set element type

Set element Ptr

Figure 5.2 Symbol Table Node Data Structure 


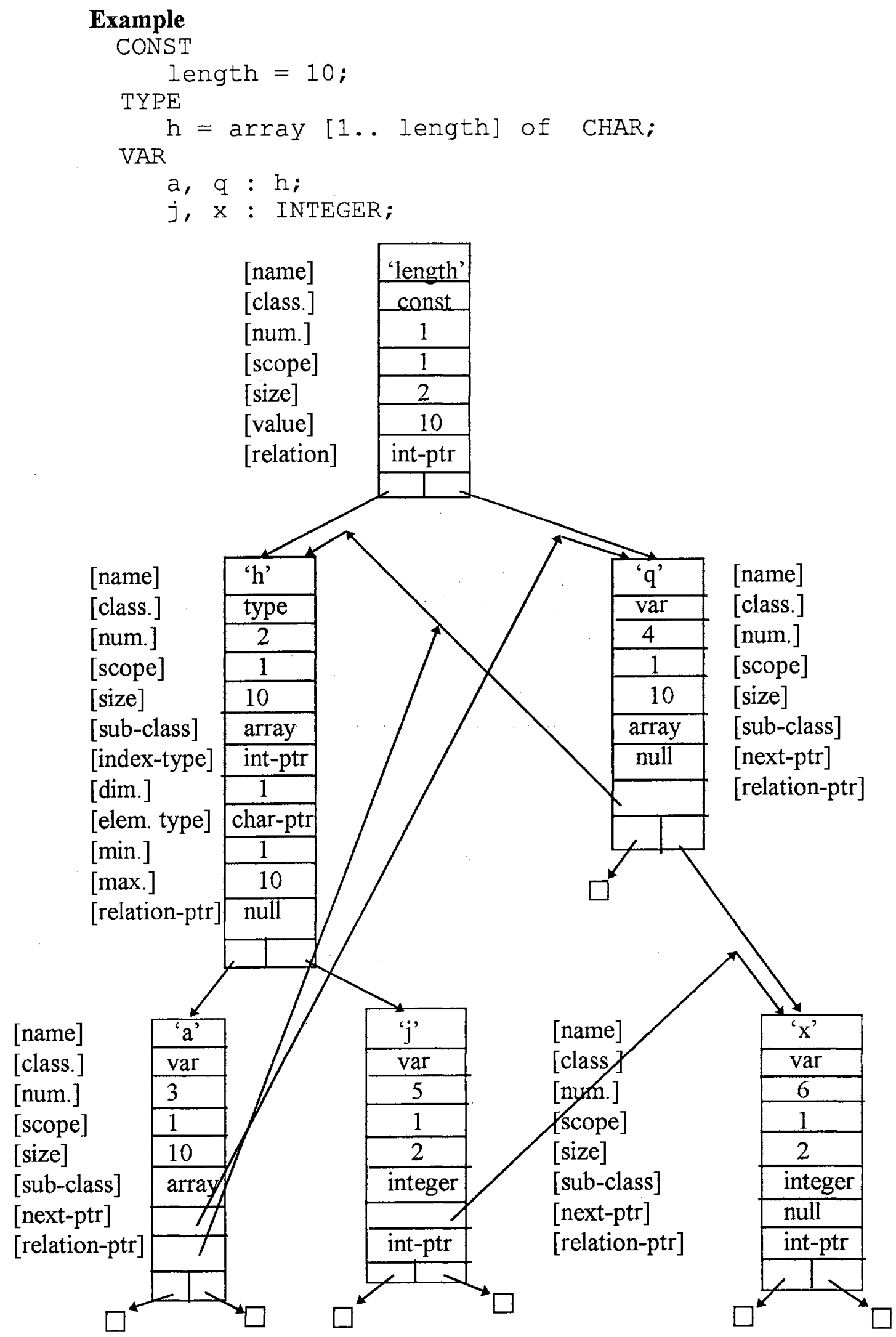

Figure 5.3 An Example of a symbol table 
Table 5.1 Sizes (in bytes) of different data types

\begin{tabular}{|c|c|c|c|c|c|c|c|c|c|}
\hline Type & int. & bool. & real & char & enum. & array & pointer & file & record \\
\hline Size & 2 & 1 & 4 & 1 & 2 & size*type & 2 & 2 & $\Sigma$ of its fields \\
\hline
\end{tabular}

\subsubsection{Identifier's Scope}

The scope of an identifier is the portion of the program where that identifier can be referenced [ASU86]. The Arabic Pascal allows the same identifier in a program to name different variables as long as the variables belong to different scopes. The scope rules of the Arabic Pascal determine which declaration of an identifier applies when that identifier appears in the source code. An identifier can be a constant, type, variable, parameter, procedure, or a function. An identifier is said to be global if it is a predefined identifier, type, procedure, function, etc., or if it is declared in the declaration section of the main program itself [Hol90]. An identifier is called local if it is declared inside a procedure or a function. In the APC, there are only two levels of global identifiers that are defined during the entire compilation process. The first level is the predefined types, identifiers, procedures, and functions. The second level is the global identifiers, if any, that are defined by the programmer in the main program. On the other hand, there are as many levels (scopes) of local identifiers as the number of nested functions and procedures. Figure 5.5 depicts the concept of the identifier scope via an example. Each scope level (block) has been enclosed in a box. The block number is shown in the upper right of the corresponding box. Within the statement part of each block the number of the blocks whose local identifiers are accessible at that point are enclosed in brackets. The lookup for an identifier starts from the local block outward to enclosing block. Note that the numbers in the brackets are sorted according to the look up procedure. 
The concept of identifier's scope plays an important role in the parsing process. Whenever the parser encounters an identifier in the body of a procedure or function (including the main program), the parser first checks the with-stack (a stack that is associated with with statements), if not empty, to concatenate the identifier with the withstack entries, one at a time, starting from the stack top, then it checks the symbol table associated with that procedure or function (local scope). If it did not find the identifier, it checks the next enclosing scope. The search continues outward within enclosing scopes towards the outermost scope (global scope). The search stops either by finding the identifier or reaching the outermost scope. In the latter case, an error message is issued to the programmer.

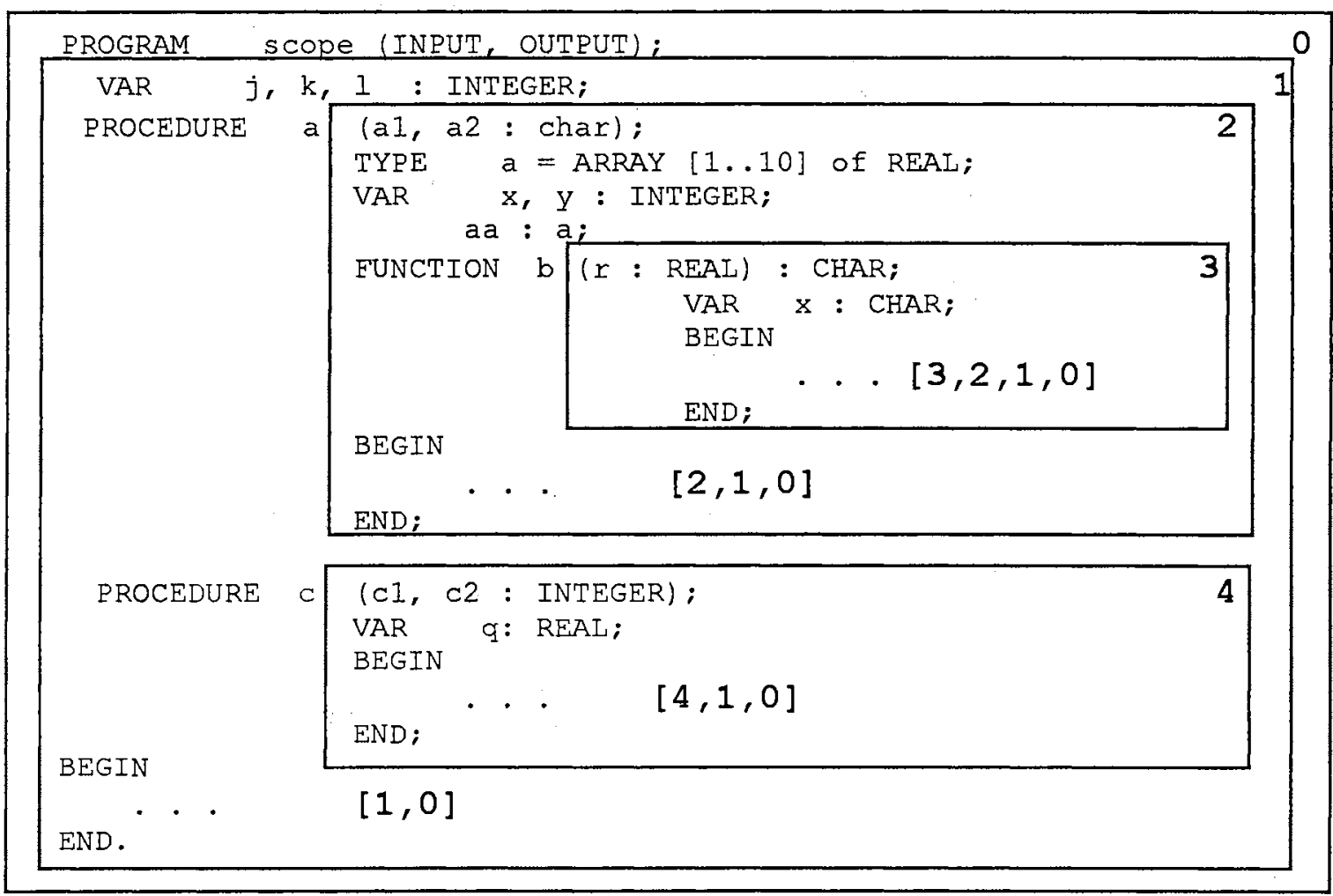

Figure 5.5 Scope structure of a Pascal program 


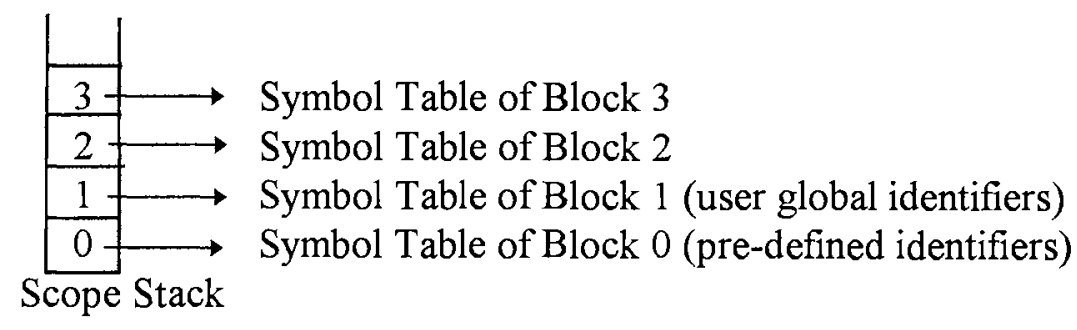

\section{Figure 5.6 A Snapshot of the Scope Stack of the program in Figure 5.5}

As stated earlier, each procedure or function (including the main program) is associated with a symbol table containing all the local identifiers. To implement the principle of scope, symbol tables are grouped in a stack, called the scope stack. Initially, the parser pushes the pre-defined identifiers' symbol table (in the bottom of the scope stack). Appendix B, Sections B.2 and B.3 list the pre-defined types and identifiers, and the built-in procedures and functions, respectively. The parser, then, pushes the global identifiers in the scope stack. When the parser enters a new subprogram (procedure or function), it pushes the subprogram's symbol table in the scope stack. As soon as the parser processes a subprogram, its corresponding symbol table is deleted to decrease memory requirements during the compilation process. Therefore, the search for an identifier starts from the top of the stack to its bottom until the identifier is found. An error message is issued for unsuccessful search. Figure 5.6 shows a snapshot of the scope stack of the program in Figure 5.5 while the parser in function $\mathrm{b}()$.

\subsubsection{The parser Algorithm}

Most of the APC coding belongs to the parser. The Arabic Pascal parser consists of two handlers and five sub-parsers. The handlers are the symbol table handler and the synchronization handler. The sub-parsers are subprogram parser, declaration parser, statement parser, expression parser, and standard procedures and functions parser. All the sub-parsers are implemented according to the structure of the Arabic Pascal syntax diagrams (as in Appendix C). 
Before explaining the details of the parser, it is important to know the approach of mapping the syntax diagrams into algorithms. Each syntax diagram in the Arabic Pascal can be decomposed into the following simple cases:

\section{Primitive case:}

This case has three forms:

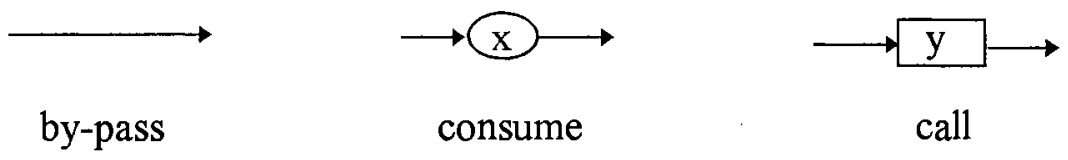

where, the circle represents a terminal symbol (token) and the rectangle represents a nonterminal symbol. The by-pass arrow in a syntax diagram is the arrow that allows bypassing (skipping) one or more syntax entities (terminal or non-terminal symbols). This arrow is used to skip optional structures. The second form makes the parser consume the token (x) and continues parsing. The last form makes the parser call subprogram $\mathrm{y}$.

\section{Branching case:}

This case has two forms:

(a) Forward branching. The branch is forward if it does not return to a previous state in the syntax diagram. The parser implements this using a case (select) statement (if more than two branches) or an if ... else statement (if only two branches and one of them is a by-pass, then the parser uses an if statement).

(b) Backward branching. The branch is backward if it returns to a previous state in the syntax diagram. The parser implements this using either while statement (if there is a by-pass arrow that permits skipping the entire backward branch) or repeat statement.

\section{Merging case:}

When two or more arrows in a syntax diagram meet, the parser ends their corresponding branching statements. 
Therefore, the first step in implementing the parser is to map all syntax diagrams into simple structures. This scheme handles only the correct structures, so we need to add error checking to the parser. Moreover, we need to embed type checking for all statements and expressions. The final step is to call the code generator to generate the equivalent assembly code where necessary.

The following subsections briefly explain the main functions of each handler or sub-parser. For the sake of simplicity and brevity, we will mention only the main syntax diagram(s) that the sub-parser is following (without writing its (their) corresponding algorithm(s)). In the first sub-parser (Section 5.2.4.3), we will give the corresponding algorithm for syntax diagram (3) as an illustrative example.

\subsubsection{Symbol Table Handler}

As stated earlier, symbol tables in the APC are constructed utilizing the binary search tree concept. They differ form the plain binary search trees in two ways. First, they have some extra pointers that relate all variables of the same type, and relate each variable with its type. Second, in the case of records, the record node is considered as the root for the fields' nodes. In other words, for each record, there is a symbol table associated with it within the main symbol table (nested symbol tables). The symbol table handler carries out three main functions: symbol table initialization, insertion, and search.

\section{(a) Initialization}

initialize the scope stack's top with zero.

insert all predefined constants, types, functions, and procedures.

(The scope for all identifiers is set to zero).

\section{(b) Insertion}

search the current symbol table to ensure the uniqueness of the identifier within that scope. 
create a new node and insert all needed information.

insert the node in its appropriate position in the symbol table.

\section{(c) search}

There are two types of searches: searching only the current symbol table (mainly used for insertion) and searching the entire scope stack starting from top to bottom (mainly used when referencing an identifier). In the latter case, the with stack is checked before starting the search to concatenate its content (as a leading string) to the identifier. Since the with stack can only be associated with the local scope, the with stack is checked only when searching the current local scope. The with stack is also checked from top to bottom. Let us take the following example:

$$
\begin{aligned}
& \text { with } \left.\quad r e c, p t r^{\wedge} \text { do } \quad \text { \{equivalent to: with rec do with } p t r^{\wedge} \text { do }\right\} \\
& x:=\ldots ;
\end{aligned}
$$

The with stack will have two items: $r e c$ and $p t r^{\wedge}\left(p t r^{\wedge}\right.$ in the top). The search goes as follows

1. search for $p t r^{\wedge} . x$ in the local symbol table, if not,

2. search for rec.x in the local symbol table, if not,

3. search for $x$ in the local symbol table, if not,

4. search for $x$ in the next symbol tables.

\subsubsection{Synchronization Handler}

When the parser encounters an error, it tries to recover from the error as soon as possible. This step is important because the parser has to continue syntax checking in a meaningful way [Bac79]. The main idea behind error recovery is to skip tokens until reaching a token that a parser can fully recognize. When the parser reaches this point, it 
re-synchronizes itself at that point and then continues the process of parsing. This type of error recovery is called panic-mode recovery [ASU86]. To implement this idea, the parser has to determine some synchronization points where syntax checking can be reliably restarted (such as semicolon or begin). Therefore, when the parser finds a synchronization point, it resumes its normal parsing as if there were no errors. Another source of errors is type mismatch where the compiler expects an identifier of a specific type and it encounters an identifier of another type. Type mismatch does not usually require a synchronization.

On the other hand, error correction is, in general, an unsuccessful approach because it is time consuming with little chance of getting the right solution. Further more, most syntax errors are usually easy to figure out manually, but the problem is with semantic errors which are almost impossible to be automatically corrected and at the same time is hard to be figured out manually.

\subsubsection{Subprogram Parser}

It mainly consists of two parts: main-program parser and procedure/function parser and both of them call a common parser called the body parser.

\section{(a) Main-program parser}

call the scanner initializer.

call the code generator to generate the main-program prolog.

call the symbol table initializer to initialize the symbol table (create the predefined identifier symbol table).

initialize the with-stack to be empty (it is used by the with-statement). call the program-body parser to parse the entire program. It follows syntax diagram (I). The program-body parser calls body parser which parses syntax diagram (3).

call the code generator to generate the main-program epilog. 
if not all labels in labels_list, if any, are marked label_seen and goto_seen call error_handler.

generate a compilation summary which includes the number of lines compiled and the number of errors.

\section{(b) Procedure/function parser}

parse the header of the subprogram, including the parameter list, if any (there should be no parameter list if the subprogram has been defined before using forward). After parsing the subprogram name, the parser enters a new scope. It follows either syntax diagram (8) or (9) based on whether it is a procedure or a function. For parsing the parameter list it follows syntax diagram (13). If the directive "forward" is encountered restore the previous scope and exit this parser.

call the code generator to generate the appropriate subprogram prolog. call the body parser to parse the subprogram body (syntax diagram (3)).. call the code generator to generate the appropriate subprogram epilog. if not all labels in labels_list, if any, are marked label_seen and goto_seen call error handler.

returns to the previous scope (pops the scope stack).

A labels_list is used to keep track of the usage of labels. A goto statement and its corresponding label have to be in the same subprogram (including the main program). When a label is encountered, it is inserted in the labels_list, if not in, and marked as label_seen. When a goto statement is encountered, its label is inserted in the labels_list, if not in, and marked as goto_seen. At the end of the subprogram, all labels in the labels_list should be marked as label_seen and goto_seen, or at least label_seen. For example,

$$
\text { label 10; }
$$


begin

GOTO 10 ;

end.

There is no label in the code for 10 (which is incorrect).

(c) The Body Parser

The algorithm follows syntax diagram (3).

$$
\begin{aligned}
& \text { if token = "label" call labelparser. } \\
& \text { if "token = "const" call constant parser. } \\
& \text { if token = "type" call type parser. } \\
& \text { if token = "var" call variable parser. } \\
& \text { while token = "function" OR "procedure" } \\
& \text { call procedure/function parser. } \\
& \text { call statement parser. }
\end{aligned}
$$

\subsubsection{Declaration Parser}

It mainly consists of four parts: label parser, constant parser, type parser, and variable parser.

\section{(a) Label parser}

The algorithm follows syntax diagram (4). A label must be an unsigned number between 0 and 9999 [Tib81].

\section{(b) Constant parser}

The algorithm follows syntax diagram (5). A constant can be a number (with or without a sign), a string, or a constant identifier.

\section{(c) Type parser}

The algorithm follows syntax diagram (6). 
Other than the predefined types (integer, real, char, boolean, and text), there are seven types: enumeration, subrange, set, file, array, record, and pointer. Each of which can be composition of two or more types within certain rules. In other words, a type can be formed using another type. For example

$$
\begin{aligned}
& \text { days = (Sat, Sun, Mon, Tue, Wed, Thu, Fri); } \\
& \text { days_set = set of days; }
\end{aligned}
$$

So, days_set is a set of another type, enumeration type. The following is a brief description about parsing each type.

1. Subrange type. The lower and the upper values can be of any ordered, simple type (excluding real type). It also accepts the previously defined enumeration data. The lower and the upper values must be from the same type and the lower value is less than or equal the upper value. The algorithm follows syntax diagram (28).

2. Enumeration type. It consists of an ordered sequence of integer constant identifiers which are enclosed between parentheses. The value of the first identifier is zero, the value of the second one is 1 , and so on. The algorithm follows syntax diagram (27).

3. Set type. It is a compound data type that accepts only subrange type or enumeration type. The number of the elements in a set should be at most 16 elements. Each element is represented by one bit according to its presence in the list. The algorithm follows syntax diagram (31).

4. File type. It accepts only integer, real, or character types. The file of characters is equivalent to text type. The algorithm follows syntax diagram (33).

5. Array type. It involves two other types: indexes' types and elements' type. The array can be of single or multiple dimensions. The parser verifies the validity of each dimension. The element type can be of any type. The size of the array (in bytes) is calculated based on 
the number of dimensions, the length of each dimension, and the size of the element. The algorithm follows syntax diagram (30).

6. Record type. The fields of the record are kept in a private symbol table that is accessible only through the record. Therefore, the same name of a field can be used outside the record without any ambiguity. For example,

$$
\begin{aligned}
r e c= & \text { record } \\
& j, k: \text { integer } ;
\end{aligned}
$$

end;

$$
j, k: \text { real } \quad\{\text { or whatever }\}
$$

is a valid definition because the $\mathrm{j}$ and $\mathrm{k}$ (inside the record) belong only to the record (in a separate symbol table). Therefore, they can be accessed either explicitly by preceding them by the record name, or inside a with statement. Other than these two cases, any reference to $\mathrm{j}$ or $\mathrm{k}$ it is a reference to the outer ones.

The record size is the sum of its fields' sizes. The algorithm follows syntax diagram (32). Note that parsing the record fields is similar to parsing the var section.

7. Pointer type. All previous types must be defined before they can be used in the definition of other types, except the pointer type. The pointer type, however, may point to a type that is defined later or to a type that is still being defined. For example:

$$
\begin{aligned}
& \text { ptr }={ }^{\wedge} \text { rec } ; \quad\{\text { 'ptr' is the left side, 'rec' is the right side }\} \\
& \text { rec }=\text { record } \\
& \quad \text { next }: \wedge_{\text {rec } ; \quad\{=p t r\}} \\
& \quad \ldots \\
& \text { end; }
\end{aligned}
$$

When parsing the definition of $p t r$, the rec identifier is not defined yet. When parsing the field next, the rec is not yet complete. The APC keeps a list of all undefined types (for 
pointers only). At the end of type parsing, all types should be defined so the parser will be able to resolve all type definitions. The algorithm follows syntax diagram (18).

\section{(d) Variable parser}

Parsing this section is almost similar to the type section with three exceptions.

1. A declaration may have one or more identifiers separated by commas, followed by the type specification. All variables that have the same type are linked together.

2. All type specifications should be previously defined including the pointer type.

3. The parser calls the code generator to generate the appropriate memory reservation for all defined identifiers.

The algorithm follows syntax diagram (7).

\subsubsection{Statement Parser}

A statement may start with a label, if so, the parser parses it and calls the code generator to generate a label. The statement parser, then, calls the appropriate subprogram based on the first token in the statement. There are nine possible tokens to start a statement. The algorithm follows syntax diagrams (10) and (14).

1. Identifier. An identifier may stand for either a variable, function or a procedure name.

(a) Variable and function name. The statement has to be an assignment statement. The assignment statement should have the following format:

variable (or function name) := expression;

\{the parameters of the function should be omitted\}

The statement parser calls the code generator to generate code for assignment. The expression parsing will be discussed later. The algorithm follows syntax diagram (19).

(b) Procedure name. If the procedure is a standard procedure, then the parser calls standard-procedures-and-functions parser. In case of user-defined procedures, the parser checks the actual parameter list, if any, for the correctness of them compared with the 
formal parameters. It also checks which of these parameters are called by reference and which are called by value. Then, it calls the code generator to generate the appropriate code. The algorithm for user-defined procedure call follows syntax diagram (25).

2. 'بـابدا' (begin). This means a compound statement. So, the parser calls the statement parser until it reaches the corresponding end. The algorithm follows the last part of syntax diagram (3).

3. 'اذهب_إلى' (goto). The parser calls the code generator to generate a jump instruction. The parser checks for the presence of the target label in the code within the same scope. The algorithm follows syntax diagram (26).

4. 'ذ!' (if). The parser calls the expression parser to evaluate the boolean expression, then it again calls the statement parser. If ' $y y^{\prime}$ ' (else) is encountered, another call for statement parser is issued. The algorithm follows syntax diagram (20).

5. 'كرور (repeat). The parser calls the statement parser until the token is 'حتى' (until). It, then, calls the expression parser to evaluate the expression. The algorithm follows syntax diagram (23).

6. 'b' (while). The parser calls the expression parser to evaluate the boolean expression, then it again calls the statement parser. The algorithm follows syntax diagram (22).

7. 'لقيسم' (for). The parser parses the header of the for statement checking the control identifier, its type, its lower value, and its upper value. It also calls the code generator to generate the appropriate assembly code. It, then, calls the statement parser to parse the body of the for statement. The algorithm follows syntax diagram (24).

8. 'حلـ' (case). The parser parses the header of the case statement by calling the expression parser. For the case values, the parser calls the code generator to generate 
assembly code as if it were nested if ... else statements (see Section 5.3.1). Since the case statement in the Standard Pascal does not have a default value, the inner most if does not have an else. The algorithm follows syntax diagram (21).

9. ' argument(s) into the with-stack (see Section 5.2.3). The statement parser, then, parses the enclosed statement(s). With statement is the only statement that has an effect on the structure of the identifiers. For example, instead of writing the full identifier name, such as rec.ident, only the ident may appear inside the with statement. Section 5.2.4.1 part (c) discussed how the search is performed in the symbol table for an identifier. The algorithm follows syntax diagram (40).

\subsubsection{Expression Parser}

The expression parser is the part of the parser that is responsible for parsing expressions, evaluating them, and ensuring the correctness of their usage. It is invoked to parse

- the actual parameters of procedures and function,

- the boolean expressions in the control statements, and

- the expressions after the assignment statements.

The expression parser calls the code generator to generate the appropriate code.

All expressions (including variables and constants) preserve their actual values when evaluated except set variables and set constants. As stated earlier, each element in a set is represented by one bit according to its position in the list. Therefore, sets need special handling in evaluating their expressions. For example, let us consider the following code (in Standard Pascal):
(1) SI : set of $5 . .10$;
(2) $s 2:$ set of $1 . .10$ 
(3) $s 1:=[5,7,9]$;

(4) $s 2:=[5,7,9]$;

(5) if (6 in sl) then ...

(6) if (6 in s2) then ...

In statement (3) the numbers 5, 7, and 9 mean nothing to set $\boldsymbol{s} 1$ except that they represent the fist, the third, and the fifth bits, respectively. While in statement (4) the same numbers represent fifth, seventh, and ninth bits, respectively, for $\boldsymbol{s} 2$. The value of $\boldsymbol{s} 1$ after executing statement (3) should be 21 (i.e., in binary 0000000000010101) and the value of $s 2$ after executing statement (4) is 336 (i.e., in binary 0000000101010000 ). Similarly, number 6 in statement (5) and (6) only represents the second bit with respect to $s 1$, and the sixth bit with respect to $\mathbf{s} 2$. Consequently, when the expression parser encounters a statement that involves a set expression, it performs the following:

1. if the set elements are of subrange type, calculate the element-value by subtracting the value of the variable or constant from the minimum value in the set declaration. The minimum value of a enumeration type is always zero. This gives the bit position in the set.

2. to set or test a particular bit in the set, a run-time function is called to find the power of 2 of the element-value.

3. the assignment statement (such as statement (3) above) is considered as a series of unions of individual set elements.

Using this approach of implementation makes a restriction on using an immediate set comparison in the Arabic Pascal. For example,

$$
\text { if } \left.\left[5, x^{*} 3\right]<=s 1 \text { then... \{where } x \text { is an integer }\right\}
$$


is not acceptable in the Arabic Pascal because the value of the set $\left[5, x^{*} 3\right]$ is unknown unless this set is associated with a specific set definition. To implement the previous code, the programmer needs to add an assignment statement as follows:

$$
\begin{aligned}
& s 3:=\left[5, x^{*} 3\right] ; \quad \text { \{assuming } s 3 \text { of the same sl type\} } \\
& \text { if } s 3<=s 1 \text { then } \ldots
\end{aligned}
$$

In this way, the compiler knows exactly the value of the set [5, $\left.x^{*} 3\right]$.

The expression parser algorithm follows syntax diagrams (35) and (37).

Note that the Arabic Pascal function has two forms. If it is in the left hand side of an assignment statement (usually inside the function body itself), it does not take any parameter. On the other hand, if it is inside an expression (such as $x * \sin (x)$ ), then it is parsed as if it were a procedure call.

\subsubsection{Standard Procedures-and-Functions parser}

It is not difficult to parse the standard functions and procedures that have a fixed number of arguments. The parser checks the correctness of the number of arguments and their types, and then calls the code generator to generate the appropriate code. Table 5.2 shows the standard functions, the acceptable types of parameters, and the type of the result. Note that all standard functions have only one parameter except eof and eoln which may have zero or one parameter. Table 5.3 shows the standard procedures, number of parameters, and the acceptable types for each parameter. Note that procedures GET and PUT are not implemented in the Arabic Pascal because they are functionally equivalent to simple read and write respectively. The procedure PAGE is also not implemented because it was used for non-interactive computers to order the printer to jump to a new page [Got94, p. 77]. Many modern versions of Pascal eliminated these functions, such as Turbo Pascal and VAX Pascal. 
The problem arises when parsing the procedures that have variable number of arguments, namely اكتب، اكتب_س، اقترأ، اترأيس (write, writeln, read, and readln). The easiest way is to parse each of which as if it were a sequence of procedures that having only one parameter. Therefore, after parsing each parameter, the parser calls the code generator to generate the appropriate code. The actual parameters of is (read and readln) must be variable. The actual parameters of اكتب و اكتبـ (write and writeln) may be expressions and each of which may be followed by field width and designators.

Table 5.2 Standard functions

\begin{tabular}{|l|l|l|}
\hline \multicolumn{1}{|c|}{ Function } & type of the parameter & \multicolumn{1}{c|}{ type of the result } \\
\hline abs and sqr & integer or real & same as the parameter type \\
\hline arctan, cos, exp, ln, sin, and sqrt & integer or real & real \\
\hline chr & integer & char \\
\hline odd & integer & boolean \\
\hline ord & char & integer \\
\hline pred and succ & integer, real, or boolean & same as the parameter type \\
\hline round and trunc & real & integer \\
\hline eof and eoln & file (if exist) & boolean \\
\hline
\end{tabular}

Table 5.3 Standard procedures

\begin{tabular}{|c|c|c|}
\hline Procedure & \# of parameters & types of parameters \\
\hline dispose and new & 1 & pointer \\
\hline $\begin{array}{l}\text { reset and } \\
\text { rewrite }\end{array}$ & 2 & 1. file 2 . string \\
\hline read & $\begin{array}{l}1 \text { or more (if the first is not file) } \\
2 \text { or more (if the first is file) }\end{array}$ & $\begin{array}{l}\text { 1. file, integer, real, or char (variable) } \\
2 \text {.. n integer, real, or char (variable) }\end{array}$ \\
\hline readln & $\begin{array}{l}0 \text { or more (if the first is not file) } \\
1 \text { or more (if the first is a file) }\end{array}$ & $\begin{array}{l}\text { 1. file, integer, real, or char (variable) } \\
2 . . \mathrm{n} \text { integer, real, or char (variable) }\end{array}$ \\
\hline write & $\begin{array}{l}1 \text { or more (if the first is not file) } \\
2 \text { or more (if the first is a file) }\end{array}$ & $\begin{array}{l}\text { 1. file, integer, real, char, boolean } \\
\text { (expression), or string } \\
2 . . \mathrm{n} \text { integer, real, char, boolean } \\
\text { (expression), or string }\end{array}$ \\
\hline writeln & $\begin{array}{l}0 \text { or more (if the first is not file) } \\
1 \text { or more (if the first is a file) }\end{array}$ & $\begin{array}{l}\text { 1. file, integer, real, char, boolean } \\
\text { (expression), or string } \\
2 . \text {. n integer, real, char, boolean } \\
\text { (expression), or string }\end{array}$ \\
\hline
\end{tabular}


All math functions follow syntax diagram (45).

Functions eof and eoln follow syntax diagram (46).

Procedures new and dispose follow syntax diagram (47).

Procedures reset and rewrite follow syntax diagram (48).

Procedures read and readln follow syntax diagrams (49) and (50).

Procedures write and writeln follow syntax diagrams (51), (52), and (53).

\subsubsection{Type Checking}

One of the major tasks of the parser is to check the validity of using the identifiers and the compatibility among related identifiers. This task is called type checking. The type checking relies heavily on the symbol tables to perform its task. There are four common categories of type checking:

1. Variables: A variable can be a simple identifier, an array, a record, a pointer, a set, or a file. Each of the above has a specific way of usage. For example, a subscript is usually associated with array variables. The type checker checks the identifier's definition in the symbol table to ensure correctness of usage. Type checking of an identifier also depends on the syntax surrounding that identifier. For example, a pointer identifier that is followed by a pointer symbol has a different semantic from a plain pointer identifier.

2. Expressions: The type checker has to check whether or not the operands of an operator are of the correct type. For example, both operands of AND operator must be of type boolean. In expressions, the type checker must specify the overall expression result type. For instance, an integer plus a real results in a real expression. Moreover, all arithmetic relations should be between two similar types (except the IN set relation where the first operand has to be from the same members' type of the second one). The relations less-than and greater-than are not defined in sets. It is also not acceptable to check the relation between two strings unless they have the same length[Tib81]. 
3. Assignments: In the Arabic Pascal, one type is assignment compatible with another type if an expression of the first type can be assigned to a variable of the second type. Type checker checks whether or not an expression value of one type can be assigned to a variable of a different type. For example, a real variable can get an integer value but not vice versa.

4. Statements: The type checker must ensure that all variables and expressions in the statement are of the correct types. For example, all control statements should have expressions of boolean type. As another example, in the for statement, both the initialvalue and the final-value have to be from the same type.

\subsection{THE CODE GENERATOR}

The final step in the compiling process is code generation. Whenever the parser encounters a complete statement or expression, it calls the code generator to generate an equivalent assembly code. The APC translates the source code into 8086 assembly language. The details of the 8086 structure and assembly language can be found in [MP86, Abe87, Hah87, BB88, BTA93, Mis93].

For the sake of simplicity, all standard procedures and functions are implemented as a run-time library. The APC calls this library whenever needed. This run-time library must be linked with the generated assembly code. It should be pointed out that the APC allocates global variables in the data segment instead of at the bottom of the stack to allow direct access to them.

The code generator generates at the beginning of each assembly program a set of directives called a prolog [BTA93]. These directives give the Turbo Assembler the needed 
information about the code. Similarly, at the end of the assembly code, some restoring actions are done and a list of global variables is placed, called epilog [BTA93].

The Turbo Assembler seems not to accept the numbers within the Arabic identifiers nor the Arabic underscore, so the code generator should eliminate these from the identifiers. This will have no effect on the uniqueness of the identifiers within the same scope because the identifier serial number will make every identifier unique in the entire assembly program. The code generator attaches a unique number (the serial number) to every identifier in the program. The need for the uniqueness of identifiers is necessary because the 8086 assembly language does not have the scope concept.

Another issue in the code generation is the conditional jump. The conditional jump instructions in the original 8086 assembly language are restricted to a distance of 127 bytes [BTA93]. On the other hand, the unconditional jump can jump to any place within the code segment. Therefore, all conditional jumps that may cause out of range jumps should be converted somehow to equivalent unconditional jumps. For example,

$$
\begin{array}{lll}
\text { cmp } & x, y & ; \text { compare } \\
\text { je } & \text { exit } & ; \text { jump if equal to exit label }
\end{array}
$$

. <may be more than 127 bytes of code>

exit: $\quad<$ the rest $>$

This code should be altered to avoid the restriction. The code generator converts it to the following:

$\begin{array}{ll}\text { mov } & \text { temp, } 1 \quad ; \text { move one to temp } \\ \text { cmp } \quad x, y & \text { je nextl }\end{array}$




\begin{tabular}{|c|c|c|c|}
\hline & $x o r$ & temp, temp & $;$ make temp $=0$ \\
\hline nextl. & $c m p$ & temp, 1 & \\
\hline & je & next2 & \\
\hline & jmp & exit & ; unconditional jump \\
\hline
\end{tabular}

next2: .

. <may be more than 127 bytes of code>

exit: <the rest>

The code generator works in two levels: statement level and expression level. The following subsections discuss these two levels.

\subsubsection{Statement Code Generator}

There are eleven different types of statements that the code generator may face:

1. assignment statement. The code generator generates code for evaluating the right hand side expression (stored in $\mathrm{AX}$ or $\mathrm{AX}: \mathrm{DX}$ for real values), then issues a move instruction from $\mathrm{AX}$ to the left hand side variable.

2. goto statement. It simply issues a jump instruction.

3. compound statement. It does nothing.

4. with statement. It does nothing.

5. procedure/function call. It pushes all the arguments (or their addresses for reference arguments) on the stack, then it calls the function or the procedure. In the case of function, the return value is stored in register $\mathrm{AX}$. In the procedure or function itself, it saves the stack pointer at the beginning and restores it at the end. 
6. standard procedure/function call. It pushes all the arguments on the stack, then it calls the equivalent function in the run-time library. In the case of function, the result is stored in register $\mathrm{AX}$.

7. while statement. The general format for the while statement is

$$
\text { while <expression }>\text { do }<\text { statement(s) }>
$$

The code generator generates the following code:

loop_begin:

$$
\begin{aligned}
& <\text { code for expression }> \\
& \text { mov Reg, } 1 \quad \text {; move one to Reg } \\
& \text { jXX next ; XX is the conditional jump, such as jle } \\
& \text { xor Reg, Reg ; let Reg equal } 0 \\
& \text { next: cmp Reg,1 ; compare } \\
& \text { je statement_label ; jump if equal } \\
& \text { jmp loop_exit ; unconditional jump } \\
& \text { statement label: } \quad<\text { code for statement(s)> } \\
& \text { jimp loop_begin } \\
& \text { loop_exit: }
\end{aligned}
$$

8. repeat statement. The general format for the repeat statement is

$$
\text { repeat }<\text { statement }(s)>\quad \text { until }<\text { expression }>
$$

The code generator generates the following code:

loop_begin:

$$
\begin{aligned}
& <\text { code for statement(s)> } \\
& <\text { code for expression }> \\
& \begin{array}{ll}
\text { mov Reg, } 1 & ; \text { move one to Reg } \\
j X X \quad \text { next } & ; X X \text { is the conditional jump, such as jle }
\end{array}
\end{aligned}
$$




$\begin{array}{llll} & \text { xor } & \text { Reg, Reg } & \text {; let Reg equal 0 } \\ \text { next: } & \text { cmp } & \text { Reg,I } & \text {; compare } \\ & \text { je } & \text { loop_exit } & ; \text { jump if equal } \\ & \text { jmp } & \text { loop_begin } & \text {; unconditional jump } \\ & & & \end{array}$

9. if statement. The general format for the if statement is

$$
\text { if }<\text { expression }>\quad \text { then }<\text { statement(s)-I }>
$$

or

$$
\text { if <expression> then <statement(s)-I> else <statement(s)-2> }
$$

The code generator generates the following code:

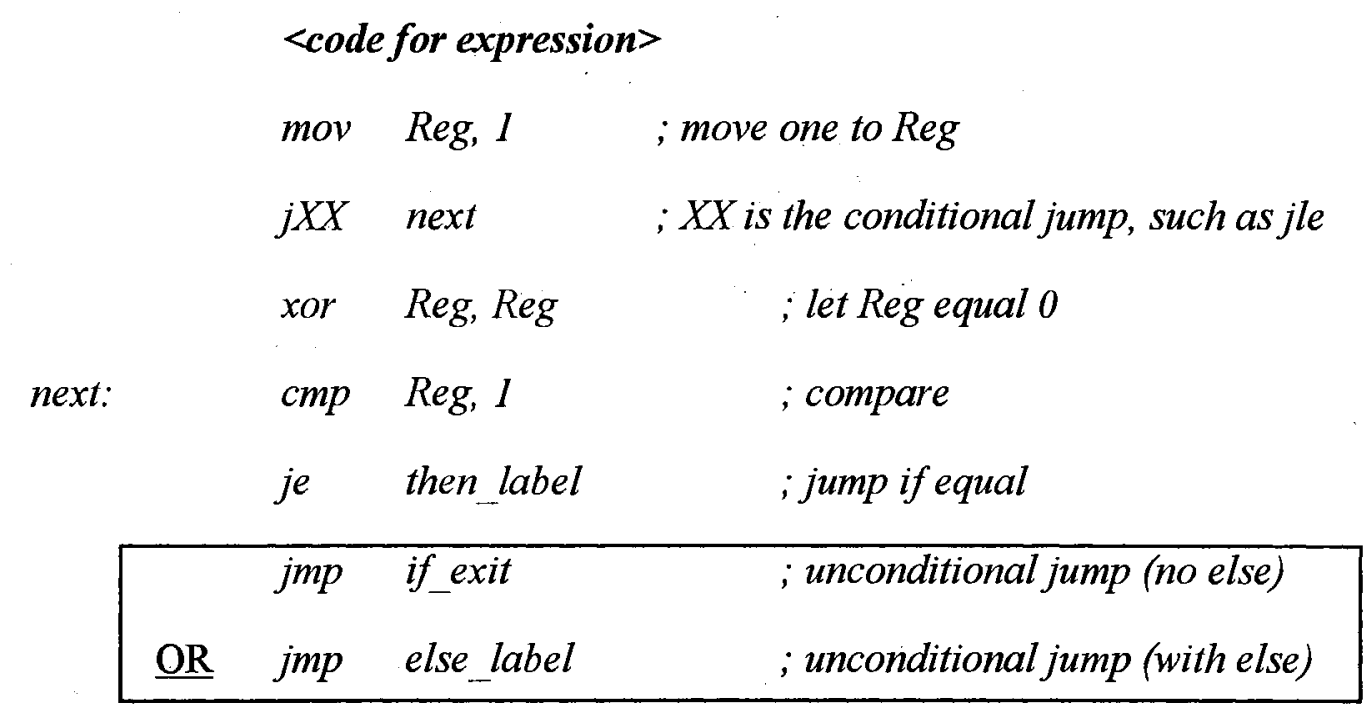

then_label:

$<$ code for statement(s)-1>

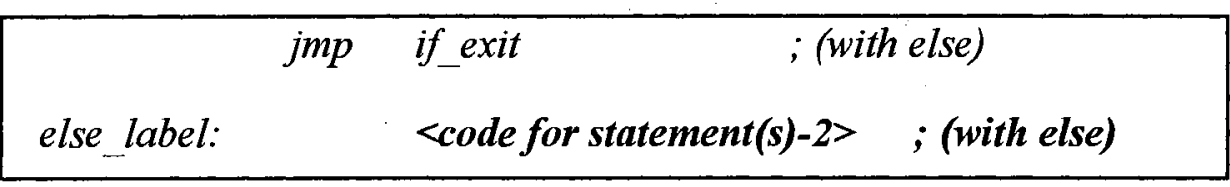

if_exit:

10. for statement. The general format for the for statement is for id:=initial_val [to/downto] final_val do $\langle$ statement(s) $\rangle$ 
The code generator generates the following code:

$$
\begin{aligned}
& <\text { code for intial_val }> \\
& \text { mov current_val, initial_val } \\
& \text { for_loop: <code forfinal_val }> \\
& \text { cmp current_val, final val }
\end{aligned}
$$

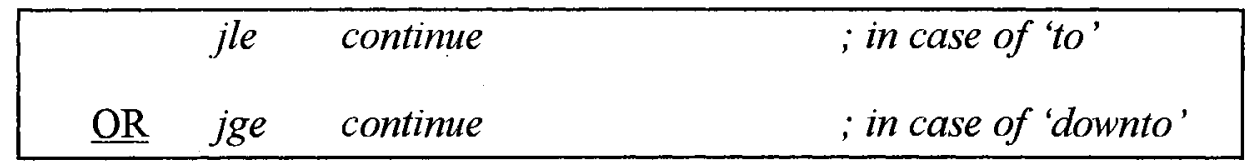

$$
\begin{aligned}
& \text { jmp loop_exit } \\
& \text { continue: } \quad<\text { code for statement(s)> }
\end{aligned}
$$

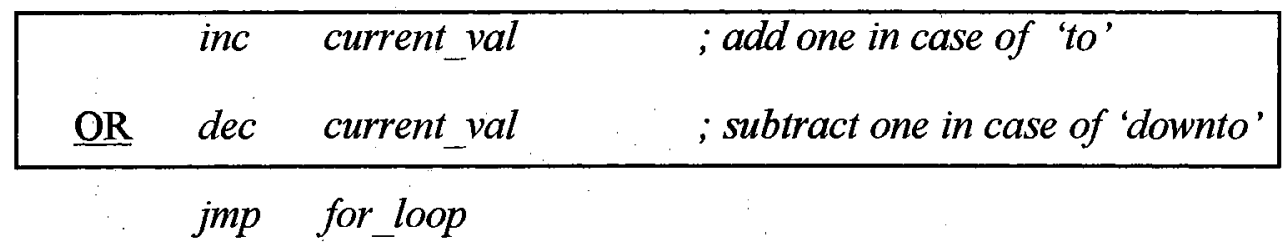

$$
\begin{aligned}
& \text { loop_exit: }
\end{aligned}
$$

11. case statement. The general format for the case statement is

$$
\begin{aligned}
& \text { case } \quad<\text { expression }>\text { of } \\
& <\text { const } I-l>I,<\text { const } l-2>, \ldots,<\text { const } l-n]: \quad<\text { statement }(s)-l>\text {; } \\
& <\text { const } 2-l>I,<\text { const } 2-2>, \ldots,<\text { const } 2-m]: \quad<\text { statement }(s)-2>\text {; } \\
& \ldots \ldots \\
& \text { end; }
\end{aligned}
$$

The code generator generates the following code:

$$
\begin{aligned}
& <\text { code for expression }>\quad ; \text { the result is stored in register } A X \\
& \text { cmp } \quad A X,<\text { const } I-I> \\
& \text { je } \quad \text { branch_l } \\
& \text { cmp } \quad \text { AX, <const } 1-2> \\
& \text { je branch_l }
\end{aligned}
$$




\begin{tabular}{|c|c|c|}
\hline & $c m p$ & $A X,<$ const $1-n>$ \\
\hline & je & branch I \\
\hline & $j m p$ & next I \\
\hline branch 1: & $<\operatorname{cod}$ & for statement(s)-1> \\
\hline & jimp & case_exit \\
\hline next 1 : & $c m p$ & $A X,<$ const $2-I>$ \\
\hline & je & branch_2 \\
\hline & $c m p$ & $A X,<$ const $2-2>$ \\
\hline & je & branch_2 \\
\hline & & \\
\hline & $c m p$ & $A X,<$ const $2-m>$ \\
\hline & je & branch_2 \\
\hline & jmp & next_2 \\
\hline branch_2: & $<\operatorname{cod}$ & for statement(s)-2> \\
\hline & $j m p$ & case exit \\
\hline next_2: & $\ldots$ & \\
\hline
\end{tabular}

\subsubsection{Expression Code Generator}

Most of the relations and operators in the Arabic Pascal has a direct equivalent instruction in the assembly code. Table 5.4 shows the simple relations and operators that have one to one correspondence between the Arabic Pascal and the 8086 assembly language. Of course, this does not include the preparation of the operands nor the details of type conversions. 
Table 5.4 Simple relations and operations in Arabic Pascal and Assembly

\begin{tabular}{|c|c|c|c|}
\hline Arabic Pascal & $\mathbf{8 0 8 6}$ Assembly & Arabic Pascal & 8086 Assembly \\
\hline$=$ & je & - (not sets) & sub \\
\hline$<$ & jne & $*$ (integer) & imul \\
\hline$\Rightarrow$ (not sets) & jle & $*$ (sets intersection) & and \\
\hline$<=$ (not sets) & jge & (div) & idiv \\
\hline$>$ & jl & $:=$ & mov \\
\hline$<$ & jg &, (and) & and \\
\hline+ (not sets) & add & , (or) & or \\
\hline+ (sets union) & or & (not) & not \\
\hline - (unary) & neg & in) & test \\
\hline
\end{tabular}

The rest of relations and operations may not have simple equivalence.

1. Real operations. Since handling real numbers are not directly supported by the 8086 assembler, the APC calls a run-time library to accomplish the real operations [Hah87]. Note that the division (/) always works with real operands (the integer operands are automatically converted to real in the APC).

2. 'باقي' (remainder). When making a idiv instruction in the 8086 assembly, the quotient is placed in the register AX and the remainder is placed in DX [Hah87]. So, the code generator performs a idiv instruction but gets the DX result. Note that some Pascal references [BTP89, JW74, Tib81] describe the mod operator with the same behavior as the remainder operator.

3. Set difference (-). In sets, the difference between two sets (s1 - s2) is equivalent to (s1 and (not s2)). Therefore, the second operand should be negated and, then, anded with the first one.

4. Set inclusion $(\Leftrightarrow$, in Arabic Pascal). In sets, $(s 1 \subseteq s 2)$ is equivalent to $(s 1-s 2=\varnothing)$. Therefore, the inclusion is implemented using the difference and set equality.

5. Set containment $(=<$, in Arabic Pascal). In sets, $(s 1 \supseteq s 2)$ is equivalent to $(s 2-s 1=$ $\varnothing)$. Therefore, the containment is also implemented using the difference and set equality. 


\subsection{THE ERROR HANDLER}

Because programmers are prone to making syntax errors, it is necessary for the compiler to handle these errors accurately and efficiently. When the APC encounters an error, it simply does the following:

1. Gives the programmer the nearest possible location of the error by pointing to it. The error handler prints the line number that has the error and the current token. Usually the error happens at the current token or in a previous token in the same line. For example, (in Standard Pascal):

$$
\text { if }(I<J) \text { then } I:=J \text {; else } J:=I \text {; }
$$

The APC cannot discover that the semicolon before else is an error until it parses the else token.

2. Prints out a descriptive error message.

Appendix D, Section D.1 lists the possible error messages the programmer may get from the compiler during program development.

The run-time errors are generated by the run-time library that takes the control when abnormal situation takes place during the execution. Appendix D, Section D.2 lists the possible run-time errors.

\subsection{EXAMPLES OF ARABIC PASCAL PROGRAMS}

The following (next pages) are two simple Arabic Pascal programs with their output. For convenience, their corresponding English Pascal programs are shown in the same lines. Remember that the Arabic language reads from right to left. More Arabic Pascal programs can be found in Appendix E. 


\section{Example 1}
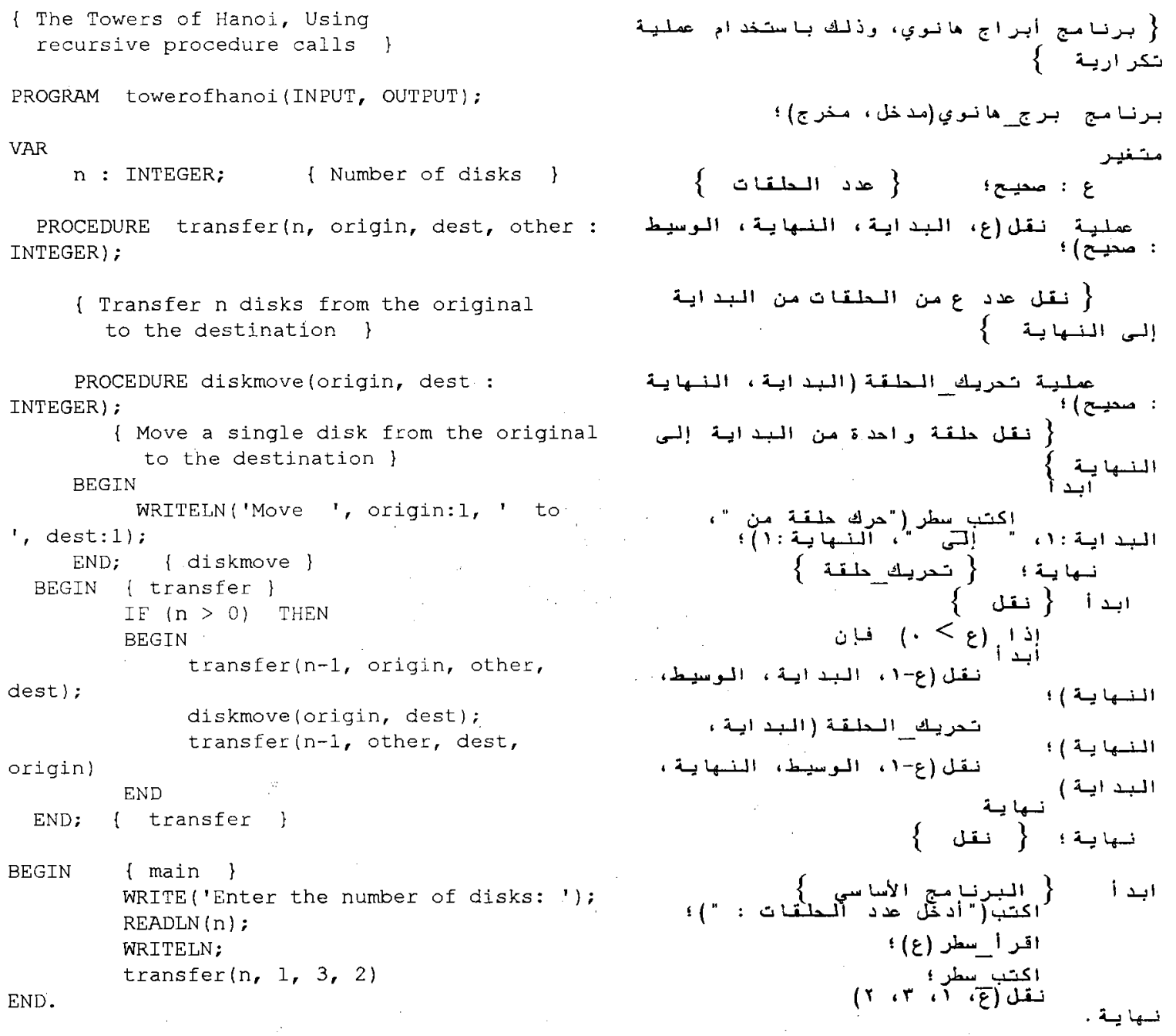

\section{Sample Output}

\begin{tabular}{llll} 
Enter & \multicolumn{3}{c}{ the number } \\
Move & 1 & to & 2 \\
Move & 1 & to & 3 \\
Move & 2 & to & 3 \\
Move & 1 & to & 2 \\
Move & 3 & to & 1 \\
Move & 3 & to & 2 \\
Move & 1 & to & 2 \\
Move & 1 & to & 3 \\
Move & 2 & to & 3 \\
Move & 2 & to & 1 \\
Move & 3 & to & 1 \\
Move & 2 & to & 3 \\
Move & 1 & to & 2 \\
Move & 1 & to & 3 \\
Move & 2 & to & 3
\end{tabular}

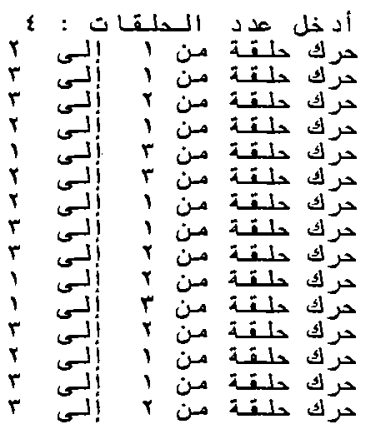




\section{Example 2}

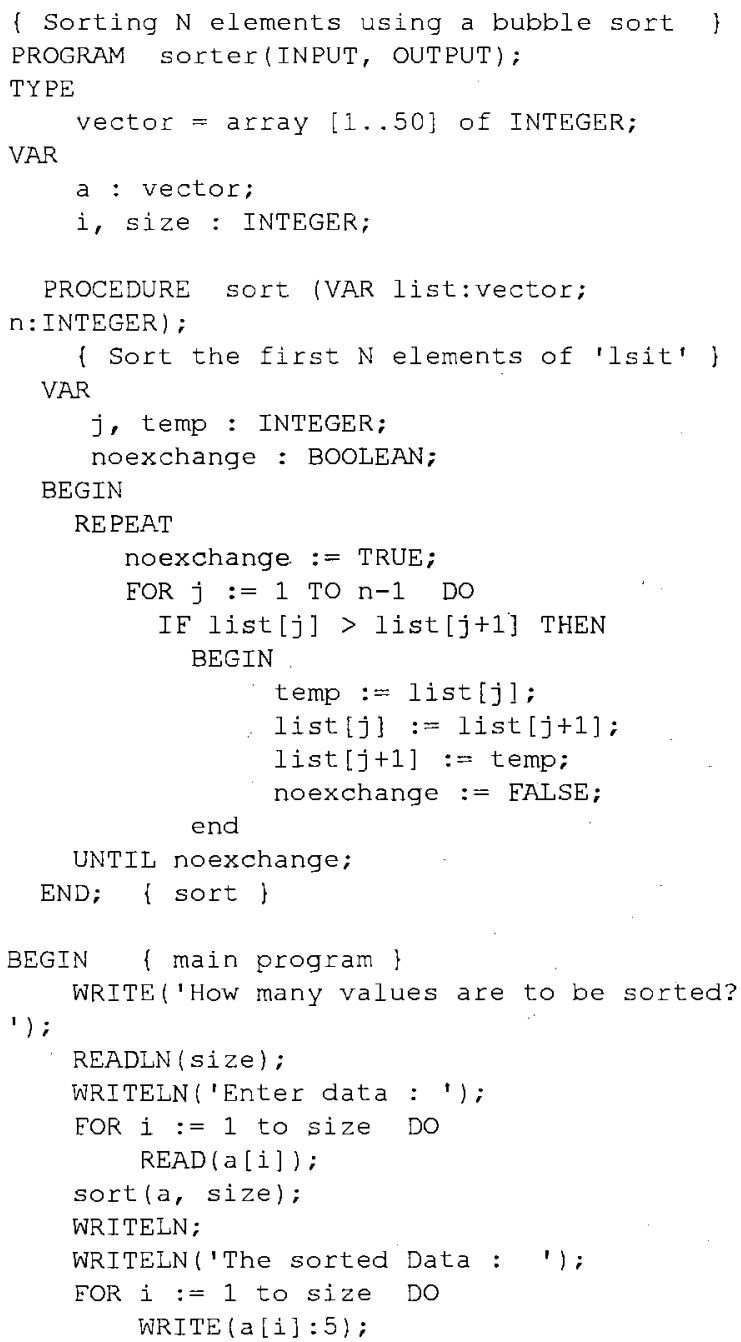

\section{Sample output}

How many values are to be sorted? 5

Enter data :

$\begin{array}{lllll}4 & 1 & 9 & 7 & 3\end{array}$

The sorted Data :

$\begin{array}{llllll}1 & 3 & 4 & 7 & 9\end{array}$

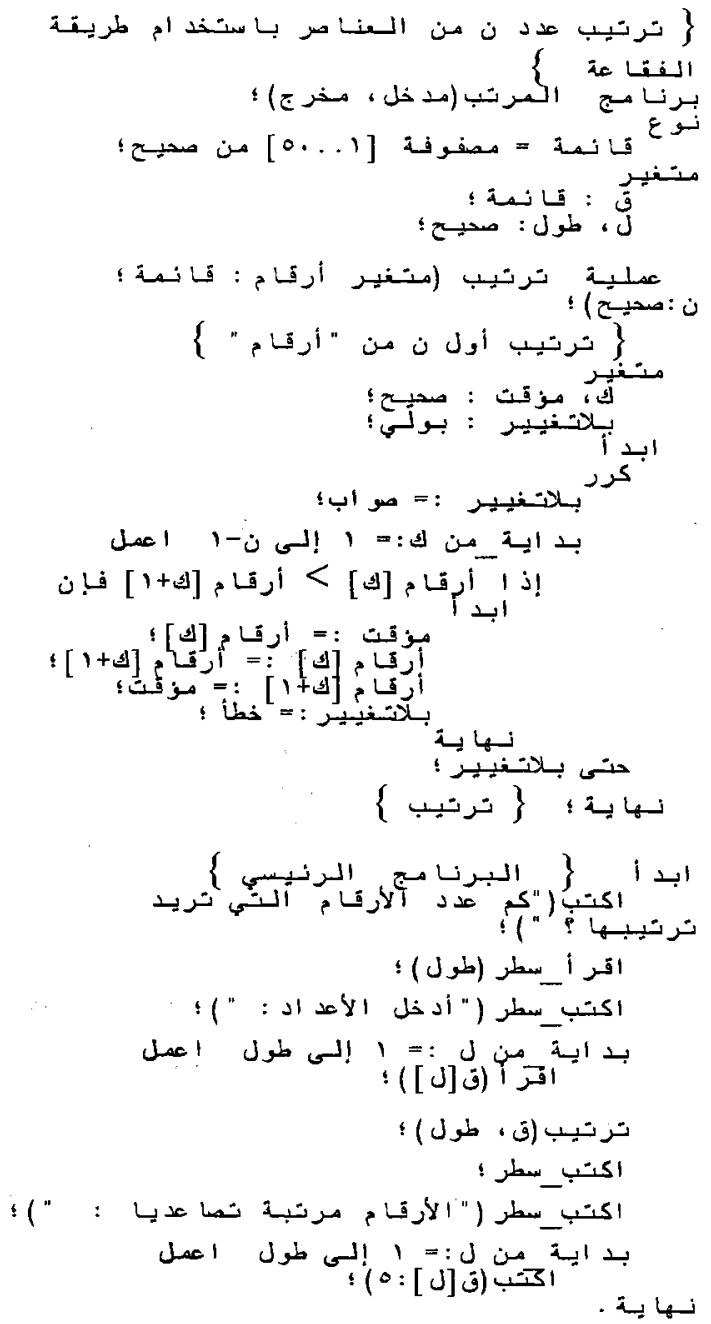

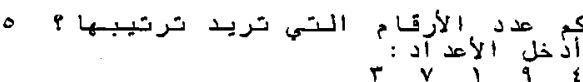

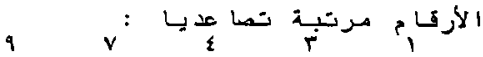




\section{CHAPTER 6}

\section{CONCLUSION AND FUTURE WORK}

The objective of this project is to build an Arabic programming language environment. The first step towards achieving such objective is to Arabize the environment that enables programmers to write programs in Arabic easily and efficiently. The environment is analogous to the programming environments that are available such as Turbo Pascal and Borland C. Therefore, the environment enables programmers to edit, compile, and execute programs. The dissertation describes, in detail, the APE design and implementation

The second step towards achieving the objective is to Arabize the Standard Pascal by designing an Arabic Pascal Compiler. The need for such an Arabized programming language is great in many Arab countries, especially in the education field. Currently available compilers are developed for languages whose lexical units are defined using the English alphabet. For students whose native language is not English, this approach imposes a burden. Therefore, it will be helpful to develop compilers with lexical units in other languages. This dissertation describes the specifications, design, and implementation of a Pascal programming language and its compiler with lexical units defined in the Arabic language. The Arabic Pascal language is an Arabized version of the Standard English Pascal. I have chosen the Standard Pascal as the target language because of its popularity. 
The analysis, design, and implementation of the scanner, the parser, the code generator, and the error handler were fully carried out in this dissertation.

Section 6.1 specifies the hardware and software requirements to run this software. Section 6.2 states the limitations of this work. Finally, Section 6.3 discusses possible future work.

\subsection{SYSTEM REQUIREMENTS}

The system requirements are as follows.

- An IBM PC (or a compatible computer).

- An Arabic version of the MS-Windows (the APE has been tested on MS-Windows version 3.1 and version 3.11).

- At least $4 \mathrm{MB}$ of RAM, to be able to run the Arabic Version of MS-Windows and, then, the APE.

- Executable files of the Turbo Assembler and the Turbo Linker. The APC compiles the source programs to assembly language. The assembly code, then, has to be assembled using the Turbo Assembler and has to be linked via the Turbo Linker. The APC has been tested using Turbo Assembler versions 3.0 and 4.0, and Turbo Linker versions 3.0, 5.1, and 6.0. However, Any version after 3.0 of both of them should work. The APC produces an assembly code with the small memory model. The Turbo Linker requires cows.obj (the standard MS-Windows initialization file), cws.lib (the small model runtime library for MS-Windows), mathws.lib (the MS-Windows math library for small model), and import.lib (the library that provides access to the built-in Windows functions). All these files should be distributed with the software.

- About $1 \mathrm{MB}$ of hard drive. The size of the executable files of APE, APC, and their complementary files is about $900 \mathrm{~K}$ without any compression. 


\subsection{SYSTEM LIMITATIONS}

Any system has some limitations. The main limitations of this software are as follows.

1. The APE does not guarantee a full Arabic interface. There are many reasons for interacting with English. Among these are the file names and system critical errors. The file name is recommended to be in English for compatibility reasons, as explained in Chapter 4. The system critical errors are the errors generated by the MS-Windows when an usual event happens, such as memory insufficient or accessing a protected memory area. The Arabic MS-Windows still displays these fatal errors in English. Thus, the APE users may receive some English messages from the system while using the APE.

2. To the best of our knowledge, the APE and APC are free of errors. However, it is not guaranteed that the software is error-free. The exhaustive testing requires several months or even years for such software.

3. The maximum file size is $32 \mathrm{~K}$. This is not a large size file, but it is enough for the majority of programs that may be written in this programming language.

4. Even though, the result size can be of any size, the APE cannot send to the printer a result of a size more than $32 \mathrm{~K}$, because the APE holds the results up to $32 \mathrm{~K}$, then discard the rest.

\subsection{FUTURE WORK}

There are many open avenues to enhance the current project. Among these avenues are the following. 
- Extending the Arabic Pascal by providing more built-in procedures and functions rather than the standard ones, and by utilizing some good programming styles, such as adding an else statement to the case statement.

- Providing more environment tools such as a runtime debugger within the APE.

- Enhancing the APE editing facilities by introducing syntax directed editing and program auto formatting (indenting).

- Supplying this software with a full documented user's manual in Arabic.

- Expanding the on-line help to provide a full explanation about the APE and the Arabic Pascal language.

- Speeding up the execution time of user programs by generating optimal object codes utilizing the code optimization techniques.

- Overcoming the $32 \mathrm{~K}$ limitation by increasing the maximum file size (using Visual $\mathrm{C}++$, instead of Visual BASIC) or by allowing more than one file to form a single program (multiple-file program)

- Modifying this software to be available under Windows 95 (currently, there is no Arabic interface in Windows 95).

- Finally, the Arabization of programming languages should be extended to all new concepts of programming languages such as object programming languages and visual programming. The limitation of man-power and the time, force us to choose a simple example, such as Standard Pascal. Such project is the seed for more sophisticated Arabic programming languages. 


\section{REFERENCES}

[AA88a] Al-Salman, A. and Al-Fantookh, A., "Towards a First Arabization of the UNIX System," B. Sc. Thesis, Computer Science Dept., King Saud University, Saudi Arabia, 1988.

[AA88b] AlFedaghi, S. and Amin, A., "Automatic Spelling Correction in Arabic," Technical Report, Electrical and Computer Engineering Department, Kuwait University, 1988.

[AA91] Amin, A. and Al-Fedaghi; S., "Machine Recognition of Printed Arabic Text Utilizing Natural Language Morphology," International Journal of Man-Machine Studies, Vol. 35, Dec. 1991, pp. 769-789.

[AA93] As-Sfran, S. and Aref, M. M., “الثمثيل الــلالي للمجمل العر بيسة,", Proceedings of the Arabic

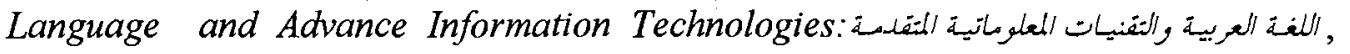
Casablanca, Morocco, Dec. 8-9 1993, pp. 45-56. In Arabic.

[AA94] Al-Daimi, K.J. and Abdel-Amir, M.A., "The Syntactic Analysis of Arabic by Machine," Computers and Humanities, Vol. 28, No. 1, 1994, pp. 29-37.

[Abd90] AbdulKader, A. A., “الحاسوب ودوره في الفهر سـة اللفظية للحديـث النبوي الشـريف," Proceedings of

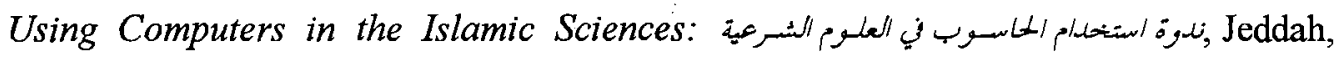
Saudi Arabia, Nov. 11-13 1990, pp. 77-104. In Arabic.

[Abe87] Abel, Peter, IBM PC Assembly Language and Programming, Prentice-Hall, 1987.

[Abu92] Abu-Salem, H.O., "A Microcomputer-Based Arabic Bibliographic Information Retrieval System with Relational Thesaurus," Ph. D. Dissertation, Computer Science, Illinois Institute of Technology, USA, 1992.

[AFC94] Arabi, M., Fischthal, S.M., Cheng, V.C., and Bart, E., "Algorithms for Arabic Name Transliteration," IBM Journal of Research and Development, Vol. 38, No. 2, March 1994, pp. 183-193.

[AG90] Abo-ElHamayl, M. A. and Gado, S. H., "تعريب نظام دوبيس/يبس," Proceedings of the 12th National Computer Conference and Exhibition, King Saud University, Riyadh, Saudi Arabia, Oct. 21-24, 1990, pp. 498-513. In Arabic. 
[AG95] Alimi, A. M. and Ghorbel, O. A., "Error Analysis in an On-Line Recognition System of Arabic Handwritten Characters," Proceedings of the 14th National Computer Conference, Riyadh, Saudi Arabia, 1-4 Apr., 1995, pp. 407-417.

[AH88] Al-Hawaj, A. Y. and Hamed, M., "Design of an Expert System for Teaching Programming Fundamentals," Proceedings of the 10th National Computer Conference, King Abdulaziz University, Jeddah, 28 Feb.-2 March 1988, pp. 835-846.

[AHD94] Abuhaiba, I. S., Holt, M. J., and Datta, S., "Straight Line Approximation and 1D Representation of Off-Line Handwritten Text," Image and Vision Computing, Vol. 12, No. 10, Dec. 1994, pp. 649-659.

[Ahm94] Ahmed, A., "إلماسوب في خدمة السنة النبوية المطهرة:" Proceedings of the 2nd Computer Arabization Symposium, King Saud University, Saudi Arabia, 27-30 March 1994, pp. 221-254. In Arabic.

[AK88] Ahmed, J. I. and Khayat, M. G., "Design and Implementation of a Database System for Display, Storage, and Retrieval of the Holy Qur'an," Proceedings of the 10th National Computer Conference, King Abdulaziz University, Jeddah, 28 Feb.-2 March 1988, pp. 774-776.

[Ala90] Alamri, A., “بمال استبادة العلوم الإسلامية من الكمبيوتر," Proceedings of Using Computers in the

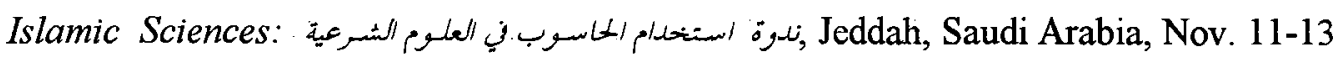
1990, pp. 43-52. In Arabic.

[Ald94] Aldarab, I. A., “تطييفات الحاسب الآلي في العلوم الشرعية," Proceedings of the 2nd Computer Arabization Symposium, King Saud University, Saudi Arabia, 27-30 March 1994, pp. 255-277. In Arabic.

[Ale94] Alemam, O., "التعر ف على الكلمات المنطوقة: نظام للغة العربيـة, Proceedings of the 2nd Computer Arabization Symposium, King Saud University, Saudi Arabia, 27-30 March 1994, pp. 39-46. In Arabic.

[Ali87] Ali, N., "Morphological Storage and Retrieval of Holy Qura'n," Proceedings of the First K.S.U. Symposium on Computer Arabization, King Saud University, Saudi Arabia, April 6-9 1987, p. 78.

[Ali88] Ali, N., "Computer Arabization: A Futuristic View," Technical Report, Alalamiah HiTech, Kuwait, 1988.

[Ali89] Ali, N., "Formalization and Computation of Arabic Syntax," Proceedings of the 11th National Computer Conference, Dahran, Saudi Arabia, 4-7 March 1989. pp. 309-320.

[Ali90] Ali, N., "نظم المعلومات-منسكلات والحلـول," Proceedings of Using Computers in the Islamic

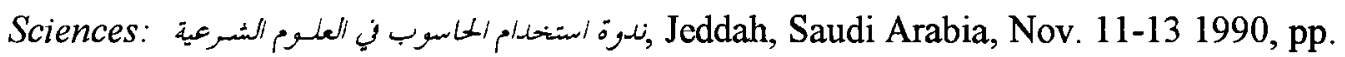
117-144. In Arabic 
[Alk90] AlKharashi, I., "An efficient Contextual Analysis Algorithm for Arabic Text Handling," Proceedings of the 12th National Computer Conference and Exhibition, King Saud University, Riyadh, Saudi Arabia, Oct. 21-24, 1990, pp. 465-474.

[Alk91] AlKharashi, I., "Micro-AIRS: A Microcomputer Based Arabic Information Retrieval System , Comparing Words, Stems, Roots, as Index Terms," Ph.D. Dissertation, Computer Science Dept., Illinois Institute of Technology, Chicago, USA, 1991.

[Alk92] Al-Khrisat, M., "Structuring the Arabic Lexicon and Thesaurus with Lexical Semantic Relations to Support Information Retrieval, Ph.D. Dissertation, Computer Science Dept., Illinois Institute of Technology, Chicago, USA, 1992.

[Alkh] Al-Khawarizmi User Manual, National Computer group. No Year.

[Alm90] Almofti, B. A., "اسمتخدام تقنيات متقدمة في خدمة الشُريعة الإسلامية" Proceedings of Using

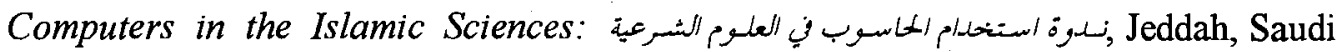
Arabia, Nov. 11-13 1990, pp. 105-116. In Arabic.

[Almua] Almuarib “"المعرب", Version 2, King Abdulaziz City for Sciences and Technology. No date. In Arabic.

[Als92] Al-Safran, S.A., "An Arabic Sentence Generator," M.S. Thesis, Computer Science, King Fahad University of Petroleum and Minerals, Saudi Arabia, 1992.

[Als96] Al-Salman, A., "An Arabic Programming Environment," Proceedings of the 1996 ACM Symposium on Applied Computing, Philadelphia, PA, Feb. 18-20, 1996, pp. 480-486.

[Aly89] Al-Yousefi, H., "Recognition of Handwritten Arabic Characters," Ph. D. Dissertation, Computer Science, Colorado State University, USA, 1989.

[AM87] Ali, N. and Morcos, I., "Data Compression Technique for Arabic Text," Proceedings of the First K.S.U. Symposium on Computer Arabization, King Saud University, Saudi Arabia, April 6-9 1987, pp. 67-77.

[AM95] AlSalman, H. A. and Mandorah, M. M., "استخلاص المعرفة لنظم تعليم الإسلام مساعدة الماسوب," Proceedings of the 14th National Computer Conference, Riyadh, Saudi Arabia, 1-4 Apr., 1995, pp. 70-84. In Arabic.

[AM94] Abo-Assamh, H. A. and Manther, A., "محرر نصوص عربي متكيف مـع المعاقين محدودي الحركة ", Proceedings of the 2nd Computer Arabization Symposium, King Saud University, Saudi Arabia, 27-30 March 1994, pp. 119-126. In Arabic.

[AMA94a] Al-Bawab, Marwan, Mrayati, Muhammad, Alam, Y. M., and Tayyan, M. H., "A Computerized Morpho-Syntactic System of Arabic," The Arabian Journal for Science and Engineering, Vol. 19, No. 3, July 1994, pp. 461-480. 
[Ama94b] Amarah, Jamal, Microsoft Visual Basic, Vol. 1 \& 2, AlMiman, 1994. In Arabic.

[AMG94] Abuhaiba, I.S., Mahmoud, S.A., and Green, R.J., "Recognition of Handwritten Cursive Arabic Characters," IEEE Transactions on Pattern Analysis and Machine Intelligence, Vol. 16, No. 6, June 1994, pp. 664-672.

[Ami88] Amin, A. M., "OCR of Arabic Texts," Proceedings of the 4th International Conference on Pattern Recognition, London, Springer, 1988.

[ASM82] ASMO, "ASMO Standard 449," Arab Organization for Standardization and Metrology, Amman, Jordan, 1982.

[ASU86] Aho, Alfred V., Sethi, Ravi, and Ullman, Jeffrey D., Compilers Principles, Techniques, And Tools, Addison-Wesley, 1986.

[AU92] Al-Yousefi, H. and Udpa, S.S., "Recognition of Arabic Characters," IEEE Transactions on Pattern Analysis and Machine Intelligence, Vol. 14, No. 8, Aug. 1992, pp. 853-857.

[AYE90] Al-Sadoun, H., Yaseen M., El-Jallad, A., and El-Jallad M., "ARbic BasIc (ARBI): A New Arabic MS-DOS Based Programming Language," Proceedings of the 12th National Computer Conference and Exhibition, King Saud University, Riyadh, Saudi Arabia, Oct. 21-24, 1990, pp. 449-464.

[Bac79] Backhouse, Roland C., Syntax of Programming Languages, Prentice-Hall, 1979.

[Bak86] Bakhit, B. B., "Arabic Data Compression, a Case Study,"," Proceedings of the 9th National Computer Conference and Exhibition, Riyadh, Saudi Arabia, 1986, pp. 10-41 to $10-4-12$.

[Bak87] Bakry, S. H., "Towards a Standard Arabic Glossary of Computer Terms," Proceedings of the First K.S.U. Symposium on Computer Arabization, King Saud University, Saudi Arabia, April 6-9 1987, pp. 28-36.

[Bas95] BASIC صنخ User Manual, Al-Alamiah Est. 1995.

[BB88] Brumm, Penn and Brumm, Don, 80386 Assembly Language, TAB Professional and Reference Books, 1988.

[Bec87] Becker, J.D., "Arabic Word Processing," Communications of the ACM, Vol. 30, No. 7, July 1987 , pp. 600-610.

[Ber78] Berry, R. E., "Experience with the Pascal P-Compiler,", Software-Practice and Experience, Vol. 8, No. 5, 1978, pp. 617-627. 
[BKN86] Booth, L., Khalid, M., Niaz, M., and Al-Waidan, H., "Arabization of an Automated Library," ," Proceedings of the 9th National Computer Conference and Exhibition, Riyadh, Saudi Arabia, 1986, pp. 10-3-1 to 10-3-40.

[BTA93] Borland Turbo Assembler User's Guide, Borland International, 1993.

[BTP89] Borland Turbo Pascal User's Guide and Reference Guide, Borland International, 1989.

[Cas85] Casey, D., "An Original Approach to Arabic," Middle East Computing, No. 21, Apr. 1985, p. 31.

[Cha87] Chaher, Y., "Production System of Morphological and Syntactical Analyzers Application to the Arabic Language," Proceedings of the First K.S.U. Symposium on Computer Arabization, King Saud University, Saudi Arabia, April 6-9 1987, pp. 4554.

[CJ88] Capon, P. C. and Jinks, P. J., Compiler Engineering Using Pascal, Macmillan, 1988.

[Coo83] Cooper, Doug, Standard Pascal User Reference Manual, Norton, 1983.

[Cro94] Crouse, K., The Windows Programming Puzzle Book, John Wiley \& Sons, 1994.

[DAM92] Dehash, K. A., AlBesher, A. A., Mathkour, H. I., "التخطيط لادنال الحاستب الآلي في مناهج" ,ومقر رات تعليم البنات," Proceedings of the 13th National Computer Conference, Riyadh, Kingdom of Saudi Arabia, 28 Nov. - 2 Dec., 1992, pp. 1-29. In Arabic.

[Dav86] Davidson, C., "Arabizing the Micro," Middle East Computing, No. 33, May 1986, p. 54.

[Del85] Delwachi, A., "Computer Processing of the Arabic Language: Problem Areas in the Treatment of Arabic in Hardware and Software Systems, " Proceedings of Computer Processing of the Arabic Language, Vol. 2, Kuwait, April 14-16 1985, pp. 1-26.

[DM86] Dehlawi, F. M. and Madorah, M.M., "J.ب.أ. : لغة بربجة أخرى."Proceedings of the 9th National Computer Conference and Exhibition, Riyadh, Saudi Arabia, 1986, Vol. 2, Section 2, pp. 20-60. In Arabic.

[DP80] Daniels, M. C. and Pemberton, S., "Implementing a Pascal Compiler on an 8085A System," Microcomputer Applications, Vol. 4, No. 3, 1980, pp. 144-150.

[Dun86] Duncan, Ray, Advanced MS-DOS, Microsoft Press, 1986.

[EB90] El-Imam, Y.A. and Banat, K., "Text-to-Speech Conversion on a Personal Computer," IEEE Micro, Vol. 10, Aug. 1990, pp. 62-74. 
[EEN89] El-Dessouki, A., El-Dessouki, O., Nazif, A., Ahmed, M., "An ATN Approach for Understanding Arabic Sentences," The 11th National Computer Conference and Exhibition, Dahran, Saudi Arabia, 4-7 March 1989, pp. 762-773.

[EG88] El-Sheikh, T. and Guindi, R., "Computer Recognition of Arabic Scripts," Pattern Recognition, Vol. 21, No. 4, 1988, pp. 293-302.

[EH89] El-Sadany, T.A. and Hashish, M.A., "An Arabic Morphological System," IBM Systems Journal, Vol. 28, No. 4, 1989, pp. 600-612.

[Ela86] El-Affendi, M. A., "نمو لغة متطورة للبربحة بالعربيسة "Proceedings of the 9th National Computer Conference and Exhibition, Vol. 2, Section 1, Riyadh, Saudi Arabia, 1986, pp. 14-28. In Arabic.

[Ela87] El-Affendi, M. A., "Efficient Algorithms for Basic System Arabization," Proceedings of the First K.S.U. Symposium on Computer Arabization, King Saud University, Saudi Arabia, April 6-9 1987, pp. 37-44.

[Ela90] El-Affendi, M. A., “A Natural Arabic Interface to MS-DOS," Proceedings of the 12th National Computer Conference and Exhibition, King Saud University, Riyadh, Saudi Arabia, Oct. 21-24, 1990, pp. 475-497.

[Eld87] El-Dessouki, O., "Dictionary-Based Arabic Text Compression Technique," Proceedings of the First K.S.U. Symposium on Computer Arabization, King Saud University, Saudi Arabia, April 6-9 1987, pp. 79-87.

[Eld94] Elder, John, Compiler Construction: A Recursive Descent Model, Prentice-Hall, 1994.

[ELS93] El-Hannach, M., Labed, L., Salhi, R., and Ghazali, S., "برنامج لساني-حاسوبي للتعرف على التعابـير المدـكو كة في اللغـة العربيـة," Proceedings of the Arabic Language and Advance

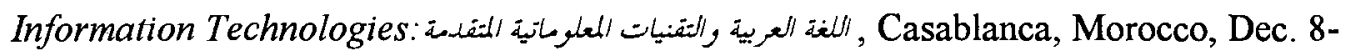
9 1993, pp. 71-90. In Arabic.

[ES89] El-Wakil, M. and Shoukry, A., "On-Line Recognition of Handwritten Isolated Arabic Characters," Pattern Recognition, Vol. 22, No. 2, 1989, pp. 97-105.

[Far89] Farghaly, A., "A natural Language Understanding System for Arabic," Proceedings of the First Kuwait Computer Conference, Kuwait, March 1989, pp. 595-622.

[Far90] Faraj, M. S. “استخدام الحاسوب الآلي في بناء الموسوعات الشرعية", Proceedings of Using Computers in the Islamic Sciences: نلوة استخدام الحاسوب في العلوم النرعية Jeddah, Saudi Arabia, Nov. 11 13 1990, pp. 53-76. In Arabic.

[FE95] Fayek, M. and Elhaweet, W., "Computer as an aid for Education," Proceedings of the 14Th National Computer Conference, Riyadh, Kingdom of Saudi Arabia, 1-4 Apr. 1995 , pp. 85-100. 
[Fed92] Feddag, A., "Arabic Morpho-Syntax and Semantic Parsing," Proceedings of the 13th National Computer Conference, Riyadh, Saudi Arabia, Nov. 11-14, 1992, Vol. 2, pp. 717-749.

[FF90] Foxley, E. and Feddag, A., "A Syntactic and Morphological Analyzer of Arabic Words," Proceedings of the 2nd Cambridge Conference on Bilingual Computing in Arabic and English, Cambridge University, UK, Sept. 5-7 1990.

[FF93] Feddag, A. and Foxley, E., "A Lexical Analyzer for Arabic," International Journal of Man-Machine Studies, Vol. 38, Feb. 1993, pp. 313-330.

[GFA95] Gembi, K. M., Farrash, A. A., and AlHarbi, A. S., "دراسة ميدانية عن تدريس مواد الحاسوب في المرحلـة الثانويـة," Proceedings of the 14Th National Computer Conference, Riyadh, Kingdom of Saudi Arabia, 1-4 Apr. 1995, pp. 2-18. In Arabic.

[Gne94] Gnemi, M. A., "الحاسـوب والتعليـم," Proceedings of the 2nd Computer Arabization Symposium, King Saud University, Saudi Arabia, 27-30 March, pp. 127-152. In Arabic.

[Gor90] Goraine, H., "Machine Recognition of Arabic Text," Ph.D. Dissertation, Computer Science, University of Reading, UK, 1990.

[Gri71] Gries, David, Compiler Construction for Digital Computers, John Wiley, 1971.

[GUA92] Goraine, H., Usher, M., and Al-Emami, S., "Off-Line Arabic Character Recognition," Computer, Vol. 27, No. 7, July 1992, pp. 71-74.

[Hah87] Hahn, Harley, The Complete Guide to IBM PC AT Assembly Language, Scott, Foresman and Company, 1987.

[Ham94a] Hamado, A. "مر احل التحليل الآلي للغة العربية تصد تحسهن الأنطاء وتصحيحها", Proceedings of the 2nd Computer Arabization Symposium, King Saud University, Saudi Arabia, 27-30 March 1994, pp. 25-38. In Arabic.

[Ham94b] Hammouri, A., "An Arabic Lexical Database to Support Natural Language Processing, Ph.D. Dissertation, Computer Science Dept., Illinois Institute of Technology, USA, 1994.

[Han85] Hansen, P. B., Brinch Hansen On Pascal Compilers, Prentice-Hall, 1985.

[HE86] Hegazi, N. H. and Elsharkawi, A. A., "Natural Arabic Language Processing," Proceedings of the 9th National Computer Conference and Exhibition, Riyadh, Saudi Arabia, 1986, pp. 10-5-1 to 10-5-17. 
[Hed75] Hedrick, G. E., Editor, Proceedings of the 1975 International Conference on ALGOL 68, Section 1-Survey of ALGOL 68 Compilers, Oklahoma State University, Stillwater, June 10-12, 19975.

[Hen90] Hendrix, J. E., A Small C Compiler, Second Edition, M\&T Books, 1990.

[Hil90] Hilal, Y., “الحاسوب في خدمة الحديث النبوي الشُريف," Proceedings of Using Computers in the Islamic Sciences: ندوة استخدام/الحاسوب في العلوم الشـرعية Jeddah, Saudi Arabia, Nov. 11-13 1990, pp. 235-253. In Arabic.

[Hol90] Holub, Allen I., Compiler Design in C, Prentice Hall, 1990.

[Ho191] Holzner, Steven, Advanced Assembly Language, Brady, 1991.

[Ibr91] Ibrahim-Shaker, M.M., "A Fast and Expert Machine Translation System Involving Arabic Language," Ph. D. Dissertation, Cranfield Institute of Technology, UK, 1991.

[Hun85] Hunter, R., Compilers: Their Design and Construction Using Pascal, John Wiley, 1985.

[IDF89] Ibrahim, A., Douglas, J., and Fahhmy, A., "Arabic in Machine Translation," Proceedings of the First Cambridge Conference on Bilingual Computing in Arabic and English, Cambridge University, UK, 1989.

[Jam91] Jambi, K.M., "Design and Implementation of a System for Recognizing Arabic Handwritten Words with Learning Ability," Ph.D. Dissertation, Computer Science, Illinois Institute of Technology, USA, 1991.

[JW74] Jensen, K. and Wirth, N., PASCAL User Manual and Report, Second Edition, Springer-Verlag, 1974.

[Kal85] Kaldirm, O., "Architecture of Arabic Computer," Proceedings of Computer Processing of the Arabic Language, Vol. 1, Kuwait, April 14-16 1985, pp. 1-7.

[KC91] Khan, E.H. and Chaudhry, F.I., "Contextual Analysis Approach for Arabization of a microcomputer," IEEE Transactions on Consumer Electronics, Vol. 37, No. 1, Feb. 1991, pp. 86-95.

[KH93] Khayat, M. G. and Hanadi, M. A., "تمثيل الدلالة الصرفية لأوزان الأنعال في النظم الآلية لفهم اللغة العربية", Proceedings of the Arabic Language and Advance Information Technologies: اللغة العربية والتفنيات المعلوماتية المتقدمة, Casablanca, Morocco, Dec. 8-9 1993, pp. 57-70. In Arabic.

[Kha86] Khayat, M.G., "Printing Arabic Text Using Dot Matrix Printers," Software-Practice and Experience, Vol. 16, No. 2, Feb. 1986, pp. 165-172. 
[MA85] Mandurah, M. M. and Al-Musa, A. O., "The use of graphics to generate high quality Arabic characters, " Proceedings of the 8th National Computer Conference, Al-Kobar, Saudi Arabia, Oct. 1-7 1985, pp. 1031-1041.

[MA94] Mandorah, M. M. and AlSalman, H. A., "الحاسوب في نحدة الدعوة الإسلامية: مشروع تطوير نظام" لبعليم القرآن لغسير المسلمين , Proceedings of the 2nd Computer Arabization Symposium, King Saud University, Saudi Arabia, 27-30 March 1994, pp. 197-210. In Arabic.

[Mac90] Mackay, Pierre (Editor), Computers and the Arabic Language, Hemisphere Publishing Co., 1990.

[Mah85] Mahjoub, A., "A New Definition of True Arabization," Middle East Computing, No. 27, Nov. 1985, pp. 61-65.

[Mah94] Mahmoud, S., "Arabic Character Recognition Using Fourier Descriptors and Character Contour Encoding," Pattern Recognition, Vol. 27, No. 6, 1994, pp. 815-824.

[Mak91] Mak, Ronald, Writing Compilers \& Interpreters, John Wiley, 1991.

[Man85] Mandorah, M..M., "Architecture of an Arabic Computer," Proceedings of Computer Processing of the Arabic Language, Vol. 2, Kuwait, April 14-16 1985, pp. 8-26.

[Man90] Mandorah, M. M., “لحاسبات في خدمة الدعوة الإسلامية," Proceedings of Using Computers in

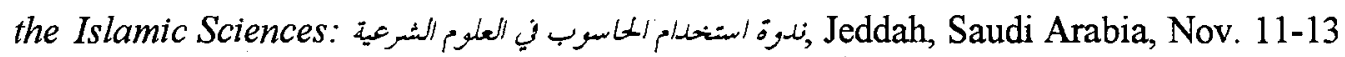
1990, pp. 191-208. In Arabic.

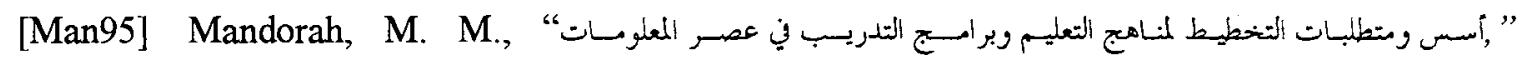
Proceedings of the 14Th National Computer Conference, Riyadh, Kingdom of Saudi Arabia, 1-4 Apr. 1995, pp. 476-489. In Arabic.

[Mic88] MicroSoft, MS DOS User's Guide Arabic Supplement, MicroSoft, 1988.

[Mic92] MicroSoft, MS-DOS Arabic Support User's Guide, MicroSoft, 1992.

[Mic93] MicroSoft, Microsoft Word- لدليل المستخدم باللغة العربية, MicroSoft, 1993. In Arabic.

[Min87] Project of introducing of computing to public school system, Ministry of Education, Internal memo, Technical committee, Jan. 87.

[Mis93] Mischel, Jim, Macro Magic with Turbo Assembler, John Wiley, 1993.

[MM87] Mahjoub, A. H. and Mandurah, M. M., "Current Issues and Future Directions in Computer Arabization," Proceedings of the First K.S.U. Symposium on Computer Arabization, King Saud University, Saudi Arabia, April 6-9 1987, pp. 1-27. 
[MM94] Mahmood, S. A. and Mandorah, M. M., "ذيثة البربحة كاتب وتطبيقاتها في تطوير نظم تعليم حاسوبية ¿ذيـ," Proceedings of the 2nd Computer Arabization Symposium, King Saud University, Saudi Arabia, 27-30 March 1994, pp. 47-94. In Arabic.

[MM95] Mankai, Chafia and Mili, Ali, "Machine Translation from Arabic to English and French,"Information Sciences, Vol. 3, No. 2, March 1995, pp. 91-109.

[Mor90] Morfeq, A.H., "BAYAN: A Text Database Management System for Arabic Engineering Documents," Ph.D. Dissertation, Computer Science, University of Colorado, USA, 1990.

[Mou87] Mouajed, M. B., "APG INGRES: An Arabic Interface for INGRES Base," Proceedings of the First K.S.U. Symposium on Computer Arabization, King Saud University, Saudi Arabia, April 6-9 1987, pp. 127-134.

[MP86] Murray, William H. and Pappas, Chris H, 80386/80286 Assembly Language Programming, Osborne McGraw-Hill, 1986.

[MSF88] Mosich, D., Shammas, N., and Flamig, B., Advanced Turbo C Programmer's Guide, John Wiley, 1988.

[MT95] Mostafa, S. M. and Takrony, Y. S., "Computer Assisted English to Arabic Translation," Proceedings of the 14th National Computer Conference, Riyadh, Saudi Arabia, 1-4 Apr., 1995, pp. 429-442.

[NA94] Noah, A. S. and Ahmed, A., "النعرف على الحرون العربية: استعراض دقيق" Proceedings of the 2nd Computer Arabization Symposium, King Saud University, Saudi Arabia, 27-30 March 1994, pp. 1-24. In Arabic.

[Najla] Najla User Manual, Saudi Computer Industries. No year.

[NEE88] Nazif, A., El-Dessouki, O. I., El-Dessouki, A., and Ahmed, M., "An Expert System for Understanding Arabic Sentences," Proceedings of the 10th National Computer Conference, King Abdulaziz University, Jeddah, 28 Feb.-2 March 1988, pp. 745-760.

[NH94] Narayanan, A. and Hashem, L., "Finite-State Abstractions on Arabic morphology,", Artificial Intelligence Review, Vol. 7, No. 6, 1994, pp. 373-399.

[NM91] Narayanan, A. and Mehdi, S., "A Computer Model for Transliterated Arabic," Applied Computer Translation, Vol. 1, No. 3, 1991, pp. 5-28.

[PD82] Pemberton, S. and Daniels, M. C., Pascal Implementation: The P4 Compiler, John Wiley, 1982.

[Pem80] Pemberton, S., "Comments on an Error-Recovery Scheme by Hartmann," SoftwarePractice and Experience, Vol. 10, No. 3, pp. 231-240.

[PP92] Pittman, Thomas and Peters, James, The Art of Compiler Design, Prentice-Hall, 1992. 
[Pys88] Pyster, Arthur B., Compiler Design and Construction, Van Nostrand Reinhold, 1988

[QHA93] Qafari, A. S., Hamruni, B. M., Al-Kharashi I. A., and Evens, M. W., “خطوات تطبيقية نحو

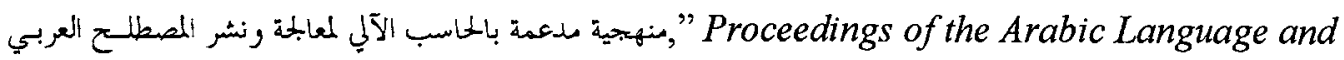

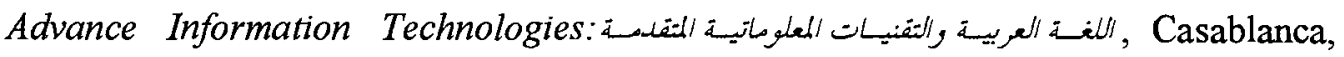
Morocco, Dec. 8-9 1993, pp. 259-278. In Arabic.

[RS93] Rafea, A.A. and Shaalan, K.F., "Lexical Analysis of Inflected Arabic Words Using Exhaustive Search of an Augmented Transition Network," Software-Practice and Experience, Vol. 23, No. 6, June 1993, pp. 567-588.

[Sam72] Sammet, J. E., "Programming Languages: History and Future," Communications of the $A C M$, Vol. 15, No. 7, 1972, pp. 601-610.

[Sau86] Saudi Soft., Al Mussaed Al Arabi, Jeddah, Saudi Arabia, 1986.

[SC92] Suleiman, Khalid A. and Citrin, Wayne, "An International Visual Language," Proceedings. of IEEE Workshop on Visual Languages, Seattle, Sept. 1992.

[SC95] Suleiman, Khalid A. and Citrin, Wayne, "A Visual Approach to Programming Language Internationalization: An Arabic Case Study," to appear in Language Problems and Language Planning, Vol. 19, No. 2, 1995, pp. 113-132.

[Sch89] Schildt, Herbert, Advanced Turbo C, Second Edition, McGraw Hill, 1989.

[Smi90] Smith, B., "Around the World in Text Displays," Byte, Vol. 15, No. 5, May 1990, pp. 262-268.

[TA90] Tayli, M. and Al-Salamah, A.I., "Building Bilingual microcomputer Systems," Communications of the ACM, Vol. 33, No. 5, May 1990, pp. 495-504.

[Tab93] Tabaza, K., "Windows on Arabia," Byte, Vol. 18, No. 7, July 1993, p. 48.

[Tay87] Tayli, M., "Integrated Arabic System," Proceedings of the First K.S.U. Symposium on Computer Arabization, King Saud University, Saudi Arabia, April 6-9 1987, pp. 135143.

[Tek90] Tekfi, C., "Design of a Computer Information System for the Algerian National Archives," Ph.D. Dissertation, Information Science, The City University, London, UK, 1990.

[Tib81] Tiberghien, Jacques, The Pascal Handbook, Sybex Computer Books, 1981.

[TNS86] Tayli, M., Nafisah, M., and Shahin, S., "Intelligent Arabic Workstation," Proceedings of the 9th National Computer Conference and Exhibition, Riyadh, Saudi Arabia, 1986, pp. 10-2-1 to 10-2-8. 
[UN84] United Nations Development Program Regional Bureau for Arab States, "Computer, Informatics, and Development in Some Arabic-Speaking Countries," Mission Report, N.Y., July 1984.

[WH86] Welsh, J. and Hay, A., A Model Implementation of Standard Pascal, Prentice-Hall, 1986.

[Wir71] Wirth, N., "The Design of a Pascal Compiler," Software-Practice and Experience, Vol. 1, No. 4, 1971, pp. 309-333.

[WQ72] Welsh, J, and Quinn, C., “A Pascal Compiler for the ICL1900 Series Computers," Software-Practice and Experience, Vol. 2, No. 1, 1972, pp. 73-77.

[You88] Young, Michael, MS-DOS Advanced Programming, Sybex, 1988.

[ZRN87] Zyoute, M., Rajouani, A., Najim, M., Ouadou, M., and Chiadmi, "Speech Synthesis of the Arabic Language," Proceedings of the First K.S.U. Symposium on Computer Arabization, King Saud University, Saudi Arabia, April 6-9 1987, pp. 88-89. 


\section{APPENDIX A}

\section{APE MESSAGES}

This Appendix consists of the messages that are generated by the APE. There are three types of messages: informative messages, error messages, and dialog messages (require a response from the user). Each message will be shown here exactly as the APE displays it, along with the English translation and the main cause for generating this message.

\section{A.1 INFORMATIVE MESSAGES}

\section{1.}

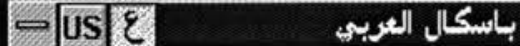

$$
\text { كل نسئ تقرجمة بنجاح }
$$

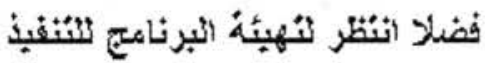

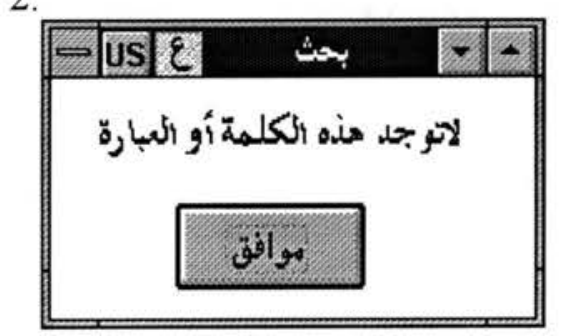

"Successful Compilation. Please wait for preparing the program for execution" This message is displayed when the user compiles a program that is free of errors and the assembling and linking is in progress. This message will disappear automatically when the program is ready for execution.

\section{"This word does not exist" (OK)}

This message is displayed when the search for a word reaches the end or the beginning of the file without finding that word. 


\section{A.2 ERROR MESSAGES}

\section{1.} باسكال العربي

لم يتم التمكن عن فتح الهلف: C:\{UTILITIEYARAB_ED2|xox.ap

$$
30.8
$$

2.

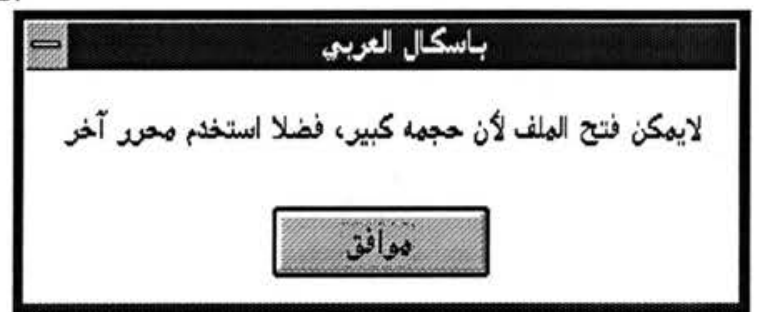

3.

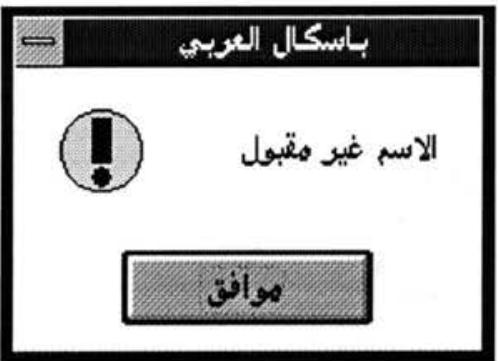

4.

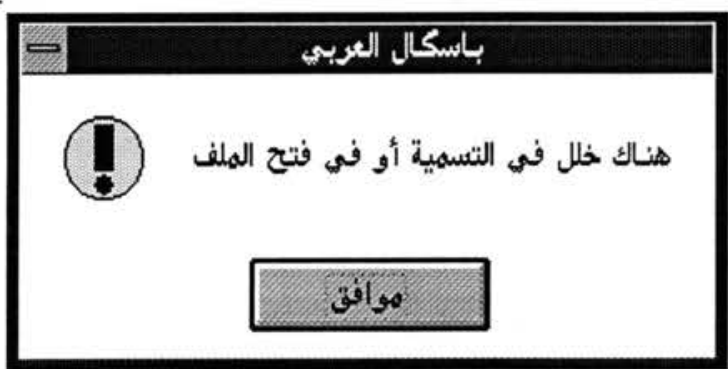

5.

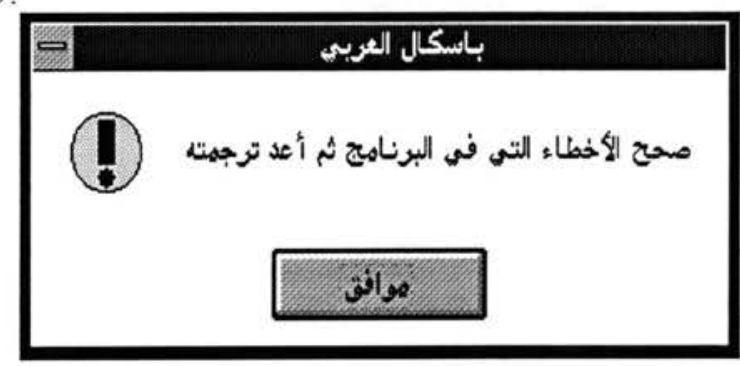

"Unable to open the file $<$ file-name $>$ " (OK)

This message is displayed when the user tries to open a file that is not found in specified path.

"Unable to open the file because it is a big file. Please try another editor" (OK)

This message is displayed when the user tries to open a file that is more than $32 \mathrm{~K}$. The text window in Visual BASIC can hold only up to $32 \mathrm{~K}$.

"The name is not acceptable" (OK) This message is displayed when the user enters some special characters (such as,$+ \mid$, or ;) as part of the file name.

"There is an error in the file name or in opening the file" $(\mathrm{OK})$

This message is displayed when the system cannot open the file due to corruption in the file name or overflow in the memory.

"Correct the errors in the program then recompile it" (OK)

This message is displayed when the user tries to execute a program (by clicking the red traffic light) that has some compilation errors. 
6.

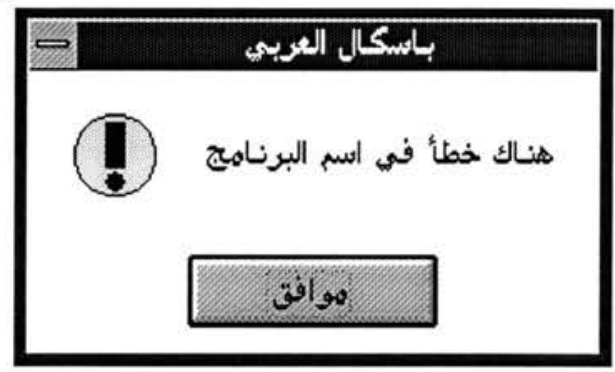

7.

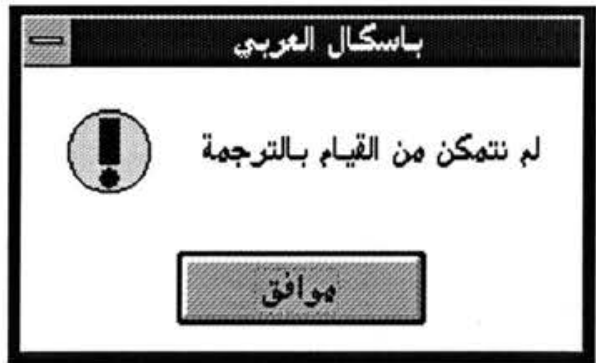

8.

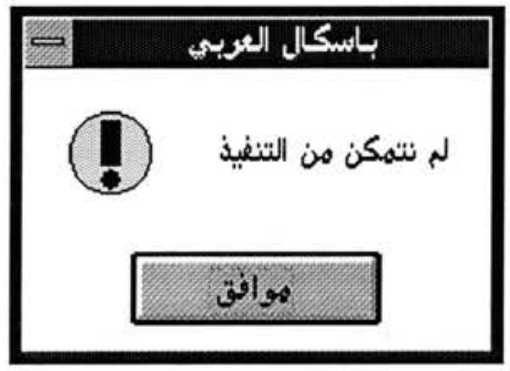

9.

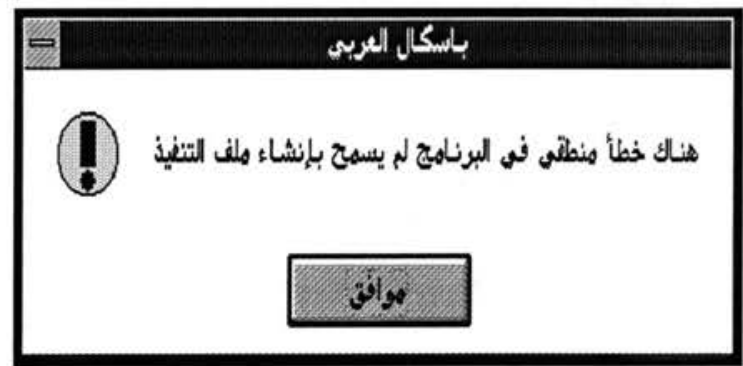

10.

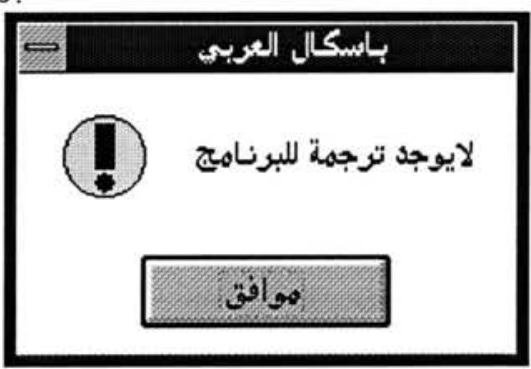

"There is an error in the file name" (OK) This message is displayed when the user tries to compile a program that has not been saved (its name is still 'Untitled' or the compiler could not find the file name.)

"Unable to do the compilation" (OK) This message is displayed when the compiler (APC) was not found in the expected path. (for example, if the user somehow deleted the compiler or altered its place in the directory).

"Unable to do the execution" (OK) This message is displayed when the tasm or tlink is not found in the expected place or the executable file was not found in the current directory.

"There is a logical error that prevents the creation of the executable file" $(\mathrm{OK})$ This message is displayed when the compiler (APC) produces an assembly code that is not recognized by the Assembler (tasm) or the Linker (tlink). In this case, please notify the author.

"There is no compilation for this program" (OK)

This message is displayed when the user tries to print the compilation window while there is no compilation window. 
11.

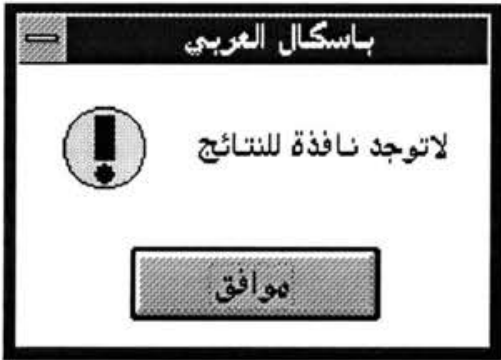

12.

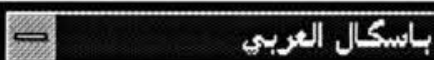

لايمكن طباعة النتائج لأن حجمها كبير جدا

\section{فㅇ.}

\section{A.3 DIALOG MESSAGES}

1.

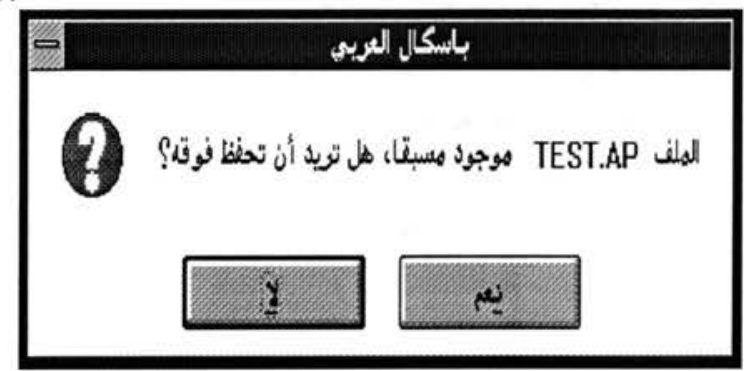

2.

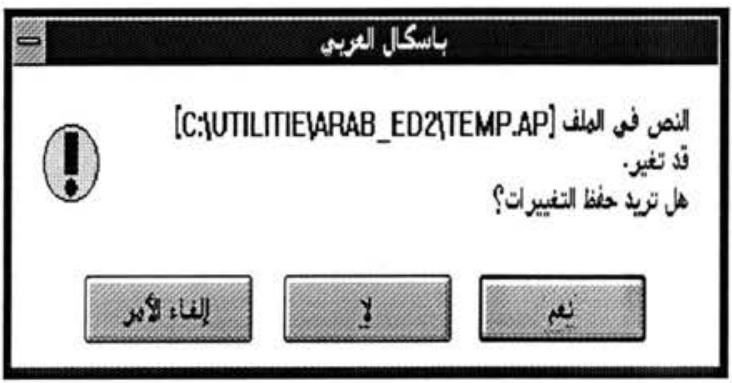

"There is no execution window" (OK) This message is displayed when the user tries to print the execution results while there is no execution window.

"Unable to print the results because the output size is very large" $(\mathrm{OK})$

This message is displayed when the user tries to print a larger than $32 \mathrm{~KB}$ file.
"The file < file-name > already exists. Do you want to overwrite it?" (YES, NO) This message is displayed when the user tries to save a file by naming it with a name that already exists.
"The file < file-name $>$ has been changed. Do you want to save it?" (YES, NO, CANCEL)

This message is displayed when the user tries to leave the APE or close a file without saving it. 


\section{APPENDIX B}

\section{LIST OF WORDS AND SYMBOLS IN THE ARABIC PASCAL}

The following are the lists of reserved words, predefined types and identifiers, built-in functions and procedures, and symbols in English Pascal and their correspondences in Arabic Pascal.

\section{B.1 RESERVED WORDS}

\begin{tabular}{|c|c|c|c|}
\hline$\overline{\text { AND }}$ & , & NIL & فارغ \\
\hline ARRAY & مصفوفة، مصفوفه & NOT & ليس \\
\hline BEGIN & ابدأ، ابدا & OF & من \\
\hline CASE & حالة، حاله & OR & أو، او \\
\hline CONST & ثابت & PACKED & مربوطة، مربوطه \\
\hline$\overline{\text { DIV }}$ & قاسم & PROCEDURE & عملية، عمليه \\
\hline$\overline{\mathrm{DO}}$ & اعمل، إعمل & PROGRAM & برنامج \\
\hline DOWNTO & نزول_إلى، نزول_اللى & RECORD & سجل \\
\hline ELSE & وإلا، والا & REPEAT & كرر \\
\hline END & نهاية، نهايه & SET & بحموعة، بجموعه \\
\hline FILE & ملف & THEN & فإِن، فان \\
\hline$\overline{\text { FOR }}$ & لقِّم & TO & إلى، اللى \\
\hline FUNCTION & دالة، داله & TYPE & نوع \\
\hline GOTO & اذهب_إلى، اذهب_اللى & UNTIL & حتى \\
\hline IF & إذا، اذا & VAR & متغير \\
\hline$\overline{\mathrm{IN}}$ & في، فى & WHILE & 46 \\
\hline
\end{tabular}




\begin{tabular}{|c|c|c|c|}
\hline LABEL & عنوان & WTTH & ع \\
\hline MOD & باقي، باقى & FORWARD* & لاحق \\
\hline
\end{tabular}

* "FORWARD" is not a reserved word; it is the only directive in Pascal Language.

\section{B.2 PREDEFINED IDENTIFIERS AND TYPES}

\begin{tabular}{|c|c|c|c|}
\hline INPUT & مدخل & INTEGER & صحيح \\
\hline OUTPUT & غخرج & BOOLEAN & منطقي، منطقى \\
\hline CHAR & حرف & REAL & حقيقي، حقيقى \\
\hline FALSE & نحطأ، نحطا & TEXT & نص | \\
\hline TRUE & صواب & & \\
\hline
\end{tabular}

\section{B.3 BUILT-IN FUNCTIONS AND PROCEDURES}

(1) Functions

\begin{tabular}{|c|c|c|c|}
\hline$\overline{\mathrm{ABS}}$ & مطلق & ORD & ترتيب \\
\hline ARCTAN & قوظا & PRED & سابق \\
\hline CHR & حرفي، حرفى & ROUND & تقريب \\
\hline $\cos$ & جنt & SIN & La \\
\hline EOF & ن & $\mathrm{SQR}$ & مربع \\
\hline EOLN & نها_س & SQRT & جذر_r \\
\hline EXP & أس، اس & SUCC & تابع \\
\hline $\mathrm{LN}$ & لو & TRUNC & بنز \\
\hline ODD & فردي، فردى & & \\
\hline
\end{tabular}

\section{(2) Procedures}

\begin{tabular}{|c|c|c|c|}
\hline DISPOSE & تخلص & RESET & قراءة، قراءه \\
\hline NEW & جديد & REWRITE & كتابة، كتابة \\
\hline READ & اقرأ، اقر | & WRITE & اكتب \\
\hline READLN & اقرأ_س، اقرا_س & WRITELN & اكتب_س \\
\hline
\end{tabular}


Note: Procedures GET, PUT, and PAGE are not implemented in the Arabic Pascal.

\section{B.4 SYMBOLS}

The following are the symbols that have been changed in the Arabic Pascal. The symbols that are not mentioned here are the same in both English Pascal and Arabic Pascal. The character " $\mathrm{E}$ " is the E-notation in real numbers.

\begin{tabular}{|c|l|l|l|l|l|l|l|}
\hline English & Arabic & & English & Arabic & English & Arabic \\
\hline 6 & $" 6$ & &, & $\ddots$ & & $>$ & $<$ \\
\hline( & ) & & ) & ( & & $<=$ & $=>$ \\
\hline$;$ & $\vdots$ & & E & $\sim$ & & $>=$ & $=<$ \\
\hline\{ & \} & & \} & \{ & & ] & {[} \\
\hline$:=$ & $=:$ & & $<$ & $>$ & & {[} & ] \\
\hline
\end{tabular}




\section{APPENDIX $\mathrm{C}$}

\section{SYNTAX DIAGRAMS FOR THE ARABIC PASCAL}

The following are the syntax diagrams which precisely define the syntax of the Arabic Pascal. The usual conventions of syntax diagrams are assumed. The circles stand for terminal symbols while the rectangles stand for non-terminal symbols. The last two pages of this Appendix give the syntax diagrams of the built-in functions and procedures.
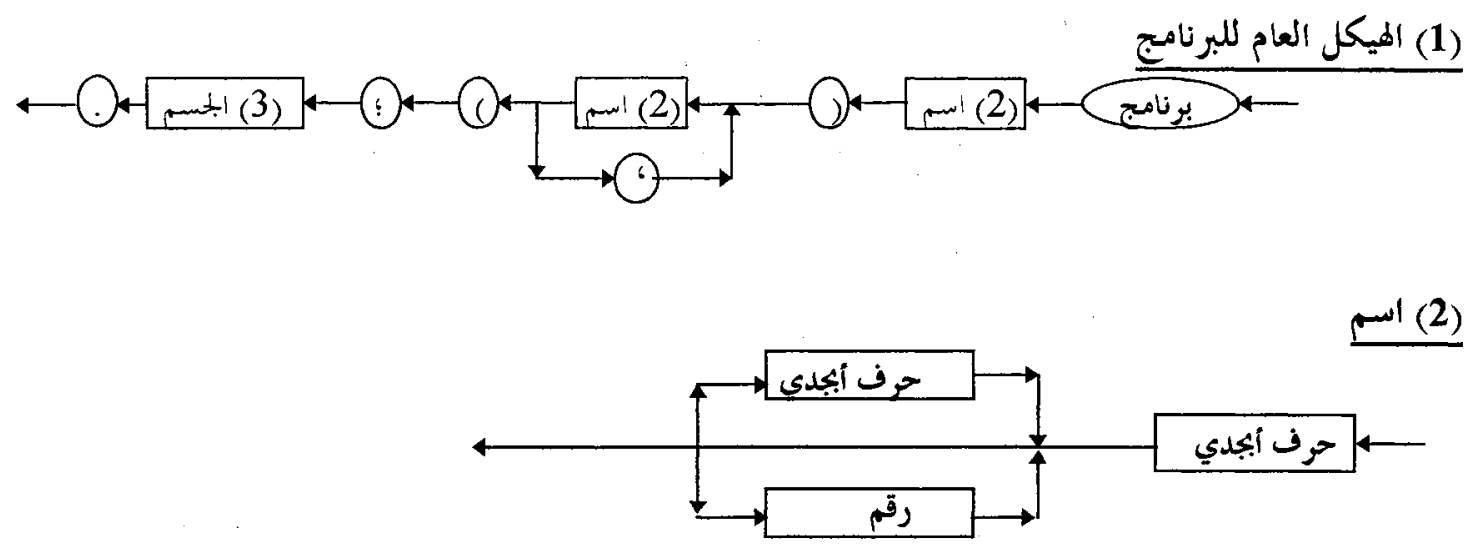

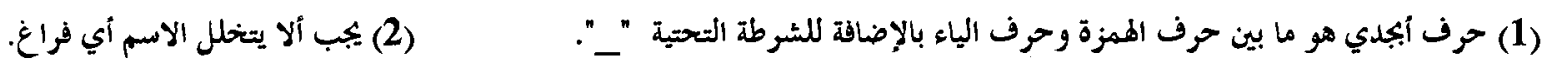

$$
\begin{aligned}
& \text { (3) الاسم محدود بطول } 80 \text { حرف. }
\end{aligned}
$$




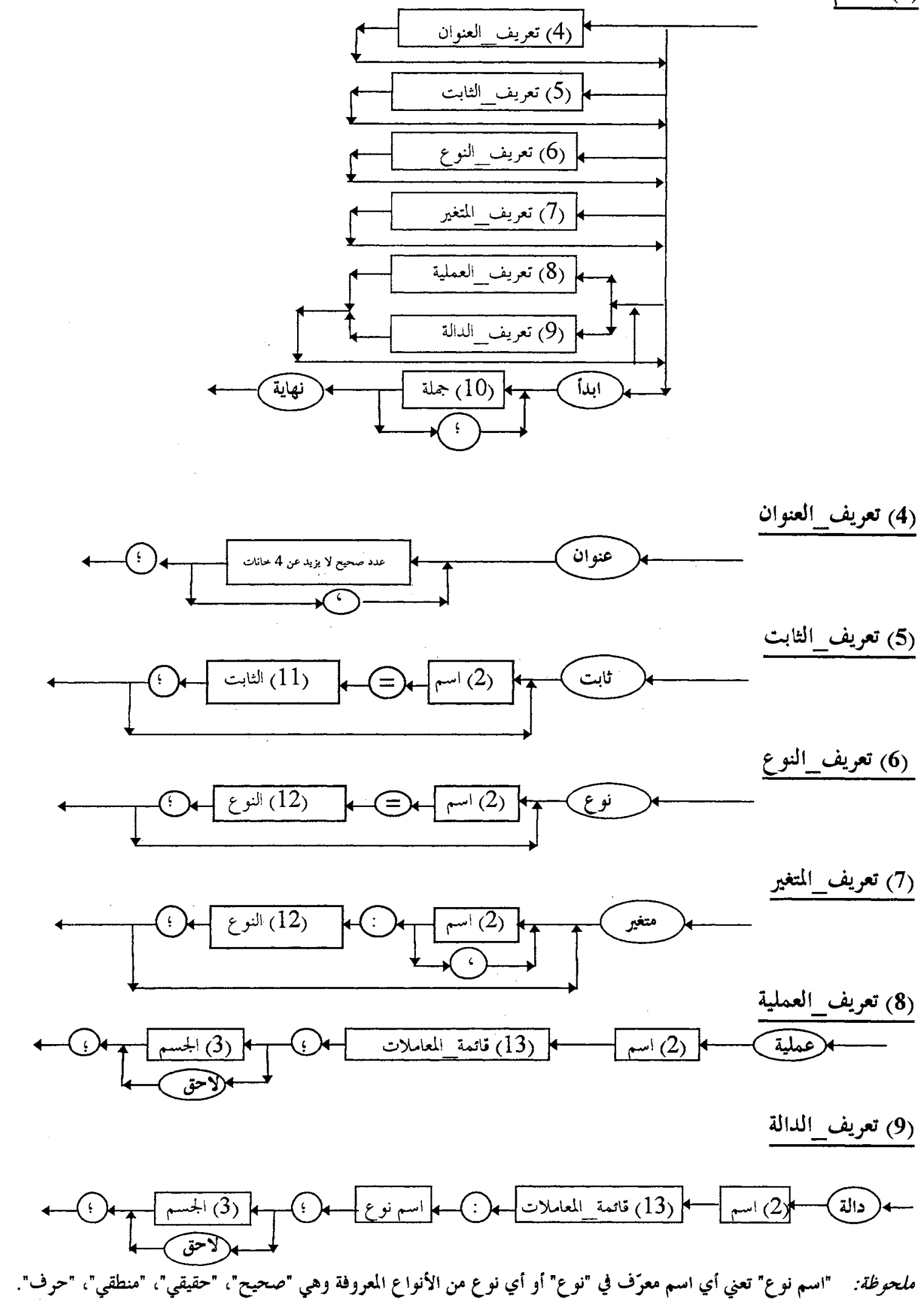

(3) الجسم 


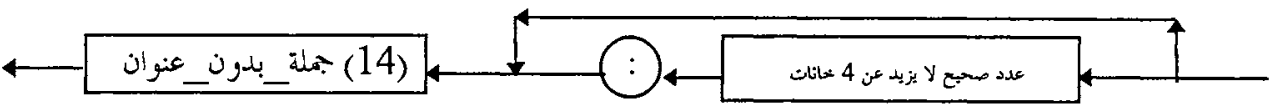

(11)

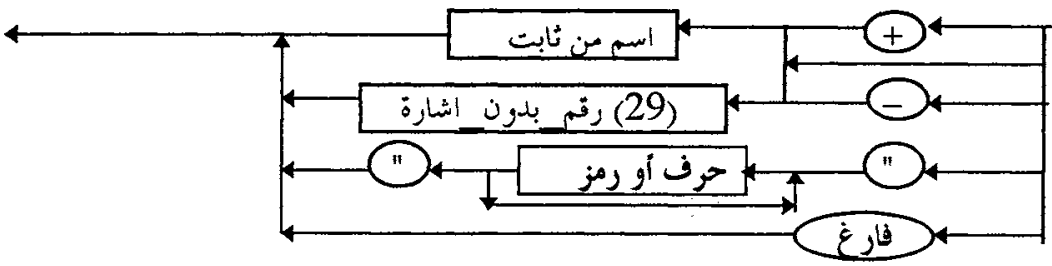

ملحوظات:

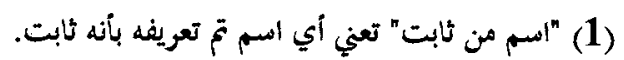

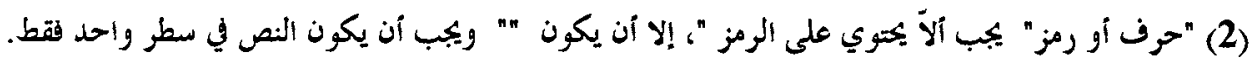

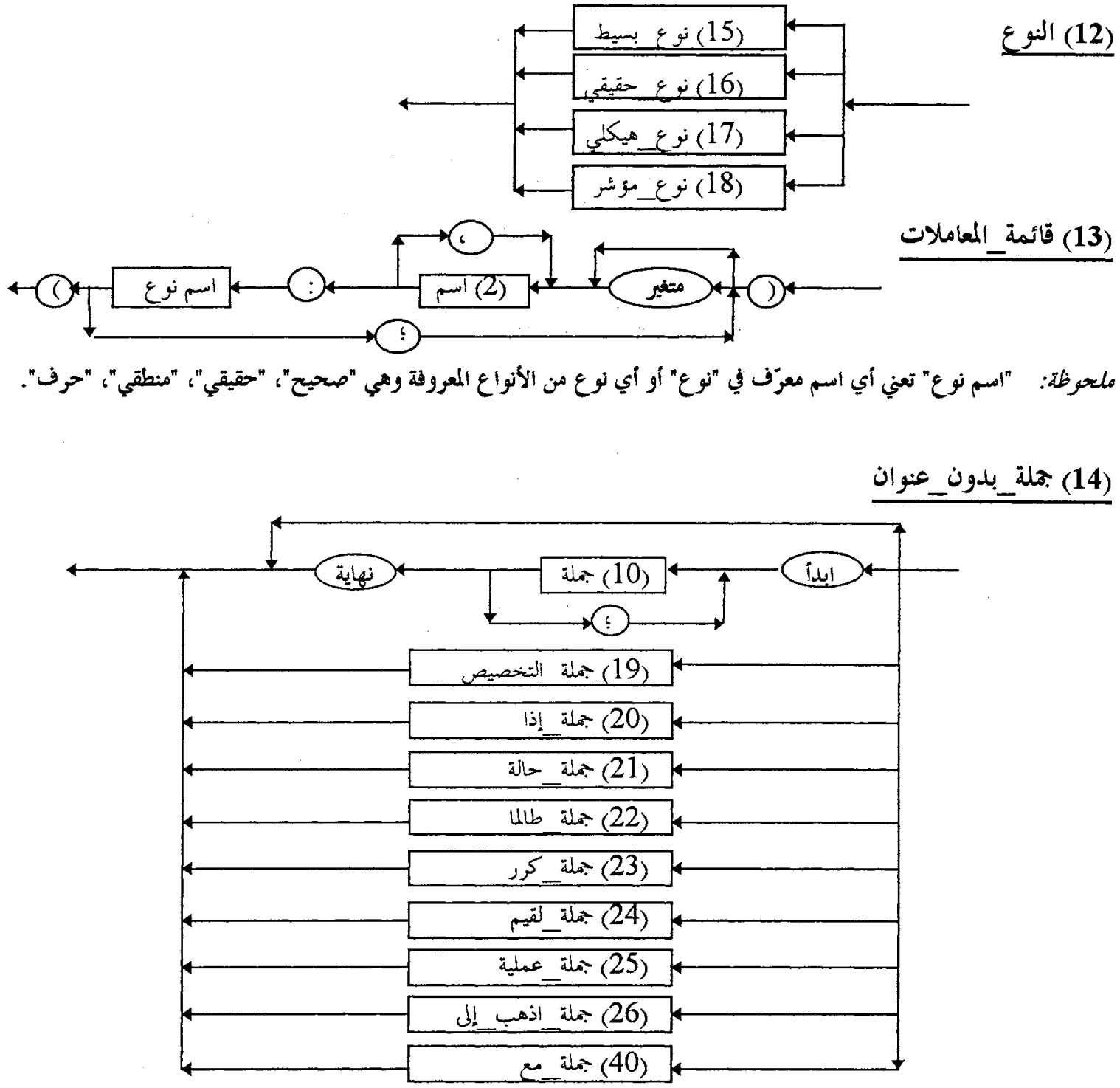

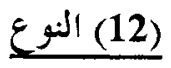


(15) نوع_بسيط

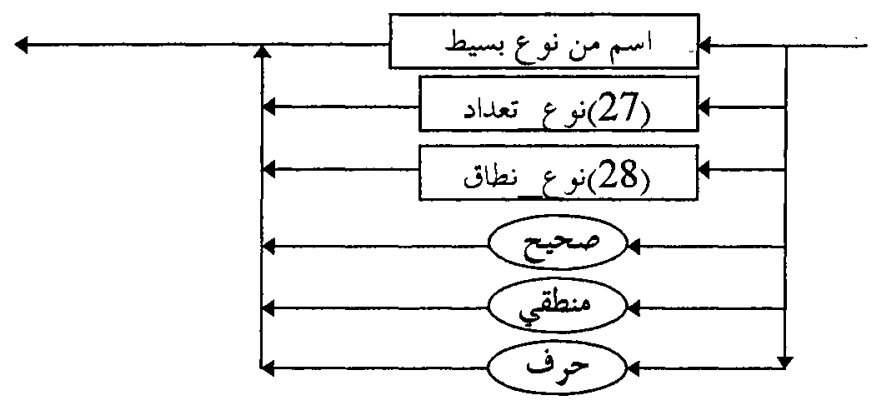

(16) نوع_حقيقي

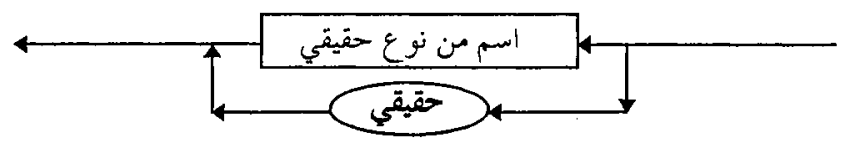

ملحوظة: "اسم من نوع حقيقي" تعني أي اسم معرَف في قسم "نوع" على أنه "حقيقي". عدد = حقرقي؛

س : علدد؛

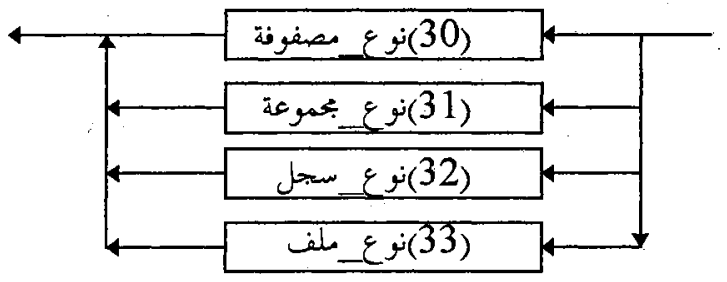

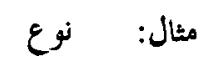
متغير

(17) نوع_هيكلي هنير

(18) نوع_مؤشر

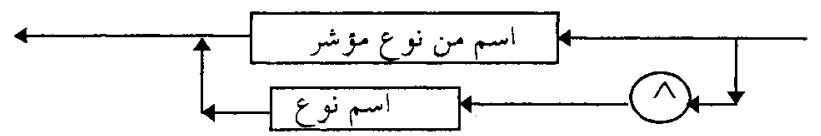

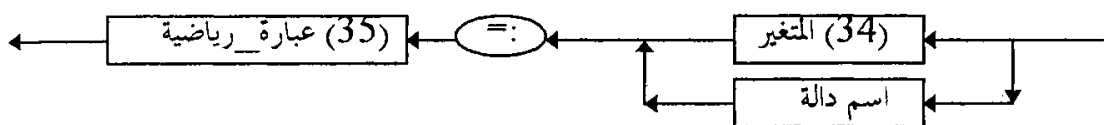

(19) هلة_التخصيص

(20) جلة_إذا

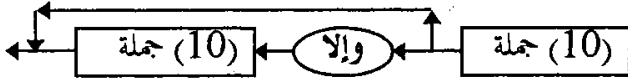

(21) جملة_حالة

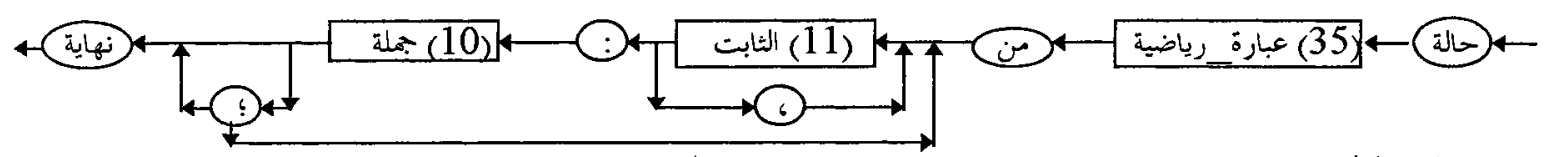

جملة_ (22)

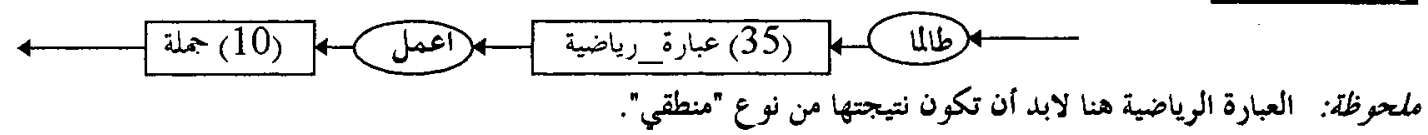


(23) بحلة كرر

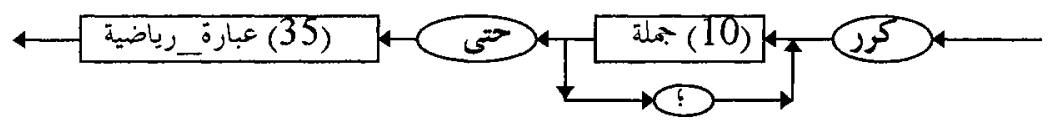

ملحوظة: العبارة الرياضية هنا لابد أن تكون نتيجتها من نوع "منطقي".

جلة_(24)

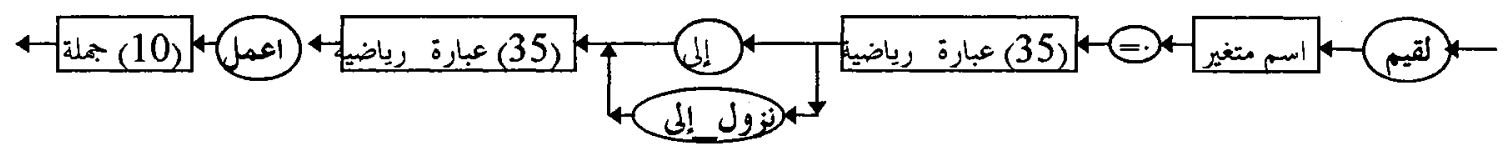

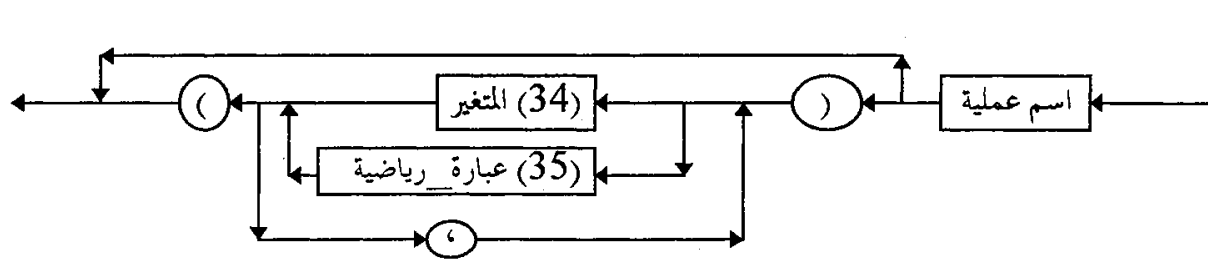

(25) جلة_عملية

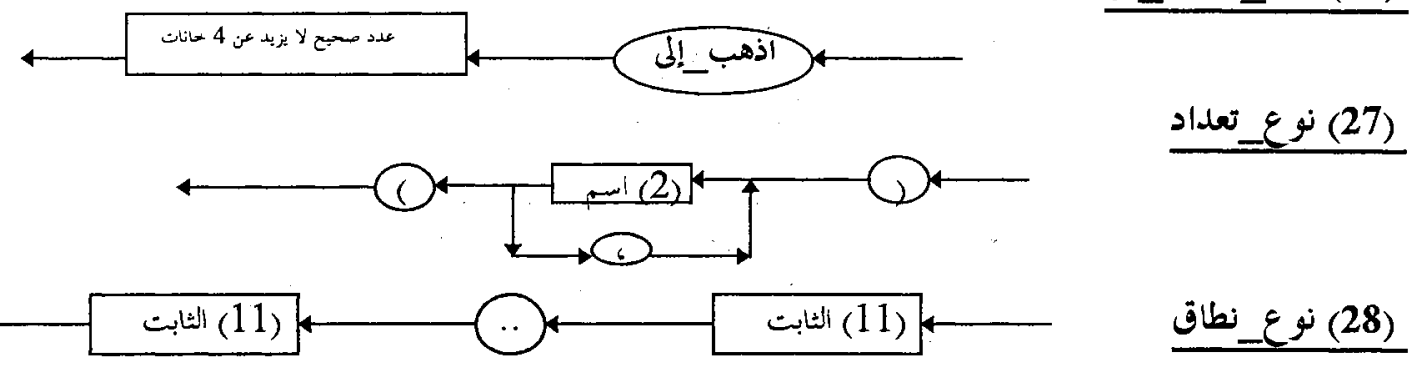

(26) بملة_اذهب_إلى

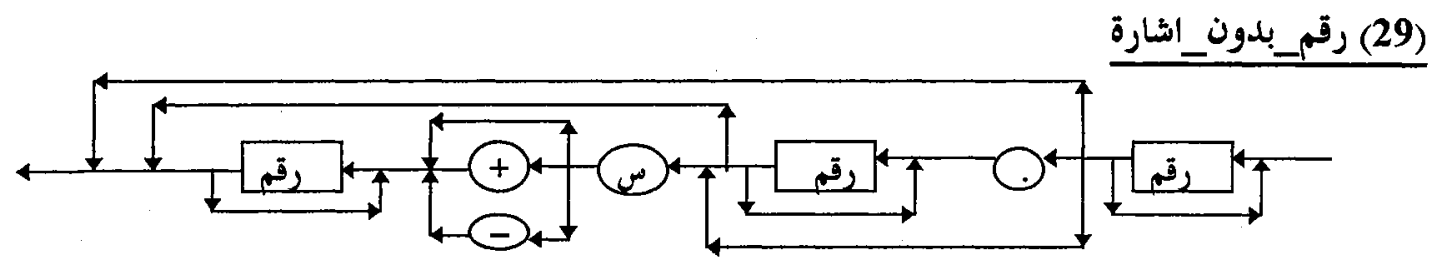

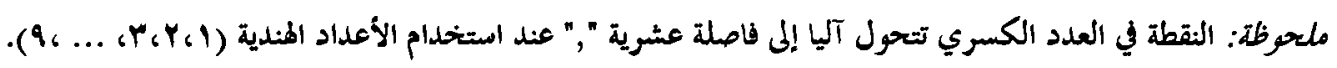
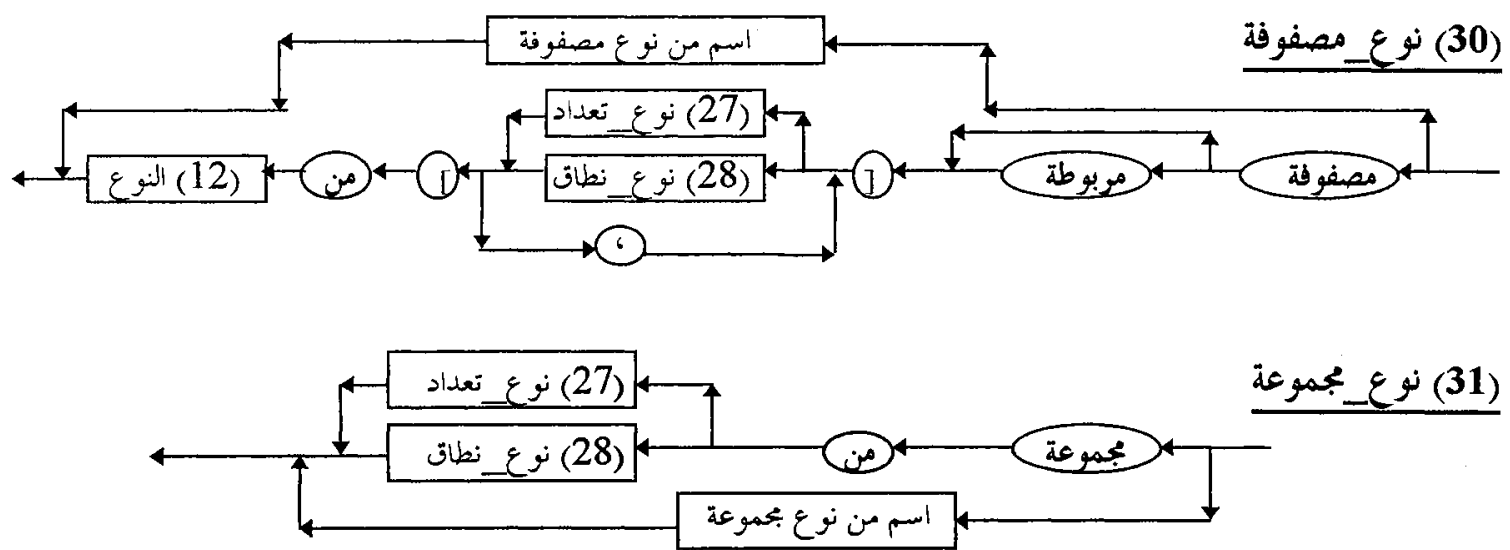


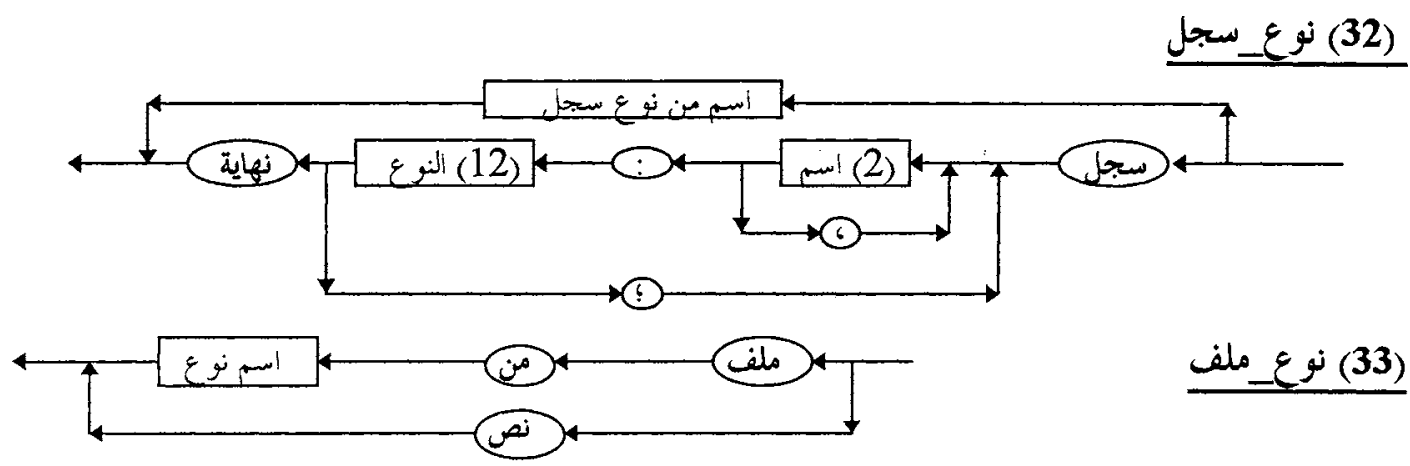

ملحوظات:

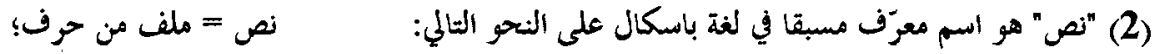

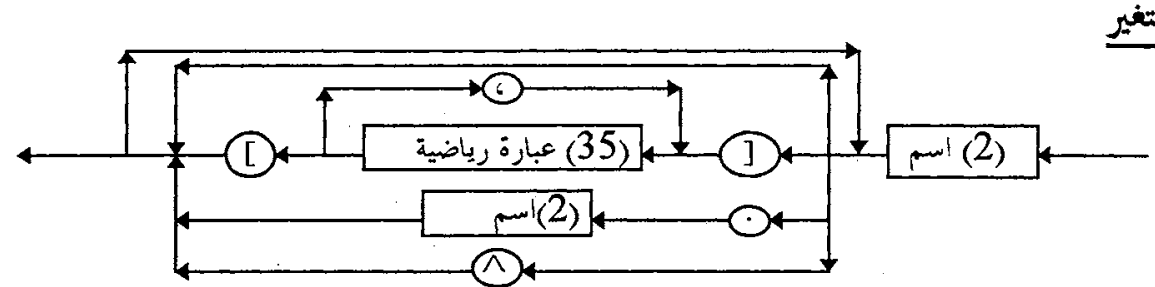

نئنير
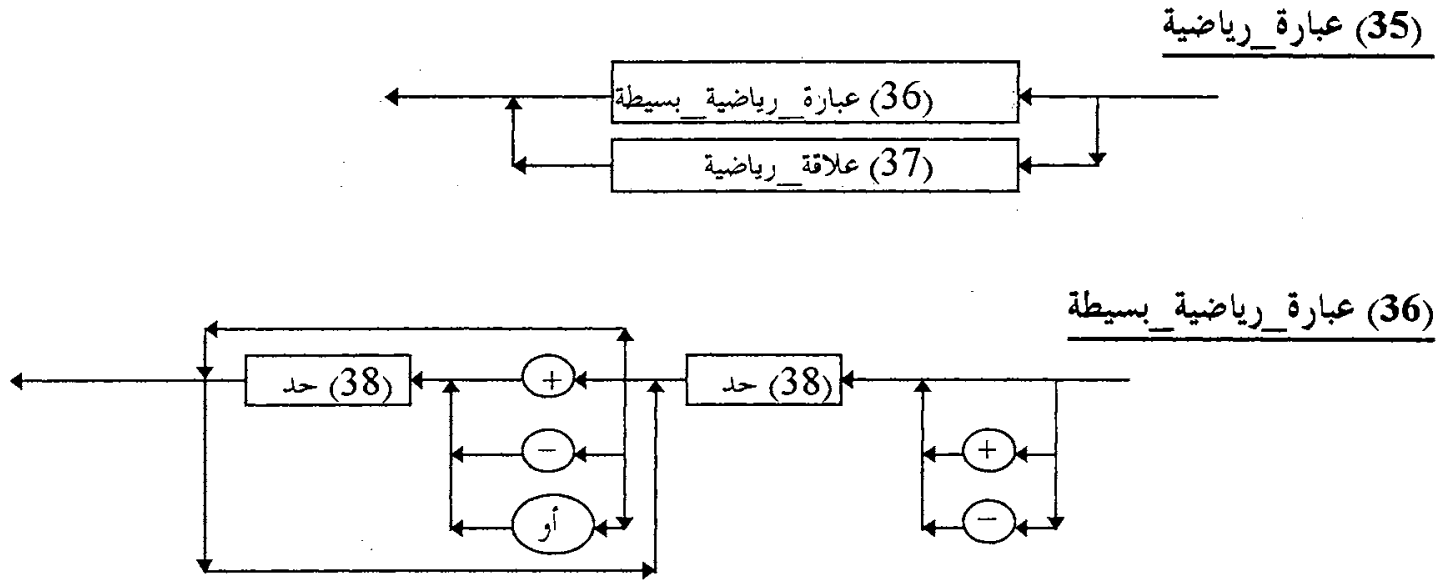



4 (36) عبارة رياضية بسيطة

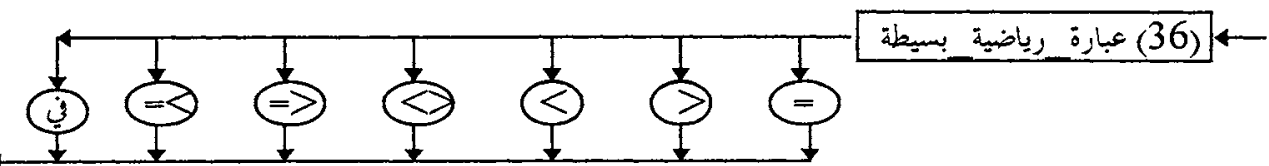

ملحوظة: الجمهوعة لها خصائص خاصة. انظر رقم (42) و (43) و (44).

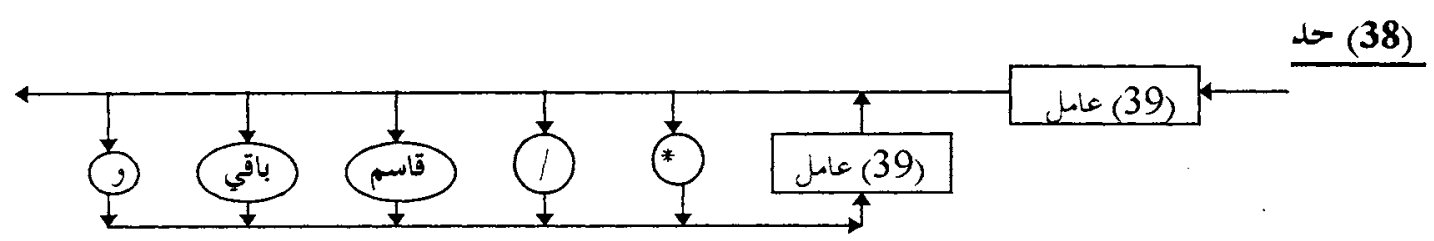




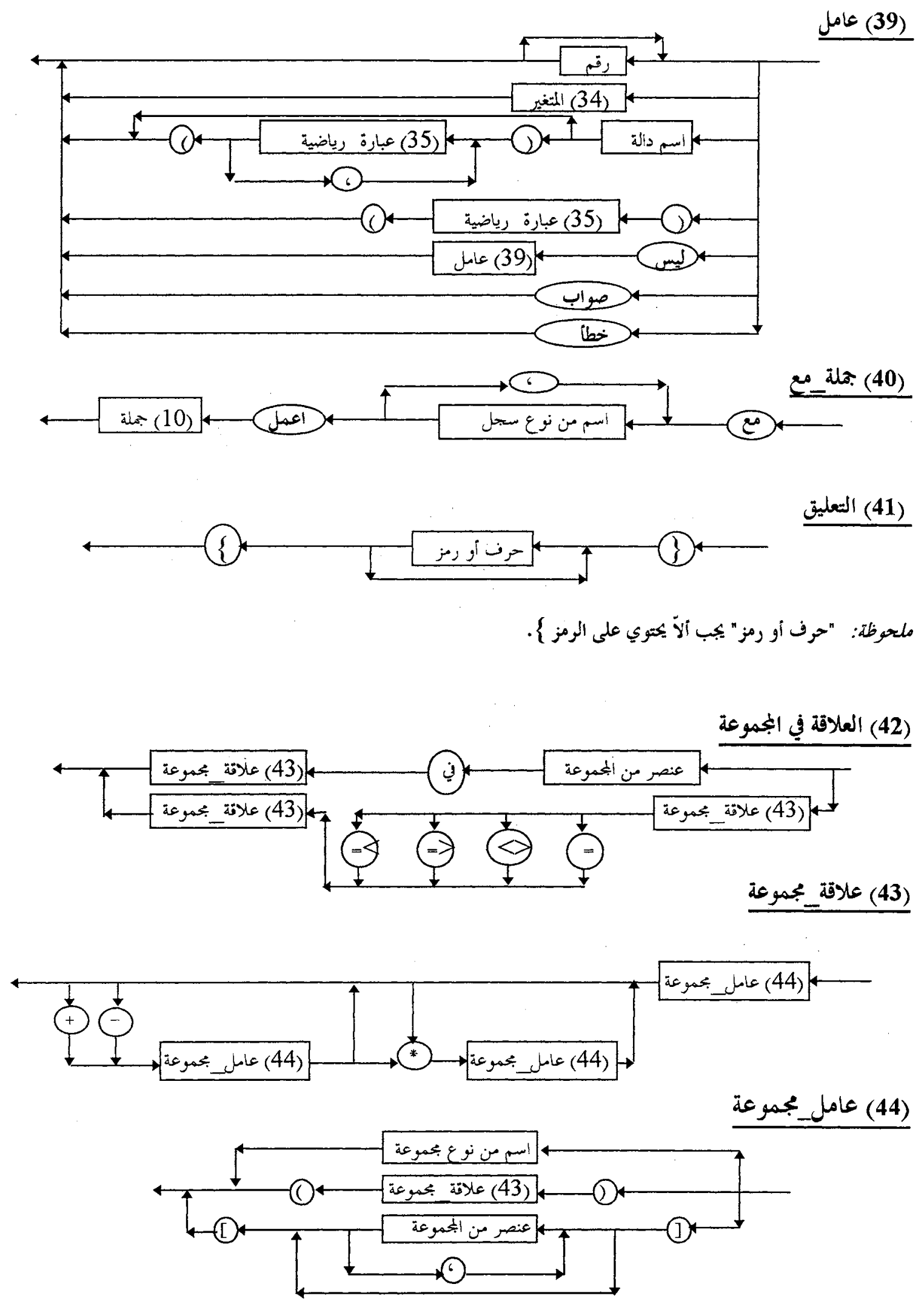




\section{Built-in Procedures and Functions in the Arabic Pascal}

الدوال والعمليات الموجودة في لغة باسكال العوبي

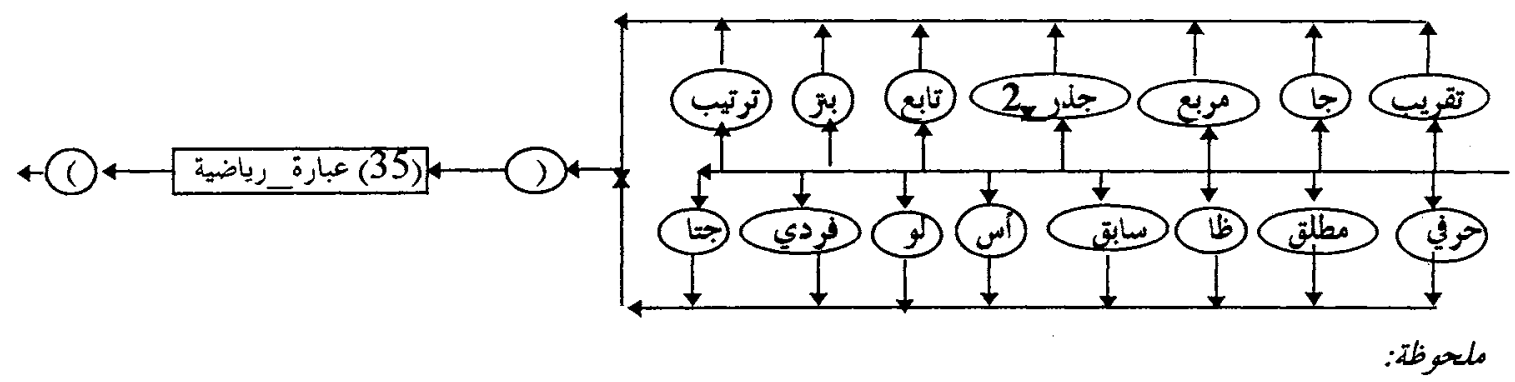

يجب أن تتوافق العبارة الرياضية مع التعريف المسبق للدالة. انظر التفصيل في القسم الحاص بالدوال المعرلة في لغة باسكال العربية

.(Section 5.2.4.6)

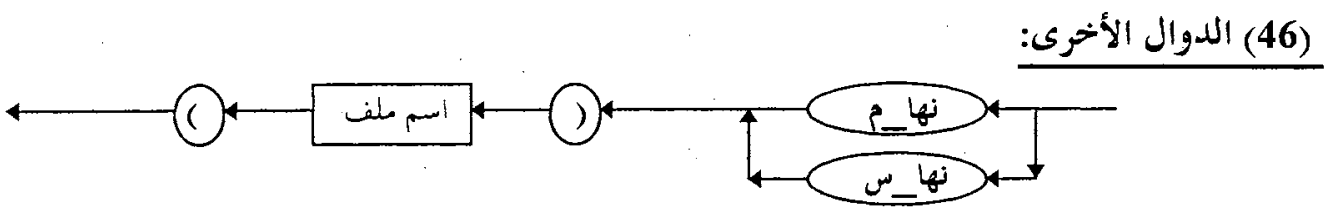

ملحوظة: اسم الملف لابد أن يكون من نوع "تص" في حالة استخدام "نها_سطر".

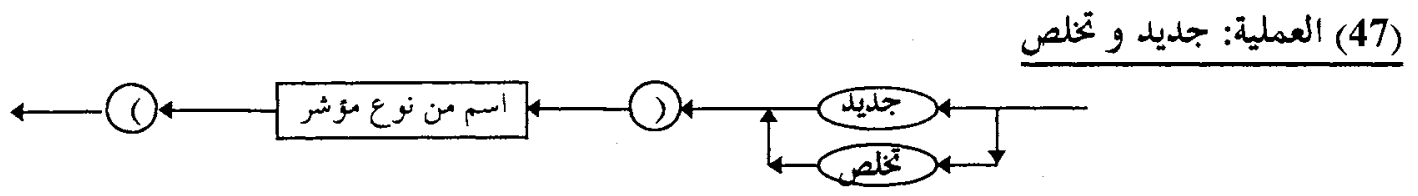

بابة (48) العملية: قراءة وكتابة

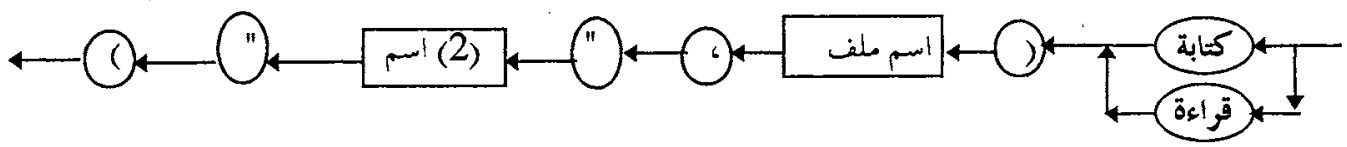

(49) (العملية: (49)

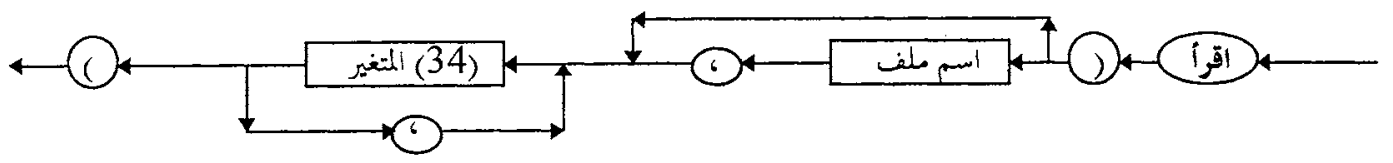


(50) العملية: اقرأ_سطر

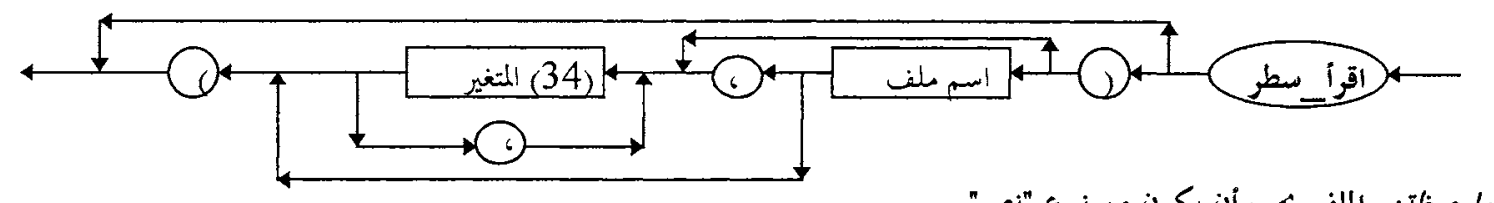

ماحوظة: الملف يجب أن يكون من نوع "نص".
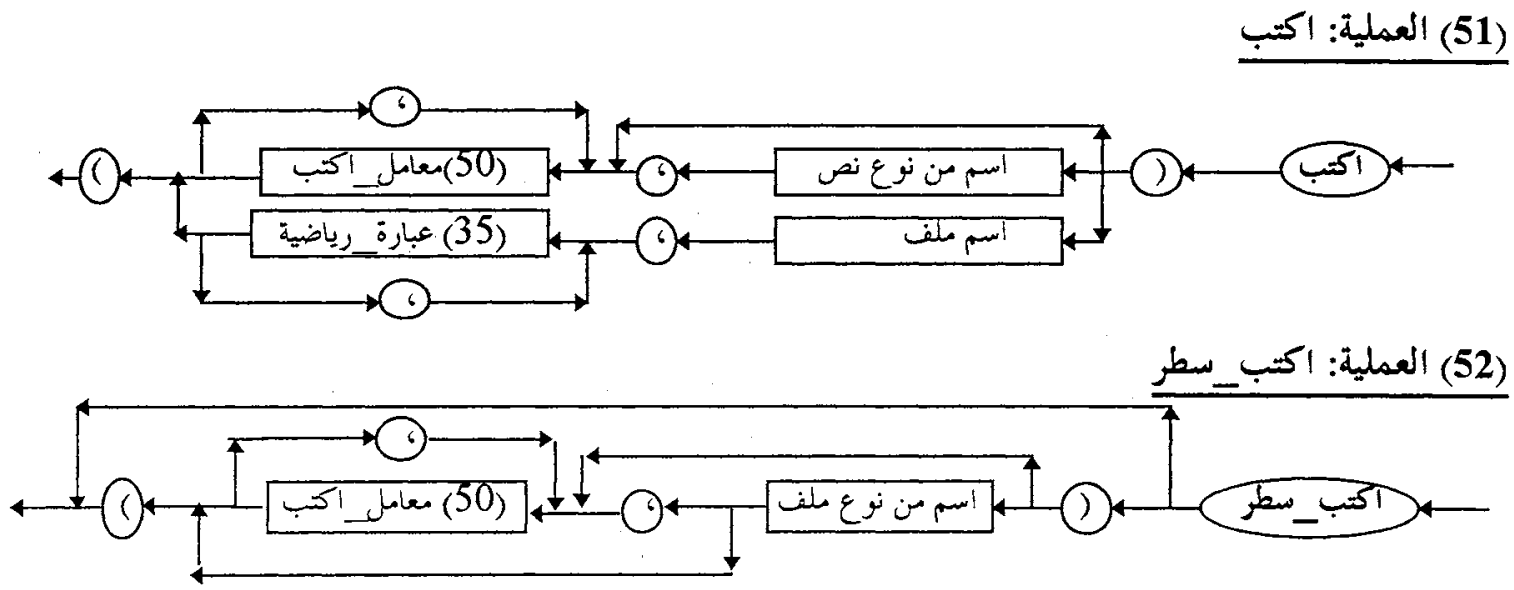

(53) معامل_اكتب_سطر

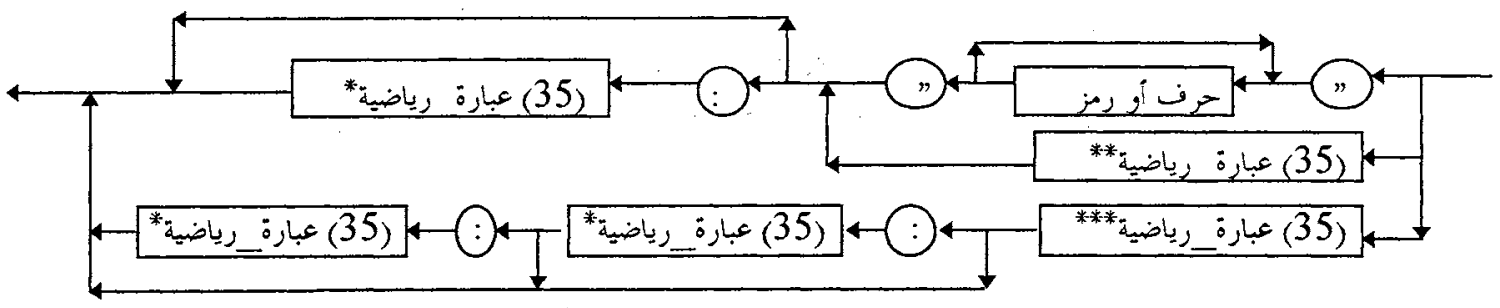

ماحوظة:

* نتيجة العبارة الرياضية لابد أن نكون من نوع "صحيح".

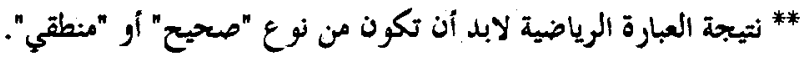

"**تيجة العبارة الرياضية لابد أن تكون من نوع "حقيقي". 


\section{APPENDIX D}

\section{ERROR MESSAGES}

The following is a list of the error messages along with their English translation. There are two types of errors related to the Arabic Pascal language. The first type of errors is the compiler generated error messages which are caused by syntax errors in the user program. The second type of errors is the run-time error messages which occur during the execution.

\section{D.1 COMPULR ERROR MESSAGES}

Cannot open the source file

Unexpected end of file

Invalid number

Invalid fraction

Invalid exponent

Too many digits in the number

Outside the real range

Outside the integer range

Missing left parenthesis

Missing right parenthesis

Invalid expression

Invalid assignment statement

Missing identifier

Missing assignment symbol :=

$$
\begin{aligned}
& \text { لم يتم الثمكن من فتح ملف البرنامج } \\
& \text { نهاية غير متوقعة في ملف البرنامج } \\
& \text { الر تم غير مقبول } \\
& \text { المجزء اللكسري غير مقبول } \\
& \text { الجزءء الأسي غير مقبول }
\end{aligned}
$$$$
\text { عدد المحانات في الرقم كثيرة جديا }
$$

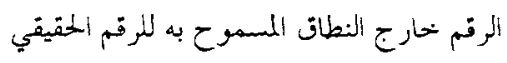

الرقم نحارج النطات المسموح به للرقم الصحيح

القوس الأيسر ')' مفقود

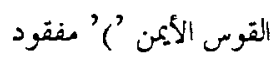

الصيغة الر باضية غير مقبولة

جملة التخصيص ':=' غير مقبولة

المتغير مفقود

علامة التخصيص ':=' مفقودة معنود 
Undefined identifier

Invalid statement

Unexpected symbol

Missing PROGRAM word

Missing BEGIN word

Missing semicolon ;

Missing DO word

Missing UNTIL word

Missing THEN word

Invalid FOR control variable

Missing OF word

Invalid constant

Missing constant

Missing colon :

Missing END word

Missing TO or DOWNTO word

The identifier has been defined before

Missing equal sign =

Invalid type

Not a type identifier

Invalid subrange type

Not a constant identifier

Missing range symbol

Mismatch in types

Invalid identifier usage

Incompatible assignment

Min. value greater than max. value

Missing ]

Missing [

Invalid index type

$$
\begin{aligned}
& \text { متغير غير معرَف } \\
& \text { الجممئة غير مقبولة } \\
& \text { حرف أو متغير غير متوقع في هذا الموقع } \\
& \text { كلمة 'برنامج' مفقودة } \\
& \text { كلمة 'ابدأ مفقودة } \\
& \text { الفاصلة المنقوطة '؛؛' مفقودة } \\
& \text { كلمة 'اعمل ' مفقودة } \\
& \text { كلمة 'حتى' مفقودة } \\
& \text { كلمة 'فإن' مفقودة } \\
& \text { المتغير الذي يتحكم في عملية التكر ار غير مقبول } \\
& \text { كلمة 'من' مفقودة } \\
& \text { الثابت غير مقبول } \\
& \text { ألثابت مفقود } \\
& \text { المرثب ':' مفقود } \\
& \text { كلمة 'نهاية' مفقودة } \\
& \text { كلمة 'إلى' أو 'نزولــإلى مفقودة } \\
& \text { لقد تم تعريف هذا المثغير سابقا } \\
& \text { الحرف '=' مفقود } \\
& \text { النوع غير مقبول } \\
& \text { ليس المتغير من الأنواع المعرفة سابقا } \\
& \text { ألنطاق المعرف غير مقبول } \\
& \text { يجب أن يكون اللرمز ثابتا وليس متغيرا } \\
& \text { النقطتان '..' مفقودتان } \\
& \text { الأنواع غير متو افقة } \\
& \text { استخدام خاطئ للمتغير } \\
& \text { الطرفان ليسا متوأفقين في النوع } \\
& \text { الحد الأدنى أكبر من الملد الأكبر } \\
& \text { المحرف '] ' مفقود } \\
& \text { الحرف ']' منقود } \\
& \text { نوع دليل المصفوفة غير مقبول }
\end{aligned}
$$


Missing period

Too many subscripts

Invalid field in the record

Nesting too deep

Already specified in FORWARD

Wrong number of actual parameters

Invalid VAR parameter

Not a record variable

Missing variable

Code segment overflow

Stack overflow

The label is invalid or missing: expecting an integer between 0 and 9999

The label is not defined

No label corresponding to GOTO

The label has been used before

The set has more than 16 elements

File must be of integer, real, or char type

The left double-quote is missing

The pointer is not defined

The variable is not of file type

The file name is missing

The file has not been opened for reading

The file has not been opened for writing

The variable is not of pointer type

The pointer symbol " $\wedge$ " is missing

Relations '> $>$ and ' $<$ are not accepted in sets

The expression is not valid in sets

One of the variables is not of set type

Too many syntax errors

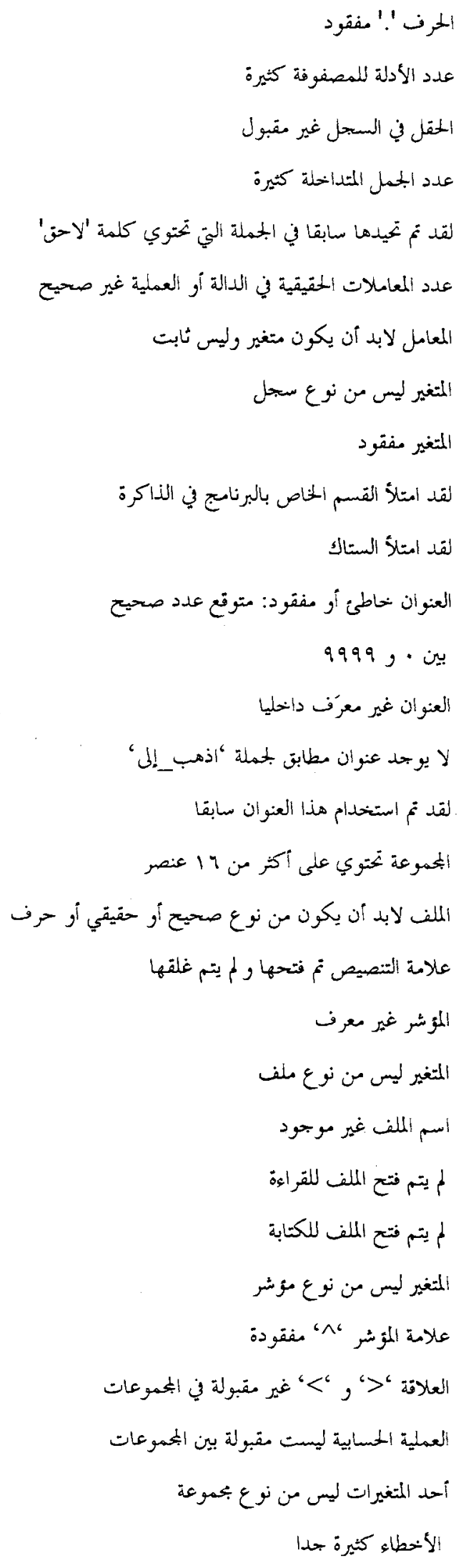




\section{D.2 RUN-TIME ERROR MESSAGES}

Run-time error messages cause the user program to display an error message and terminate. Run-time errors do not include all errors that may occur during execution. There are two types of errors that are not reported by the Arabic Pascal. The first is the errors that need a considerable overhead in the compiler generated code to report them, while they are not fatal errors (from the system point of view). Examples of this type are an integer operation that may cause an out of range result and out of range index values. Both Turbo Pascal and Turbo $\mathrm{C}$ do not perform such checking in their default mode [BTP89, MSF88]. In this case, it is the responsibility of the programmer to ensure the correctness of usage. The second type is the fatal errors that are related to the MSWindow functions. When such an error happens, the MS-Windows takes over any of its application to report a system error. Examples of this type are out of memory to load the execution code and accessing a protected area in the MS-Windows. The MS-Windows (including the Arabic versions) display these errors in English. The following is a list of possible run-time error messages that may occur during the execution.

The entered number is not an integer The entered number is out of the integer range

The entered number is not a real The entered number is out of the real range Error in real number operation (out of range)

Cannot open the file for reading Cannot open the file for writing Out of memory Divide by zero Negative number in the square root

Out of the set limits Abnormal Program Termination Stack Overflow

$$
\begin{aligned}
& \text { ألرقم الذي تمت قراعته ليس عددا صحيحا } \\
& \text { ألرقم الذي تمت قرائه نحارج نطاق العدد الصحيح } \\
& \text { الرقم الذي تمت قراءته ليس عددا حقيقيا } \\
& \text { الرقم الذبي تمت قرأوته نحارج نطاق العدد المقيقي } \\
& \text { خطأ في الأعداد المقيقية (خحارج النطاق) } \\
& \text { لم يتم التمكن من فتح الملف للقراءة }
\end{aligned}
$$

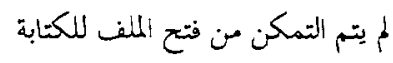

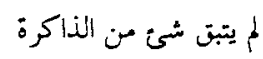

$$
\begin{aligned}
& \text { قسمة على صفر } \\
& \text { الرتم تحت الملذر التزبيعي سالب مبكر }
\end{aligned}
$$

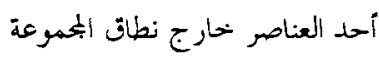

$$
\begin{aligned}
& \text { البرنامج أنتهى بشـكل غير طبيعي }
\end{aligned}
$$

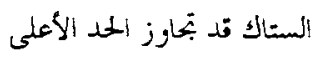




\section{APPENDIX E}

\section{TEST PROGRAMS}

In Chapter 5, Section 5.5, I gave two examples of Arabic Pascal programs along with their corresponding English Pascal programs. In this Appendix, I will give some test programs translated directly from a well-known book "Pascal User Manual and Report" [JW74]. These programs are used to test the APC. At the beginning of each example, I will give the example number and page number in that reference. At the end of each program, I will also give some sample input and the output. The sample input is usually same as the one provided in that book. In some programs, the code for reading the input is added if the original program assumes the input has been already read. Note that some real numbers are printed by the APC as fixed point real numbers while they are printed in the reference using the E-notation. The reason is that the APC selects the format that produces the shortest output (similar to the \%g specifier in C language).

The last example, E.23, complements the other programs in utilizing some concepts that are not examined in that book. For example, the book does not have a complete program that explains the case statement.

\section{Program 0.1 (Page 3)}

It Computes the annual inflation rates of 7, 8, 10 per cent for 10 years.

This program mainly tests constant definition, integer and real variables, simple statements, and repeat statement. 


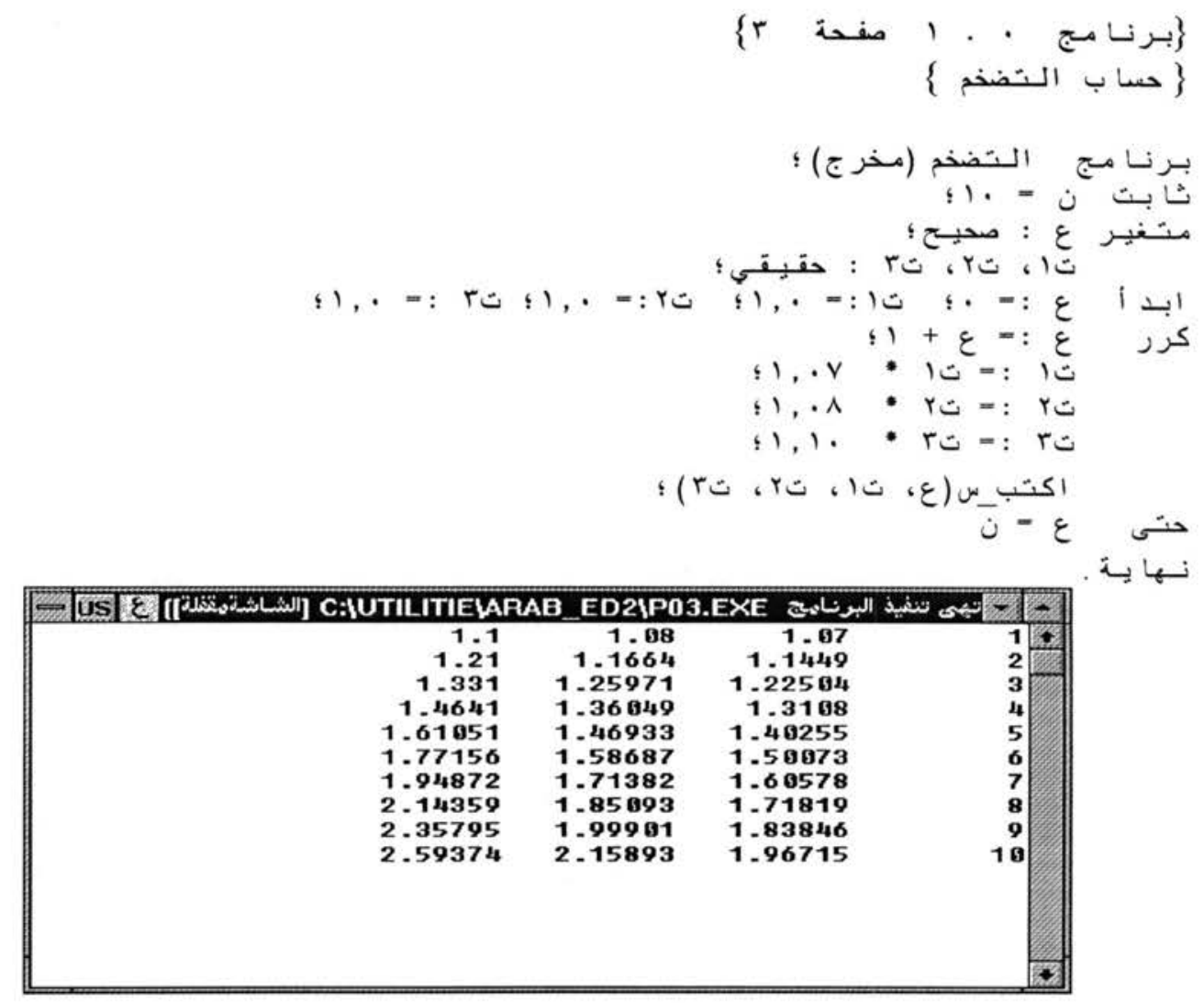

\section{Program 3.1 (Page 17)}

Example of constant definition. It converts the Celsius degree to Fahrenheit.

This program mainly tests constant definitions: integer, real, and string, subrange variables, for statement, if statement, and round and odd functions.

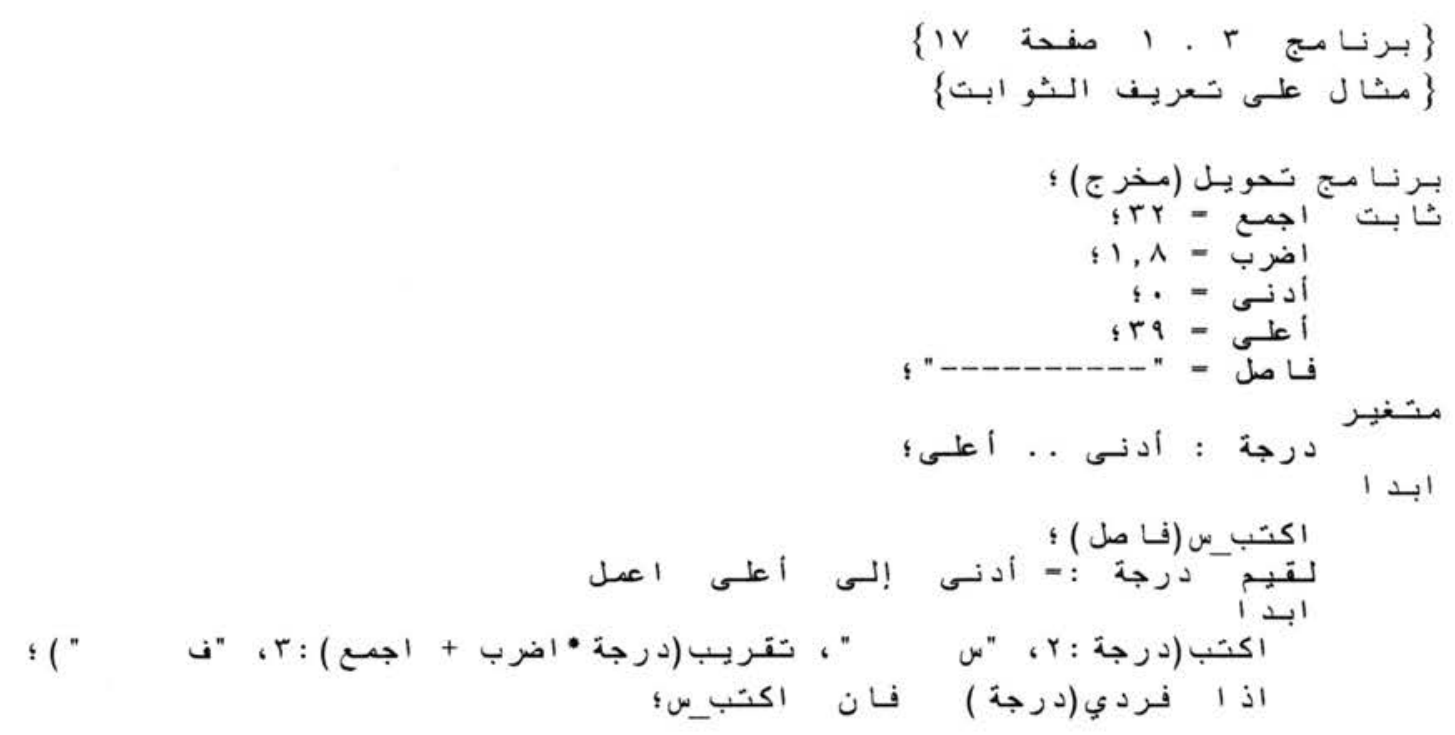




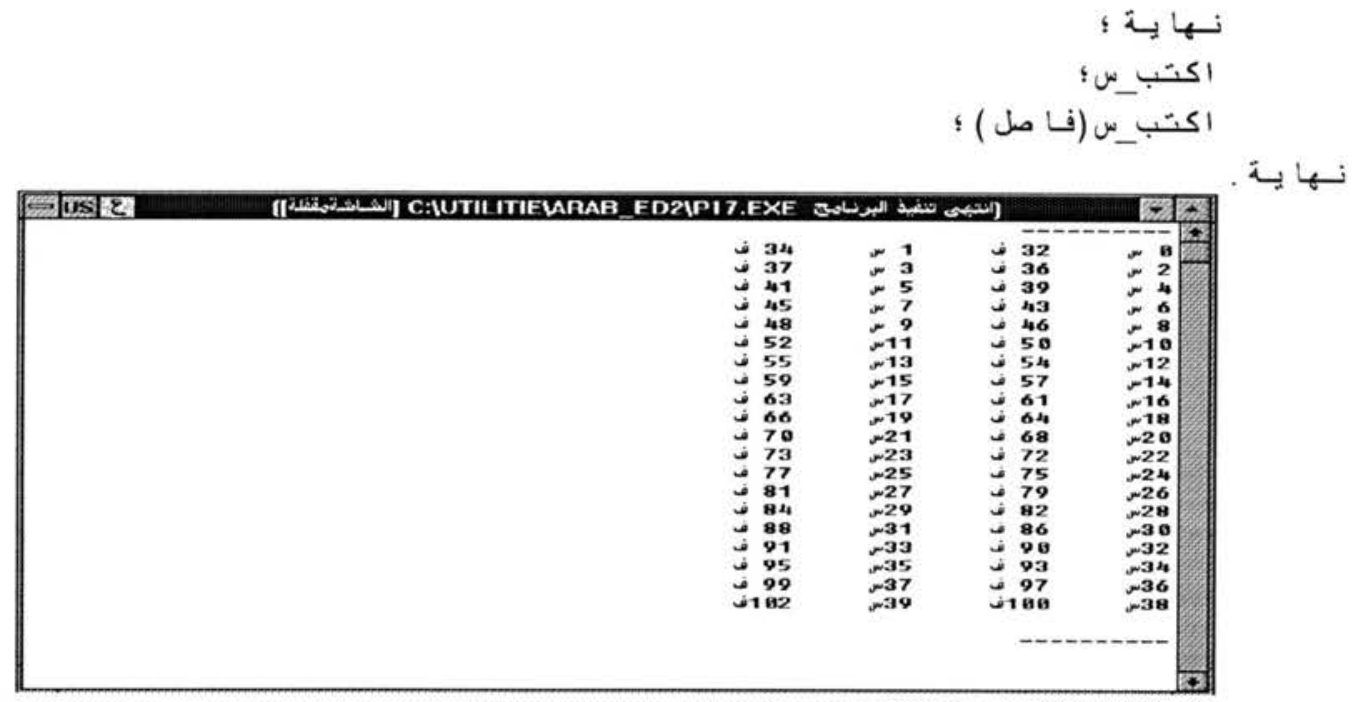

\section{Program 4.4 (Page 24)}

Compute $h(n)=1+1 / 2+1 / 3+\ldots+1 / n$. Examples 4.1 to 4.3 are trivial programs that test compound, while, and repeat statements, respectively. These statements are tested in other examples also.

This program mainly tests for statement with downto.

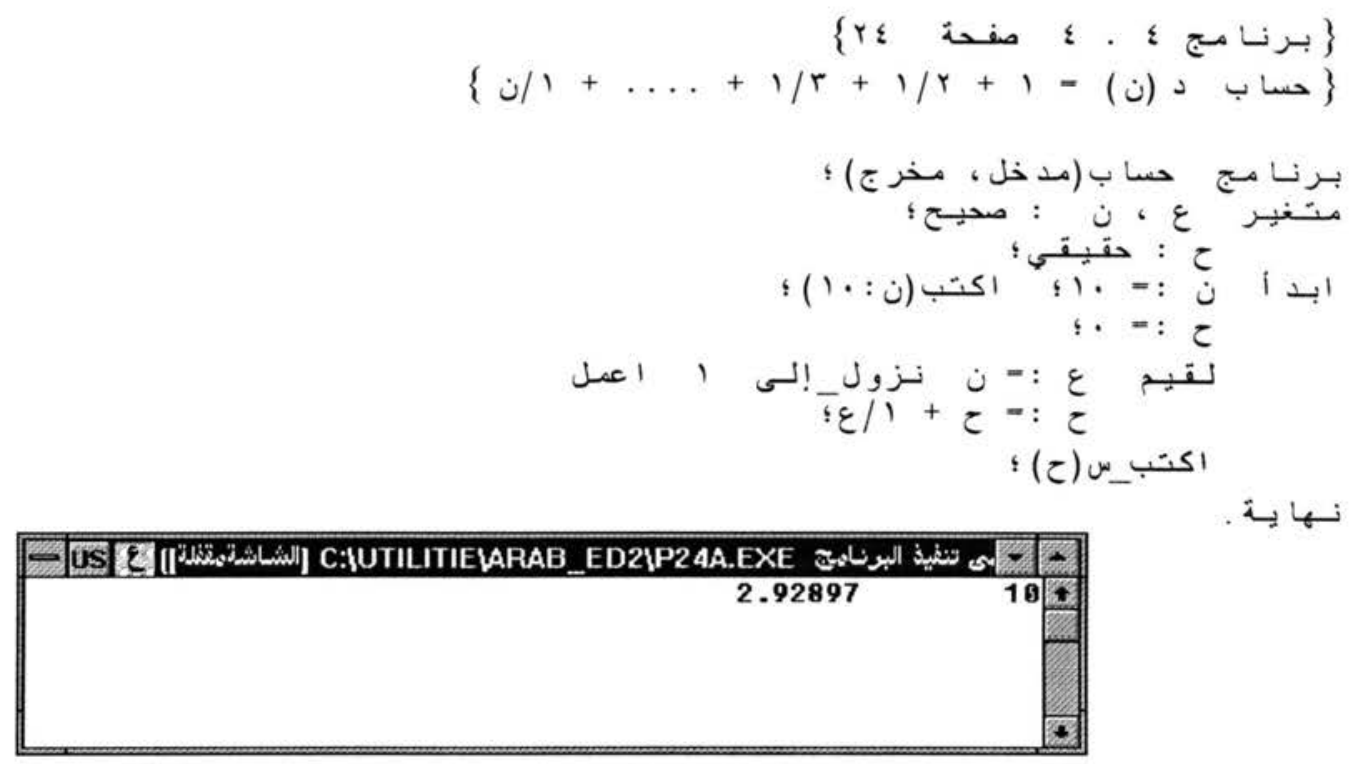

\section{Program 4.5 (Page 24)}

Computing cosine using the expansion:

$$
\cos (x)=1-x^{2} /(2 * 1)+x^{4} /(4 * 3 * 2 * I)-\ldots .
$$


This program mainly tests for statement, while statement, abs and sqr functions, and reading from a file of real numbers. The original program reads from the standard input.

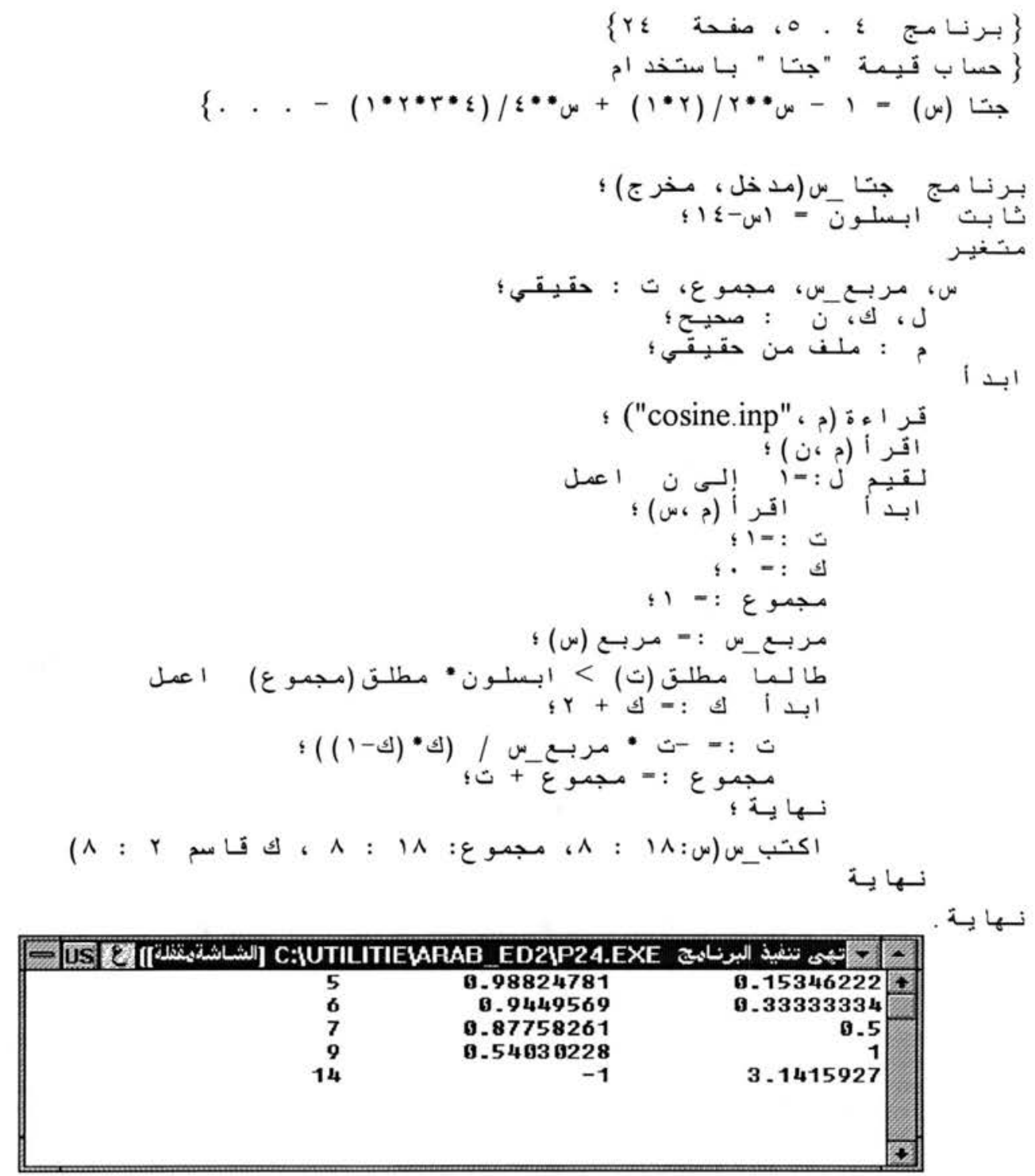

\section{Program 4.6 (Page 25)}

Compute $1-1 / 2+1 / 3-\ldots+1 / 9999-1 / 10000$ in four different ways.

1) left to right, in succession

2) left to right, all positive and negative terms, then subtract

3) right to left in succession

4) right to left, all positive and negative terms, then subtract 
This program mainly tests for statement.

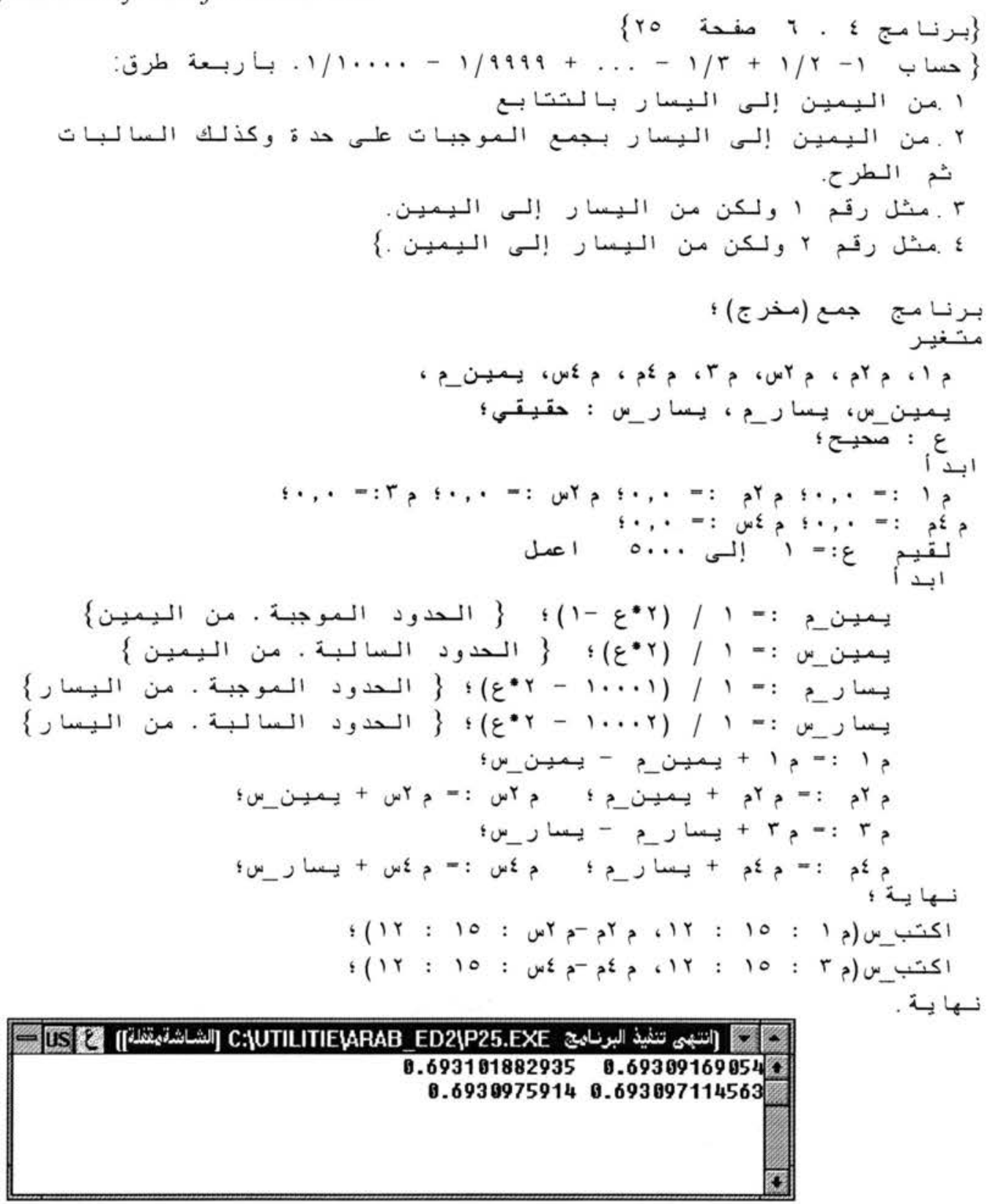

\section{Program 4.7 (Page 28)}

Write Roman numerals. Note that the printed Roman numbers are read from right to left in the output. Examples 4.8 and 4.9 will be skipped because examples 11.8 and 6.2 , respectively, are expansions for these two examples.

This program mainly tests repeat, while, and if statements. 


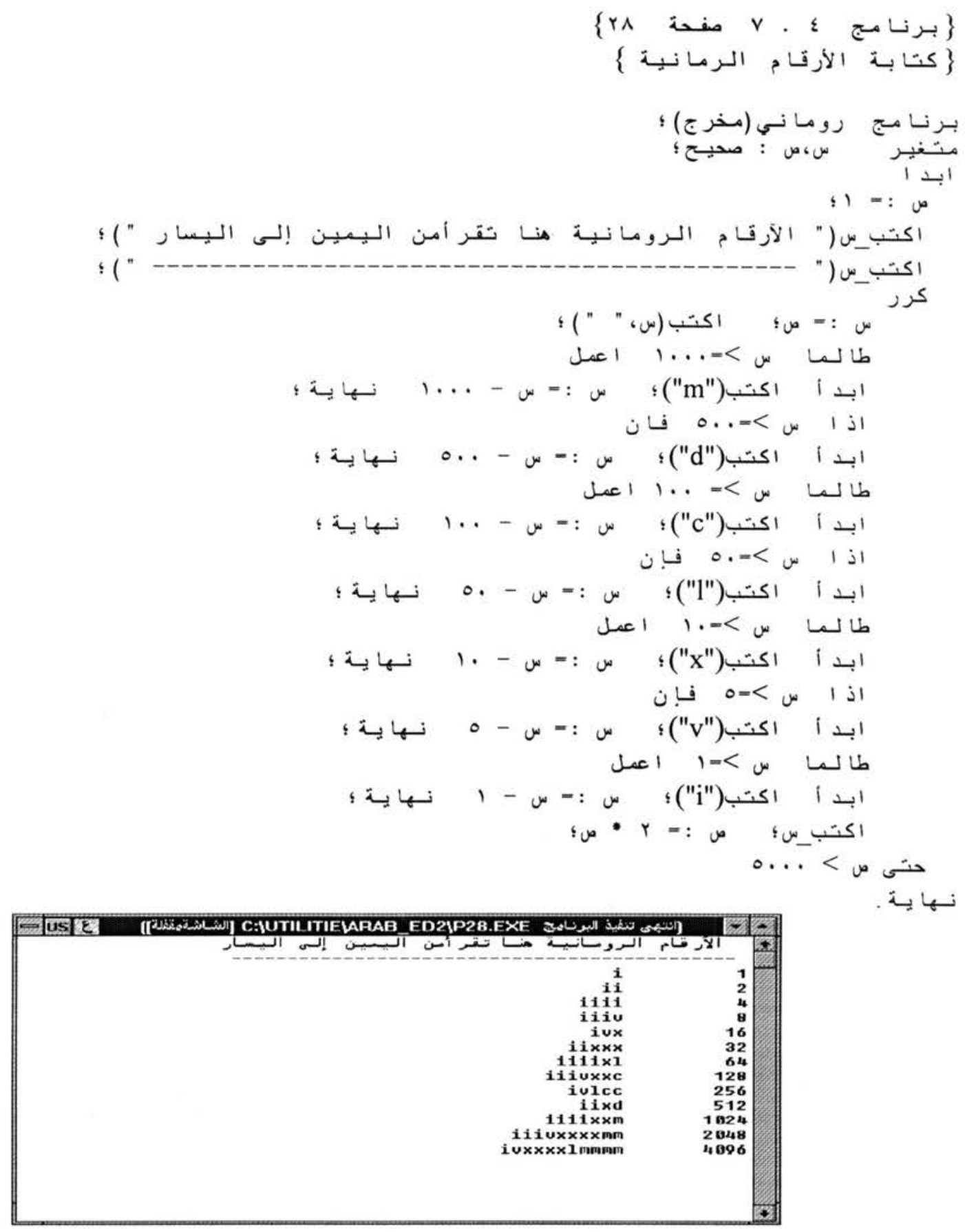

\section{Program 6.1 (Page 37)}

Find the largest and smallest number in a given list.

This program mainly tests while and if statements, array of integers, and reading from a file of integers. 


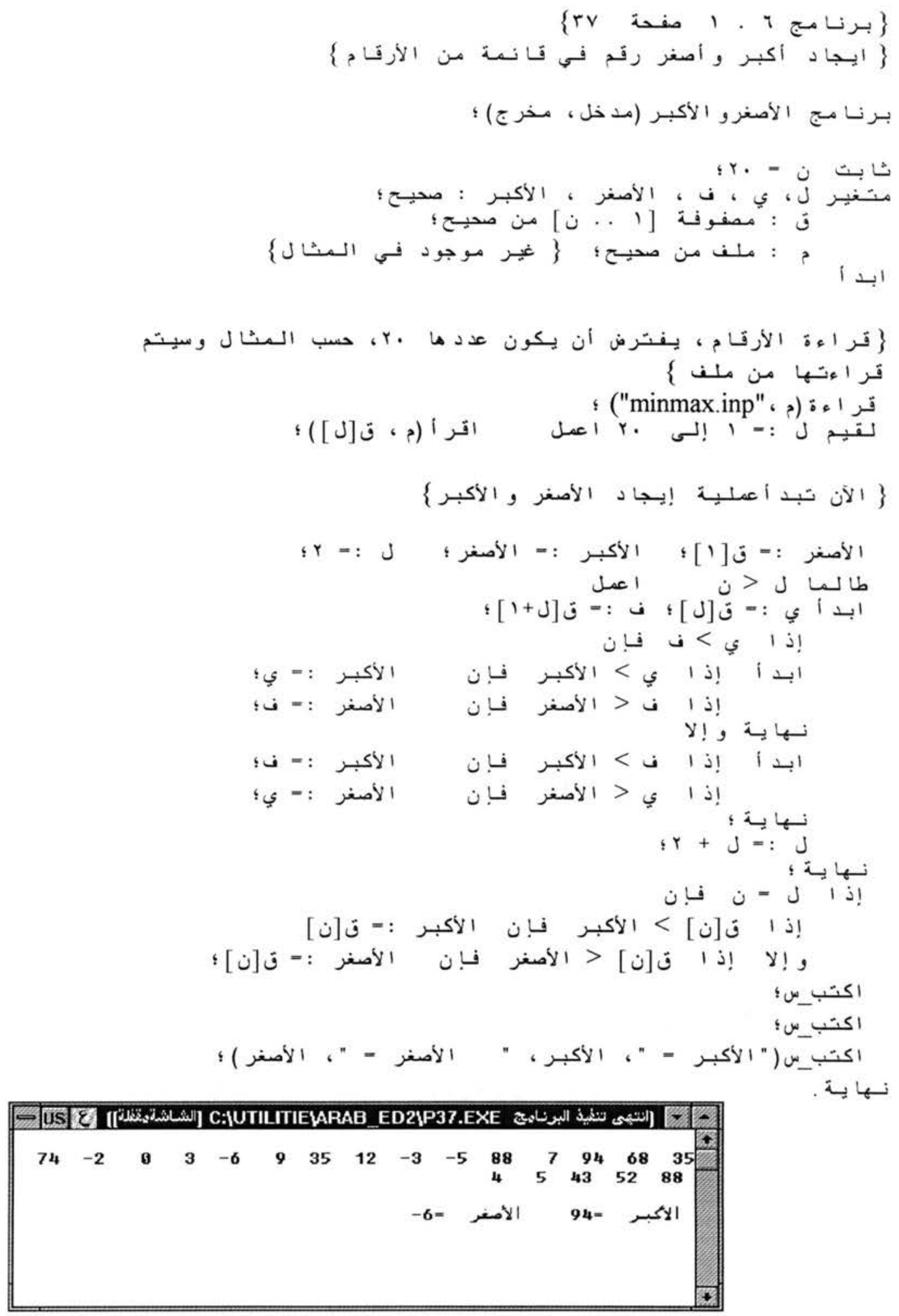




\section{Program 6.2 (Page 38)}

The program plots a real-valued function $f(x)=\exp (-x) * \sin \left(2^{*} p i^{*} x\right)$. This program extends program 4.9 (page 30 ) to print $x$-axis. The $x$-axis is printed vertically. Due to the limitation of the output screen (not all the output will show in the output window, the result of the Arabic program is printed here directly from an output file that has been opened for this purpose. Note that the left hand side of the $x$-axis is the positive side (reverse of the English view).

This program mainly tests for statement, sin and exp functions, and array of characters.

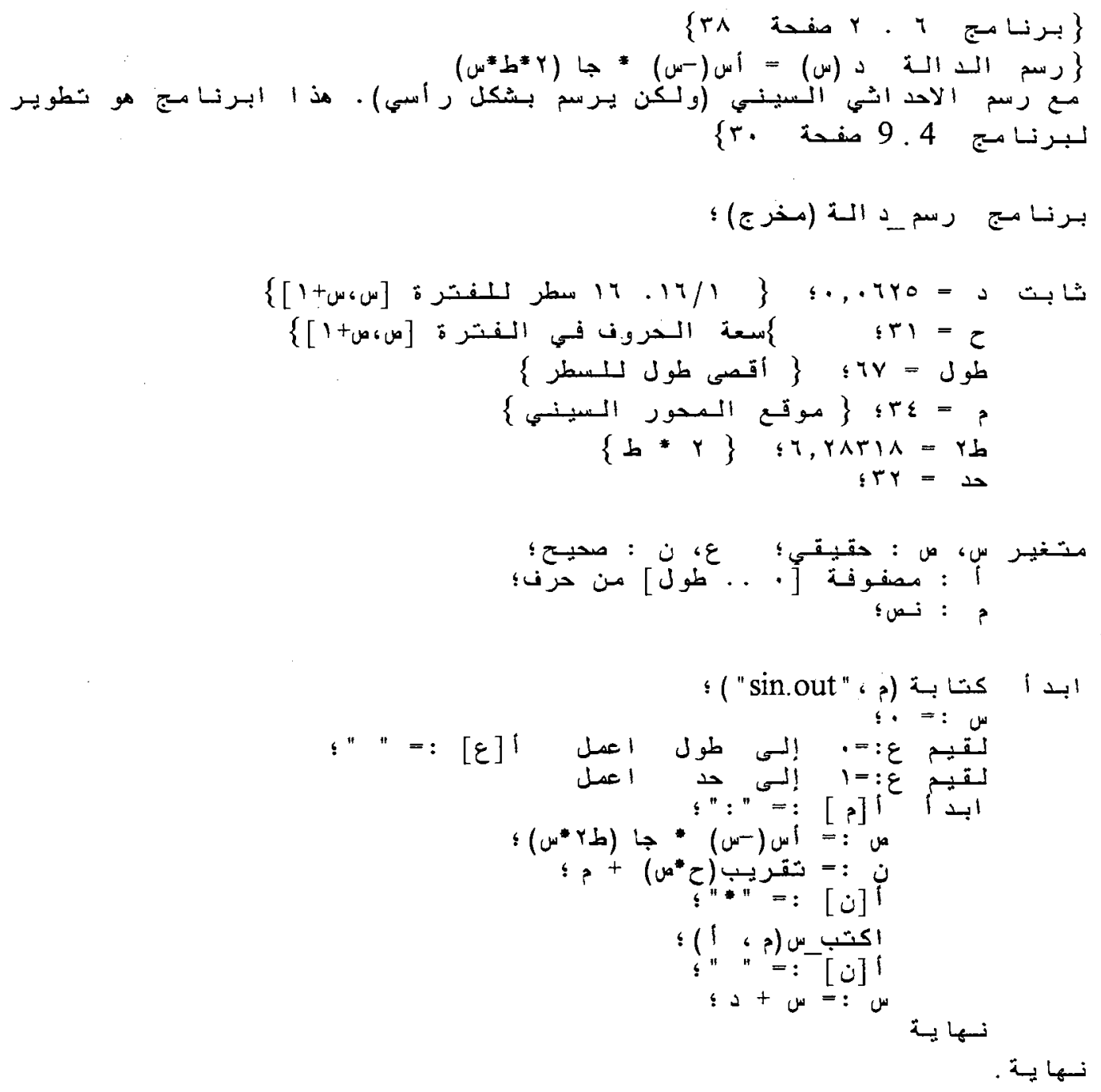




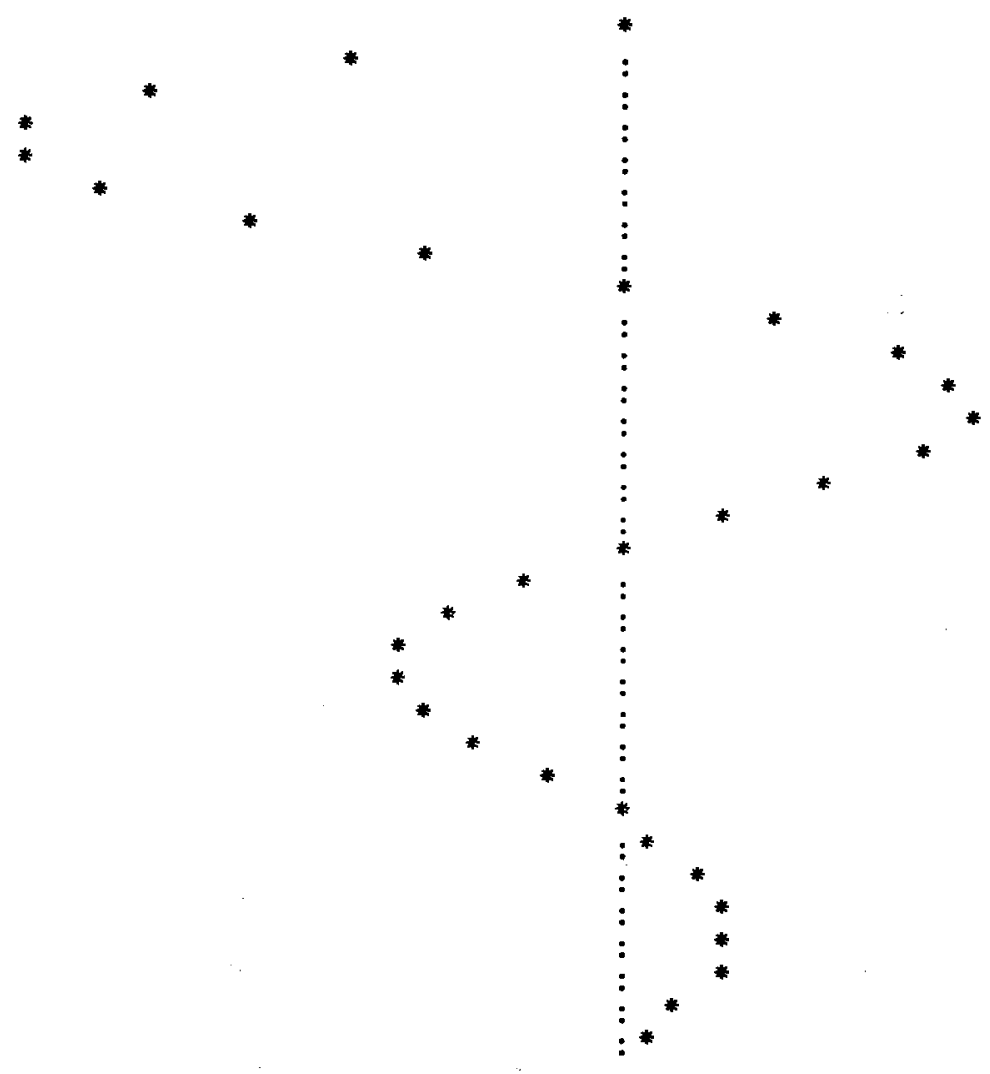

\section{Program 6.3 (Page 40)}

Matrix multiplication

This program mainly tests nested for statements and two-dimensional array.

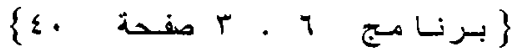

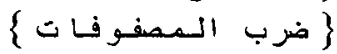

$$
\begin{aligned}
& \text { برنسا مـج ضرب_مصفوفات تمد خل، مخر ج)؛ }
\end{aligned}
$$

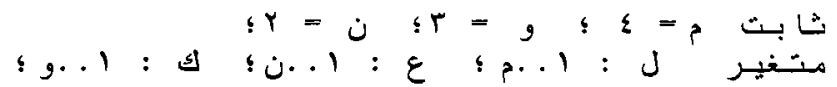

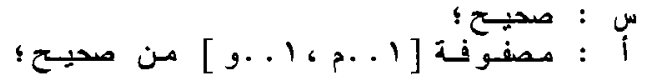

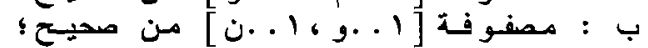

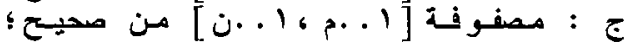

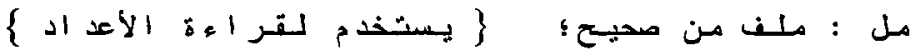

$$
\begin{aligned}
& \text { ابند أ }
\end{aligned}
$$

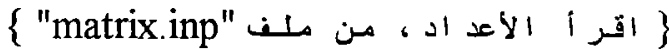

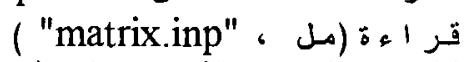

$$
\begin{aligned}
& \text { וs. }
\end{aligned}
$$

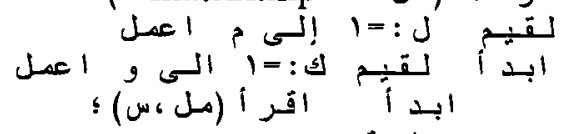

$$
\begin{aligned}
& \text { نسبا بـانة }
\end{aligned}
$$




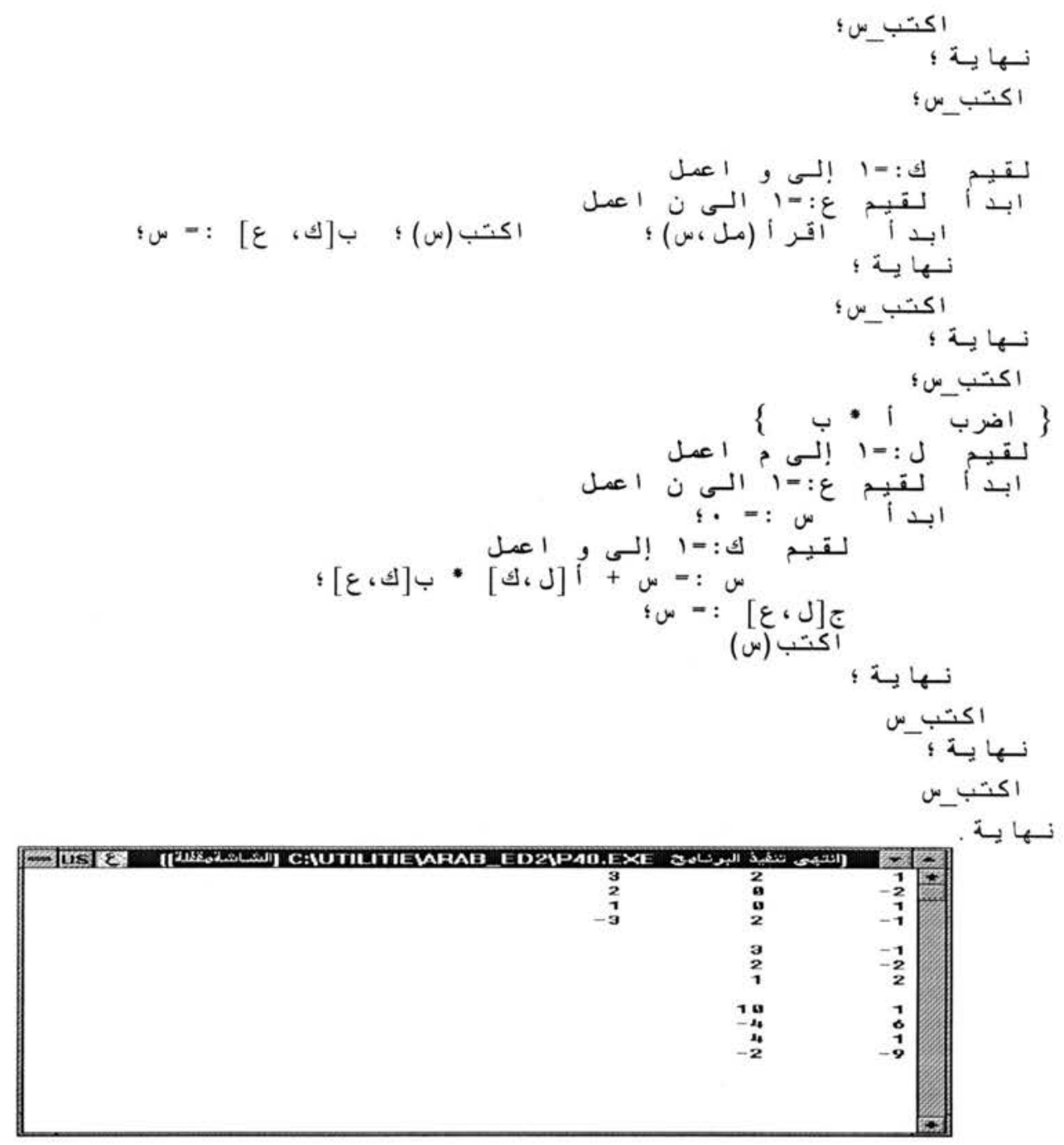

\section{Program 7.1 (Page 44)}

Operations (addition and multiplication) on complex numbers.

This program mainly tests usage of records.

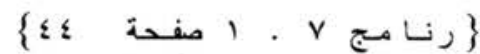

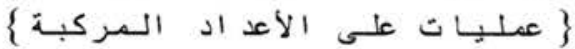

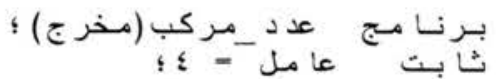

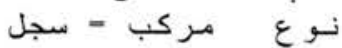

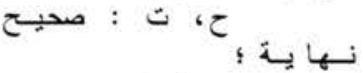

$$
\begin{aligned}
& \text { متغير س، صل : مركب؛ } \\
& \text { ن : : صحبـ : : : : }
\end{aligned}
$$

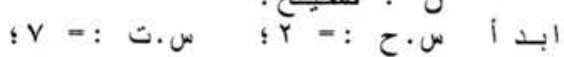

$$
\begin{aligned}
& \text { ؛ } r=: \text { : }
\end{aligned}
$$




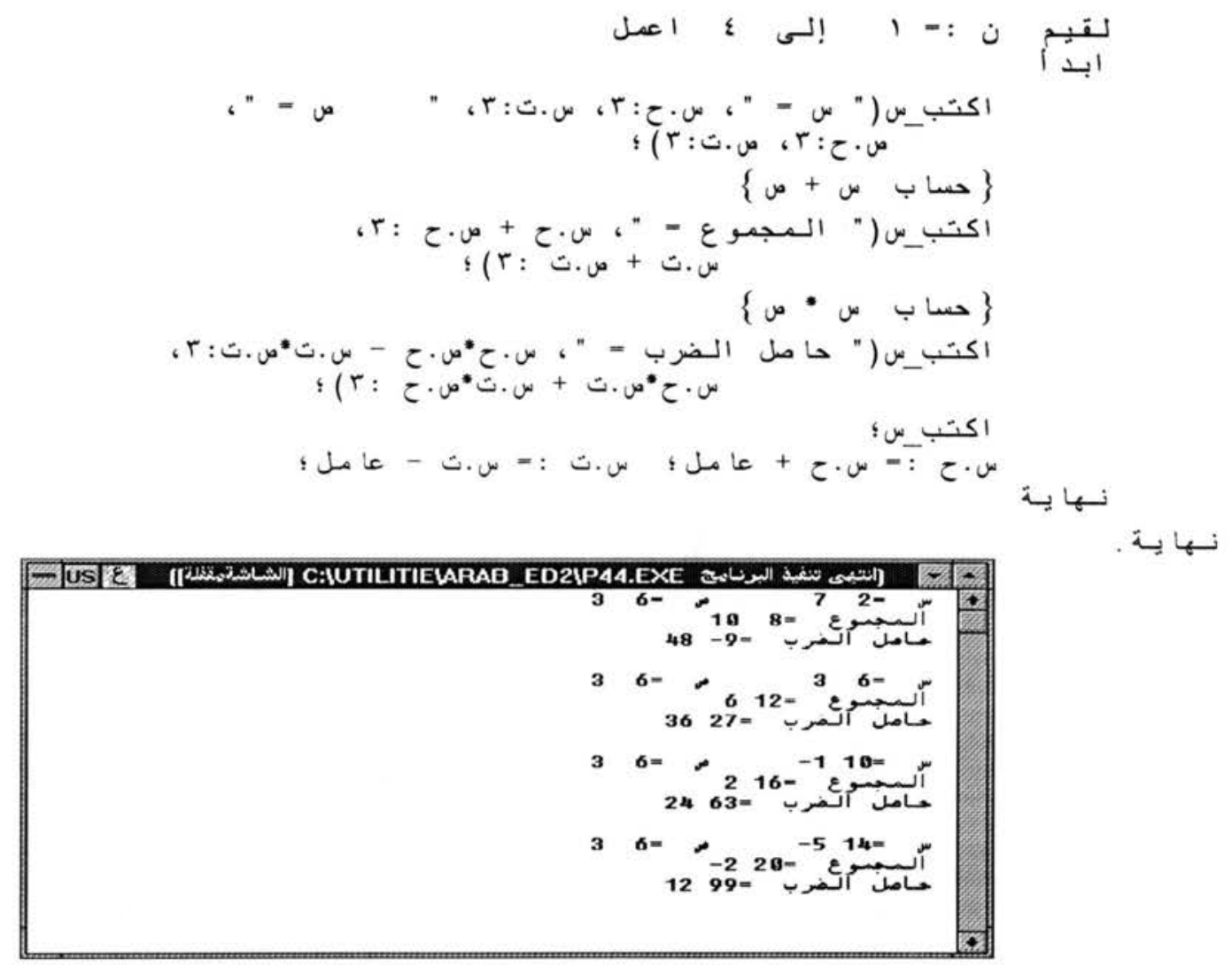

\section{Program 8.1 (Page 51)}

Example of set operations.

This program mainly tests emumeration and set types, operations on sets, and procedure calls.

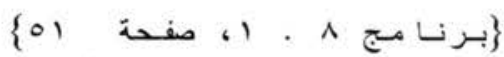

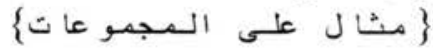

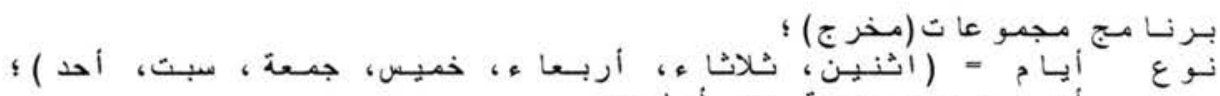

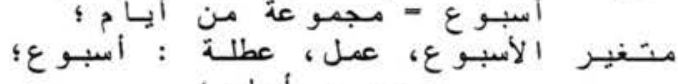

$$
\begin{aligned}
& \text { يسوم : أبسام؛ }
\end{aligned}
$$

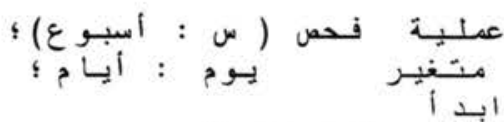

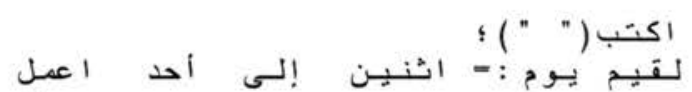

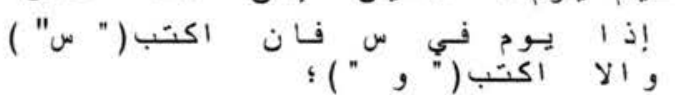

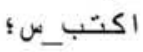




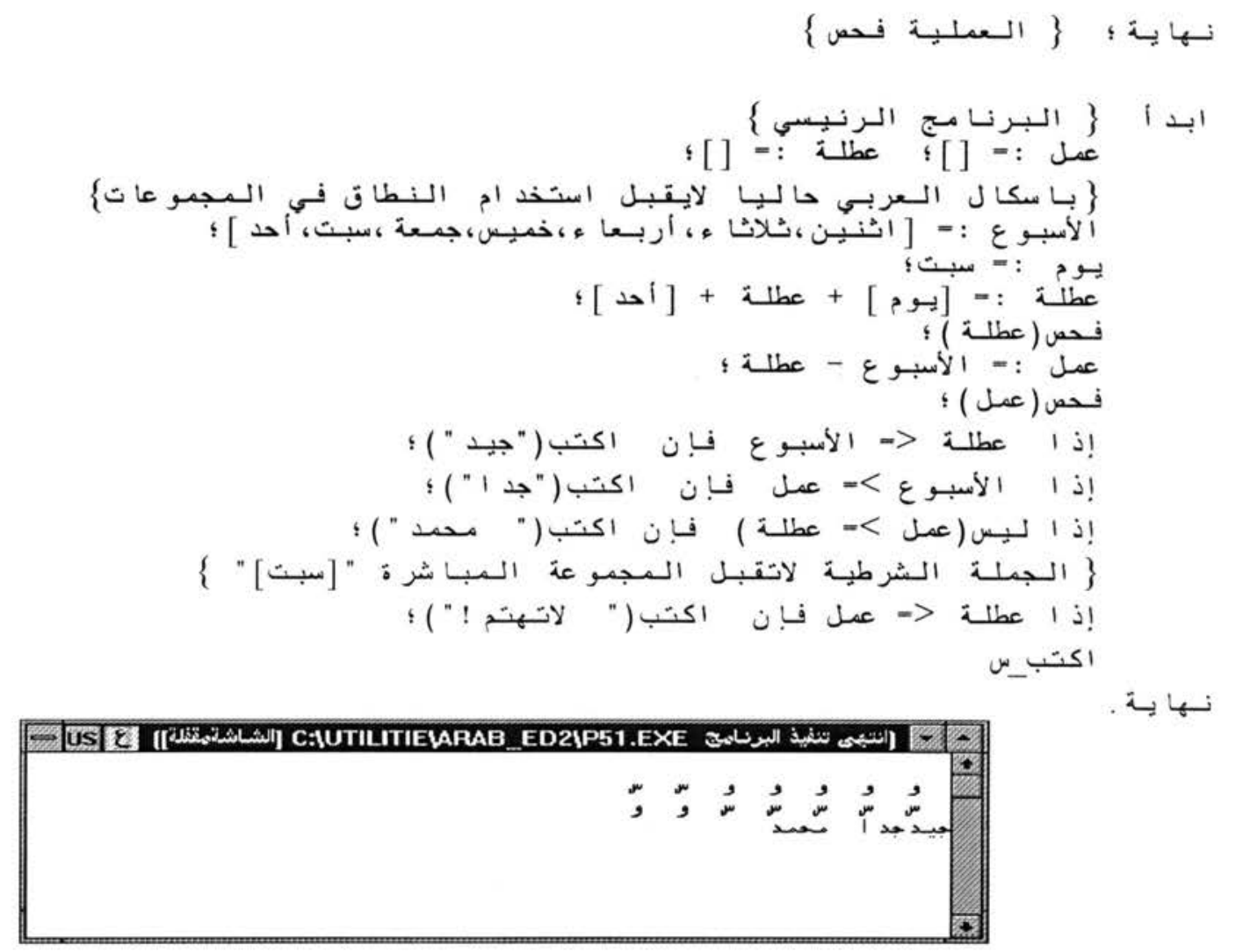

\section{Program 8.2 (Page 54)}

Generating prime numbers between 3 and around 1000. using a sieve containing odd integers in this range. The program has some implementation dependent constants (the maximum size of sets). To accommodate the prime numbers in one output screen, the prime numbers are computed up to 1000 instead of 10,000 . The original program left the output undeveloped [JW74, p. 53], however, this program provides an output.

This program mainly tests set and record types, compound structures (array of sets), with statement, nested control statements, and succ function.

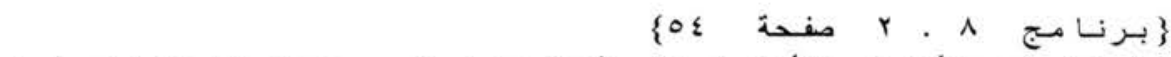

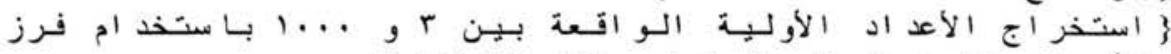

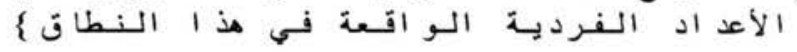

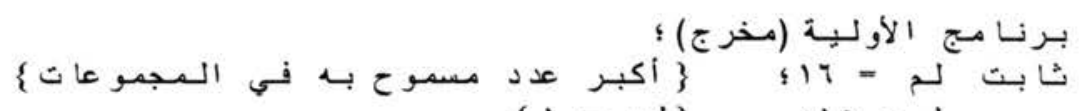

$$
\begin{aligned}
& \{1-2\}\} \text { \$10 }=J \\
& \text { ص ا }
\end{aligned}
$$

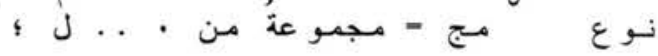




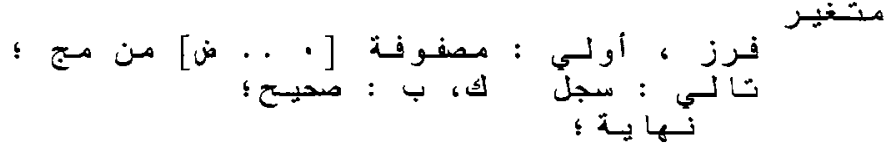

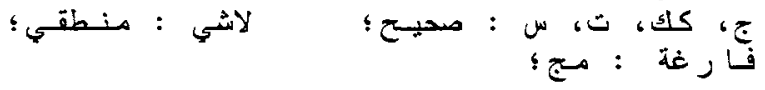

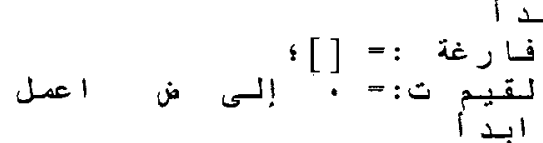

$$
\begin{aligned}
& \text { فرز [ت] }
\end{aligned}
$$

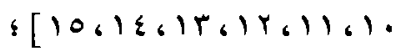

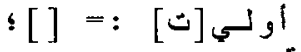

$$
\begin{aligned}
& \text { [ن }
\end{aligned}
$$

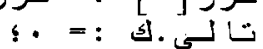

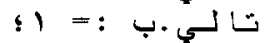

$$
\begin{aligned}
& \text { لاشي := خطا ؛ : }
\end{aligned}
$$

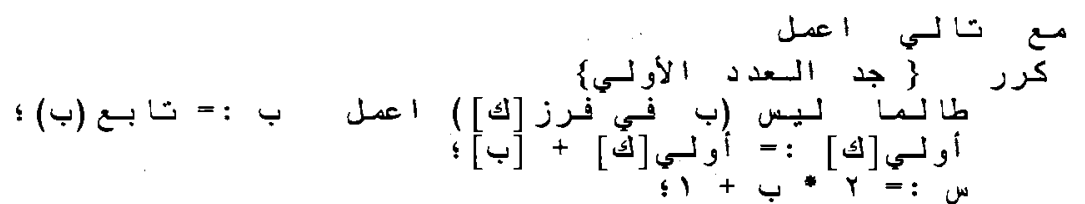

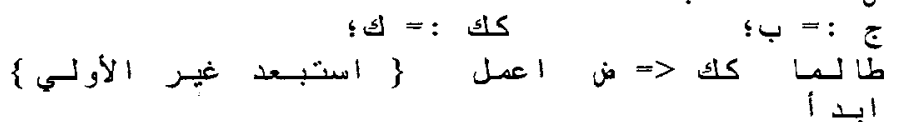

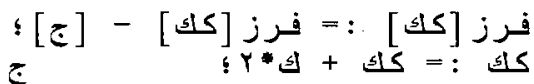

$$
\begin{aligned}
& \text { ج }
\end{aligned}
$$

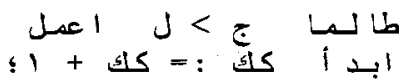

$$
\begin{aligned}
& \text { ج } \\
& \text { نها يسة }
\end{aligned}
$$

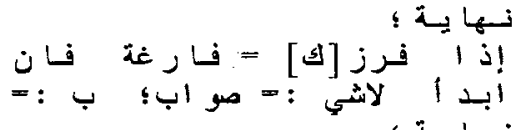

$$
\begin{aligned}
& \text { نها بـانة }
\end{aligned}
$$

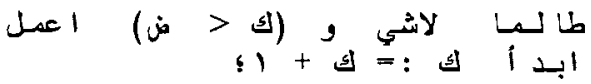

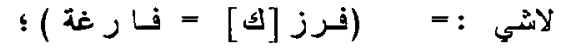

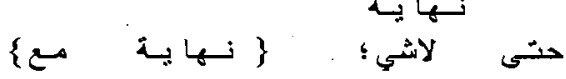

$$
\begin{aligned}
& \text { \{ طبا عة الاعد اد الأولسبة }
\end{aligned}
$$

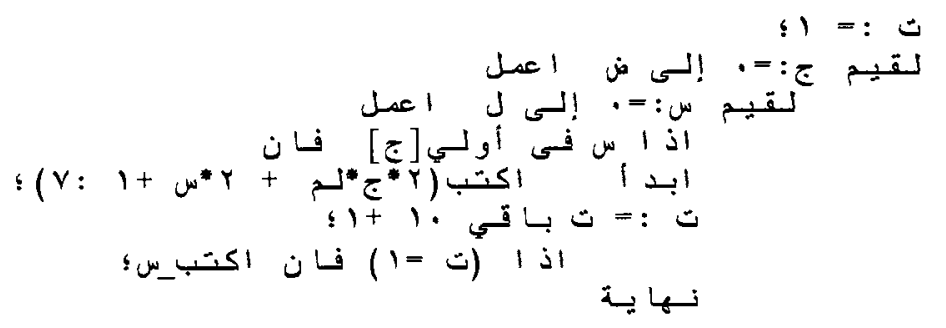




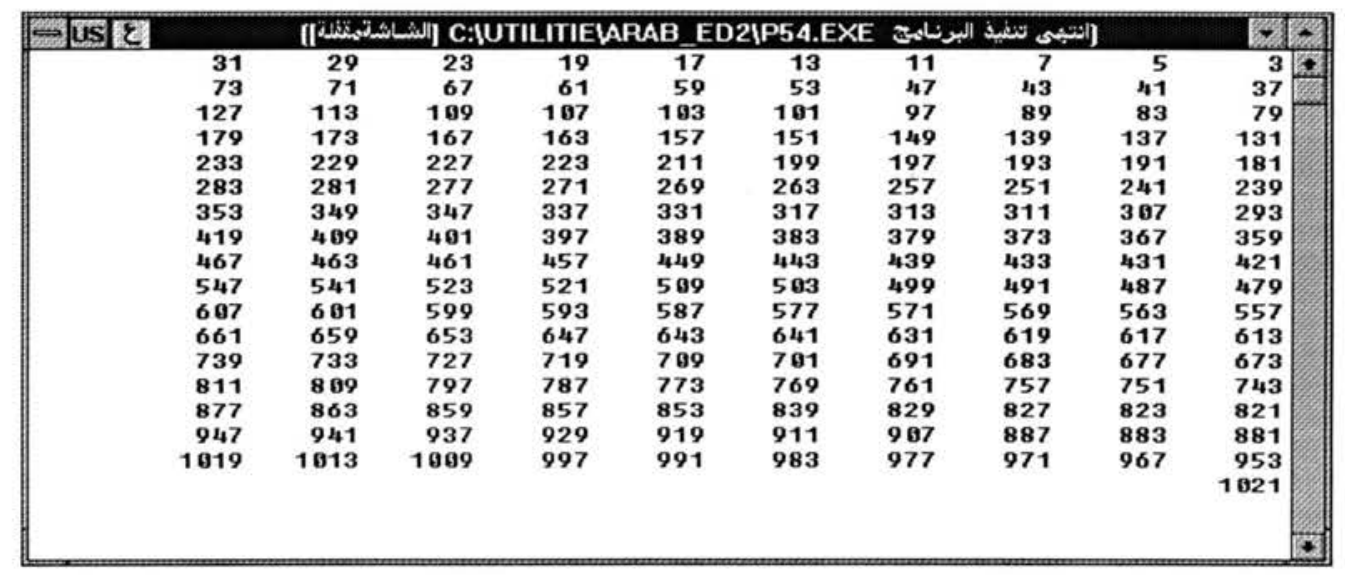

\section{Program 9.1 (Page 60)}

Frequency count of digits in an input file. The original program counts the frequency of letters, not digits. The Arabic Pascal has a limit of 16 elements in the set. Therefore, counting the frequency of alphabets is not applicable in the Arabic Pascal using sets.

This program mainly tests array and set types, and eof and eoln functions.

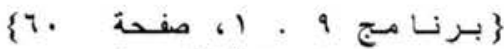

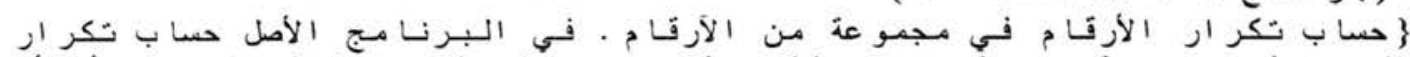

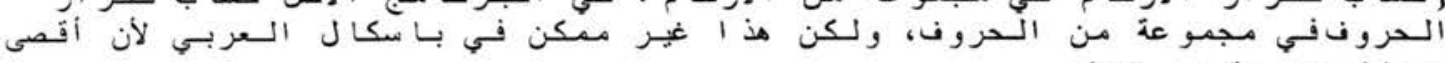

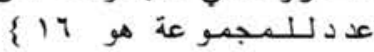

$$
\begin{aligned}
& \text { برنسامـج الستكر ار (مدخل، مخرج)؛ }
\end{aligned}
$$

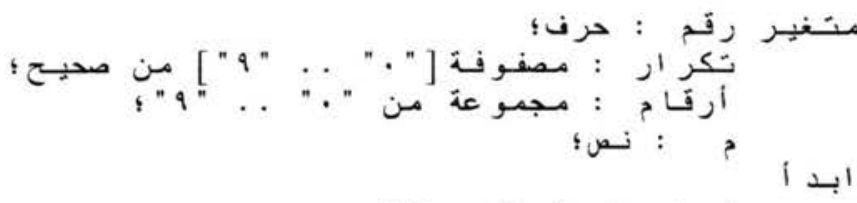

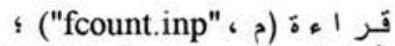

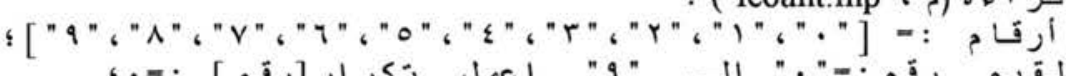

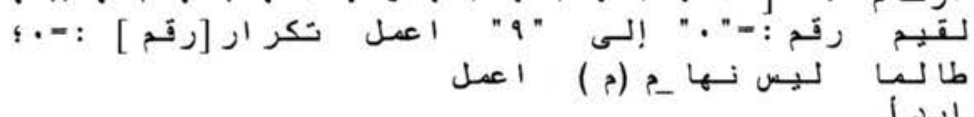

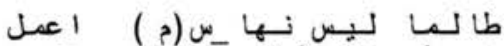

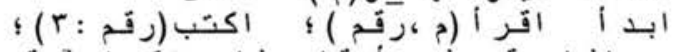

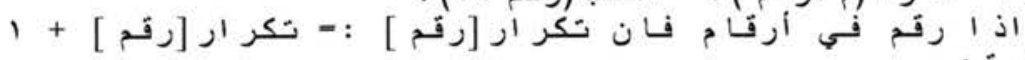

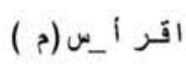

$$
\begin{aligned}
& \text { ؛ } \\
& \text { ؛ }
\end{aligned}
$$

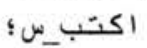

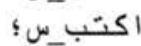

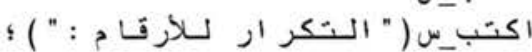




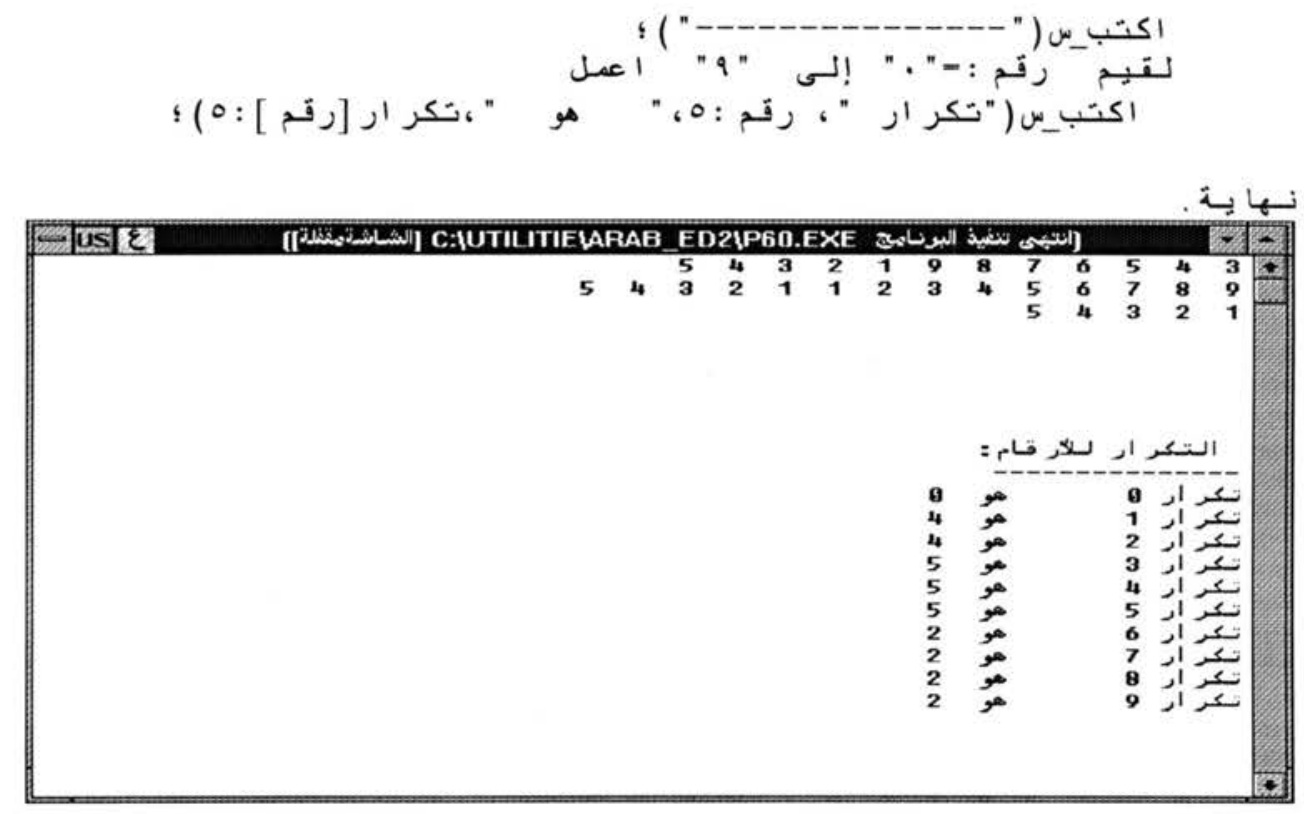

\section{Program 9.2 (Page 61)}

Inserting leading blanks at the beginning of each line while copying it from one file to another. The original program reads from the standard input and writes to the standard output, while this program reads from a file and writes to another file (more general, to test the file operations). Note that the execution window will not show up in running this program because there is no input nor output to the standard input/output. After the program source code, both input and output files are shown.

This program mainly tests reading from one file and writing to another file.

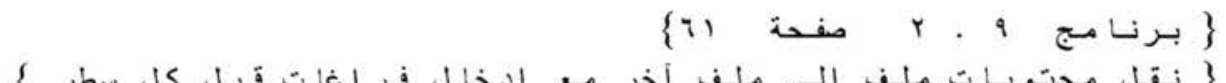

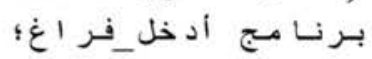

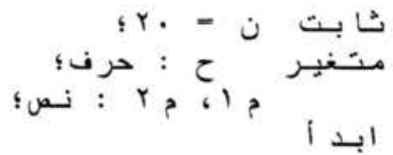

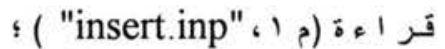

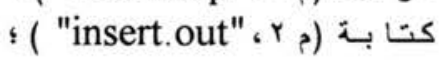

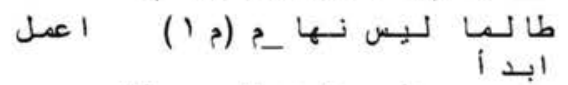

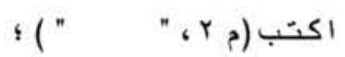

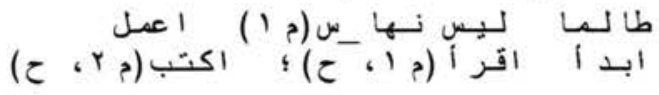




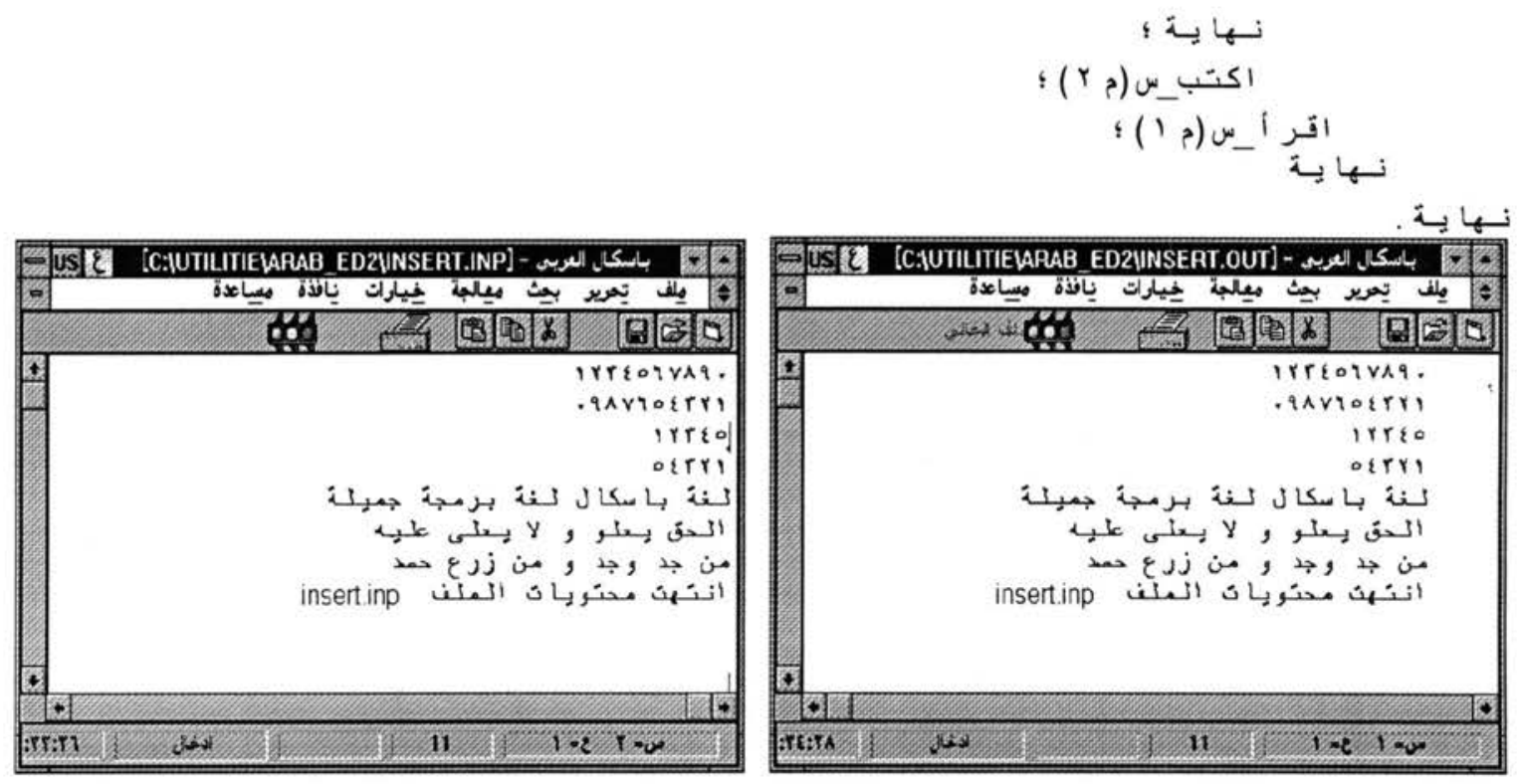

\section{Program 11.2 (Page 70)}

Find the minimum, the maximum, and the difference between the minimum and the maximum for a list of numbers. This program is an extension to program 11.1.

This program mainly tests array type and call-by-reference.

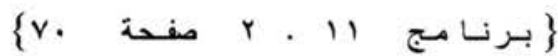

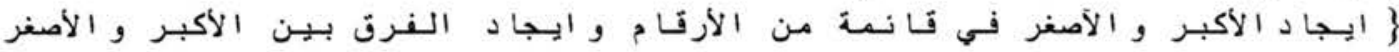

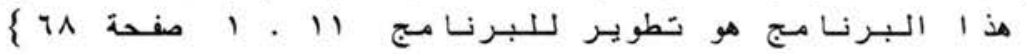

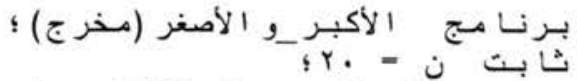

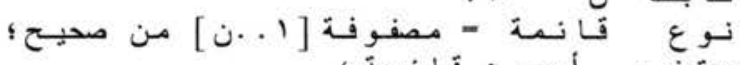

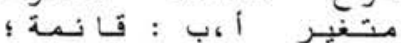

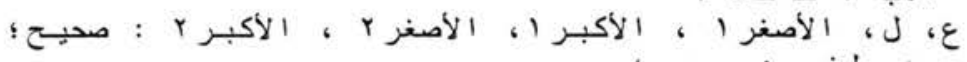

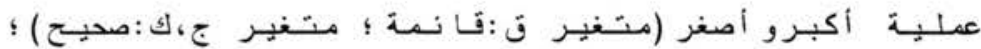

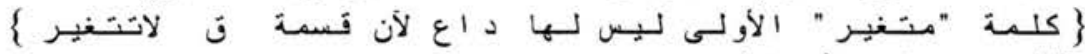

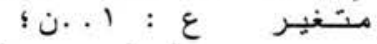

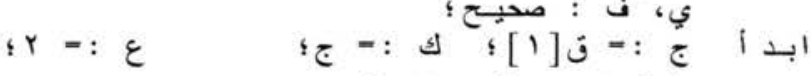

$$
\begin{aligned}
& \text { ابـدأسبا }
\end{aligned}
$$

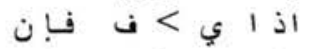

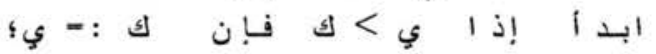

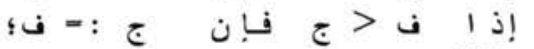

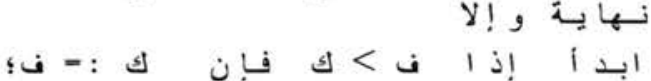




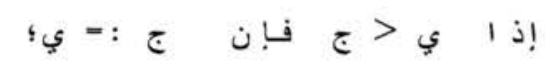

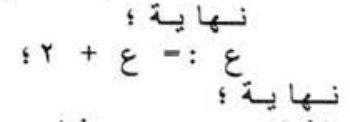

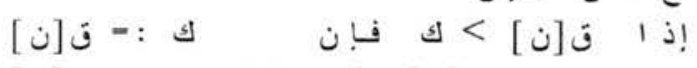

$$
\begin{aligned}
& \text { و إلا } \\
& \text { \{ نهبا يـة ؛ }
\end{aligned}
$$

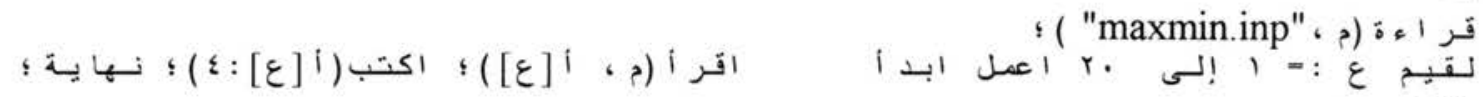

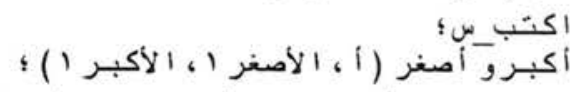

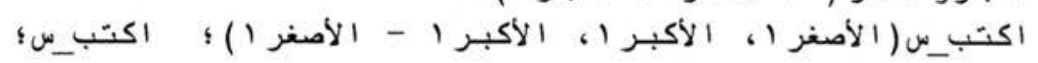

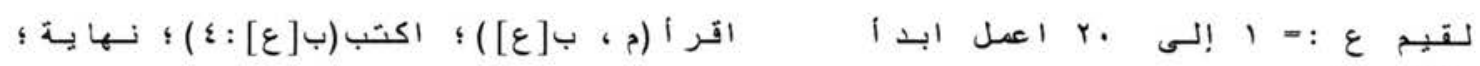

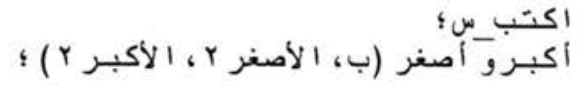

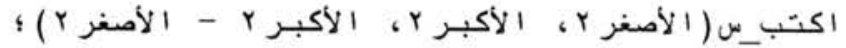

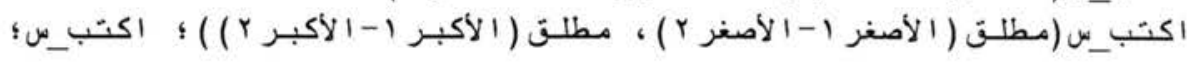

$$
\begin{aligned}
& \text { لـقبّ }
\end{aligned}
$$

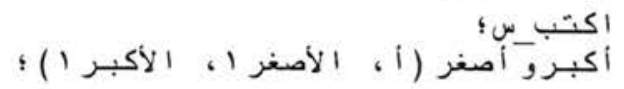

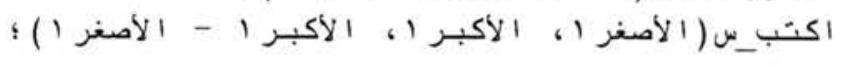

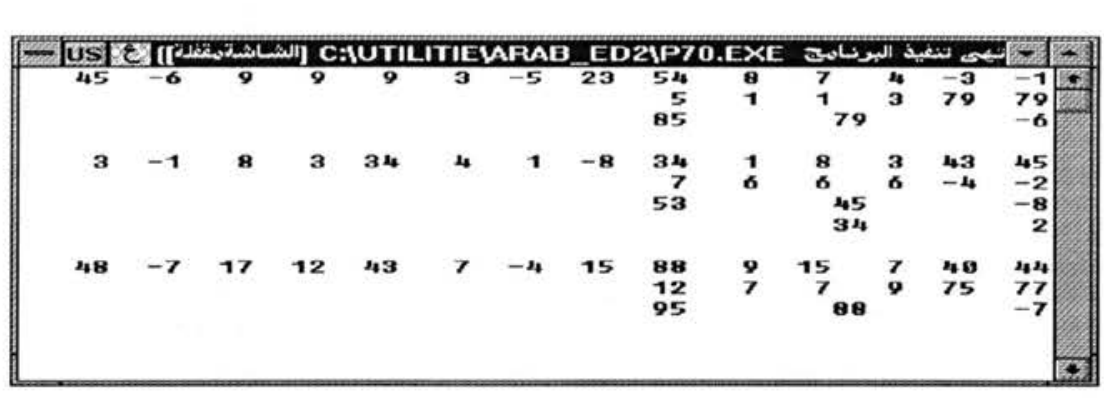

\section{Program 11.3 (Page 72)}

Procedure parameters.

This program mainly tests the difference between call-by-value and call-by-reference parameter passing conventions.

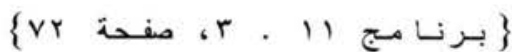

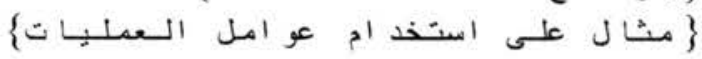




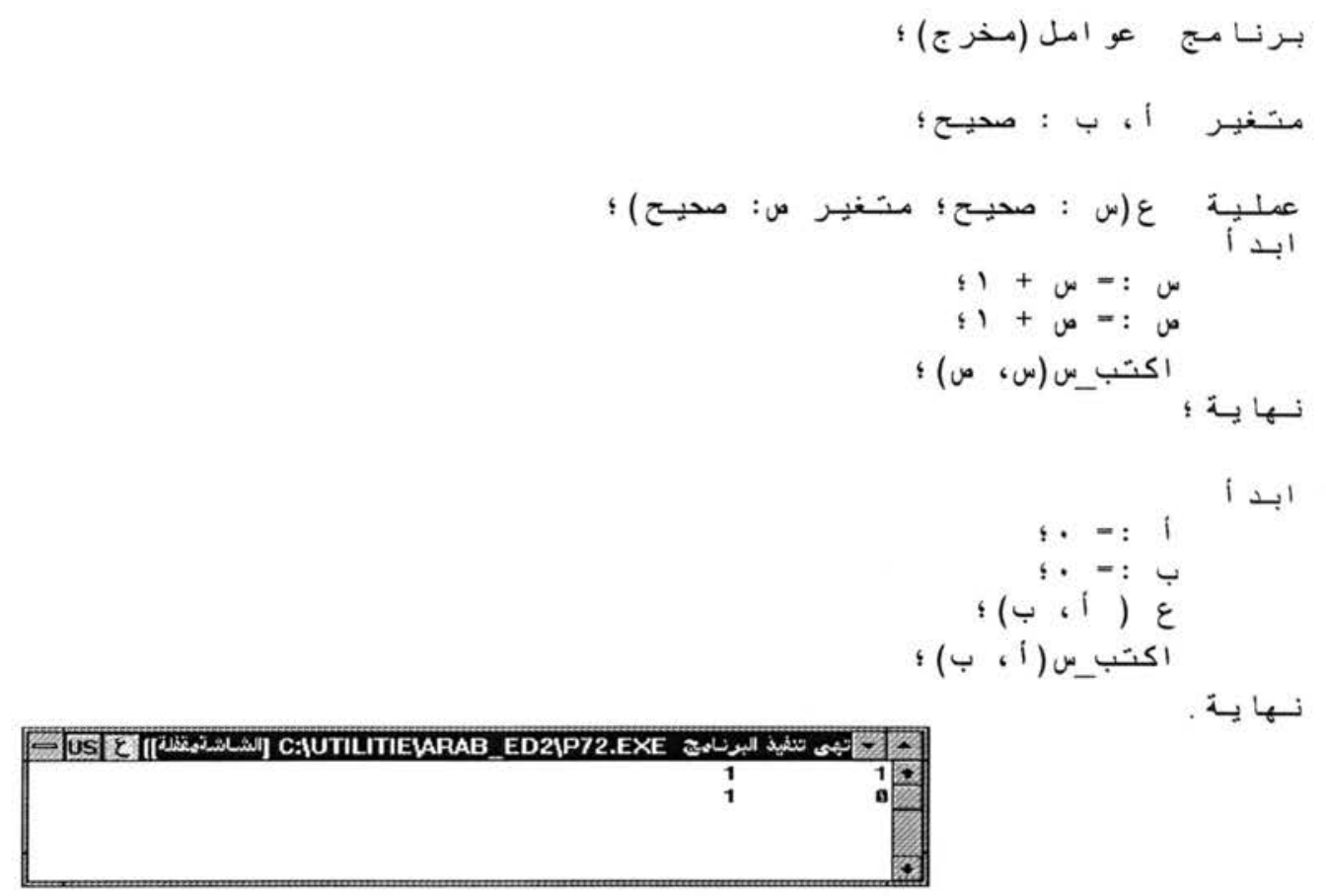

\section{Program 11.4 (Page 75)}

Construct a program to convert the infix expression into postfix form. The program uses the recursive approach instead of the stack implementation.

This program mainly tests nested procedures, recursive procedures.

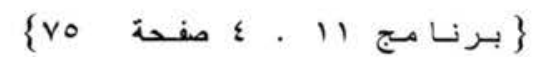

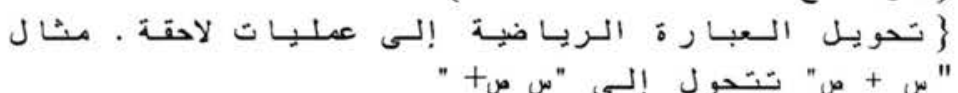

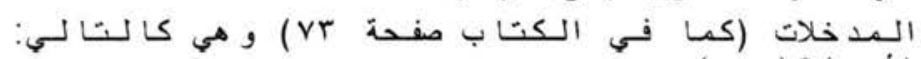

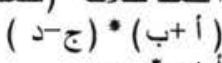

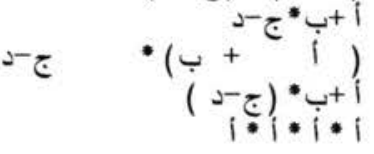

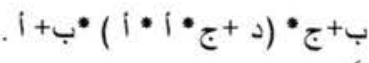

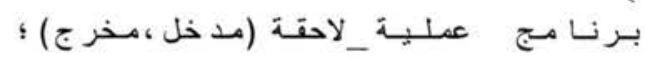

$$
\begin{aligned}
& \text { منتغيـر, }
\end{aligned}
$$

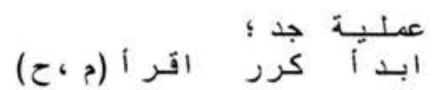

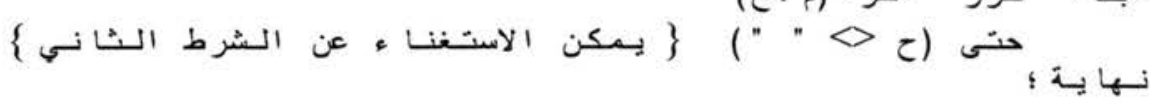




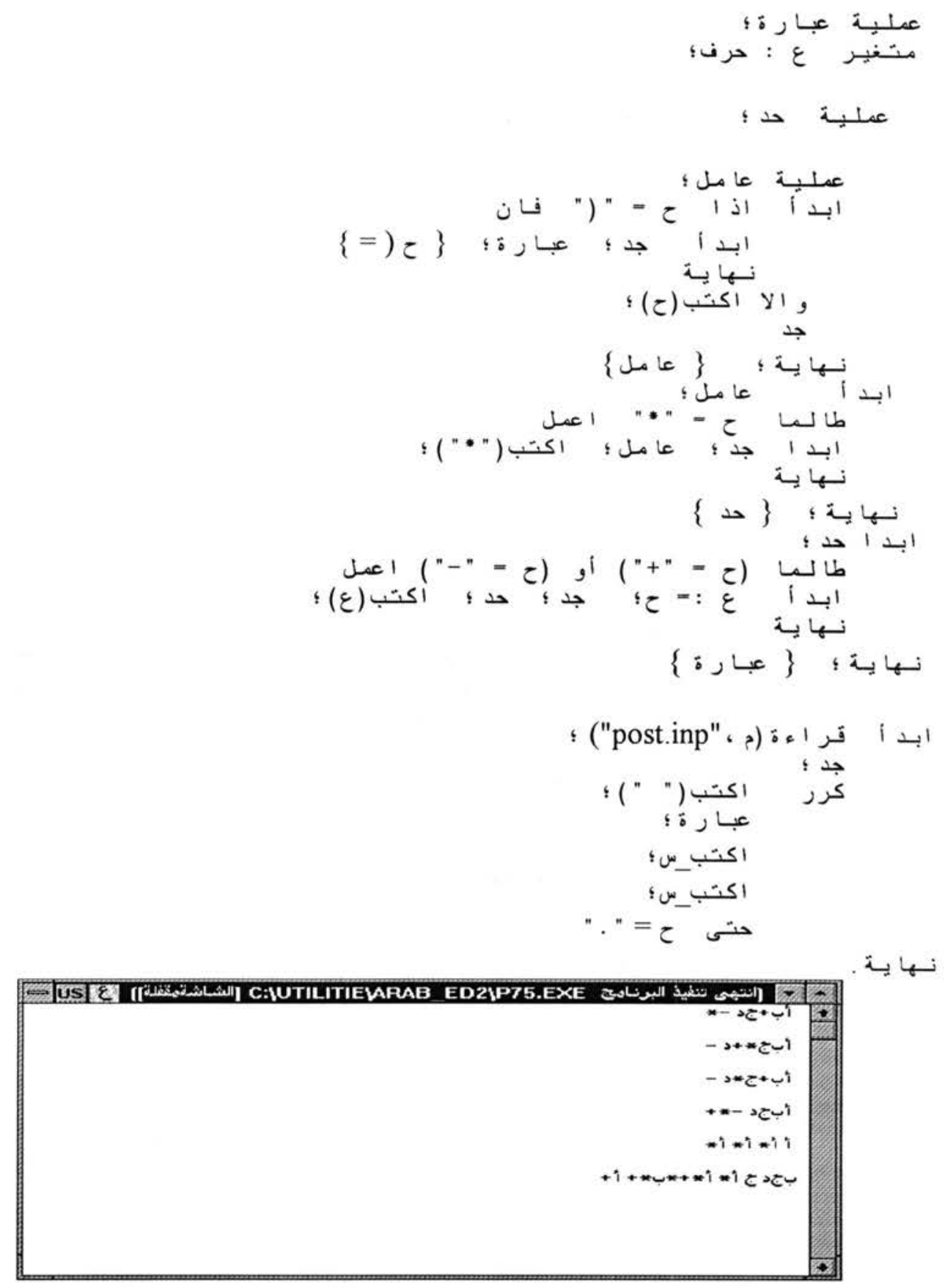

\section{Program 11.5 (Page 77)}

Binary tree traversal. The original program uses unusual procedure names; it uses postorder to mean inorder and endorder for postorder.

This program mainly tests pointer and record types, call-by-reference, recursive calls, and function calls (enter procedure has been converted to a function to test function calls). 


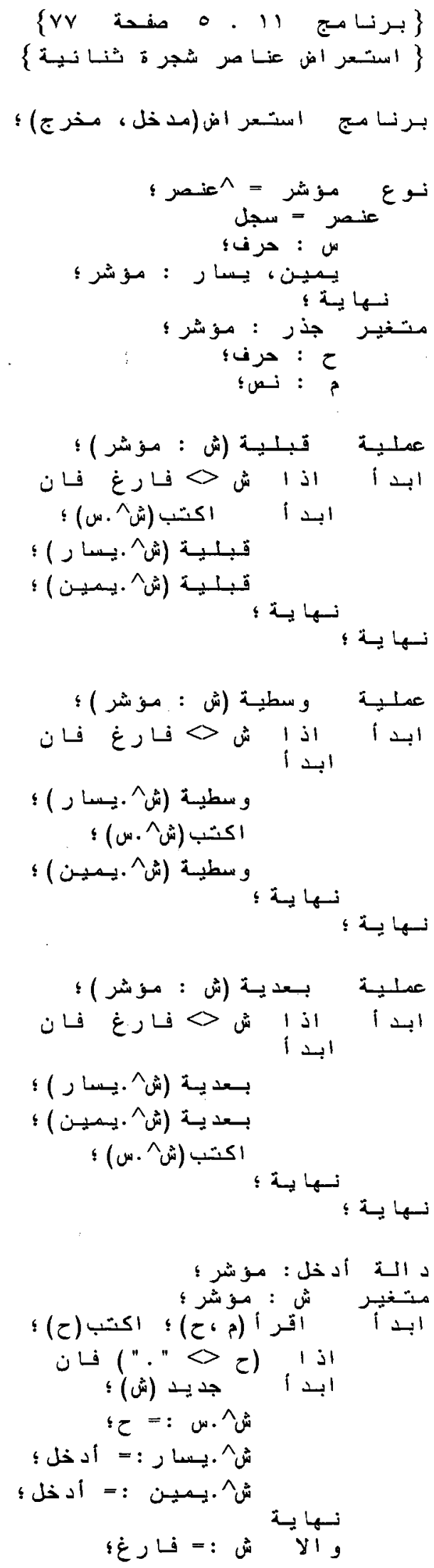




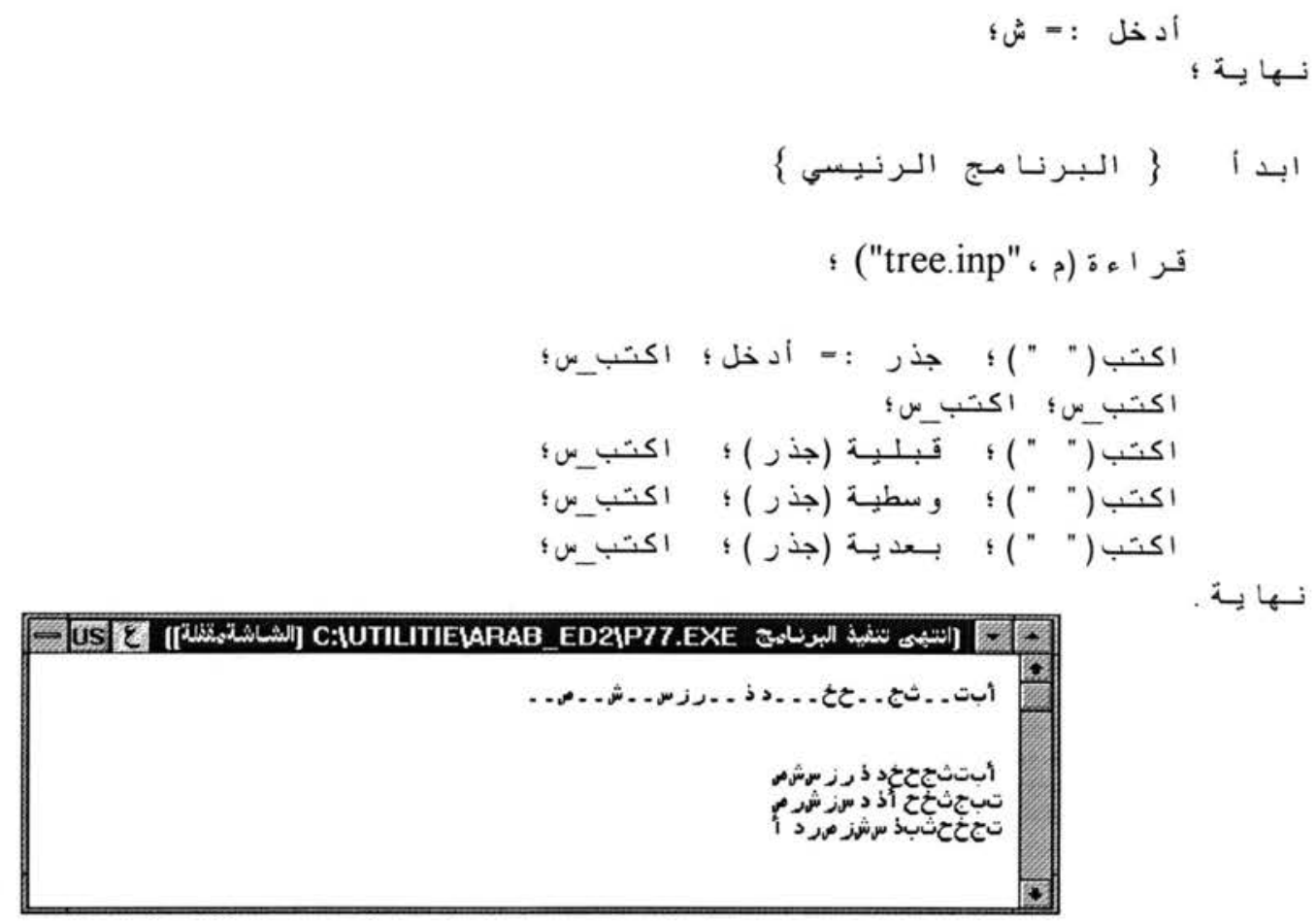

\section{Program 11.6 (Page 79)}

Find zero of a function by bisection. The original program caused an infinite loop in the second input (for evaluating the $\cos$ function). I have tested this program using Turbo Pascal and the same thing happens. It seems that the problem comes from the limitation of the real numbers. Therefore, I have added a counter to stop the looping after 100,000 iterations. The APC does not accept a function as a parameter. So, the function parameter in the original program has been transformed to a boolean parameter that activates the required function.

This program mainly tests function calls with parameters.

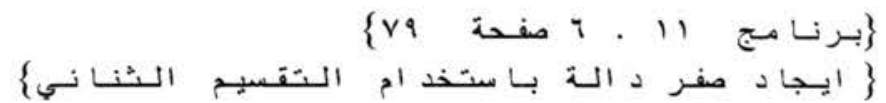

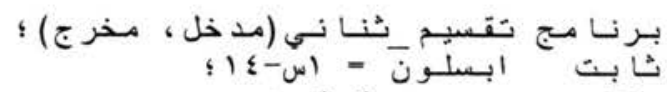

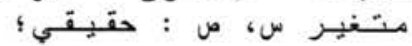

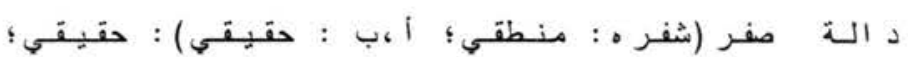

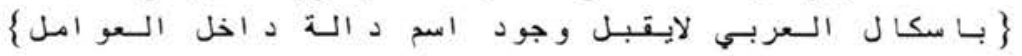




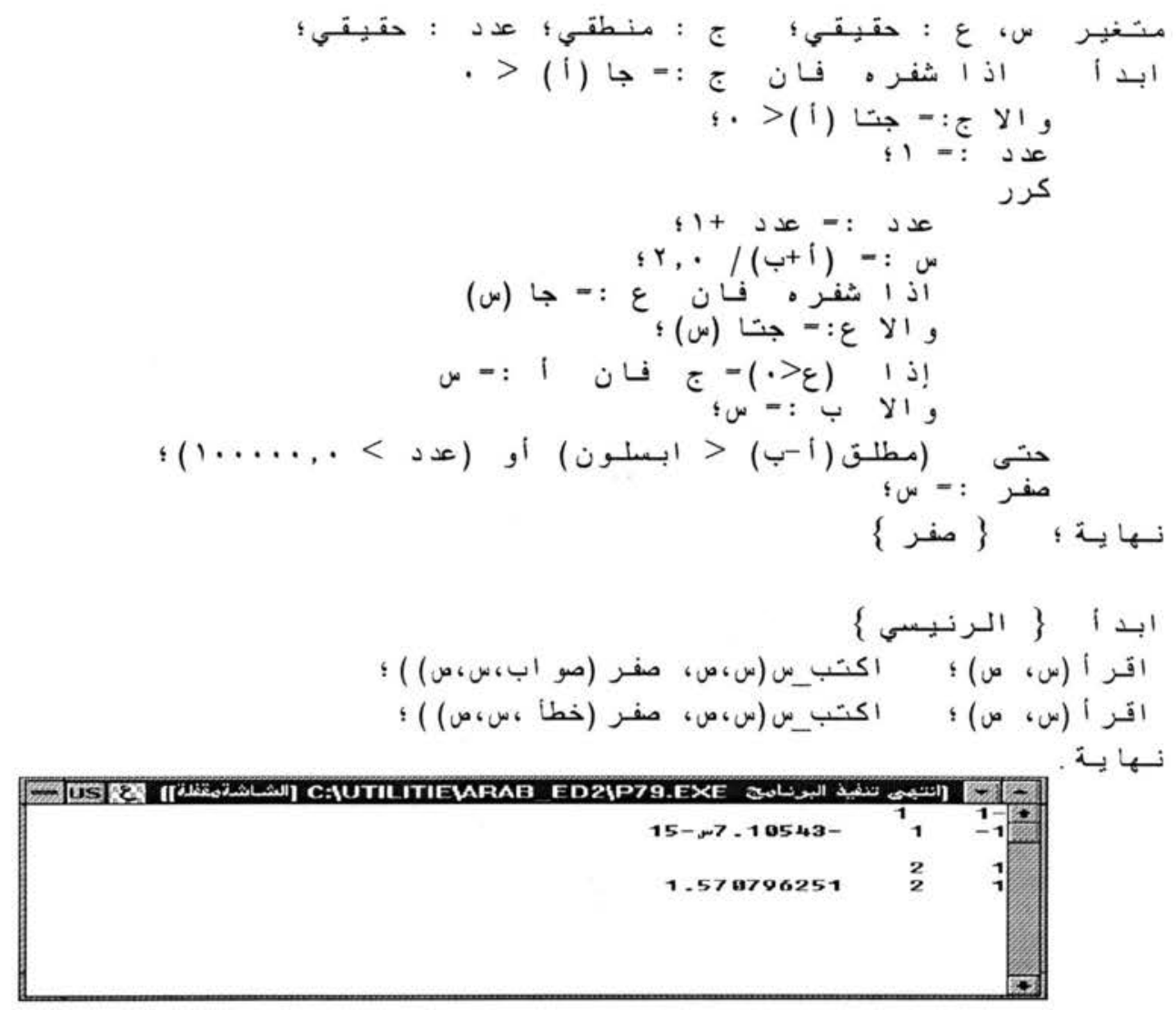

\section{Program 11.7 (Page 80)}

Testing the side effect that may be caused by using functions.

This program mainly tests function calls.

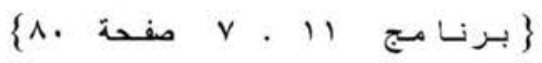

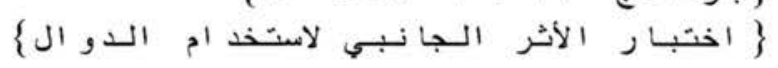

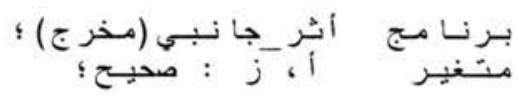

$$
\begin{aligned}
& \text { د الـ ت (س: صحبّ) : صحبح؛ }
\end{aligned}
$$

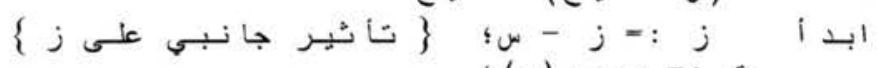

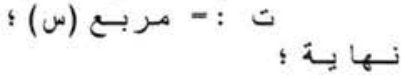

$$
\begin{aligned}
& \text { ابـد أ } \\
& \text { ؛ } \\
& \text { ز : : : : : } \\
& \text { ز } \\
& \text { نسها بـة . }
\end{aligned}
$$




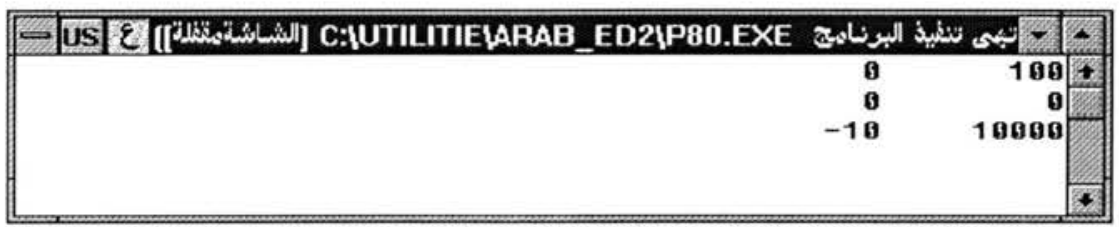

\section{Program 11.8 (Page 81)}

Compute the value of $x$ to the power of $y$. This program is an extension to

program 4.8 in page 29.

This program mainly tests function calls.

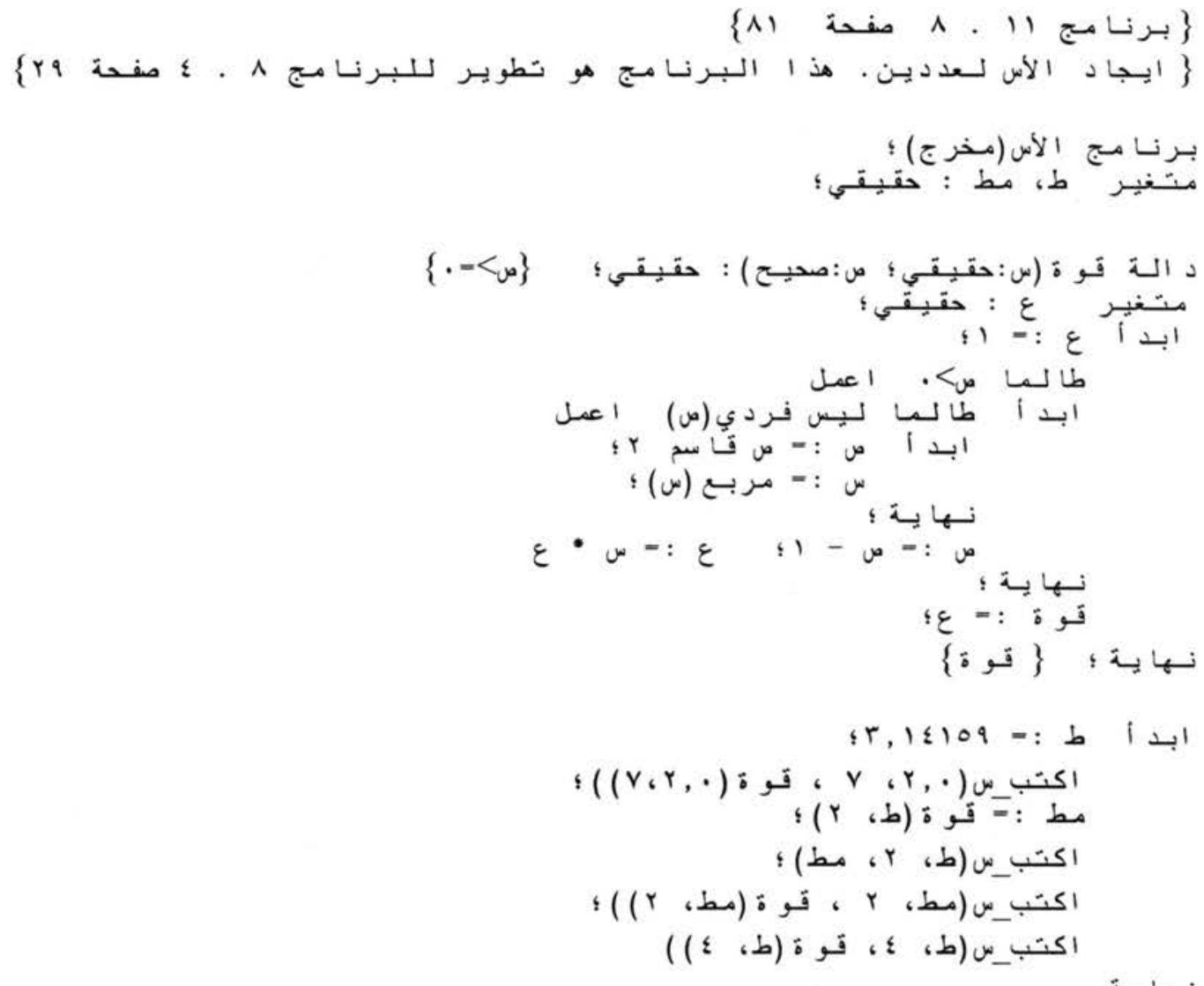

\begin{tabular}{|c|c|c|c|c|}
\hline 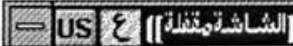 & C:|UTILITIE |ARAB_ED2\P81.EXE & لبرناويج & - أبهى تنفيذ & 12 \\
\hline & $\begin{array}{r}128 \\
9.86959 \\
97.4088 \\
97.4088\end{array}$ & $\begin{array}{l}7 \\
2 \\
2 \\
4\end{array}$ & $\begin{array}{r}2 \\
3.14159 \\
9.86959 \\
3.14159\end{array}$ & + \\
\hline
\end{tabular}




\section{Program 11.9 (Page 82)}

Recursive formulation of $g c d$.

This program mainly tests recursive function calls and procedure calls.

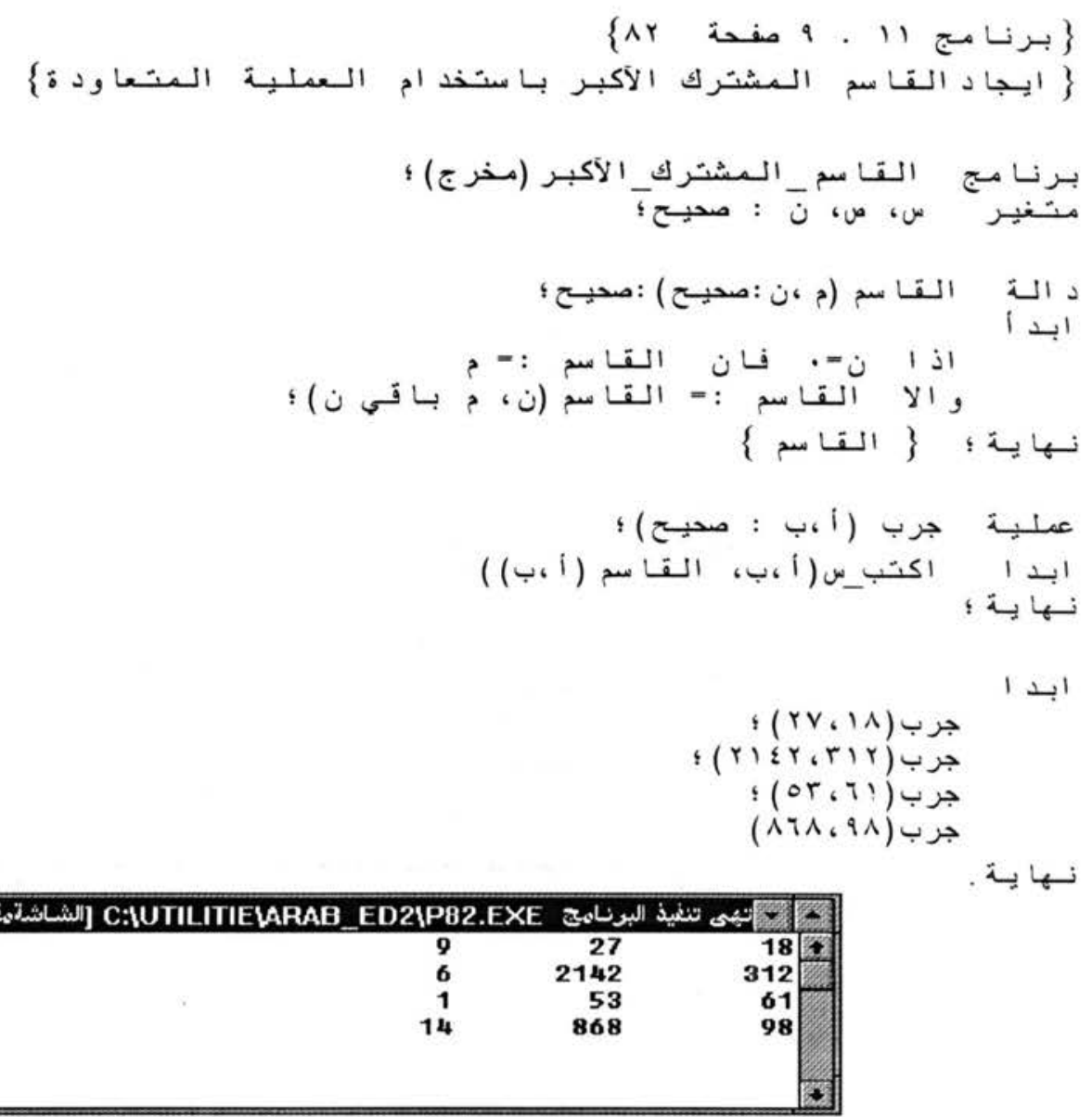

\section{Complementary Example}

This example is not in Jensen and Wirth book. It contains some concepts that are not mentioned in that book, namely:

1. Case statement.

2. Built-in procedures: new and dispose (dynamic allocation and deallocation).

3. Mutual recursion. Two procedures, each one calls the other, communicating through a variable parameter.

4. Call-by-reference utilizing a non simple type (array type). 


\section{Goto statement.}

6. Built-in functions: arctan, ord, chr, ln, pred, and sqrt.

The full translation of this example is available at the end of this example.

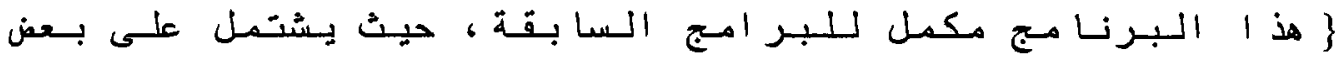

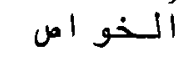

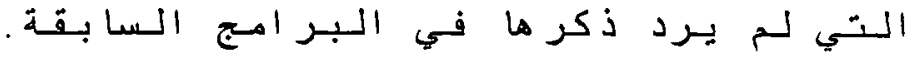

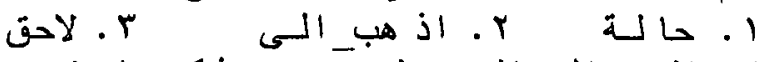

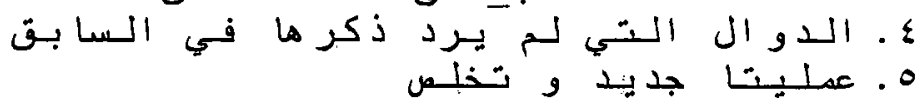

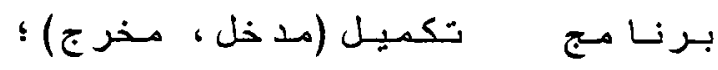

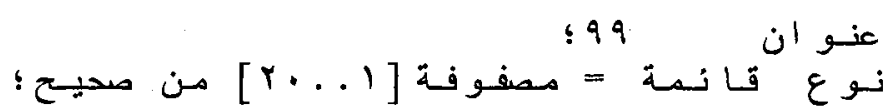

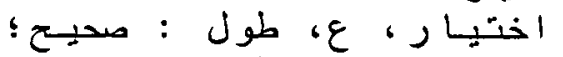

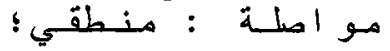

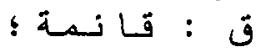

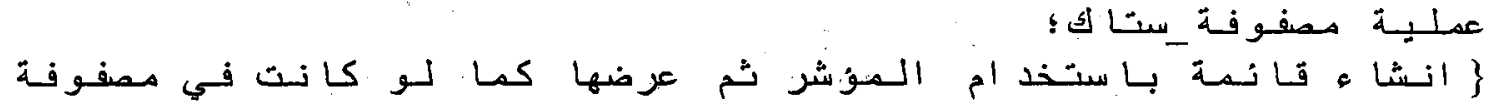

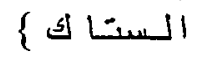

$$
\begin{aligned}
& \text { قا طر } \\
& \text { رقم }
\end{aligned}
$$

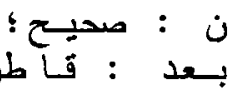

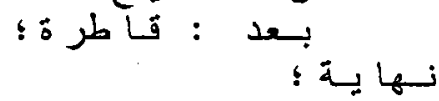

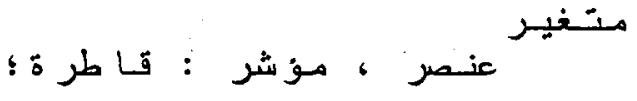

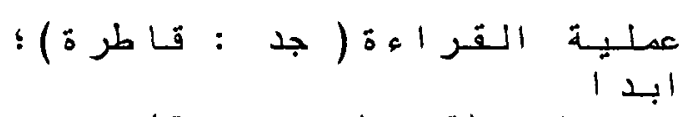

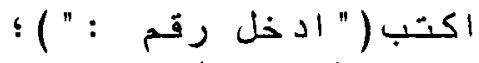

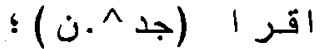

$$
\begin{aligned}
& \text { نهـا يـة ؛ }
\end{aligned}
$$

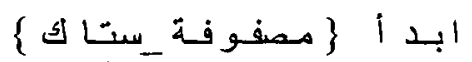

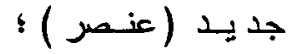

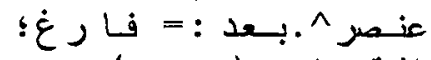

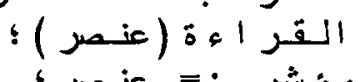

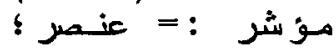

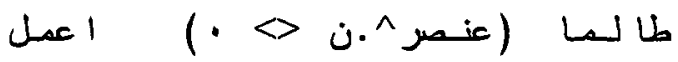




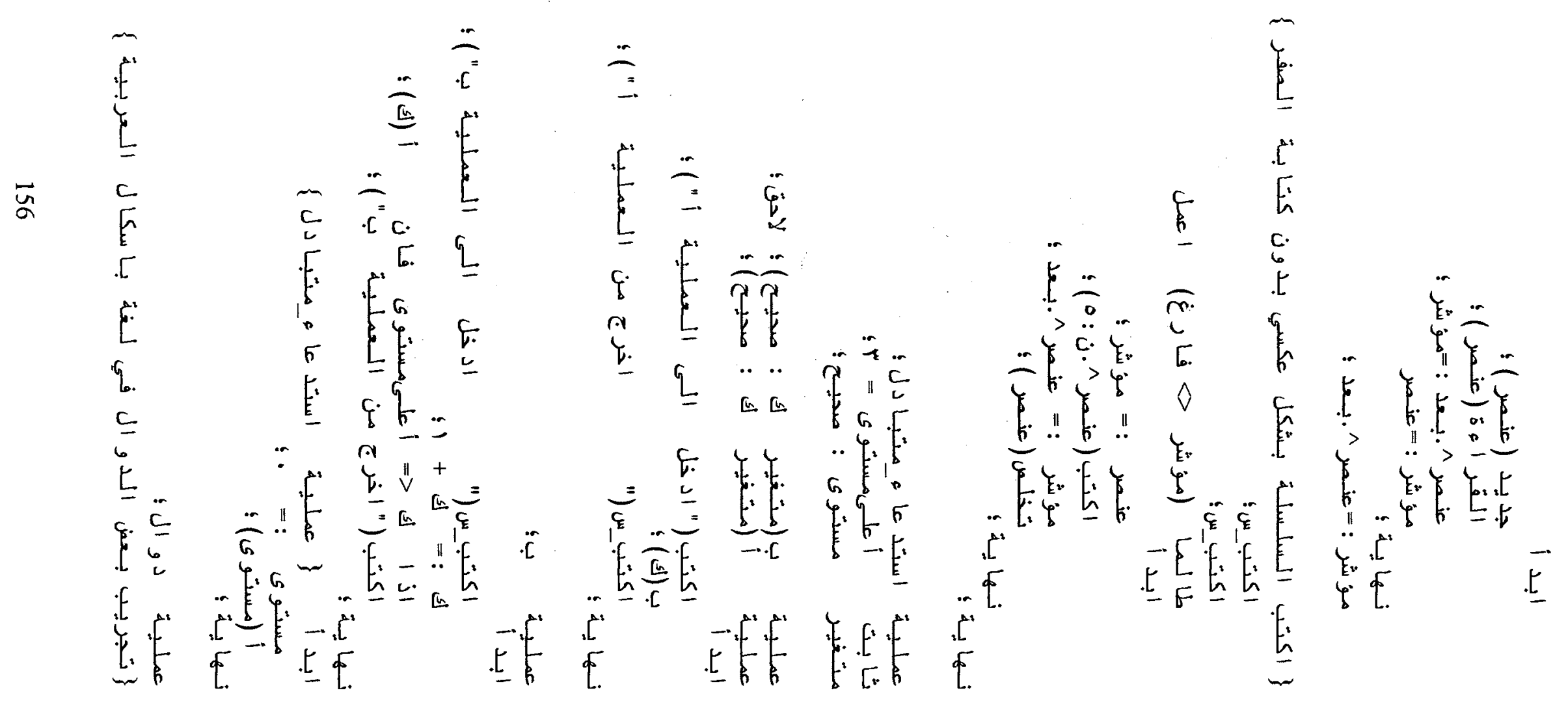




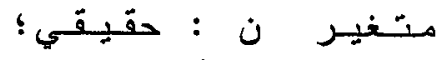

$$
\begin{aligned}
& \text { : }
\end{aligned}
$$

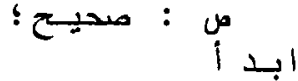

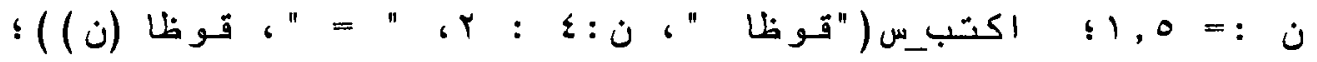

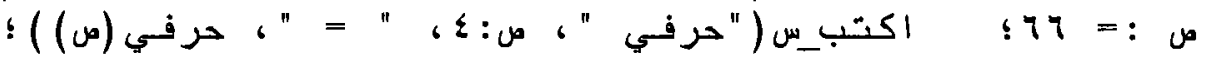

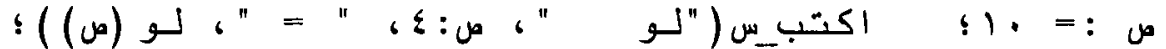

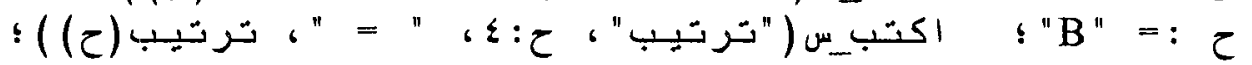

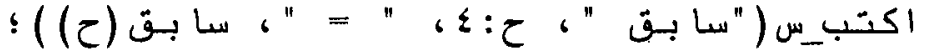

$$
\begin{aligned}
& \text { نـها يحة : ؛ إه }
\end{aligned}
$$

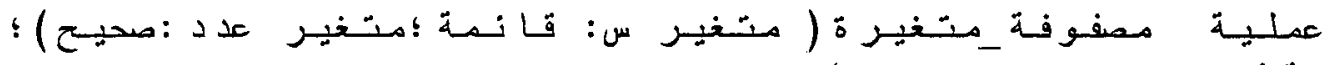

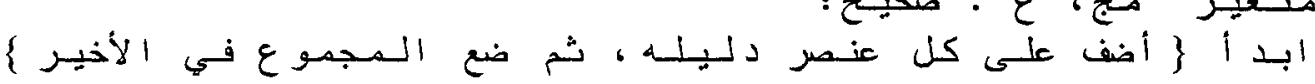

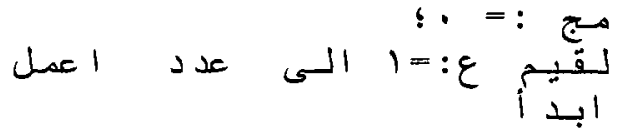

$$
\begin{aligned}
& \text { ق } \\
& \text { مـ }
\end{aligned}
$$

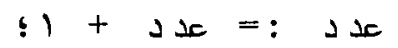

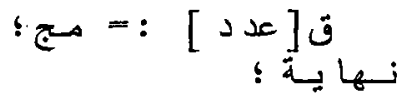

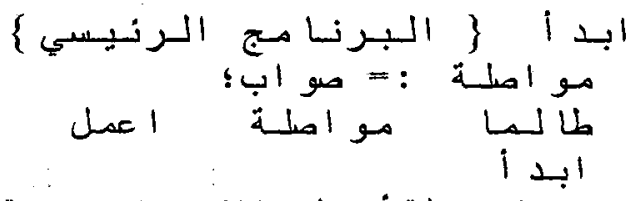

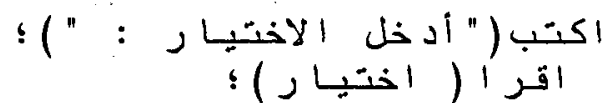

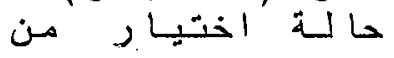

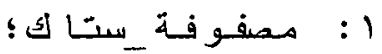

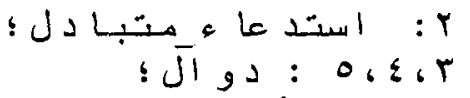

$$
\begin{aligned}
& \text { أبـأ }
\end{aligned}
$$

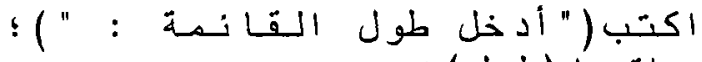

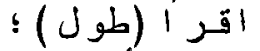

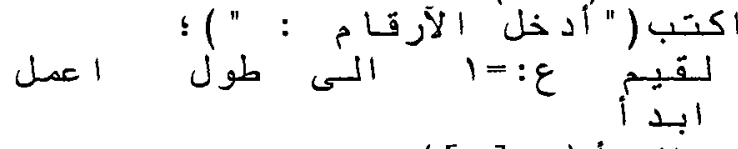

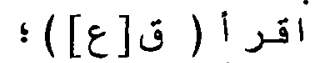

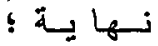

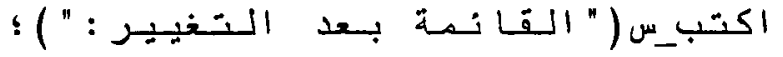

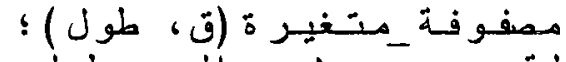

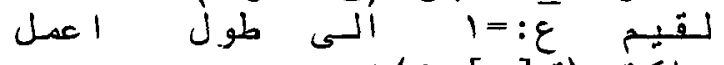

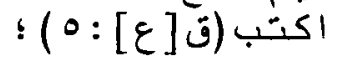




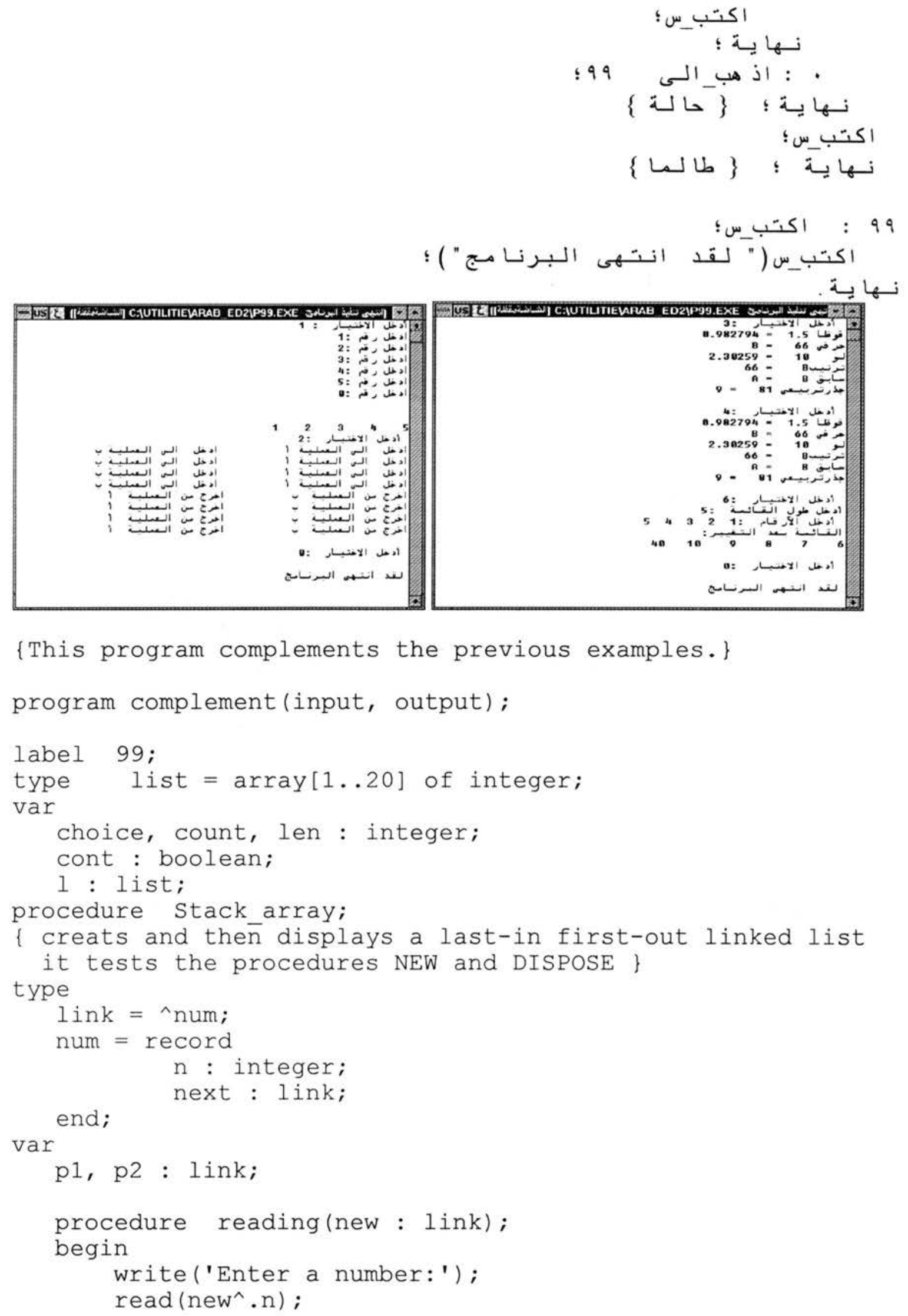




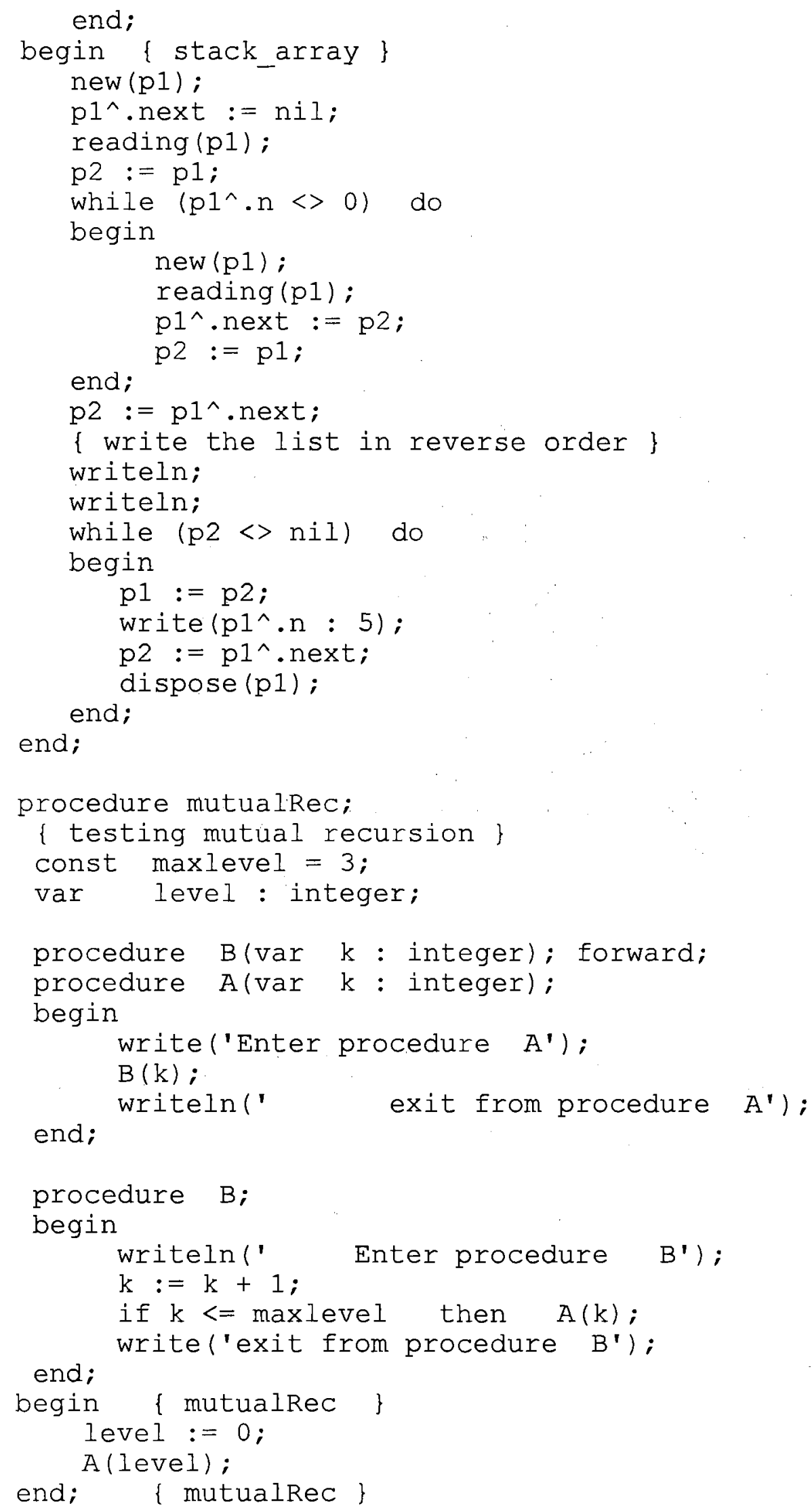




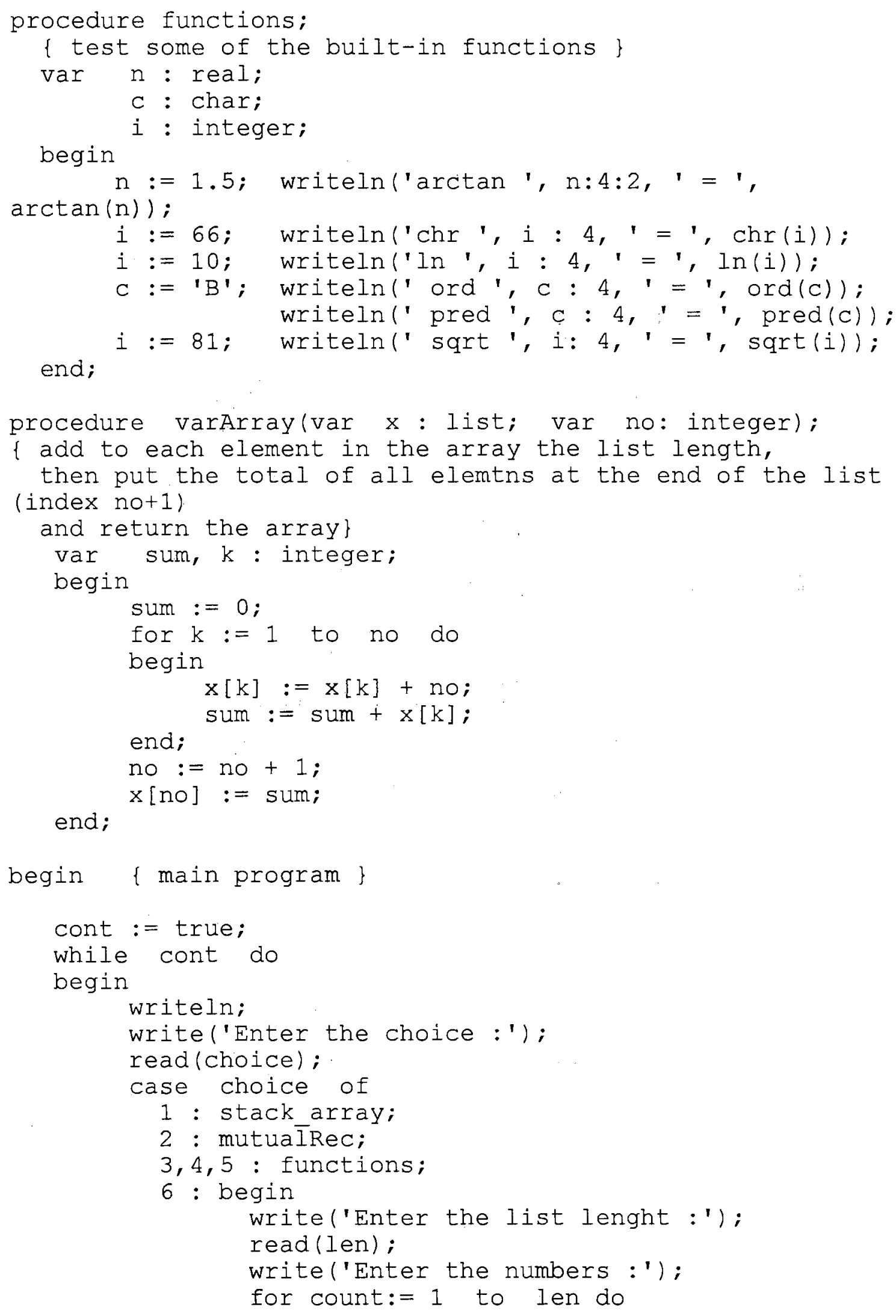




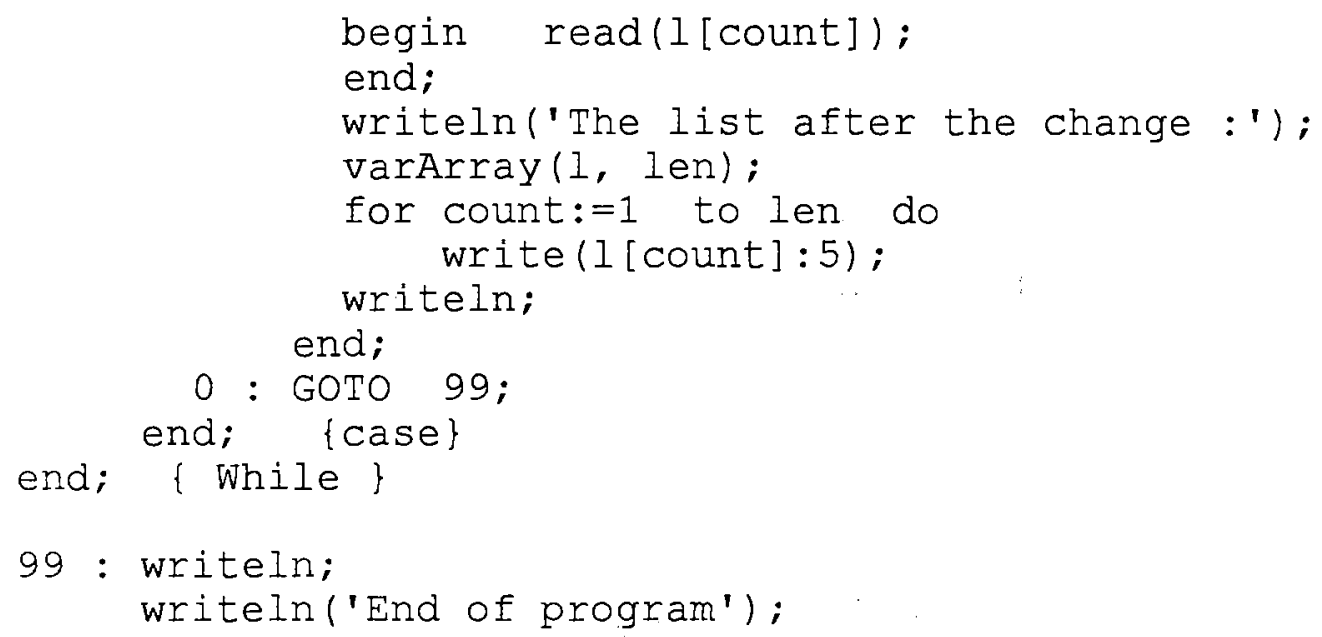


VITA

\author{
AbdulMalik S. Al-Salman \\ Candidate for the Degree of \\ Doctor of Philosophy
}

Thesis: AN ARABIC PROGRAMMING ENVIRONMENT

Major Field: Computer Science

Biographical:

Personal Data: Born in Riyadh, Saudi Arabia, On October 16, 1966.

Education: Graduated from El-Shafa High School, Riyadh, Saudi Arabia, in June 1983; received Bachelor of Science degree in Computer Science from King Saud University, Riyadh, Saudi Arabia in June 1988; received Master of Science degree in Computer Science from University of Georgia, Athens, Georgia in July 1992.

Completed the requirements for the Doctor of Philosophy with a major in Computer Science at Oklahoma State University in July 1996.

Experience: employed as systems analyst by the Royal Saudi Marine Forces in Summer 1986 and 1987; employed by King Saud University, Department of Computer Science as teaching assistant in 1988-1989.

Professional Memberships: Association for Computing Machinery (ACM). 